Hélio Teruo Hashizume dos Santos

\title{
Dinâmica de cúspides praiais e fatores condicionantes: Massaguaçú, SP
}

\begin{abstract}
Dissertação apresentada ao Instituto Oceanográfico da Universidade de São Paulo, como parte dos requisitos para a obtenção do título de Mestre em Ciências, área de Oceanografia Geológica.
\end{abstract}

Orientador:

Prof. Dr. Eduardo Siegle

São Paulo

2015 


\title{
UNIVERSIDADE DE SÃO PAULO \\ INSTITUTO OCEANOGRÁFICO
}

\section{Dinâmica de cúspides praiais e fatores condicionantes}

\author{
Hélio Teruo Hashizume dos Santos
}

Dissertação apresentada ao Instituto Oceanográfico da Universidade de São Paulo, como parte dos requisitos para obtenção do título de Mestre em Ciências, área de Oceanografia Geológica.

(VERSÃO CORRIGIDA)

Julgada em

Prof. Dr.

Conceito

Prof. Dr.

Conceito

Prof. Dr.

Conceito 
"Don't ory to quitt. You already in pain, you abready hurtt. Get a reward from itl"

Exic Thomas 


\section{Sumário}

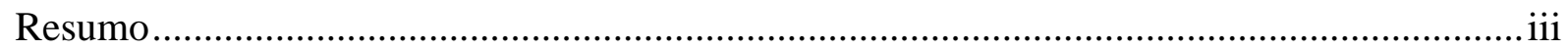

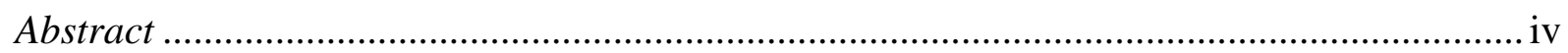

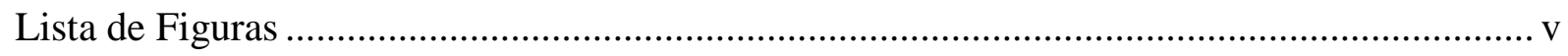

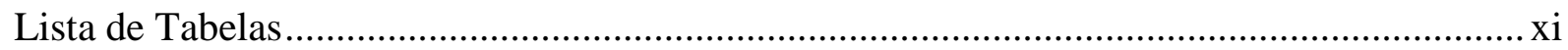

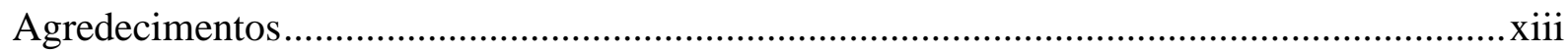

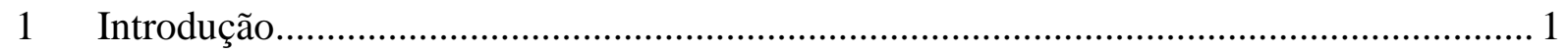

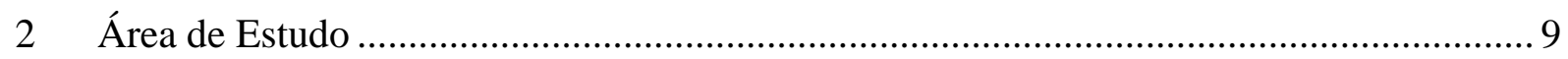

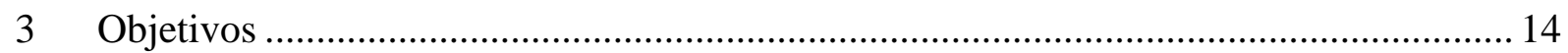

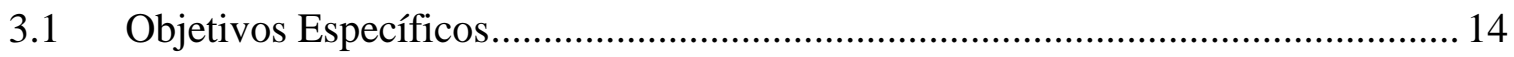

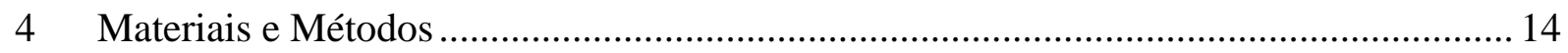

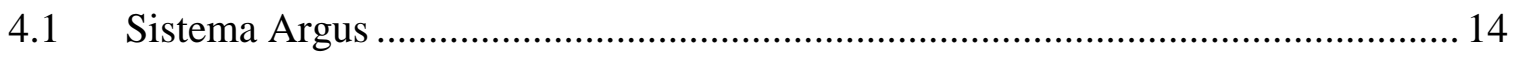

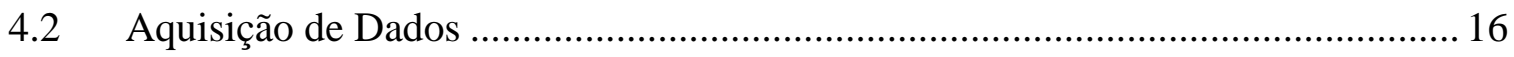

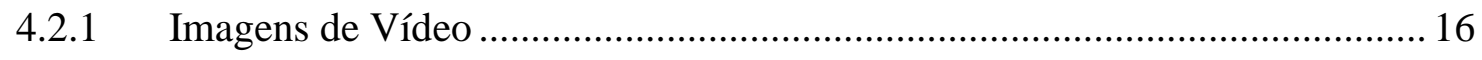

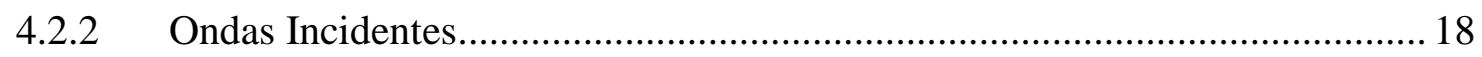

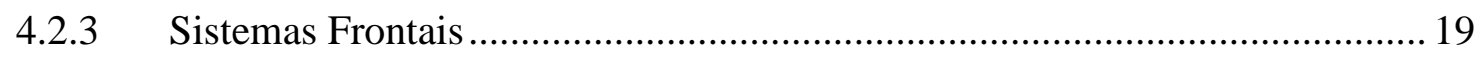

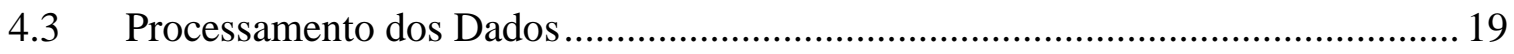

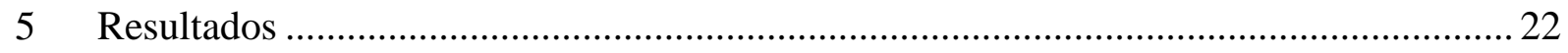

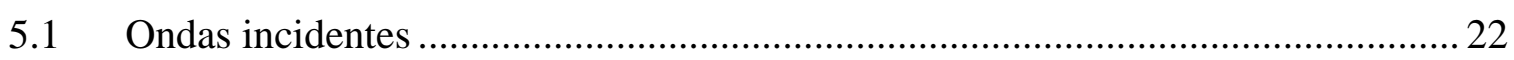

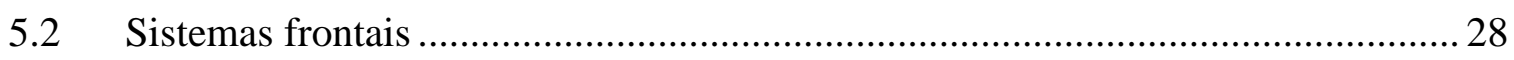

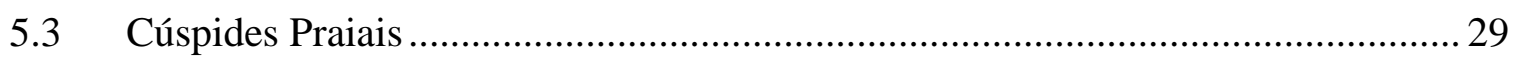




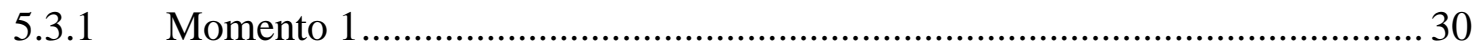

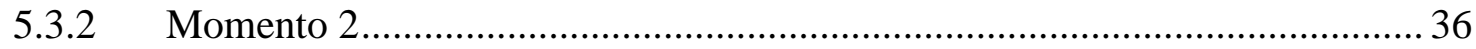

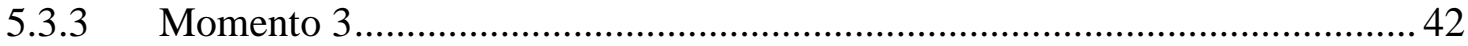

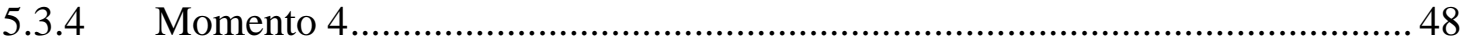

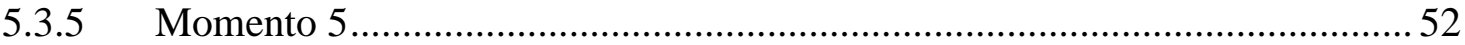

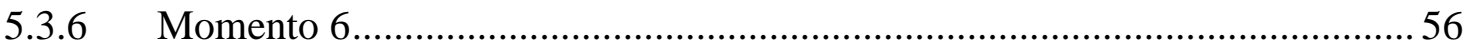

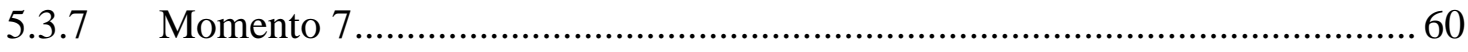

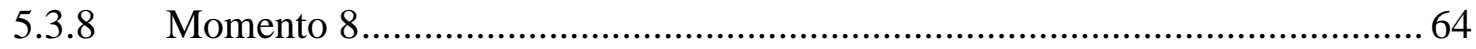

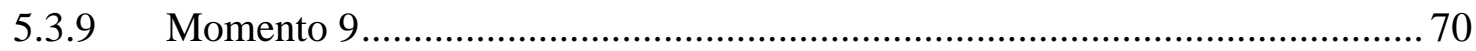

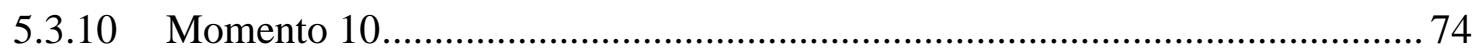

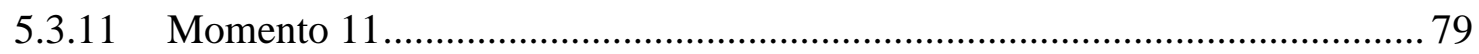

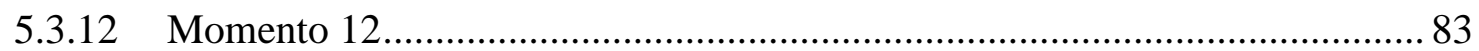

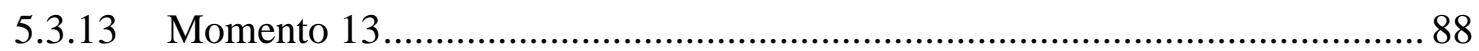

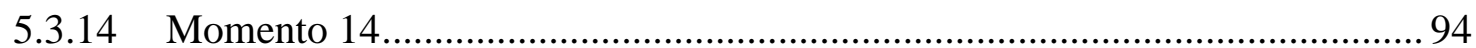

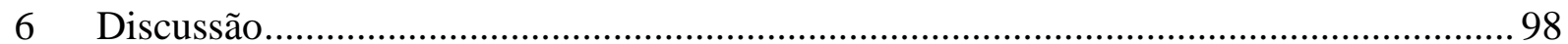

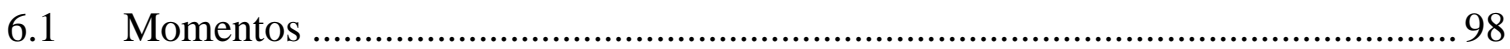

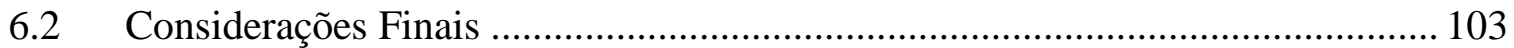

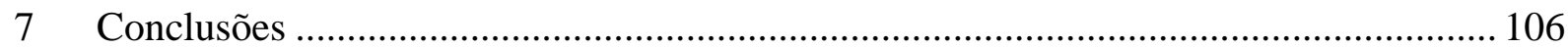




\section{Resumo}

O presente trabalho tem por objetivo relacionar a ação das ondas incidentes no arco praial de Massaguaçú com a presença e o comportamento de feições morfológicas como as cúspides praiais. O conjunto de dados utilizados consiste em uma série de imagens provenientes do sistema Argus. Esse sistema utiliza cinco câmeras de alta resolução resultando em uma cobertura de $180^{\circ}$ da zona costeira. A partir destas imagens realizou-se a digitalização das cúspides praiais encontrando-se duas linhas de cúspides, uma na face praial superior (CFS) e a outra na face praial inferior (CFI). Em conjunto com os dados de imagem foi analisado o clima de ondas atuantes durante o período. A presença de feições rítmicas foi alta no arco praial de Massaguaçú, sendo praticamente predominante na face praial superior. O espaçamento médio da CFS foi superior ao espaçamento da CFI e a alternância das condições atuantes foi determinante na redução do espaçamento assim como condições energéticas baixas. O aumento do espaçamento das cúspides ocorreu sob condições energéticas médias à altas e sob condições extremas observou tanto a destruição como o aumento das feições rítmicas. A interação entre o espraiamento e a morfologia existente, modulado pela variação do nível d'água, foi um dos motores para a formação de cúspides em níveis inferiores enquanto que as condições extremas causaram sua destruição.

Descritores: Cúspides Praiais, feições rítmicas, morfodinâmica praial, sistema Argus 


\section{Abstract}

This study aims to relate the action of incident waves on Massaguaçú's beach with the presence and the behavior of morphological features such as beach cusps. The set of data used consists in a series of images from the Argus system. This system uses five high-resolution cameras resulting in a $180^{\circ}$ coverage of the coastal zone. From these images, realize the presence of beach cusps lying in two rows on the beach face, one in the upper beach face (CFS) and the other in the lower beach face (CFI). At the same time with the image data the wave regime acting at Massaguaçú's beach was analyzed during the period. The presence of rhythmic features was almost constant Massaguaçú's beach face, nearly predominant on the upper beach face. The average spacing of CFS was greater than the spacing of the CFI and the interchange in active conditions was crucial in reducing the spacing as well as low energy conditions. The increased spacing of the cusps occurred under medium to high energy conditions and under extreme conditions both as increased and destruction of the rhythmic features were observed. The interaction between the swash motions and the existing morphology, modulated by varying the water level, was important for the formation of cusps at lower levels while the extreme conditions caused its destruction.

Keywords: Beach cusps, rhythmic features, beach morphodynamic, Argus System 


\section{Lista de Figuras}

Figura 1.1: Cúspides praiais na praia de Massaguaçú a partir de imagens da câmera um do sistema Argus fixado no Hotel Brisa Flat.

Figura 1.2: Esquema sobre as cristas e as cavas das cúspides, baseado de Holland \& Holman 1996.

Figura 1.3: Evolução de cúspides praiais segundo a teoria de auto-organização. 1) depressão incipiente inicial; 2) aumento da feição inicial devido a interação do espraiamento com a topografia; surgimento lateral de feições similares devido a ação desigual do espraiamento gerada pela nova topografia; 4) interação entre topografia e espraiamento gerando uma feição rítmica ao longo do arco praial.

Figura 1.4: Esquema de circulação atuante nas cúspides, baseado de Komar (1998).

Figura 1.5: Exemplo esquemático da onda resultante da somatória de uma onda incidente e uma onda de borda. As regiões altas ocorrem quando a onda incidente e de borda estão em fase; as regiões mais baixas, quando estão fora de fase (baseado de Bowen \& Inman, 1969).

Figura 2.1: Localização da área de estudo. Na porção superior da esquerda para direita; América, Região Sudeste do Brasil, Litoral norte do Estado de São Paulo e na imagem em destaque a Praia de Massaguaçú onde se encontra o Sistema Argus. 11

Figura 2.2: Setor 1, 2 e 3 e seus diferentes graus de risco (Fonte: Sousa, 2011). 13 Figura 4.1: Fotografia instantânea (a, snapshot), imagens de longa exposição (b, timex) e imagem com as variações (c, var).

Figura 4.2: Figura com as cinco câmeras do sistema Argus centralizada e com as imagens adquiridas de cada câmera ao redor. 17

Figura 4.3: Área analisada nas imagens do arco praial de Massaguaçú (retângulo em vermelho).

Figura 4.4: Localização dos dados de onda utilizados para comparação com as feições rítmicas. Em amarelo a posição referente aos dados de ondas e em vermelho a posição referente ao sistema Argus, 18

Figura 4.5: Último plano de bit (acima), imagem original (abaixo). 20

Figura 4.6: Esquema representativo de cúspides em trecho do arco praial de Massaguaçú. Em vermelho as cúspides na face praial superior e em azul cúspides na face praial inferior. 21 Figura 4.7: Cúspides digitalizadas: em azul cúspides na face praial inferior e em vermelho as cúspides na face praial superior. 
Figura 4.8: Imagem com exemplo das linhas digitalizadas utilizadas para calcular a largura do perfil praial (amarelo - linha d'água; vermelho - linha de vegetação.

Figura 5.1: Histogramas de direção e altura (m) para toda série temporal.

Figura 5.2: Histogramas de direção e altura $(\mathrm{m})$ para toda série temporal $(\mathrm{N}, \mathrm{NE}, \mathrm{E}, \mathrm{SE}, \mathrm{S}, \mathrm{SO}$, $\mathrm{O}, \mathrm{NO})$.

Figura 5.3: Histogramas de direção e período (s) para toda série temporal.

Figura 5.4: Histogramas de direção e período (s) para toda série temporal (N, NE, E, SE, S, SO, $\mathrm{O}, \mathrm{NO})$. 25

Figura 5.5: Evolução da altura, período e direção para toda série temporal. .25

Figura 5.6: Evolução da altura, período e direção atuantes no arco praial de Massaguaçú..... 26

Figura 5.7: Histogramas de direção e altura (m) atuantes no arco praial de Massaguaçú. ...... 27

Figura 5.8: Histogramas de direção e período (s) atuantes no arco praial de Massaguaçú...... 28

Figura 5.9: Número de sistemas frontais ao longo da América do Sul, costa brasileira e Ubatuba.

Figura 5.10: Espaçamento médio das cúspides durante o período. Em vermelho são as cúspides localizadas na face praial superior e em azul cúspides localizadas na face praial inferior. ..... 31 Figura 5.11: Histograma direcional de altura (m, a esquerda) e período (s, a direita) das ondas atuantes durante o período.

Figura 5.12: Evolução da altura, período e direção atuantes durante o período, onde a linha em azul representa a direção normal a face praial.

Figura 5.13: Cúspides digitalizadas durante o período (apenas os 10 primeiros dias). Em vermelho são as cúspides localizadas na face praial superior e em azul cúspides localizadas na face praial inferior.

Figura 5.14: Cúspides digitalizadas durante o período (os 11 dias restantes). Em vermelho são as cúspides localizadas na face praial superior e em azul cúspides localizadas na face praial inferior. 35

Figura 5.15: Espaçamento médio das cúspides durante o período. Em vermelho são as cúspides localizadas na face praial superior e em azul cúspides localizadas na face praial inferior. ..... 36 Figura 5.16: Histograma direcional de altura (m, a esquerda) e período (s, a direita) das ondas atuantes durante o período.

Figura 5.17: Evolução da altura, período e direção atuantes durante o período, onde a linha em azul representa a direção normal a face praial. 39 
Figura 5.18: Cúspides digitalizadas durante o período (apenas os 12 primeiros dias). Em vermelho são as cúspides localizadas na face praial superior e em azul cúspides localizadas na face praial inferior.

Figura 5.19: Cúspides digitalizadas durante o período (10 dias restantes). Em vermelho são as cúspides localizadas na face praial superior e em azul cúspides localizadas na face praial inferior.

Figura 5.20: Espaçamento médio das cúspides durante o período. Em vermelho são as cúspides localizadas na face praial superior e em azul cúspides localizadas na face praial inferior. 42 Figura 5.21: Histograma direcional de altura (m, a esquerda) e período (s, a direita) das ondas atuantes durante o período.

Figura 5.22: Evolução da altura, período e direção atuantes durante o período, onde a linha em azul representa a direção normal a face praial.

Figura 5.23: Cúspides digitalizadas durante o período (apenas os 10 primeiros dias). Em vermelho são as cúspides localizadas na face praial superior e em azul cúspides localizadas na face praial inferior. 46

Figura 5.24: Cúspides digitalizadas durante o período (9 dias restantes). Em vermelho são as cúspides localizadas na face praial superior e em azul cúspides localizadas na face praial inferior.

Figura 5.25: Espaçamento médio das cúspides durante o período. Em vermelho são as cúspides localizadas na face praial superior e em azul cúspides localizadas na face praial inferior. ..... 48 Figura 5.26: Histograma direcional de altura (m, a esquerda) e período (s, a direita) das ondas atuantes durante o período. .50

Figura 5.27: Evolução da altura, período e direção atuantes durante o período, onde a linha em azul representa a direção normal a face praial.

Figura 5.28: Cúspides digitalizadas durante o período. Em vermelho são as cúspides localizadas na face praial superior e em azul cúspides localizadas na face praial inferior.. 51 Figura 5.29: Espaçamento médio das cúspides durante o período. Em vermelho são as cúspides localizadas na face praial superior e em azul cúspides localizadas na face praial inferior......52 Figura 5.30: Histograma direcional de altura (m, a esquerda) e período (s, a direita) das ondas atuantes durante o período.

Figura 5.31: Evolução da altura, período e direção atuantes durante o período, onde a linha em azul representa a direção normal a face praial.

Figura 5.32: Cúspides digitalizadas durante o período. Em vermelho são as cúspides localizadas na face praial superior e em azul cúspides localizadas na face praial inferior. .55 
Figura 5.33: Espaçamento médio das cúspides durante o período. Em vermelho são as cúspides localizadas na face praial superior e em azul cúspides localizadas na face praial inferior...... 56 Figura 5.34: Histograma direcional de altura (m, a esquerda) e período (s, a direita) das ondas atuantes durante o período

Figura 5.35: Evolução da altura, período e direção atuantes durante o período, onde a linha em azul representa a direção normal a face praial.

Figura 5.36: Cúspides digitalizadas durante o período. Em vermelho são as cúspides localizadas na face praial superior e em azul cúspides localizadas na face praial inferior. 59 Figura 5.37: Imagem de variação evidenciando o espraiamento diferencial devido ao afogamento da morfologia existente no arco praial de Massaguaçú.

Figura 5.38: Espaçamento médio das cúspides durante o período. Em vermelho são as cúspides localizadas na face praial superior e em azul cúspides localizadas na face praial inferior. ..... 60 Figura 5.39: Histograma direcional de altura (m, a esquerda) e período (s, a direita) das ondas atuantes durante o período.

Figura 5.40: Evolução da altura, período e direção atuantes durante o período, onde a linha em azul representa a direção normal a face praial.

Figura 5.41: Cúspides digitalizadas durante o período. Em vermelho são as cúspides localizadas na face praial superior e em azul cúspides localizadas na face praial inferior.

Figura 5.42: Espaçamento médio das cúspides durante o período. Em vermelho são as cúspides localizadas na face praial superior e em azul cúspides localizadas na face praial inferior. ..... 64 Figura 5.43: Histograma direcional de altura (m, a esquerda) e período (s, a direita) das ondas atuantes durante o período.

Figura 5.44: Evolução da altura, período e direção atuantes durante o período, onde a linha em azul representa a direção normal a face praial.

Figura 5.45: Cúspides digitalizadas durante o período (apenas os 12 primeiros dias). Em vermelho são as cúspides localizadas na face praial superior e em azul cúspides localizadas na face praial inferior. .68

Figura 5.46: Cúspides digitalizadas durante o período (12 dias restantes). Em vermelho são as cúspides localizadas na face praial superior e em azul cúspides localizadas na face praial inferior.

Figura 5.47: Imagem da interação entre a morfologia existente e o espraiamento atuante. .... 70 Figura 5.48: Espaçamento médio das cúspides durante o período. Em vermelho são as cúspides localizadas na face praial superior e em azul cúspides localizadas na face praial inferior. ..... 70 
Figura 5.49: Histograma direcional de altura (m, a esquerda) e período (s, a direita) das ondas atuantes durante o período

Figura 5.50: Evolução da altura, período e direção atuantes durante o período, onde a linha em azul representa a direção normal a face praial.

Figura 5.51: Cúspides digitalizadas durante o período. Em vermelho são as cúspides localizadas na face praial superior e em azul cúspides localizadas na face praial inferior. .73 Figura 5.52: Espaçamento médio das cúspides durante o período. Em vermelho são as cúspides localizadas na face praial superior e em azul cúspides localizadas na face praial inferior. ..... 74 Figura 5.53: Histograma direcional de altura (m, a esquerda) e período (s, a direita) das ondas atuantes durante o período.

Figura 5.54: Evolução da altura, período e direção atuantes durante o período, onde a linha em azul representa a direção normal a face praial. .77

Figura 5.55: Cúspides digitalizadas durante o período (apenas os 10 primeiros dias). Em vermelho são as cúspides localizadas na face praial superior e em azul cúspides localizadas na face praial inferior. 78

Figura 5.56: Espaçamento médio das cúspides durante o período. Em vermelho são as cúspides localizadas na face praial superior e em azul cúspides localizadas na face praial inferior. ..... 79 Figura 5.57: Histograma direcional de altura (m, a esquerda) e período (s, a direita) das ondas atuantes durante o período. 81

Figura 5.58: Evolução da altura, período e direção atuantes durante o período, onde a linha em azul representa a direção normal a face praial.

Figura 5.59: Cúspides digitalizadas durante o período. Em vermelho são as cúspides localizadas na face praial superior e em azul cúspides localizadas na face praial inferior.

Figura 5.60: Espaçamento médio das cúspides durante o período. Em vermelho são as cúspides localizadas na face praial superior e em azul cúspides localizadas na face praial inferior. ..... 83 Figura 5.61: Histograma direcional de altura (m, a esquerda) e período (s, a direita) das ondas atuantes durante o período. .85

Figura 5.62: Evolução da altura, período e direção atuantes durante o período, onde a linha em azul representa a direção normal a face praial. .85

Figura 5.63: Cúspides digitalizadas durante o período (apenas os 10 primeiros dias). Em vermelho são as cúspides localizadas na face praial superior e em azul cúspides localizadas na face praial inferior. .86 
Figura 5.64: Cúspides digitalizadas durante o período (10 dias restantes). Em vermelho são as cúspides localizadas na face praial superior e em azul cúspides localizadas na face praial inferior.

Figura 5.65: Espaçamento médio das cúspides durante o período. Em vermelho são as cúspides localizadas na face praial superior e em azul cúspides localizadas na face praial inferior. ..... 88 Figura 5.66: Histograma direcional de altura (m, a esquerda) e período (s, a direita) das ondas atuantes durante o período. 91

Figura 5.67: Evolução da altura, período e direção atuantes durante o período, onde a linha em azul representa a direção normal a face praial.

Figura 5.68: Cúspides digitalizadas durante o período (apenas os 9 primeiros dias). Em vermelho são as cúspides localizadas na face praial superior e em azul cúspides localizadas na face praial inferior. 92

Figura 5.69: Cúspides digitalizadas durante o período (10 dias restantes). Em vermelho são as cúspides localizadas na face praial superior e em azul cúspides localizadas na face praial inferior. 93

Figura 5.70: Espaçamento médio das cúspides durante o período. Em vermelho são as cúspides localizadas na face praial superior e em azul cúspides localizadas na face praial inferior...... 94 Figura 5.71: Histograma direcional de altura (m, a esquerda) e período (s, a direita) das ondas atuantes durante o período .96

Figura 5.72: Evolução da altura, período e direção atuantes durante o período, onde a linha em azul representa a direção normal a face praial. .96 Figura 5.73: Cúspides digitalizadas durante o período. Em vermelho são as cúspides localizadas na face praial superior e em azul cúspides localizadas na face praial inferior. 97 Figura 6.1: Formação de feições rítmicas causadas pela excursão do espraiamento na face praial superior..... 101 


\section{Lista de Tabelas}

Tabela 5.1: Características de ondas para toda série temporal.

Tabela 5.2: Características de ondas no arco praial de Massaguaçú para toda série temporal. 27

Tabela 5.3: Número de sistemas frontais ao longo da América do Sul, costa brasileira e Ubatuba.

Tabela 5.4: Subdivisões de todo o período analisado com suas respectivas datas de início e fim, $\mathrm{n}^{\mathrm{o}}$ de dias analisados em cada subperíodo e a predominância, ou não, de feições rítmicas na face praial inferior (CFI) e superior (CFS)

Tabela 5.5: Características das ondas atuantes no arco praial de Massaguaçú durante o período.

Tabela 5.6: Espaçamento médio das cúspides na face praial inferior e superior.

Tabela 5.7: Características das ondas atuantes no arco praial de Massaguaçú durante o período.

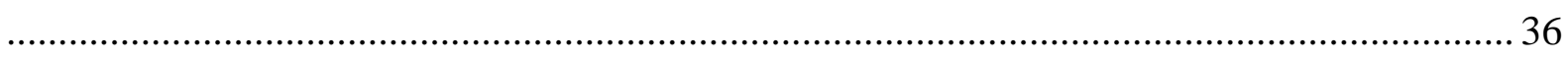

Tabela 5.8: Espaçamento médio das cúspides na face praial inferior e superior. 38

Tabela 5.9: Características das ondas atuantes no arco praial de Massaguaçú durante o período.

Tabela 5.10: Espaçamento médio das cúspides na face praial inferior e superior. 44

Tabela 5.11: Características das ondas atuantes no arco praial de Massaguaçú durante o período.

Tabela 5.12: Espaçamento médio das cúspides na face praial inferior e superior.

Tabela 5.13: Características das ondas atuantes no arco praial de Massaguaçú durante o período.

Tabela 5.14: Espaçamento médio das cúspides na face praial inferior e superior. .53

Tabela 5.15: Características das ondas atuantes no arco praial de Massaguaçú durante o período.

Tabela 5.16: Espaçamento médio das cúspides na face praial inferior e superior. .57

Tabela 5.17: Características das ondas atuantes no arco praial de Massaguaçú durante o período.

Tabela 5.18: Espaçamento médio das cúspides na face praial inferior e superior. 61

Tabela 5.19: Características das ondas atuantes no arco praial de Massaguaçú durante o período.

Tabela 5.20: Espaçamento médio das cúspides na face praial inferior e superior. 66 
Tabela 5.21: Características das ondas atuantes no arco praial de Massaguaçú durante o período. .70

Tabela 5.22: Espaçamento médio das cúspides na face praial inferior e superior. .71

Tabela 5.23: Características das ondas atuantes no arco praial de Massaguaçú durante o período.

Tabela 5.24: Espaçamento médio das cúspides na face praial inferior e superior. .76

Tabela 5.25: Características das ondas atuantes no arco praial de Massaguaçú durante o período.

Tabela 5.26: Espaçamento médio das cúspides na face praial inferior e superior. 80

Tabela 5.27: Características das ondas atuantes no arco praial de Massaguaçú durante o período.

Tabela 5.28: Espaçamento médio das cúspides na face praial inferior e superior. 84

Tabela 5.29: Características das ondas atuantes no arco praial de Massaguaçú durante o período. .88

Tabela 5.30: Espaçamento médio das cúspides na face praial inferior e superior 90

Tabela 5.31: Características das ondas atuantes no arco praial de Massaguaçú durante o período.

Tabela 5.32: Espaçamento médio das cúspides na face praial inferior e superior. .95

Tabela 6.1: Classificação de condição energética de ondas incidentes .98

Tabela 6.2: Resumo sobre os principais efeitos e seus processos geradores. 105 


\section{Agredecimentos}

Ao final de mais etapa gostaria de agradecer as pessoas que fizeram parte desse caminho:

- A minha família, principalmente aos meus pais Antônio e Floripes pelo esforço de ambos em me conceder condições para alcançar as oportunidades.

- Ao meu orientador Eduardo Siegle pela orientação, apoio, paciência e companheirismo.

- Aos amigos que fiz no Instituto Oceanográfico em especialmente a galera da minha turma e a galera do laboratório.

- Aos Professores e Técnicos do Instituto pelos ensinamentos passados

- A CAPES pelo financiamento deste trabalho

- A minha namorada Heliane pelo companheirismo e paciência na conclusão deste trabalho e pelas minha inúmeras viagens de campo.

Resumindo o resumido agradeço a todos que participaram e participam dos bastidores. 


\section{Introdução}

Os processos litorâneos ligados à morfologia costeira resultam da combinação de forças naturais e humanas. Muito frequentemente a costa é formada por material arenoso, que responde rapidamente as forçantes hidrodinâmicas, através do transporte de sedimentos.

Por esta razão, a zona costeira torna-se um ambiente altamente dinâmico, onde contínuas mudanças ocorrem devida à interação entre a topografia, e seus materiais constituintes com os agentes hidrodinâmicas atuantes. Esse processo ocorre principalmente na interface entre o continente e o mar, conhecida como a linha de costa. As razões pelas quais a posição da linha de costa se altera de tempos em tempos ganha importância, à medida que, aproximadamente dois terços da população mundial estão vivendo nas zonas costeiras (Komar, 1998).

A evolução dos sistemas litorâneos está ligada à morfodinâmica costeira, resultando na retroalimentação entre a topografia e as forçantes externas, que conduzem o transporte de sedimentos alterando a morfologia em diferentes escalas de tempo e espaço. Este transporte fornece o mecanismo de ajuste para o balanço morfodinâmico praial que tende a buscar um equilíbrio dinâmico ao longo do tempo (Wright \& Thom, 1977).

Muitos sistemas costeiros não respondem linearmente e, assim, exibem mecanismos de retroalimentação positiva ou negativa. Na retroalimentação positiva ocorre o crescimento de instabilidades, conferindo propriedades de auto-organização do sistema, que resulta em novos modelos de operação. Na retroalimentação negativa se mantém um equilíbrio através da autorregulação, em reposta às menores perturbações (Carter \& Woodroffe, 1994).

Este equilíbrio dinâmico faz com que grandes quantidades de sedimento estejam em frequentemente movimento, mas em média o material que entra numa área, em um dado intervalo de tempo, é igual à quantidade que dela sai no mesmo intervalo de tempo. Este 
equilíbrio dinâmico faz com que a posição da linha média da costa seja relativamente estável por um período de meses ou anos, enquanto a posição instantânea sofre oscilações de curto período. Por estas razões, é mais realístico ver o equilíbrio como um estado morfológico continuo se esforçando para alcançar um equilíbrio (Wright \& Thom, 1977).

Nesse ambiente extremamente dinâmico algumas feições morfológicas figuram na face praial em resposta das condições hidrodinâmicas presentes no sistema praial. Feições que por características singulares atraem uma enormidade de olhares curiosos que tentam entender os mecanismos regentes para a presença ou não de tal feição morfológica.

Uma morfologia que atenta os olhares de alguns pesquisadores e com ínfimos estudos no Brasil são as cúspides praiais. Essas feições estão intimamente relacionadas com as condições hidrodinâmicas presentes. Essas condições também são responsáveis pelas alterações na largura e no volume de sedimento presente no sistema praial, ou seja, as variações no volume de sedimento podem acarretar processos erosivos ou deposicionais no sistema que podem estar relacionados com a presença ou não da morfologia rítmica característica.

Portanto, o entendimento dos processos costeiros atuantes bem como a geomorfologia presente é de fundamental importância para o esclarecimento científico e o fomento nas decisões de obras públicas.

O presente trabalho pretende estudar as forçantes hidrodinâmicas e relaciona-las com a presença de cúspides praiais e para isso é necessário o entendimento dos agentes hidrodinâmicos que atuam na zona de espraiamento e na zona de arrebentação do sistema praial.

As cúspides praiais são estruturas que alteram a linearidade da zona costeira com projeções e reentrâncias (Figura 1.1). Essas feições podem ser únicas e isoladas no arco praial, mas comumente ocorrem em séries espaçadas uniformemente umas das outras (Komar, 1998). 


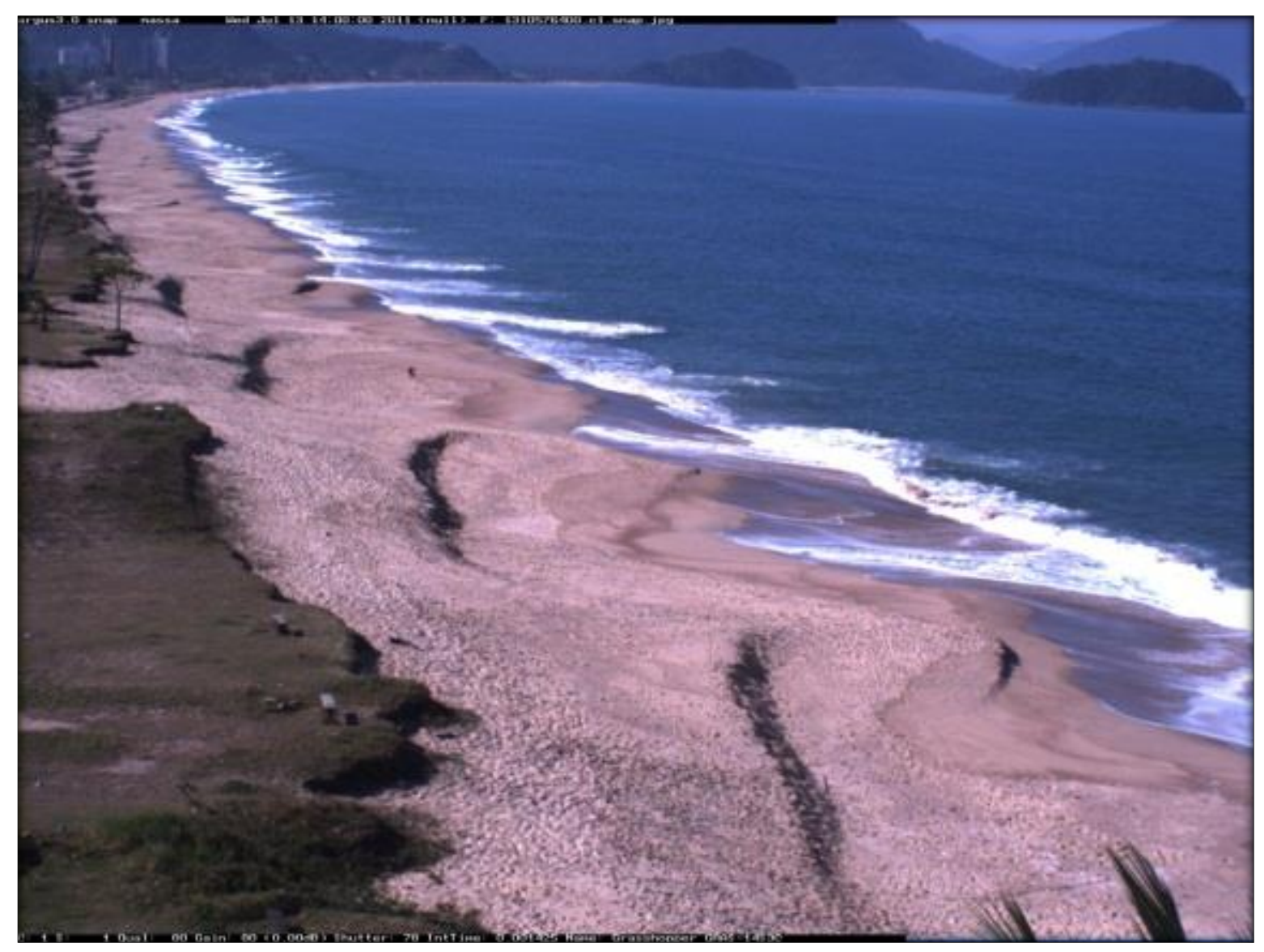

Figura 1.1: Cúspides praiais na praia de Massaguaçú a partir de imagens da câmera um do sistema Argus fixado no Hotel Brisa Flat.

Essas feições rítmicas dependem do tamanho do grão do sedimento, do ângulo de inclinação da face praial, da variação da maré e da incidência das ondas. São formadas na antepraia superior (foreshore), comumente mais próximo ao nível de maré mais alta, correspondendo à face praial.

Elas mostram melhor desenvolvimento sobre praias de grãos mais grossos, de pequeno alcance de maré e com grande declive para que as ondas incidentes produzam uma substancial elevação do espraiamento na face da praia. As cúspides respondem rapidamente às mudanças das condições de maré e ao clima de ondas (Masselink et al. 1997; Coco et al., 2004).

As marés modulam a posição transversal das feições rítmicas em relação à linha de costa: durante a preamar, a extensão transversal das cúspides decresce e, durante a baixa-mar, essa extensão aumenta. Ondulações com direção normal em relação a face praial estimulam a 
sua construção, enquanto ondas gravitacionais obliquamente incidentes tendem a reduzir a proeminência de sua morfologia, já que a formação de cúspides é claramente mais favorável quando as ondas aproximam-se normais à praia (Johnson, 1919).

Essas forçantes modificam a linha de costa formando uma morfologia caracterizada por um esporão em direção ao mar chamado de crista (cusp horn) e um suave embaiamento chamado de cava (cusp embayment) (Figura 1.2).

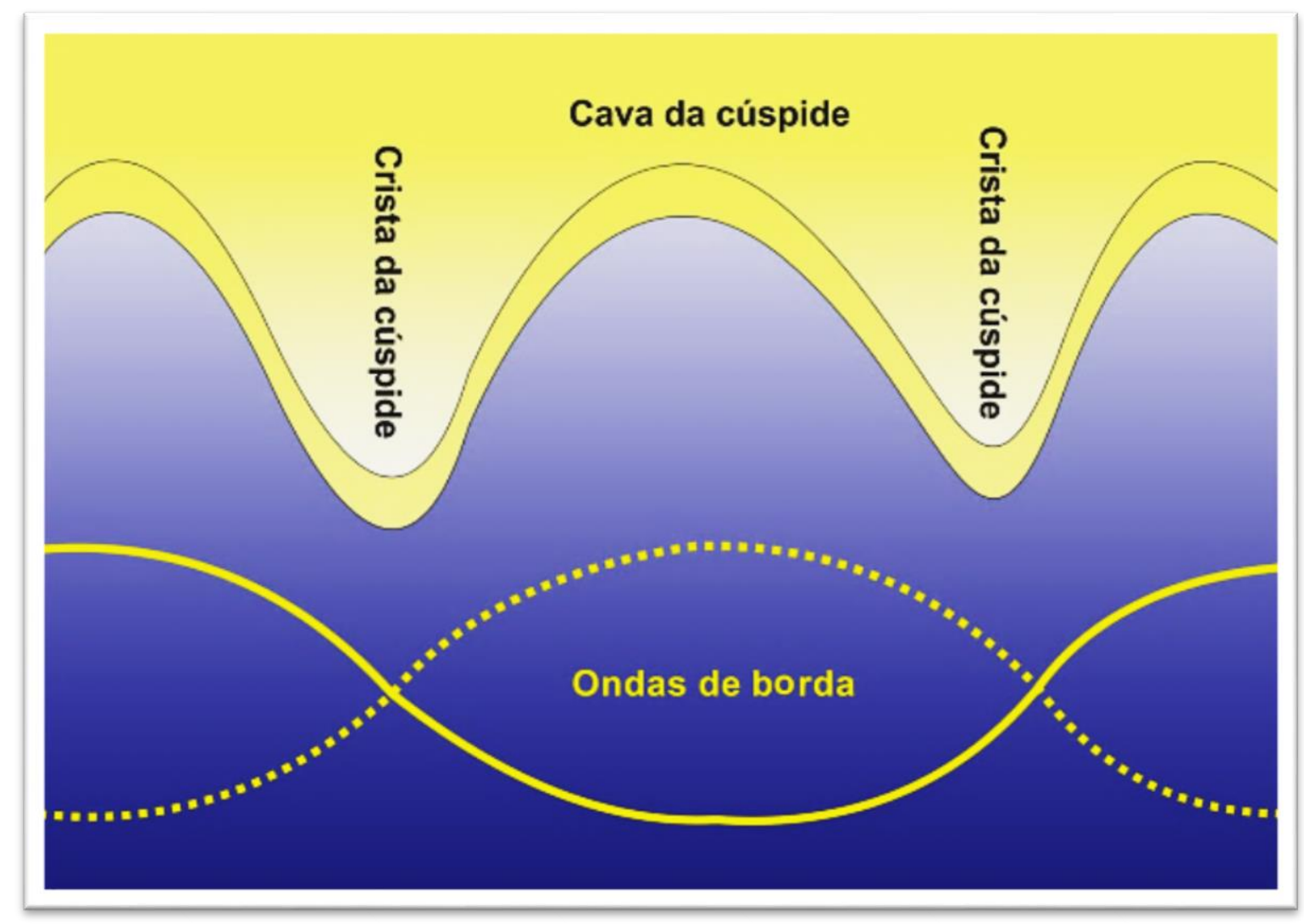

Figura 1.2: Esquema sobre as cristas e as cavas das cúspides, baseado de Holland \& Holman (1996).

As hipóteses mais discutidas sobre a formação das cúspides praiais são a teoria de ondas de borda (edge waves) (Figura 1.2) e a teoria de auto-organização (self-organization). A teoria de ondas de borda consiste em uma onda presa ao longo da linha de costa que se soma às ondas incidentes e esse somatório altera a intensidade do espraiamento de uma maneira ritmada como as cúspides (Bowen \& Inman, 1971; Inman \& Guza, 1982). 
A teoria de auto-organização (Figura 1.3) consiste na retroalimentação entre a morfologia e o fluxo, ou seja, a partir de uma incipiente depressão (Figura 1.3-1) na linha de costa, o fluxo do espraiamento, ao perder competência na antepraia, deposita o sedimento nas bordas da depressão e ao voltar pelo centro da depressão, a erode. Ou seja, o fluxo é mais competente na porção central da depressão, erodindo essa região enquanto as bordas são pouco ou nada erodidas.

Essa interação entre a topografia e o espraiamento causa uma erosão na depressão e uma acresção na borda da mesma (Figura 1.3-2). Nesse momento que a borda é a feição mais proeminente da linha de costa, a área adjacente começa a erodir e subsequentemente a área seguinte começa a depositar (Figura 1.3-3) até o momento em que o arco praial possui uma linha rítmica ao longo da face praial (Figura 1.3-4) (Werner \& Fink, 1993).

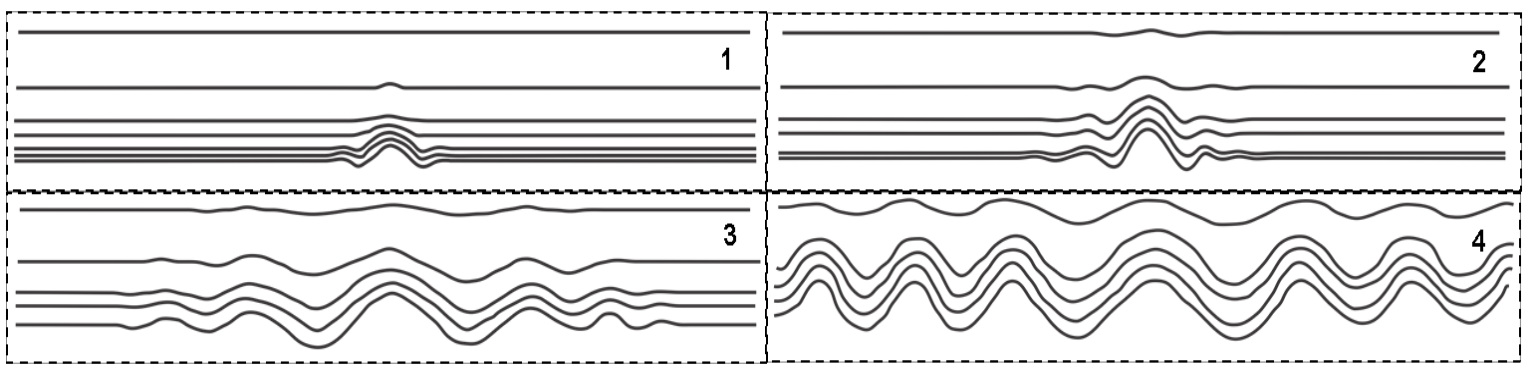

Figura 1.3: Evolução de cúspides praiais segundo a teoria de auto-organização. 1) depressão incipiente inicial; 2) aumento da feição inicial devido a interação do espraiamento com a topografia; surgimento lateral de feições similares devido a ação desigual do espraiamento gerada pela nova topografia; 4) interação entre topografia e espraiamento gerando uma feição rítmica ao longo do arco praial.

As duas teorias de formação das cúspides praiais se relacionam com a dinâmica de fluidos adjacentes à linha de costa e segundo Komar (1976), a combinação das ondas incidentes com as ondas de borda produz uma alternância de arrebentações mais altas e mais baixas ao longo da linha de costa, causando um padrão de células de circulação na forma de correntes de retorno (Figura 1.4). Por causa do padrão senoidal da onda estacionária confinada paralelamente à costa há pontos nodais e antinodais. $\mathrm{O}$ ponto antinodal aumenta ou diminui a altura da onda 
dependendo se estão em fase ou fora de fase $\left(180^{\circ}\right)$. Os pontos nodais e antinodais se somam às ondas incidentes alterando a altura das ondas que chegam à zona de arrebentação (Figura 5).

O resultado dessa interação é um padrão regularmente espaçado de circulação de correntes de retorno localizadas nas posições antinodais, onde as ondas são menores (Komar, 1976).

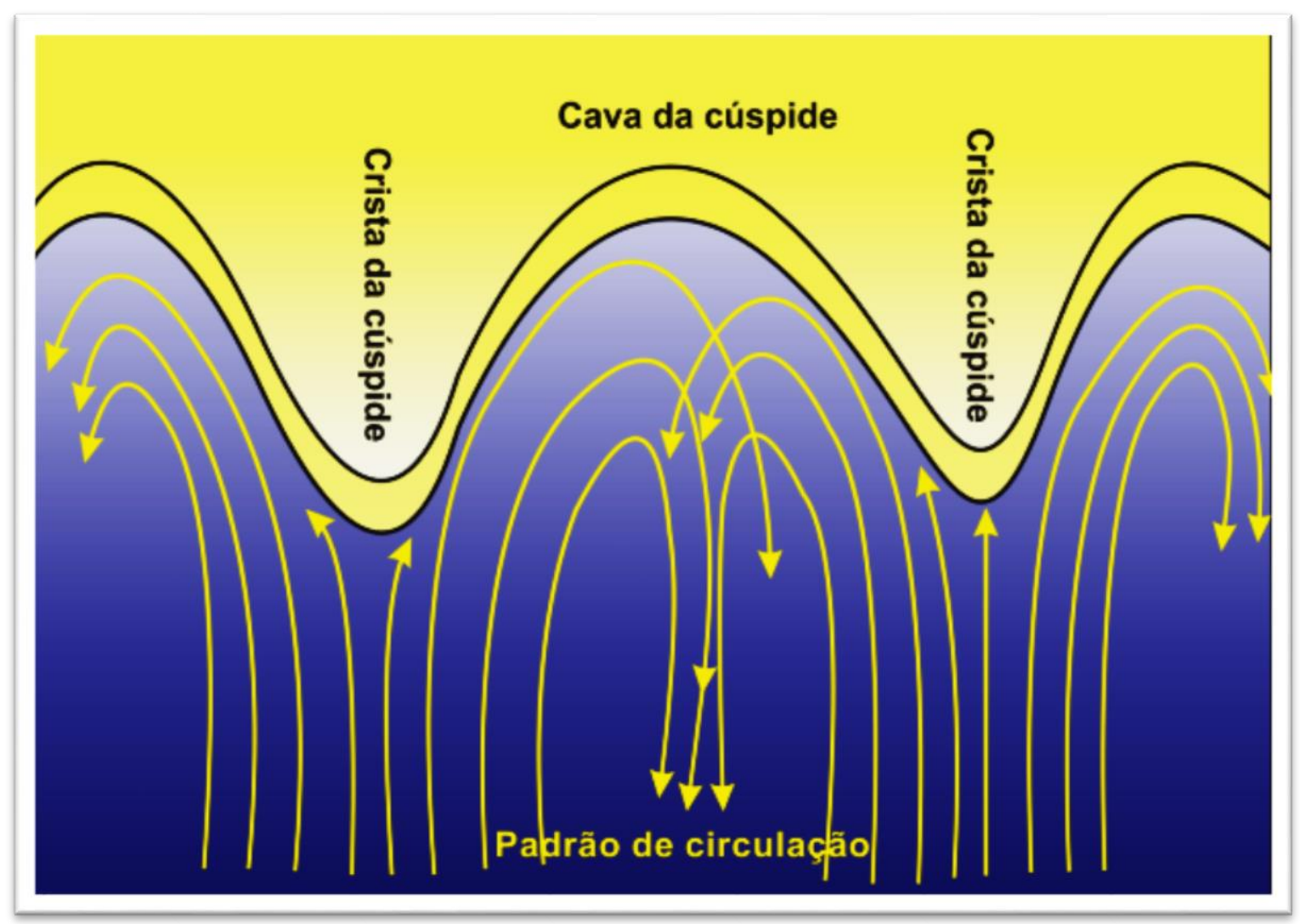

Figura 1.4: Esquema de circulação atuante nas cúspides, baseado de Komar (1998).

Essas feições ocorrem zona de espraiamento, região definida como a parte da praia alternadamente coberta e exposta pelo elevação do nível da água em direção à costa (espraiamento em direção a costa) e pelo retorno da elevação do nível de água em direção ao mar (espraiamento em direção ao mar). Este é um processo muito dinâmico e altamente variável e é suscetível a fenômenos que variam desde de segundos em praias refletivas, inclinadas e calmas, a minutos em praia dissipativas, de baixo gradiente e energéticas (Masselink \& Puleo, 2006). 
Dessa forma, a zona de espraiamento é caracterizada por fluxos fortes, nãoestacionários, com altos níveis de turbulência, com grandes taxas de transporte de sedimentos e de rápidas mudanças morfológicas (Puleo et al., 2000).
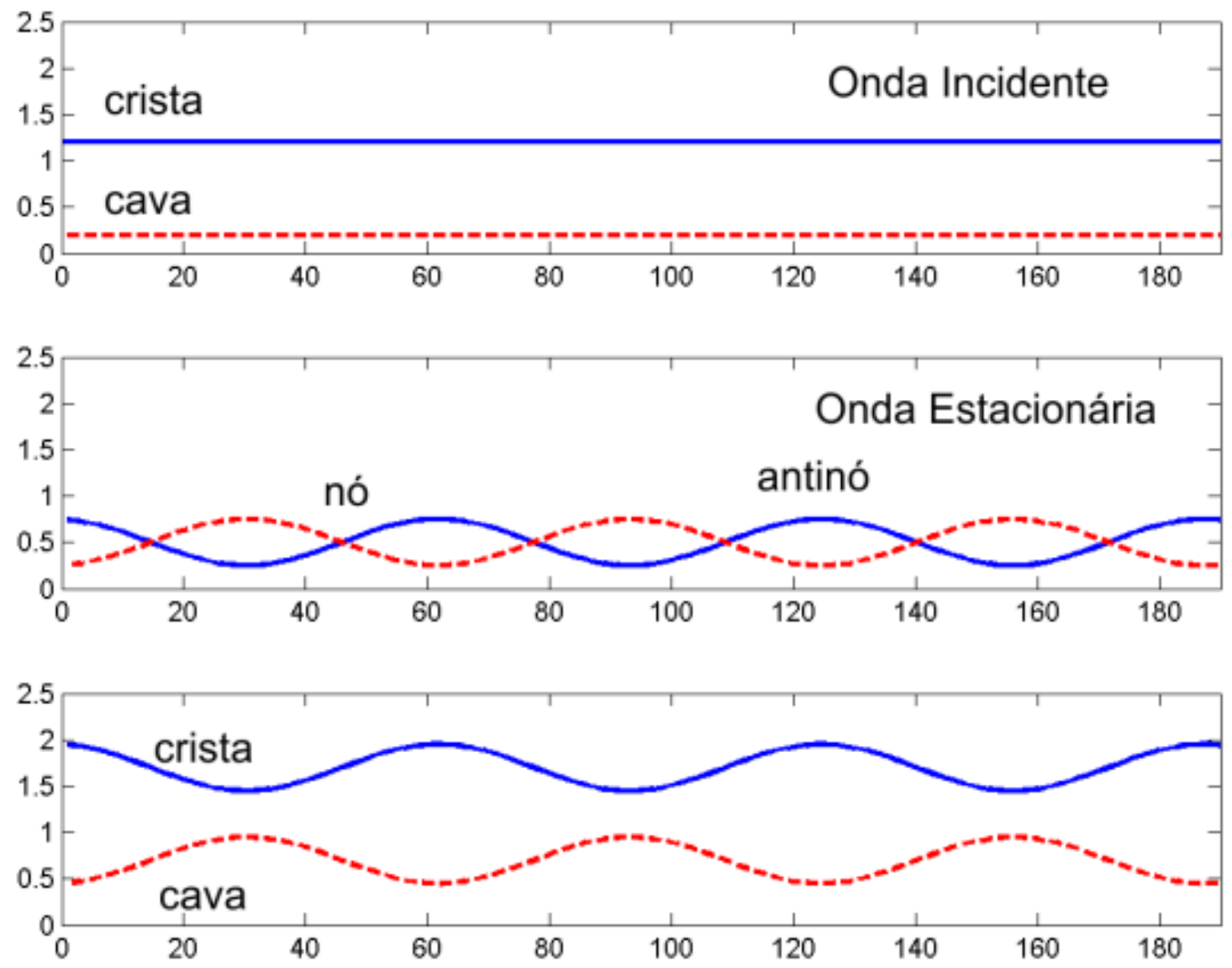

Figura 1.5: Exemplo esquemático da onda resultante da somatória de uma onda incidente e uma onda de borda. As regiões altas ocorrem quando a onda incidente e de borda estão em fase; as regiões mais baixas, quando estão fora de fase (baseado de Bowen \& Inman, 1969).

O transporte de sedimentos na zona de espraiamento contribui significativamente para a acresção e erosão da linha de costa. Grande parte do transporte de sedimentos longitudinais ocorrem nesta zona, especialmente em praia inclinadas (Wellen et al., 2000). A configuração da declividade da face praial está atribuída à assimetria dos fluxos de espraiamento, principalmente ao espraiamento em direção a costa (Bagnold, 1940). Os dois fluxos possuem importantes características para a interação entre a zona de espraiamento, a morfologia da praia, o transporte de sedimentos e as condições de ondas incidentes. 
O espraiamento em direção a costa é dominado pela turbulência gerada pela frente formada pela quebra das ondas, especialmente em praias refletivas, e devido a essa turbulência os sedimentos tendem a ser misturados na coluna de água e transportados como carga de suspensão.

O espraiamento em direção ao mar é dominado pela dissipação da turbulência e a concentração dos sedimentos em uma camada limite junto ao fundo, e dessa maneira os sedimentos são transportados, em sua maioria, como carga de fundo.

As velocidades dos ciclos são similares entre o espraiamento em direção a costa e o espraiamento em direção ao mar, mas a duração de cada fluxo é diferente, sendo maior a duração do espraiamento em direção ao mar. Devido a essa diferença, assimetria da velocidade na zona de espraiamento é predominantemente negativo (Masselink \& Puleo, 2006).

Como o espraiamento em direção a costa e o espraiamento em direção ao mar são gerados por processos com grande variabilidade temporal, frequentemente ocorrem interações entre os mesmos. A interação entre um forte fluxo do espraiamento em direção ao mar e a frente de onda posterior, pode resultar em uma frente de onda quase-estacionária ou na criação de uma condição hidráulica, onde a frente da onda que está chegando é suprimida ou retraída pela rápida aceleração dos fluxos em direção ao mar (Masselink \& Puleo, 2006).

No meio de todo esse sistema caótico é que se inserem as cúspides praiais, feições que ocorrem na zona de espraiamento e são frequentemente descritas com seus espaçamentos variando de $10^{-1} \mathrm{~m} \mathrm{a} 10^{2} \mathrm{~m}$ (Coco et al., 1999). Aliado às características morfológicas, Komar (1973) observa uma granulometria média de $1,157 \mathrm{~mm}$ nas cristas e $0,946 \mathrm{~mm}$ nas cavas. Da mesma maneira Coco et al. (2003) e van Gaalen et al. (2011) também não observaram nenhuma diferença estatisticamente significativa entre o tamanho do grão nas cristas e nas cavas.

Essas diferenças morfológicas e sedimentológicas levaram inúmeros pesquisadores a debaterem sobre as características sedimentares das cúspides praiais a fim de descobrir se as 
feições são acreacionais, erosivas ou ambas. Johnson (1919) descreveu as cúspides praiais como feições erosivas ao observar a erosão das cavas durante a passagem do espraiamento. Russell \& McIntire (1965) observaram nas cristas sedimentos maiores aos das cavas e associaram essa diferença com o aumento do hidrodinamismo caracterizando as cúspides praiais como feições deposicionais.

Masselink et al. (1997) afirma que cristas e cavas interagem com o espraiamento causando uma retroalimentação negativa onde o aumento da crista aumenta a área erosiva e o aumento das cavas aumenta a área deposicional, portanto caracterizando a feição como erosiva e deposicional.

No entanto van Gaalen et al. (2011) identificou a relação entre cúspides de diferentes escalas, ou seja, cúspides se comportavam como deposicionais quando estavam associadas a crista de uma megacúspide e erosivas quando associadas a cavas de uma megacúspides.

Coletas que estudam estes padrões de evolução temporal (presença ou não de cúspides), usualmente limitam-se por eventos únicos que registram um determinado instante. A observação através de vídeos consegue descrever a evolução temporal de uma feição analisando um ciclo completo de ocorrência das cúspides.

\section{2 Área de Estudo}

A área de estudo está localizada no Litoral Norte de São Paulo, faixa litorânea de transição entre a Serra do Mar e o Oceano Atlântico, mais especificamente no município de Caraguatatuba, que faz limite a sul com São Sebastião, a norte com Ubatuba e a oeste com o Vale do Paraíba.

O sistema praial de Massaguaçú (Figura 2.1) é constituído por uma praia em enseada dividida popularmente em três subdivisões: Praia do Capricórnio ao sul, Praia de Massaguaçú no centro e na sua extremidade norte a Praia da Cocanha. Para evitar confusões nesse trabalho, 
foram considerado como o arco praial de Massaguaçú as praias do Capricórnio, de Massaguaçú e da Cocanha sendo os limites extremos o rio Massaguaçú ao sul e o fim da praia da Cocanha ao norte.

O arco praial de Massaguaçú possui uma extensão aproximada de 7,5 km, situando-se ao norte da baía de Caraguatatuba, e é cortada pelos rios Capricórnio e Bracuí (Modenesi et al. 1983). Essa pequena planície costeira possui baixa densidade de drenagem com padrão meandrante e é recoberta por sedimentos holocênicos, flúvio-lagunares e coluviais (Suguio \& Martin, 1978).

A partir de três perfis praiais, Souza (1990) identificou características distintas ao longo do arco praial de Massaguaçú. No perfil mais ao norte ele obteve largura média e inclinação praial média de $32 \mathrm{~m} \mathrm{e} 7^{\circ}$ respectivamente, na porção central $17 \mathrm{~m} \mathrm{e} 10^{\circ}$ e na porção mais ao sul $20 \mathrm{~m} \mathrm{e} 7^{\circ}$.

Nuber (2008) realizou 36 perfis e 6 campos (de novembro de 2006 à março de 2008) espaçados a cada 200 metros e encontrou um decréscimo da largura do arco praial das extremidades para o centro do mesmo. O autor concluiu que ao longo dos anos ocorreram variações morfológicas e volumétricas do conteúdo praial prevalecendo acresção nas extremidades e erosão no centro do arco praial.

Segundo Souza (1990), a praia de Massaguaçú é constituída predominantemente de areias médias a grossas moderadamente selecionadas, com 4 classes texturais e também modais, sendo o carbonato bidetrítico ausente. A classe modal predominante é de areia grossa seguida de areia média. Cumpre ressaltar que predominam os valores normais de assimetria e curtose, ou seja, curvas simétricas e mesocúrticas, ressaltando o caráter unimodal desses sedimentos e/ou concentração em torno de uma ou duas classes granulométricas. 

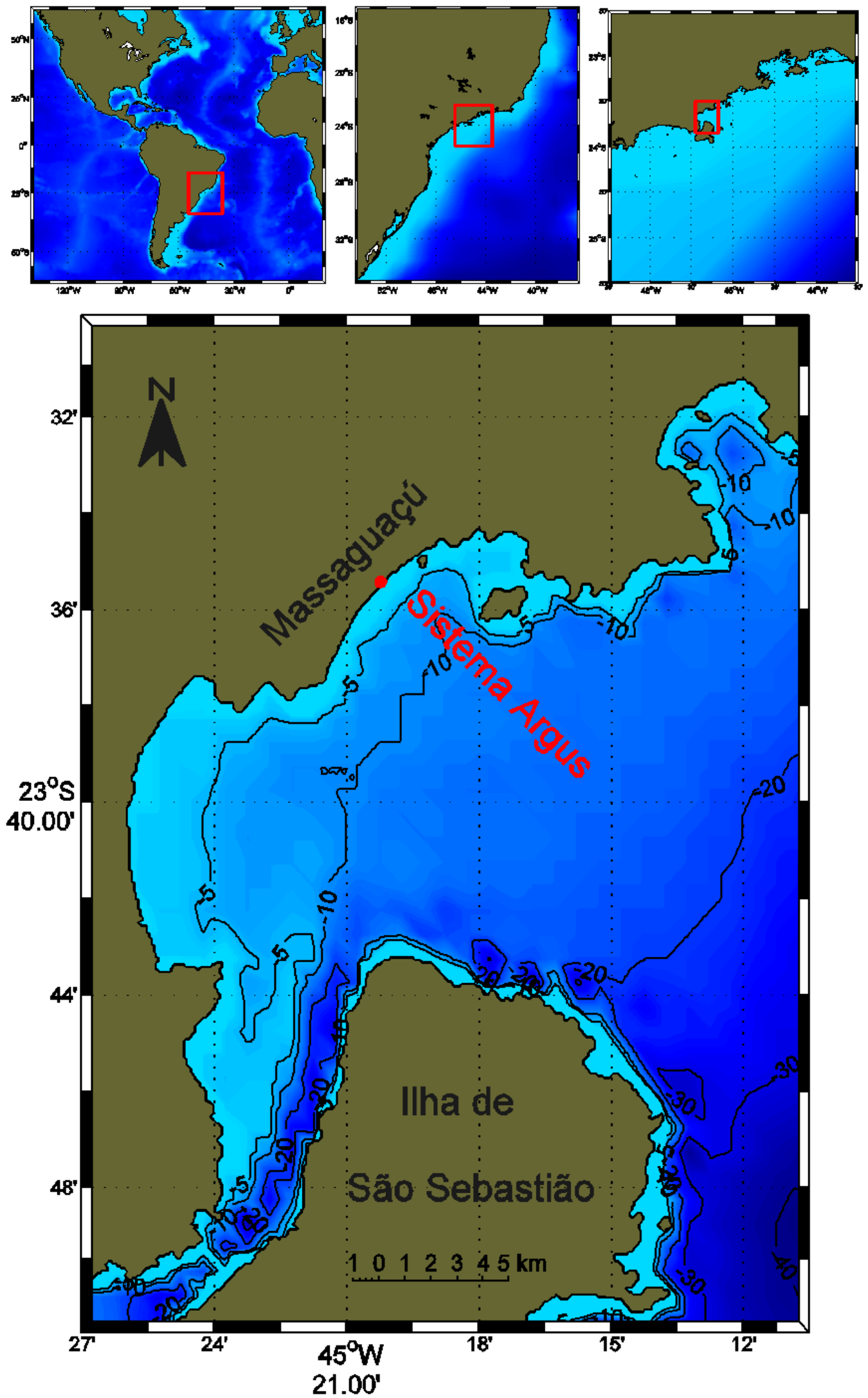

Figura 2.1: Localização da área de estudo. Na porção superior da esquerda para direita; América, Região Sudeste do Brasil, Litoral norte do Estado de São Paulo e na imagem em destaque a Praia de Massaguaçú onde se encontra o Sistema Argus. 
Nuber (2008) observou que a classe areia grossa foi dominante ao longo do arco praial ocorrendo areia média em 4 pontos de coleta, dois na porção central e dois situado mais ao norte do arco praial de Massaguaçú. Nuber (2008) também percebeu um decréscimo no tamanho médio do grão no arco praial de Massaguaçú no sentido da praia do Capricórnio à praia da Cocanha (de Sul para Norte).

A principal característica associada aos trens de ondas que atingem a costa de São Paulo é a relação com os ventos gerados no oceano, onde um dos centros geradores se encontra a leste e o outro a sul. O primeiro é predominante e está associado às ondas com alturas variando de 0,5 a $1 \mathrm{~m}$, o segundo está associado a valores que alcançam $2 \mathrm{~m}$. Com relação ao período dominante, predominam valores entre 0,6 e 20 segundos, no entanto há uma forte ocorrência de valores situados entre 9 e 11 segundos (Poçano et al., 1999). Segundo Tessler (1988) o trem de ondas predominante é de sudeste (SE), porém ocorrem ondas de sul (S) e sudoeste (SW) associado a sistemas de frentes que possuem maior energia para o transporte de sedimentos. Tessler (1988) ainda acredita que as ondas de SE são mais efetivas no transporte de sedimentos na costa paulista.

Rogacheski (2010), a partir de dados medidos na enseada adjacente à praia de Massaguaçú, afirma que ondulações de leste (E) e de leste-nordeste (E-NE) causam uma deriva litorânea para sul e a resultante do transporte em condições de alta energia, ondulações de S e SW, é para norte.

Pianca et al. (2010) estudou o clima de ondas baseada em uma série temporal de 11 anos para o ponto $\mathrm{W} 2\left(26^{\circ} \mathrm{S}, 45^{\circ} \mathrm{W}\right)$ localizado próximo ao ponto da boia de Santos e observou que durante os meses de inverno exibiam valores de altura e período máximos de 5,8 m e 16,2 s, mínimos de 0,5 m e 3,1 s, médios de 2,2 m e 8,7 s e direção média de $134^{\circ}$.

Sousa (2011) dividiu a praia de Massaguaçú em três setores (Setor 1, Setor 2 e Setor 3 (Figura 2.2) e analisou o risco devido à agentes ambientais e antropogênicos. O setor 1 é 
caracterizado por um recente crescimento urbano sem um planejamento, principalmente em torno da desembocadura do rio Massaguaçú, e é constituído majoritariamente de casas de veraneio, com uma taxa de ocupação de $24 \%$ e risco de $40 \%$.

A porção central, o setor 2, possui um alto nível de urbanização devido, em grande parte, à presença da rodovia Rio-Santos, responsável por um grande fluxo de veículos na região. A taxa de urbanização nesse setor é de $48 \%$ e as edificações se encontram a 70 m da linha de maré alta e a rodovia a $25 \mathrm{~m}$ desta mesma linha.

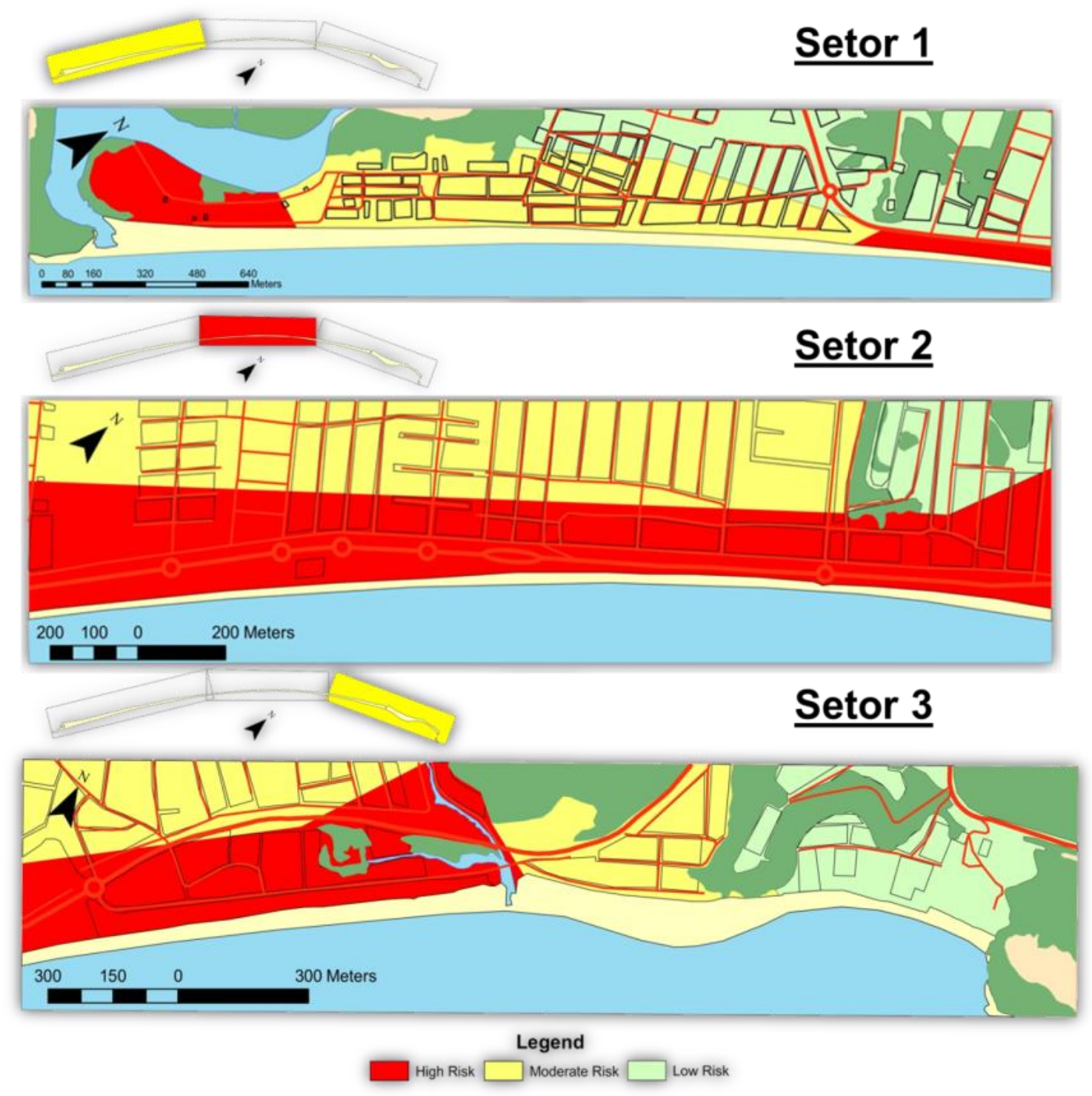

Figura 2.2: Setor 1, 2 e 3 e seus diferentes graus de risco (Fonte: Sousa, 2011). 
Durante eventos de alta energia, as ondas alcançam a rodovia causando destruições, obrigando a prefeitura a construir barricadas com sacos de areia para minimizar os efeitos destrutivos das ondas. Esse setor está visivelmente em uma situação de erosão com risco de $50 \%$, onde a atual situação de urbanização corrobora no desenvolvimento deste processo. A taxa de ocupação no setor 3 corresponde a $36 \%$ e o risco é de $40 \%$. A ocupação recente é limitada pelo relevo e pela guinada da rodovia na direção norte.

\section{Objetivos}

Relacionar as condições de ondas incidentes no arco praial de Massaguaçú com a presença e o comportamento de feições morfológicas como cúspides praiais.

\subsection{Objetivos Específicos}

- Avaliar quais as condições favoráveis ao aumento/diminuição do espaçamento das cúspides no arco praial de Massaguaçú.

- Avaliar as condições nas quais há formação/destruição de cúspides no arco praial de Massaguaçú.

\section{Materiais e Métodos}

\subsection{Sistema Argus}

Uma ferramenta que permite observar de forma contínua a região costeira são as estações Argus, que consistem na aquisição de dados remotos a partir de câmeras digitais instaladas na área de estudo de interesse. Esse sistema de sensoriamento remoto da zona costeira, Argus, foi desenvolvido pela equipe do Coastal Imaging Laboratory (CIL) da Oregon State University (OSU) e através do projeto "Análise da tridimensionalidade costeira integrando 
imagens de vídeo, experimentos de campo e modelagem numérica" financiado pelo CNPq, este sistema foi instalado no mês de junho de 2010 na Praia da Massaguaçú.

Uma estação Argus funciona como um coletor de dados através de imagens coloridas (1240 x 768 pixels) com uma visão de quase $180^{\circ}$ (Figura 4.2). Essas imagens são adquiridas a cada hora, sendo de três tipos: foto instantânea, imagem com exposição de 10 minutos e imagem com variações durante 10 minutos (Holman \& Stanley, 2007).

O primeiro tipo, imagens instantâneas (snapshot), é uma fotografia tirada no começo de cada hora que ajuda a interpretar dados coletados focando para uma análise quantitativa e não qualitativa (Figura 4.1, a). O segundo tipo é a imagem de longa exposição (10 minutos, timex) que representa a média de todas as imagens coletadas durante 10 minutos com uma frequência de dois Hz. Nesse tipo de aquisição a zona de arrebentação aparece como uma área clara que consiste na média das fotos instantâneas coletadas durante 10 minutos (Figura 4.1, b).

O terceiro tipo, variância (var), é a imagem com variações durante 10 minutos representando um conjunto de imagens onde se aplica o desvio padrão ao quadrado. Dessa maneira exaltam-se as regiões de máxima variação (em claro) e de mínima variação (em escuro) (Figura $4.1 \mathrm{c}$ ).

Almar et al. (2008) após analisar três anos de imagens observou que eventos de alta energia como tempestades desestabilizam as cúspides praias e em períodos de condições calmas há um desenvolvimento das cúspides praiais como documentado por Masselink et al (1997) que observou acresções causadas pela diminuição no fluxo do espraiamento nas cúspides praiais. Almar et al. (2008) também observou alterações no espaçamento entre as cúspides causadas pela junção de feições consecutivas, na maioria das vezes, simultaneamente às mudanças no padrão e espraiamento. 


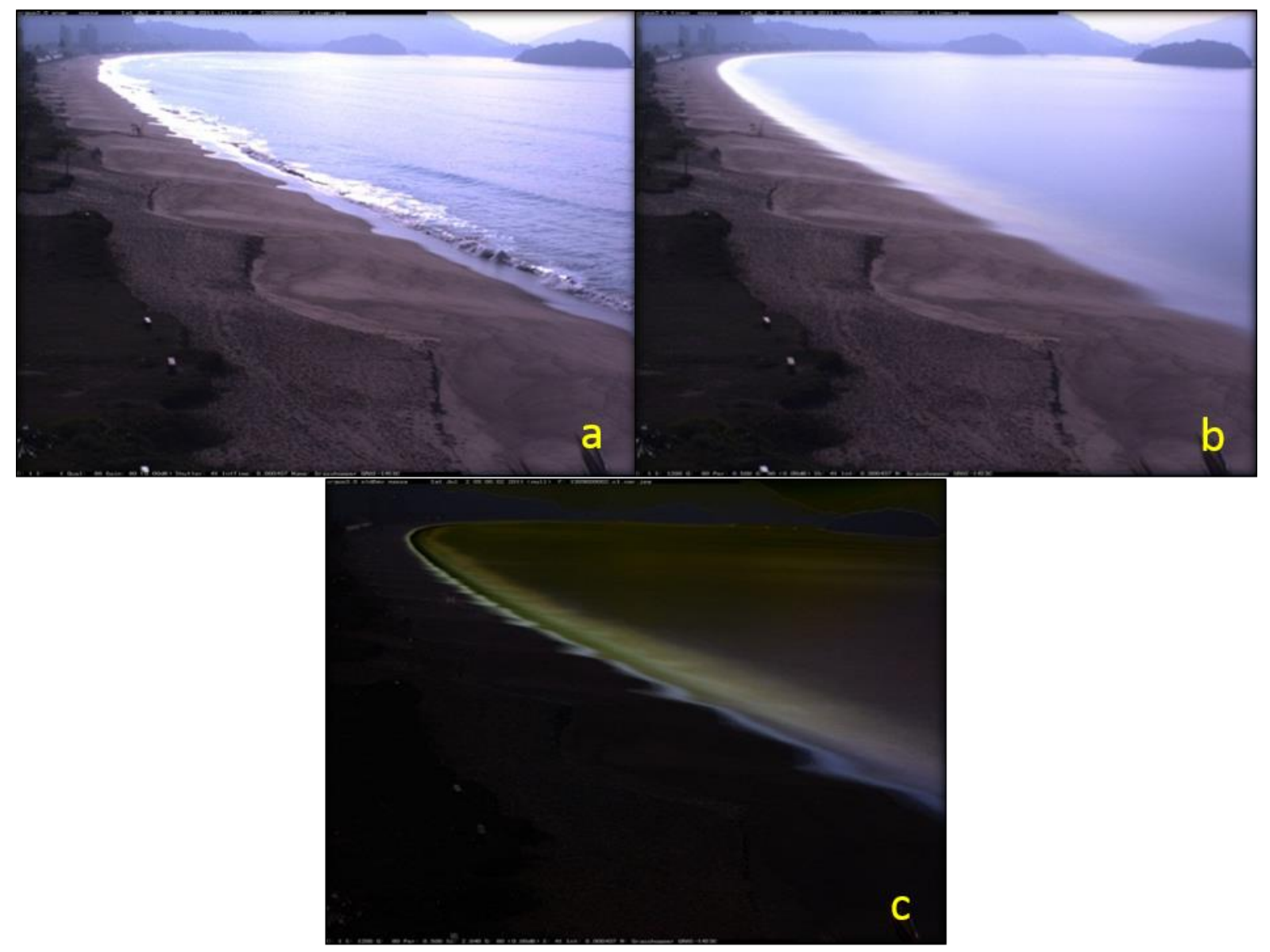

Figura 4.1: Fotografia instantânea (a, snapshot), imagens de longa exposição (b, timex) e imagem com as variações (c, var).

\subsection{Aquisição de Dados}

\subsubsection{Imagens de Vídeo}

As câmeras do sistema Argus encontram-se fixadas em um tubo de aço de $6 \mathrm{~m}$ de comprimento no topo do telhado do Hotel Brisa Flat, situado em frente à praia. As mesmas estão localizadas nas coordenadas $23^{\circ} 35^{\prime} 42.43^{\prime}$ ' S e $45^{\circ} 20^{\prime} 22.64^{\prime \prime}$ W e observam $180^{\circ}$ graus da praia de Massaguaçú.

Nesse trabalho são analisados $500 \mathrm{~m}$ de cada lado do arco praial, resultando em imagens de $1000 \mathrm{~m}$ de comprimento (Figura 4.3). Foram analisadas 210 imagens de cada tipo (snapshot, timex, var) entre 9 de abril à 30 de dezembro de 2012 


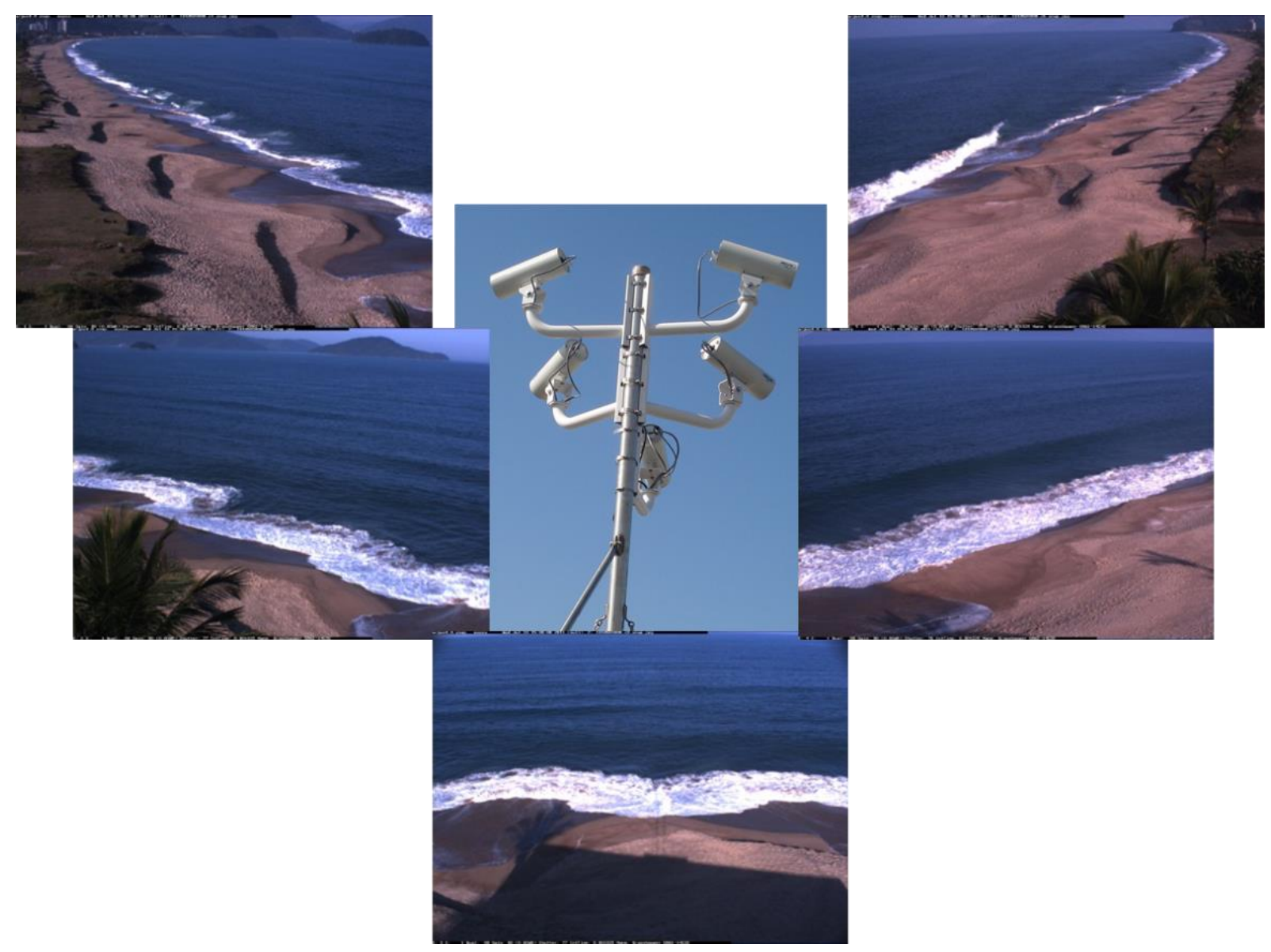

Figura 4.2: Figura com as cinco câmeras do sistema Argus centralizada e com as imagens adquiridas de cada câmera ao redor.

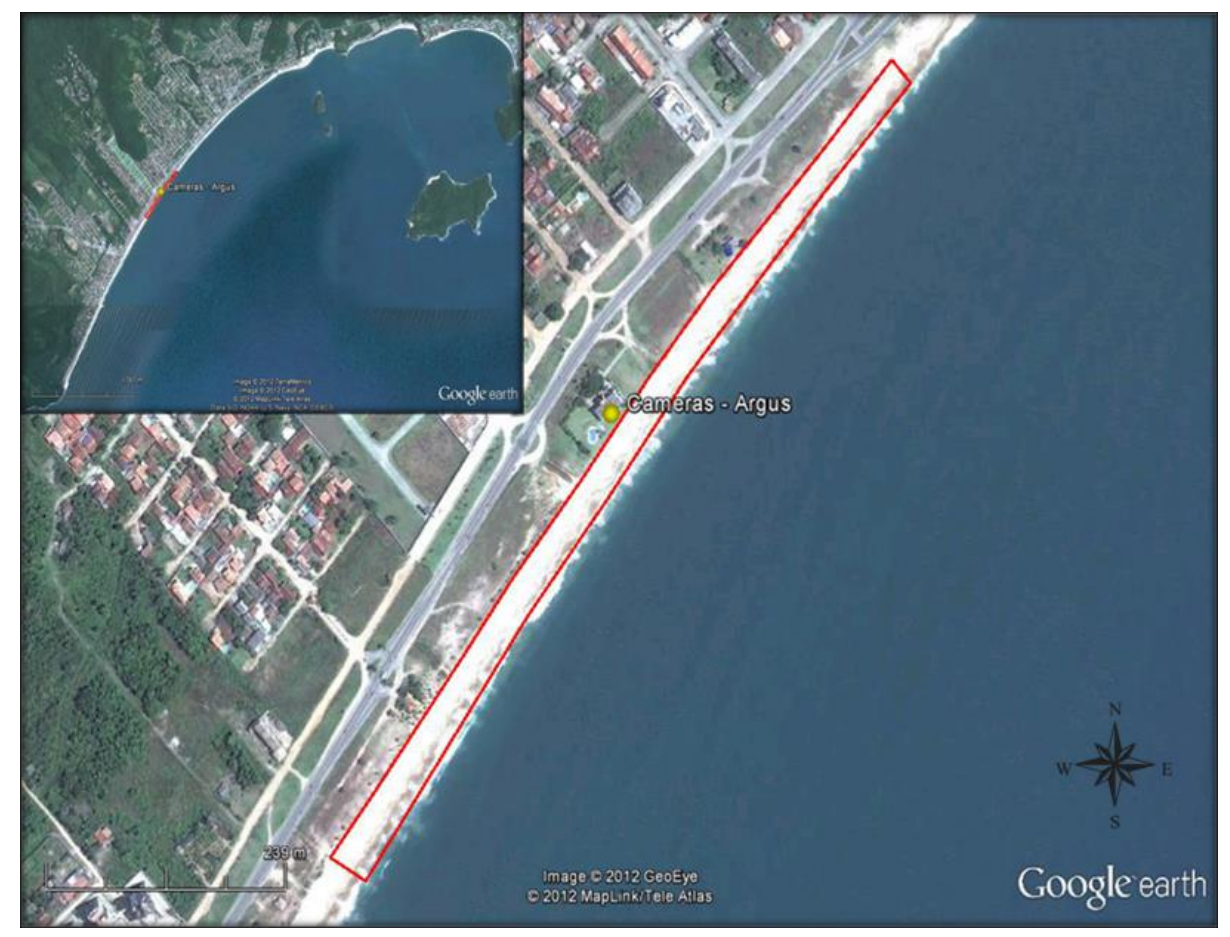

Figura 4.3: Área analisada nas imagens do arco praial de Massaguaçú (retângulo em vermelho). 


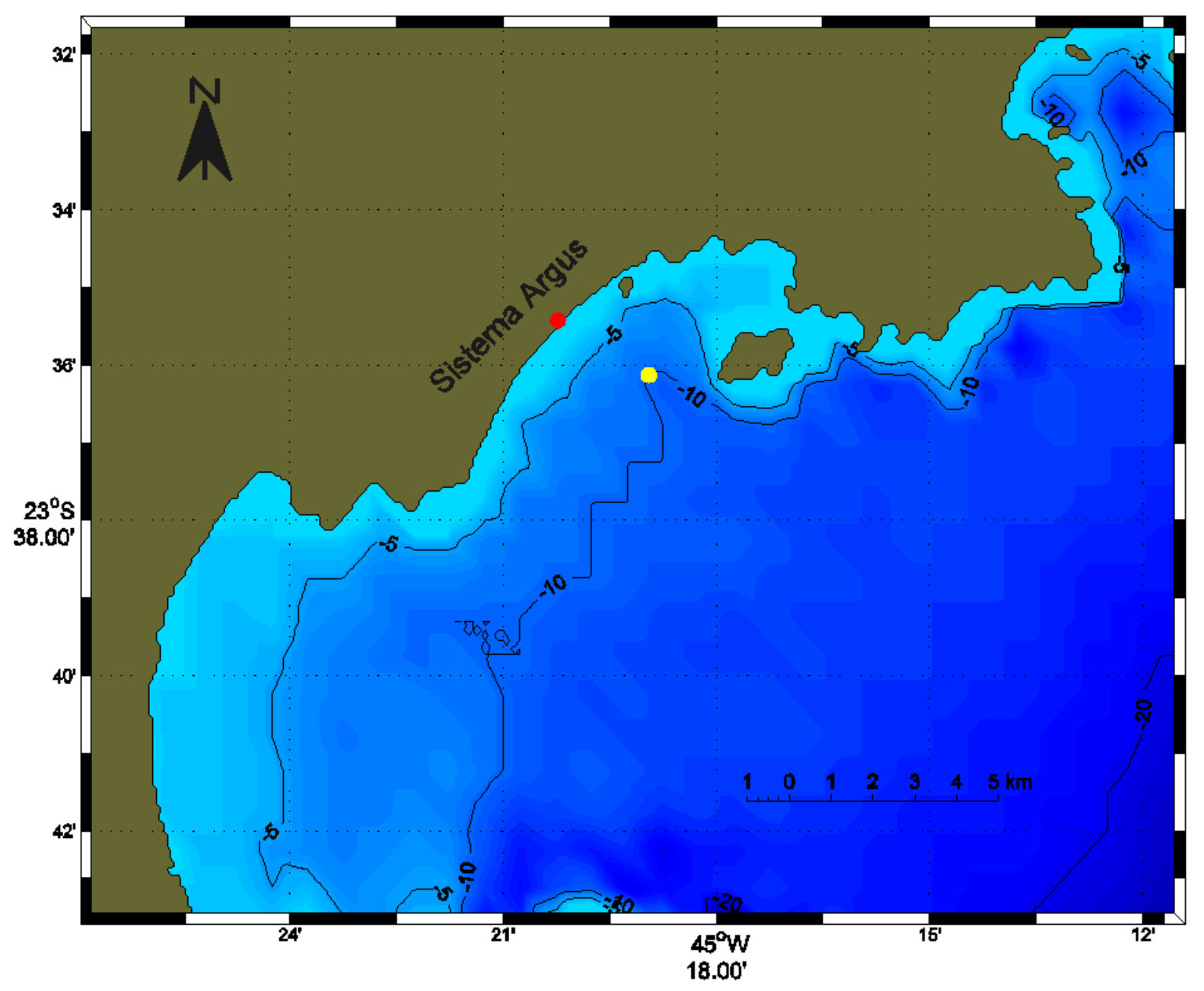

Figura 4.4: Localização dos dados de onda utilizados para comparação com as feições rítmicas. Em amarelo a posição referente aos dados de ondas e em vermelho a posição referente ao sistema Argus,

\subsubsection{Ondas Incidentes}

As informações de ondas utilizadas nesse trabalho são referentes ao período de coleta das imagens analisadas (2012) e foram fornecidas pelo Laboratório de Dinâmica Costeira (LDC-IOUSP) através de seu modelo São Paulo (SP). O modelo SP é a aplicação do módulo de propagação de ondas do modelo numérico Delft3D (Deltares) para o estado de São Paulo. Esse modelo é baseado em informações de ondas extraídas do modelo global de geração de ondas WaveWatch III (NWWIII - NOAA/NCEP - Tolman, 1999) propagadas para a costa através do modelo de propagação de ondas para águas rasas. O modelo SP, cujos resultados foram utilizados nesse trabalho, abrange grande parte da plataforma continental do estado de 
São Paulo e adjacências. A resolução da malha varia no domínio, com maior resolução nas áreas costeiras. Para esse caso específico maior resolução foi definida na baía de Caraguatatuba. A condição de contorno utilizada foi a série temporal de dados extraídos do modelo global NWWIII na região da quebra da plataforma para o ano de 2012. A série temporal de ondas utilizada foi extraída na isóbata de aproximadamente 10 m na região da baía de Caraguatatuba (Figura 4.4).

\subsubsection{Sistemas Frontais}

Os dados referentes ao número de sistemas frontais atuantes na costa brasileira durante o período analisado são disponibilizados pelo Centro de Previsão de Tempo e Estudos Climáticos do Instituto Nacional de Pesquisas Espaciais (CEPTEC-INPE). Estes dados são disponibilizados por meio de cartas mensais de síntese sinótica sobre o acompanhamento dos principais sistemas meteorológicos que atuaram acima do paralelo $40^{\circ} \mathrm{S}$.

\subsection{Processamento dos Dados}

As imagens do sistema Argus foram processadas através de um conjunto de algoritmos desenvolvidos em ambiente Matlab. O processamento inicial envolve técnicas de transformação de imagem e requer alta resolução e boa compreensão da geometria da imagem. O primeiro passo é a transformação fotogramétrica entre as coordenadas 3D do terreno e as da imagem 2D. O resultado é uma imagem retificada com dimensões corrigidas para a projeção no plano cartesiano, o que permite medições das escalas morfológicas da praia (Holman \& Stanley, 2007).

Em seguida, transforma-se os valores dos pixels em tipo double (esse tipo permite números com mais casas) para a realização de futuros cálculos. Dessa maneira podemos transformar a imagem original colorida em tons de cinza e, portanto cada pixel desta imagem possuirá um valor correspondente. Esse valor pode ser transformado em uma sequência binária 
de 8 bits, ou seja, os números são representados por 8 valores de 0 e/ou 1 (ex. 8=00001000, $4=00000100,5=00000101,33=00010001,255=11111111)$.

Com os pixels representados por sequências binárias podemos dividir a imagem em 8 planos, portanto o primeiro plano só representa o último 0 ou 1 da sequência da mesma forma que o último plano só representa o primeiro 0 ou 1 da sequência.
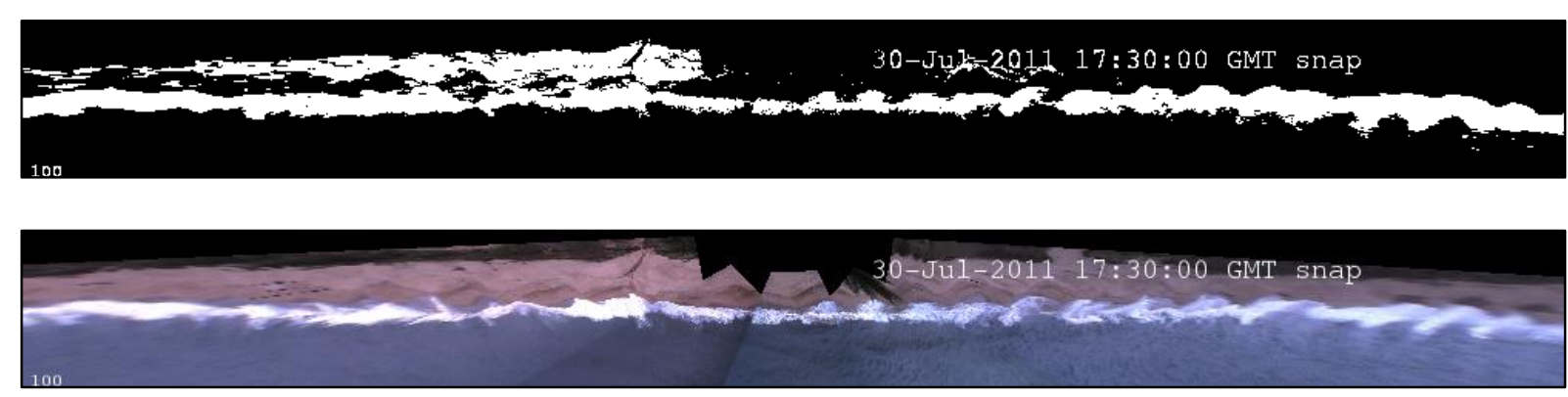

Figura 4.5: Último plano de bit (acima), imagem original (abaixo).

Com esse processamento pode se observar alguns sinais nas imagens, devido a facilidade em se observar uma diferença entre 0 (preto) e 1 (branco) do que uma diferença entre 233 (cinza escuro) e 234 (cinza um pouco mais escuro) quando esses valores aparecem como uma figura (Figura 4.5).

Com esses dois tipos de imagens digitalizaram-se as cúspides de todas as imagens utilizando o programa Surfer 10 (Golden Software) gerando duas digitalizações, uma na linha d'água, cúspides localizadas na região de espraiamento e outro no máximo alcance do espraiamento observado, cúspides localizadas na região da berma, como se pode observar na Figura 4.7. Essa digitalização gerou arquivos de extensão .dat posteriormente processados no programa Matlab r2013a e representados de maneira gráfica.

A partir das digitalizações, calculou-se ponto a ponto a largura entre a linha de vegetação e a linha d'água (Figura 4.8) e as variações diárias ao longo do mês de julho e início de agosto.

O processamento dos dados de ondas foi realizado no programa Matlab, gerando histogramas de direção, altura, período e elevação, assim como da evolução dessas variáveis durante a aquisição de imagens. 


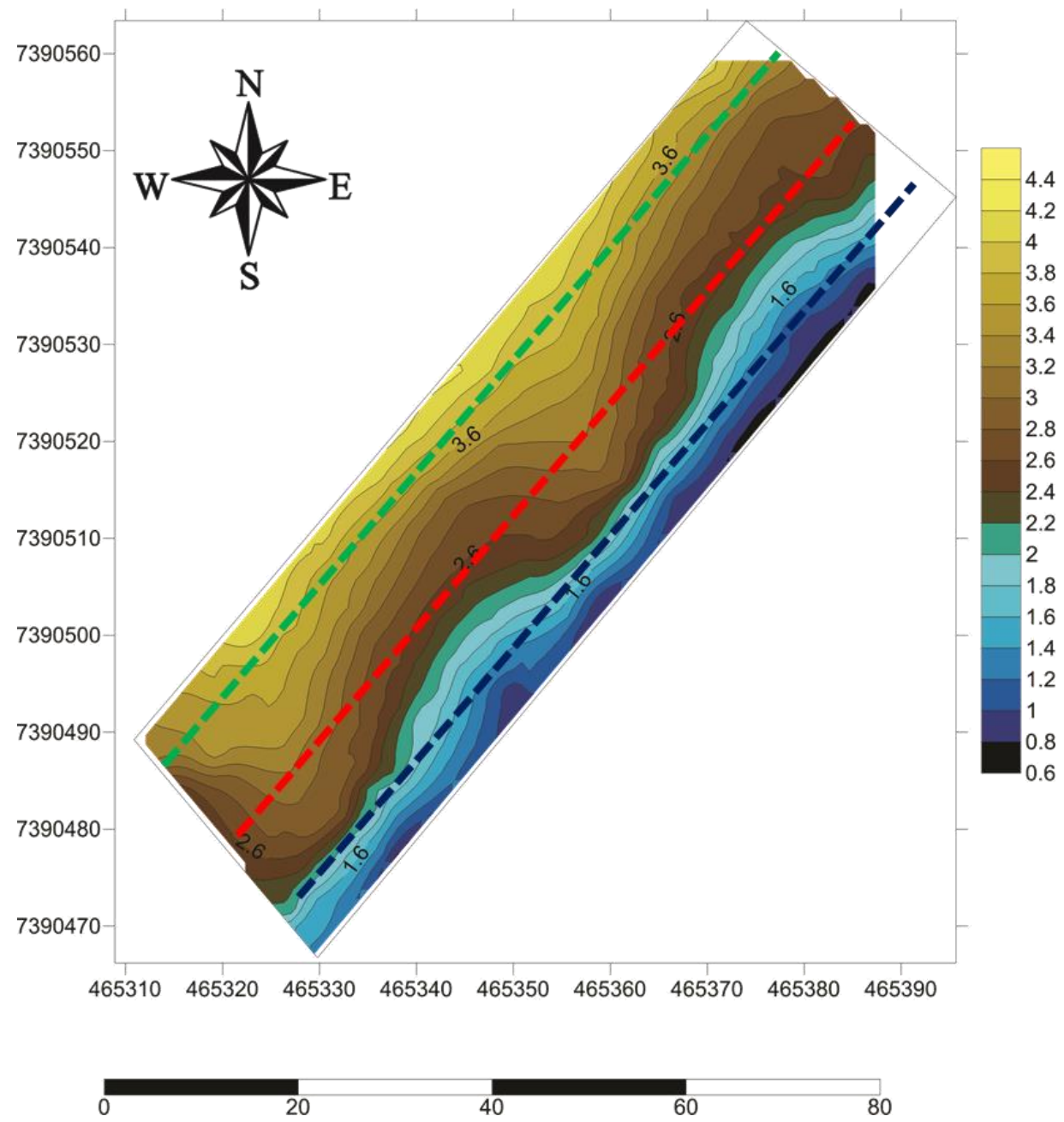

Figura 4.6: Esquema representativo de cúspides em trecho do arco praial de Massaguaçú. Em vermelho as cúspides na face praial superior e em azul cúspides na face praial inferior.

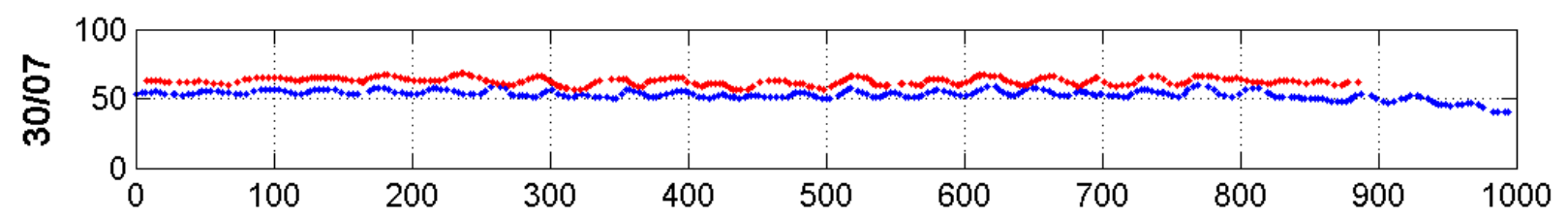

Figura 4.7: Cúspides digitalizadas: em azul cúspides na face praial inferior e em vermelho as cúspides na face praial superior.

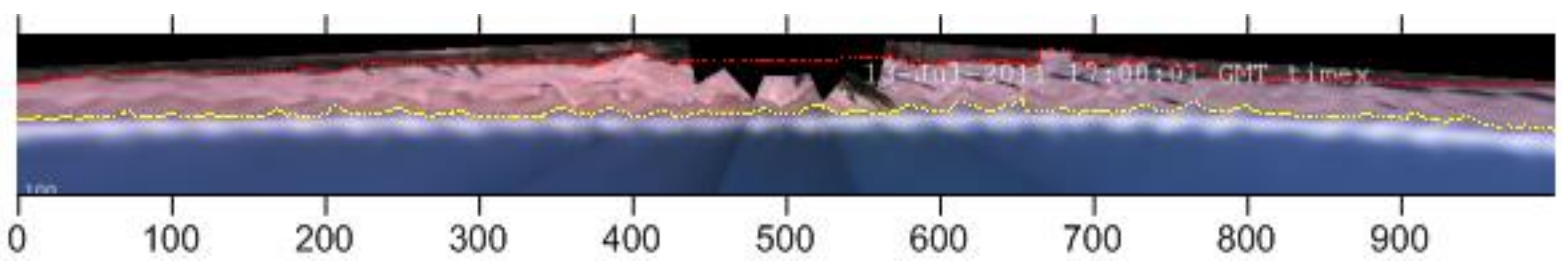

Figura 4.8: Imagem com exemplo das linhas digitalizadas utilizadas para calcular a largura do perfil praial (amarelo - linha d'água; vermelho - linha de vegetação. 


\section{Resultados}

O conjunto de dados de imagens do Sistema Argus compreende o período de 9 de abril de 2012 à 30 de dezembro de 2012. Desses 266 dias, 210 dias foram analisados, devido a disponibilidade das imagens. Foram utilizadas para a digitalização as imagens de longa exposição (timex) por elas reproduzirem melhor o espaçamento entre cristas consecutivas. Em algumas imagens o espraiamento encobria tanto as cristas como as cavas das cúspides mascarando o espaçamento das feições rítmicas. Além das imagens de longa exposição (timex), para auxiliar nas análise e interpretação as imagens instantâneas e de variância também foram utilizadas.

Para o mesmo período foram analisados as ondas atuantes e as passagens de frente frias no sistema praial de Massaguaçú que compreende o período do dia um de abril de 2012 à 31 de dezembro de 2012.

\subsection{Ondas incidentes}

Em todo o período analisado as ondas encontradas estavam entre oeste-sudoeste e nordeste-leste, sendo as maiores alturas registradas na direção sudoeste-sul. A altura, o período e a direção mais frequentes no período estudado foram $1,93 \mathrm{~m}, 8,94 \mathrm{~s}$ e $193,96^{\circ}$ respectivamente indicando uma predominância nas ondulações vindas de sudoeste-sul (Figuras 5.1, 5.3, 5.5; e Tabela 5.1).

Apresentando os histogramas direcionais com apenas 8 divisões (N, NE, E, SE, S, SW, W, NW) percebemos uma primeira predominância em relação as ondulações de sul e uma segunda predominância das ondulação vindas de leste da mesma forma que encontrado por Pianca et. al. (2010) (Figuras 5.2 e 5.4).

Apesar de a ilha de São Sebastião situar-se a sul do arco praial de Massaguaçú e causar claras influências ao clima de ondas provenientes do quadrante sul (Tessler, 1988), as 
ondulações que alcançam o arco praial chegam quase paralelamente a praia com uma predominância da direção sudeste.

Além disso, a formação das cúspides são mais fávoraveis nas praias em enseada (Komar, 1998), como a praia de Massaguaçú, pois ondas que incidem oblíquamente são menos prováveis de ocorrer devido ao processo de refração das ondas incidentes causado pela batimetria local.

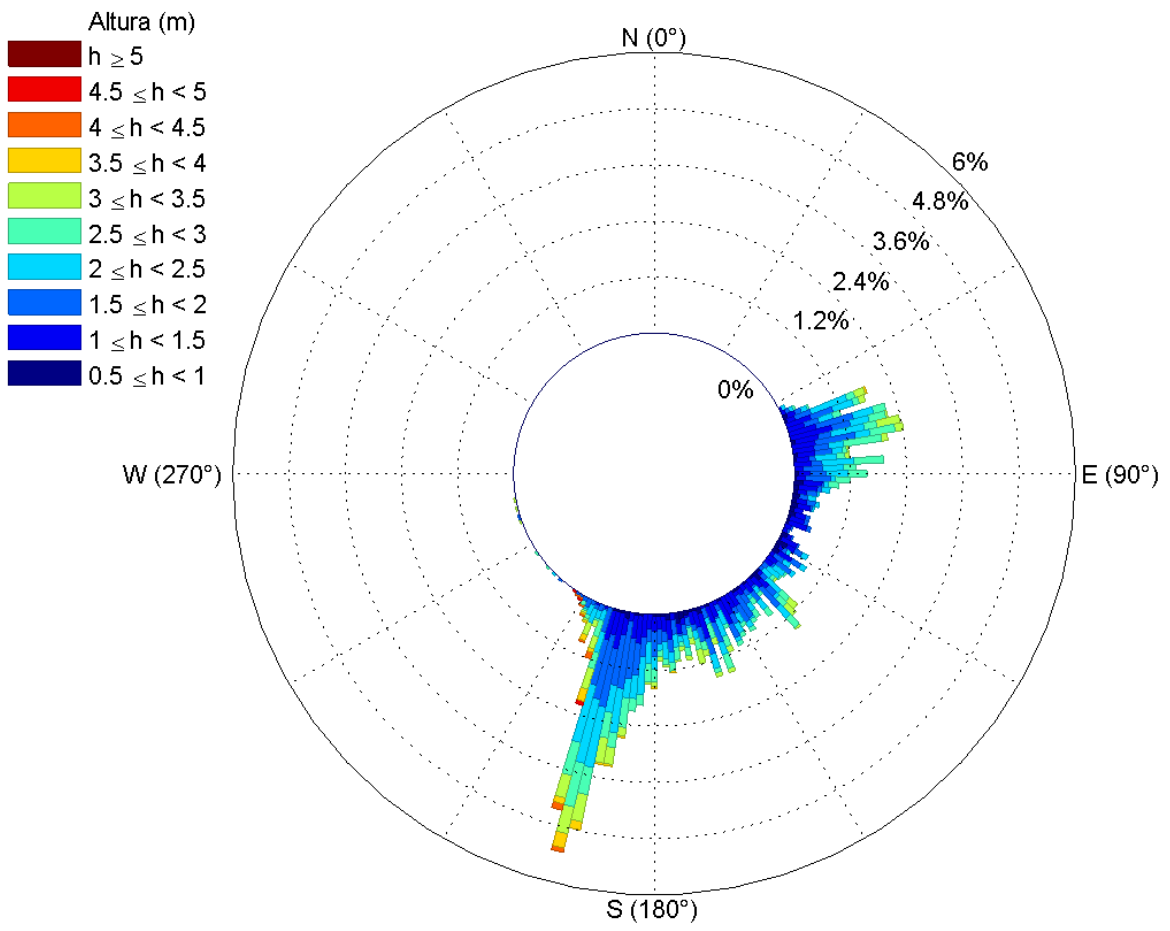

Figura 5.1: Histogramas de direção e altura (m) para toda série temporal. 


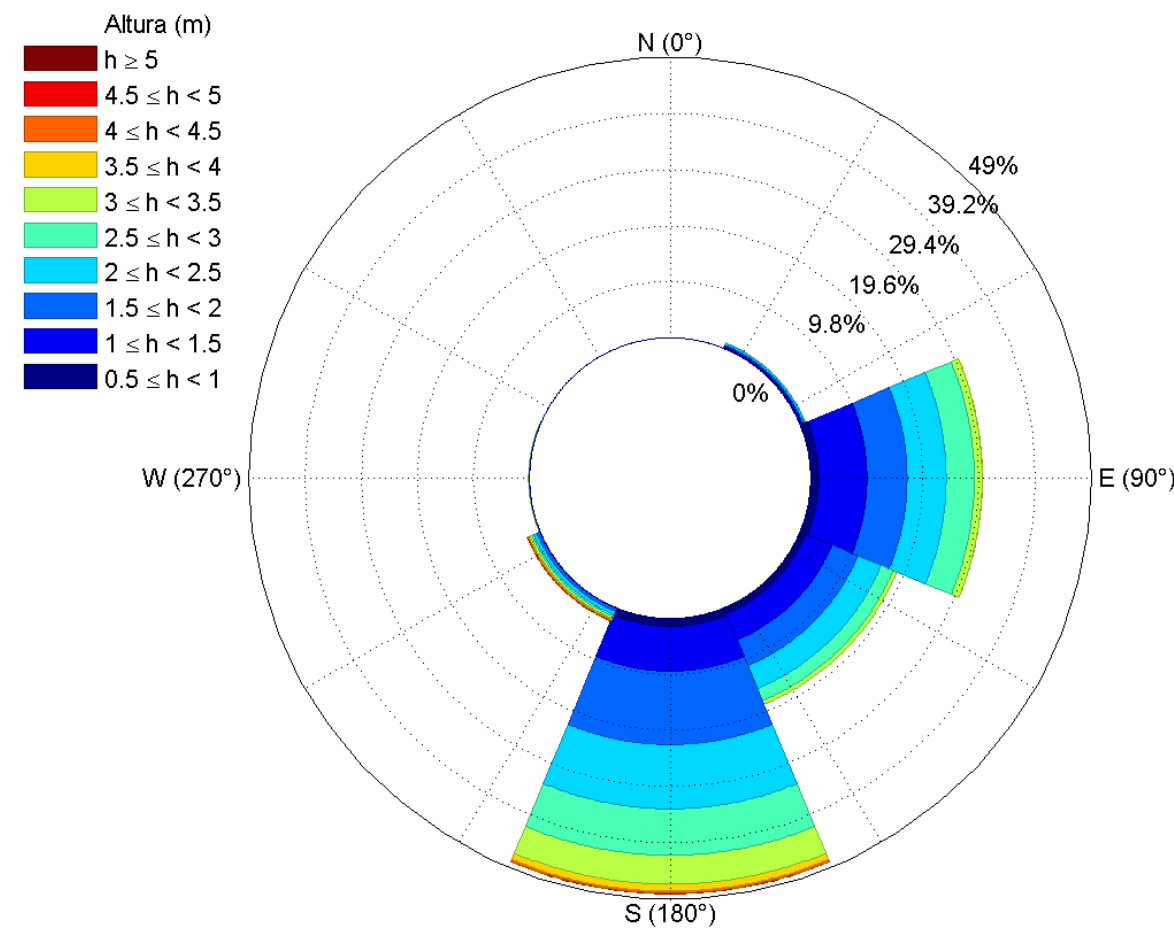

Figura 5.2: Histogramas de direção e altura (m) para toda série temporal (N, NE, E, SE, S, SW, W, NW).

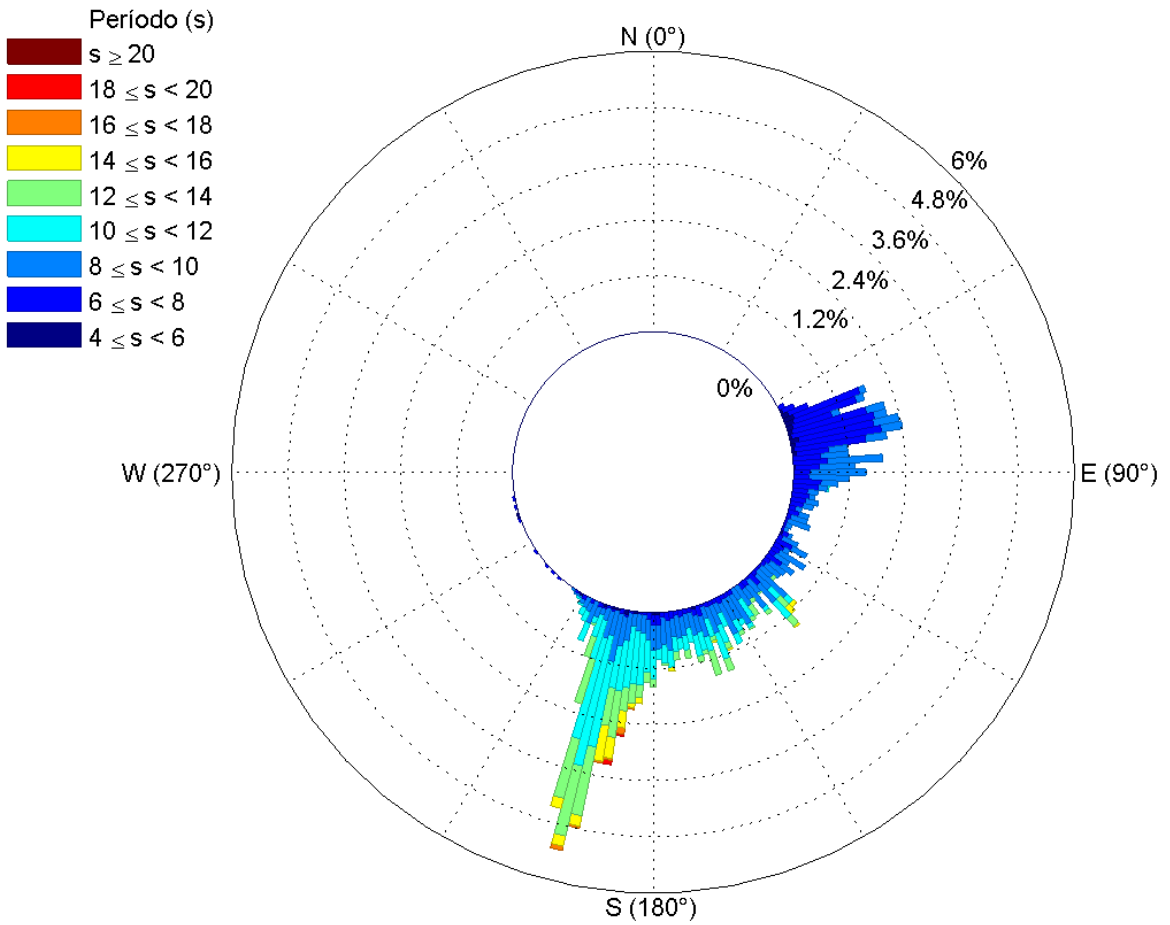

Figura 5.3: Histogramas de direção e período (s) para toda série temporal. 


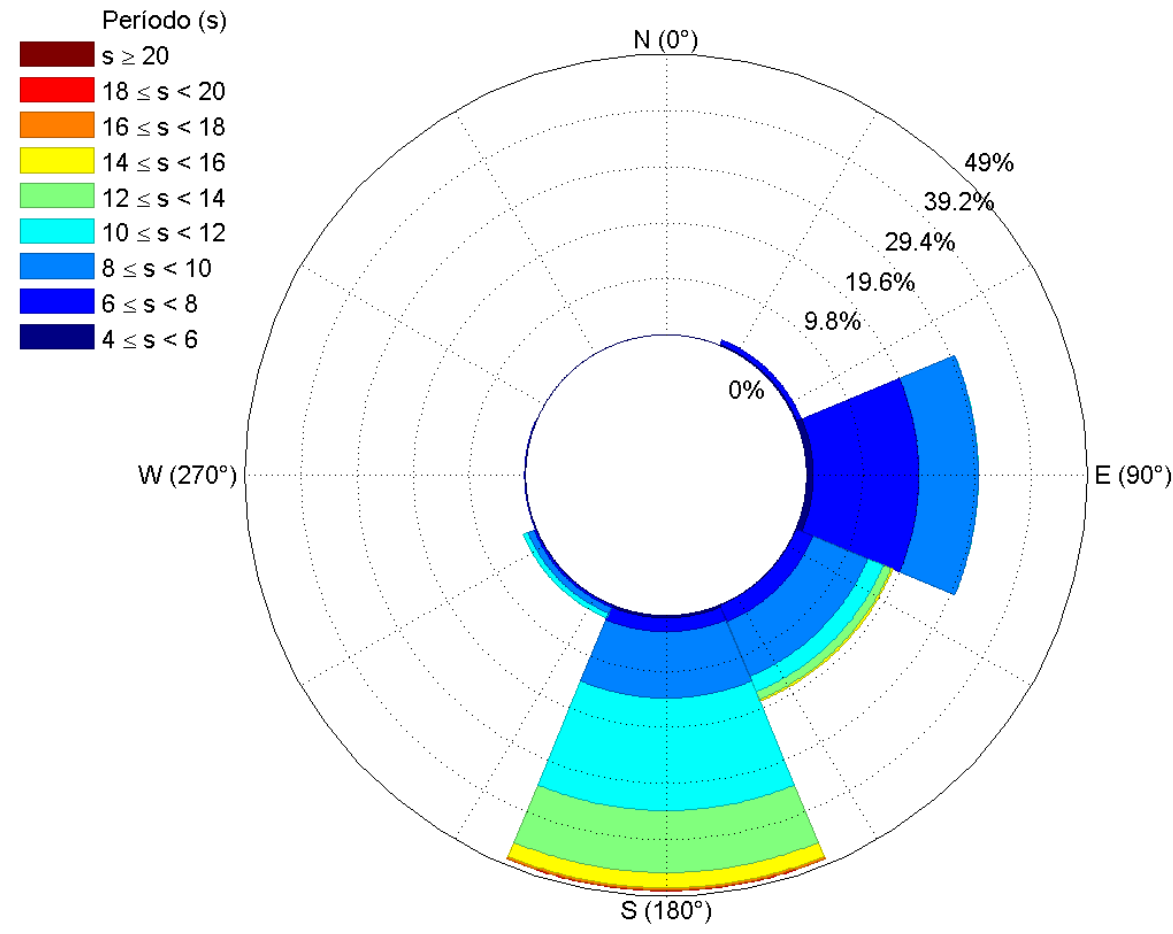

Figura 5.4: Histogramas de direção e período (s) para toda série temporal (N, NE, E, SE, S, SW, W, NW).
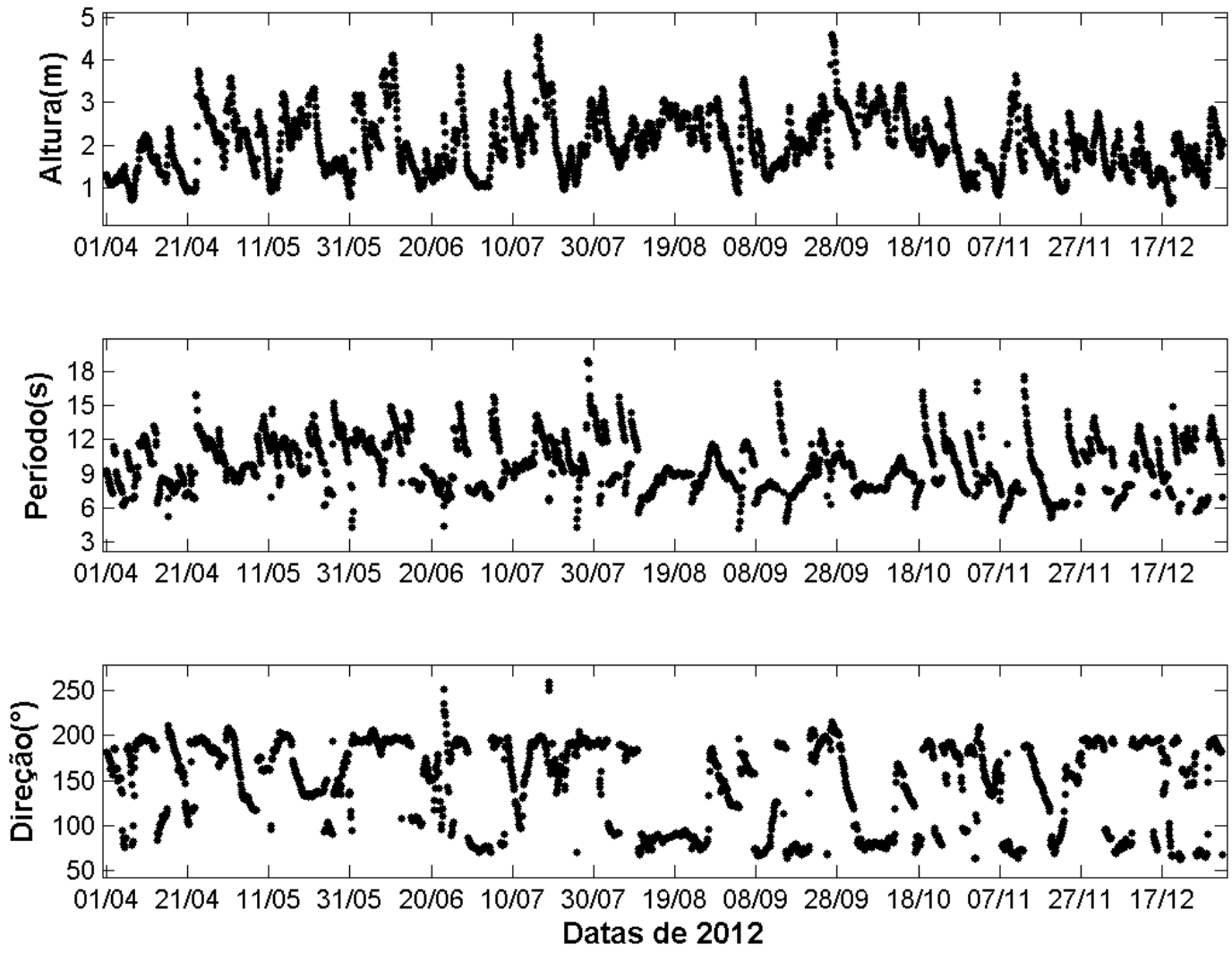

Figura 5.5: Evolução da altura, período e direção para toda série temporal. 

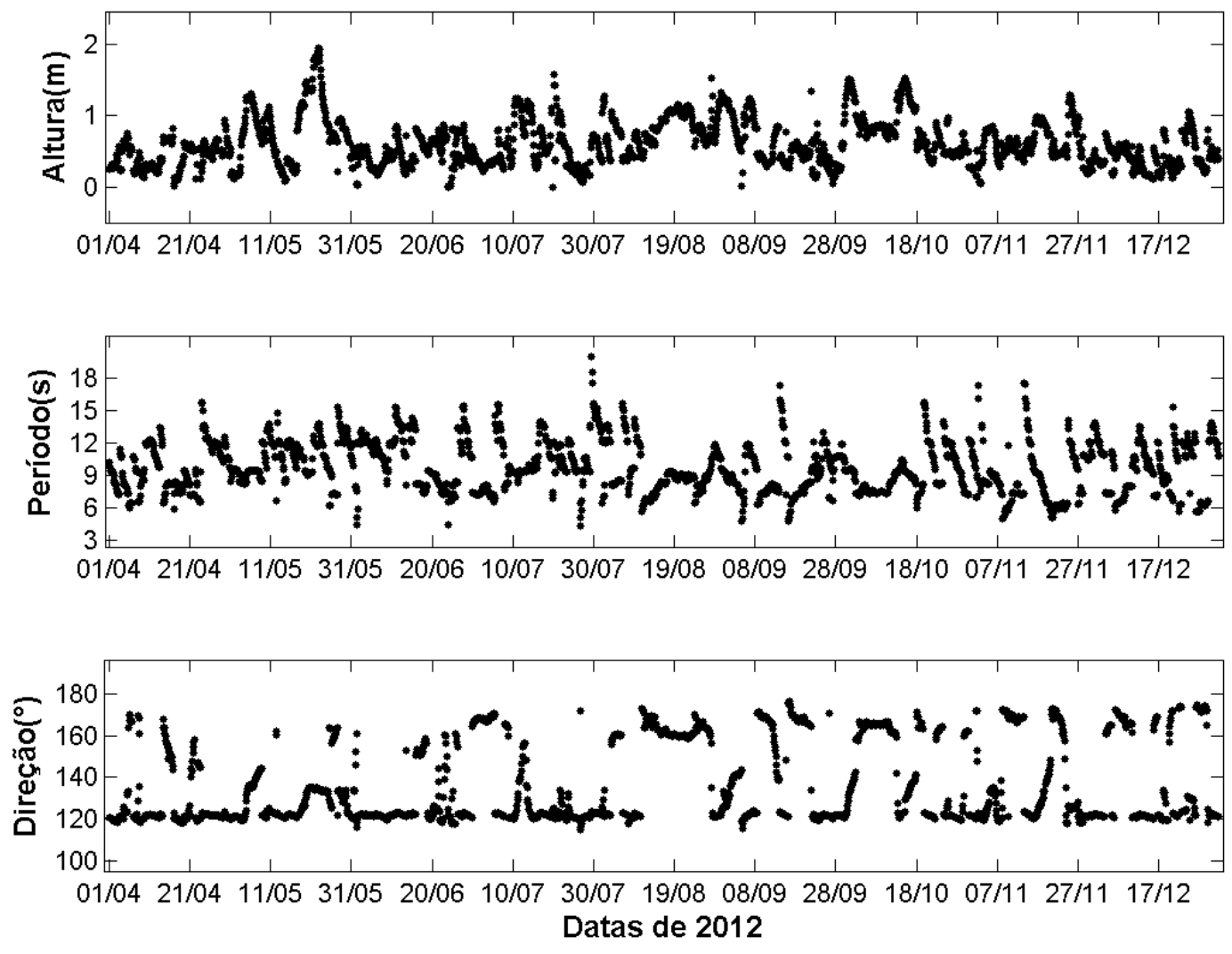

Figura 5.6: Evolução da altura, período e direção atuantes no arco praial de Massaguaçú.

A direção normal ao arco praial de Massaguaçú é de $128,22^{\circ}$ e nesse período a direção predominânte foi de $121,80^{\circ}$ que consiste na direção sudeste-leste pode-se dizer que valores acima ou a baixo geram transporte lateral.

Rogacheski (2010) observou que as ondulações de leste-nordeste promovem uma deriva litorânea para sul e eventos de alta energia provocam o transporte, paralelo ao arco praial, para norte. Esse transporte pode ser a causa de destruição de feições rítmicas ao longo do arco praial de Massaguaçú e as ondulações de sudeste favoráveis a geração das mesmas.

A altura, o período e a direção mais frequentes foram respectivamente 1,06 m, 12,10 s e 121,80 indicando uma predominância de ondas quase paralelas ao arco praial de Massaguaçú (Figuras 5.6, 5.7 e 5.8; e Tabela 5.2). 
Tabela 5.1: Características de ondas para toda série temporal (Plataforma).

\begin{tabular}{|c|c|c|c|} 
& Altura $(\mathbf{m})$ & Período $(\mathbf{s})$ & Direção $\left(^{\circ}\right.$ ) \\
\hline Máximo & 4.59 & 18.87 & 258.97 \\
\hline Mínimo & 0.63 & 4.23 & 62.72 \\
\hline Média & 2.03 & 9.66 & 145.35 \\
\hline Moda & 1.93 & 8.94 & 193.96 \\
\hline Desvio Padrão & 0.70 & 2.23 & 47.09 \\
\hline
\end{tabular}

Tabela 5.2: Características de ondas no arco praial de Massaguaçú para toda série temporal.

\begin{tabular}{|c|c|c|c|} 
& Altura $(\mathbf{m})$ & Período $(\mathbf{s})$ & Direção $\left(^{\circ}\right)$ \\
\hline Máximo & 1.95 & 20.00 & 176.41 \\
\hline Mínimo & 0.00 & 4.36 & 114.90 \\
\hline Média & 0.61 & 9.64 & 136.78 \\
\hline Moda & 1.06 & 12.10 & 121.80 \\
\hline Desvio Padrão & 0.33 & 2.33 & 19.52 \\
\hline
\end{tabular}

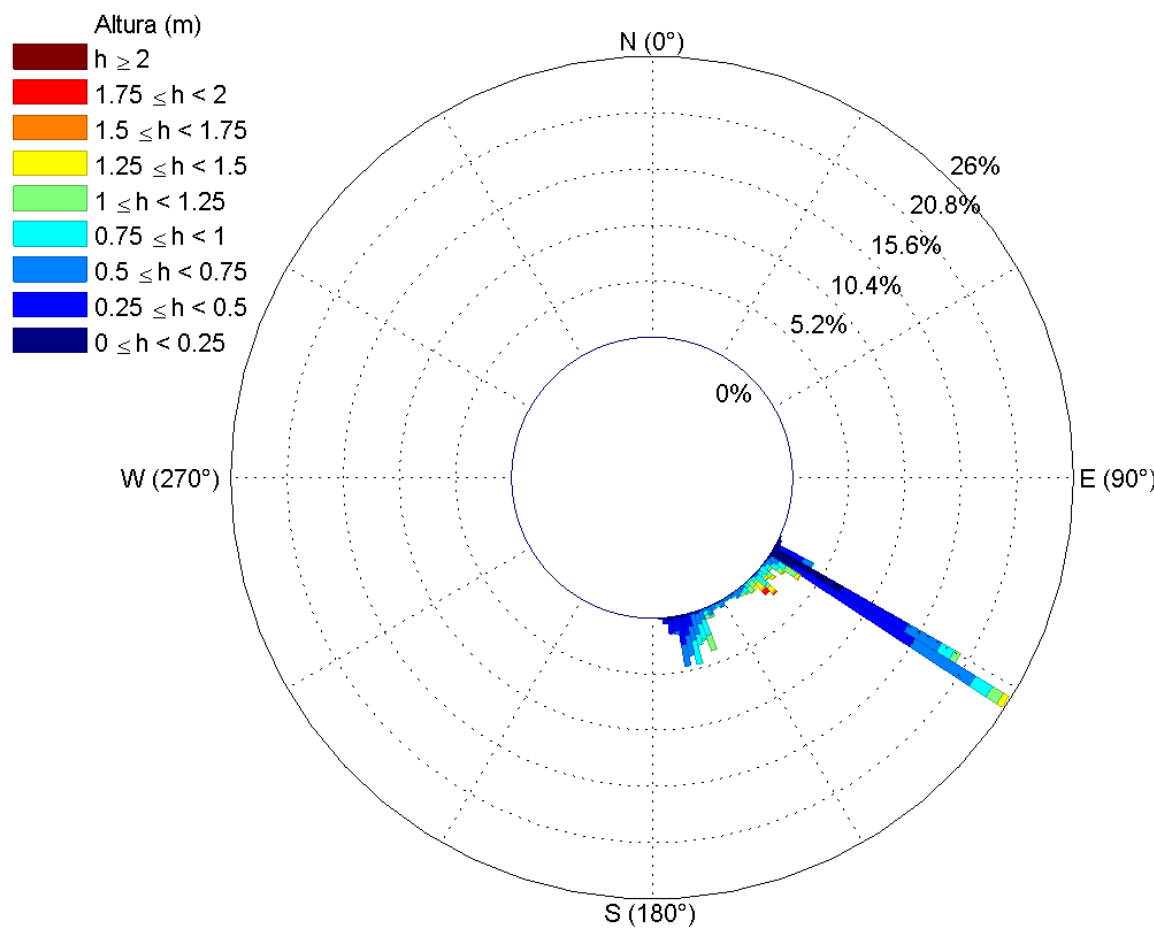

Figura 5.7: Histogramas de direção e altura (m) atuantes no arco praial de Massaguaçú. 


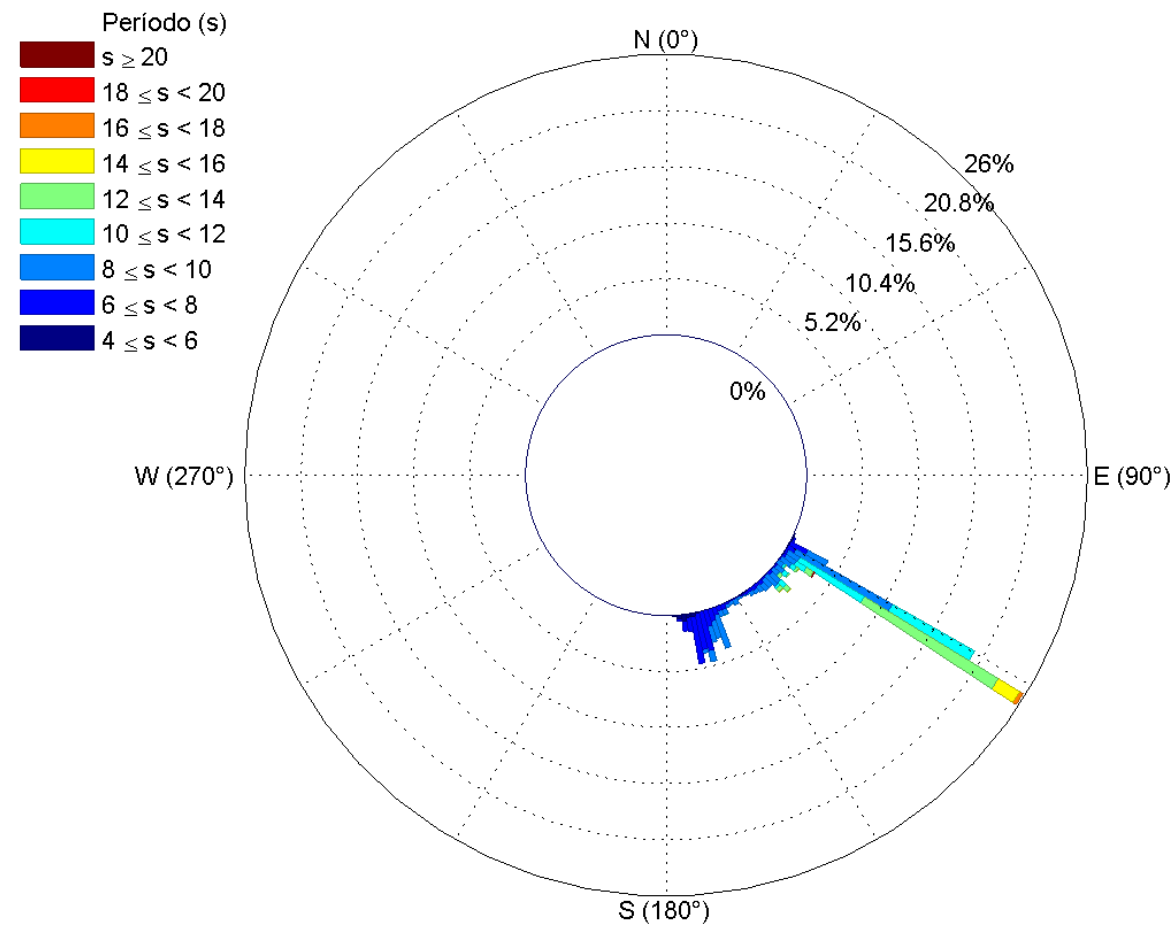

Figura 5.8: Histogramas de direção e período (s) atuantes no arco praial de Massaguaçú.

\subsection{Sistemas frontais}

A presença de sistemas frontais atuantes durante todo o período analisado variou consideravelmente. A Tabela 5.3 e a Figura 5.9 demostram o número de frente frias atuantes na costa sudeste brasileira.

Tabela 5.3: Número de sistemas frontais ao longo da América do Sul, costa brasileira e Ubatuba.

\begin{tabular}{|c|c|c|c|}
\hline & América do Sul & Costa Brasileira & Ubatuba \\
\hline Abr/2012 & 9 & 6 & 2 \\
\hline Mai/2012 & 7 & 3 & 3 \\
\hline Jun/2012 & 10 & 10 & 5 \\
\hline Jul/2012 & 11 & 7 & 2 \\
\hline Ago/2012 & 9 & 7 & 3 \\
\hline Set/2012 & 8 & 6 & 2 \\
\hline Out/2012 & 12 & 4 & 1 \\
\hline Nov/2012 & 7 & 6 & 0 \\
\hline Dez/2012 & 11 & & 2 \\
\hline
\end{tabular}


Durante o período analisado os meses que apresentaram o maior número de ocorrências foram os meses de junho, julho, outubro e dezembro, com 10, 11, 12, 11 ocorrências respectivamente. $\mathrm{O}$ mês com o menor número de ocorrências foi novembro, com 7 ocorrências.

Dos sistemas frontais que conseguiram adentrar na costa brasileira o meses com o maior e menor número de ocorrências foram respectivamentes julho com 10 ocorrências registradas e maio com 4.

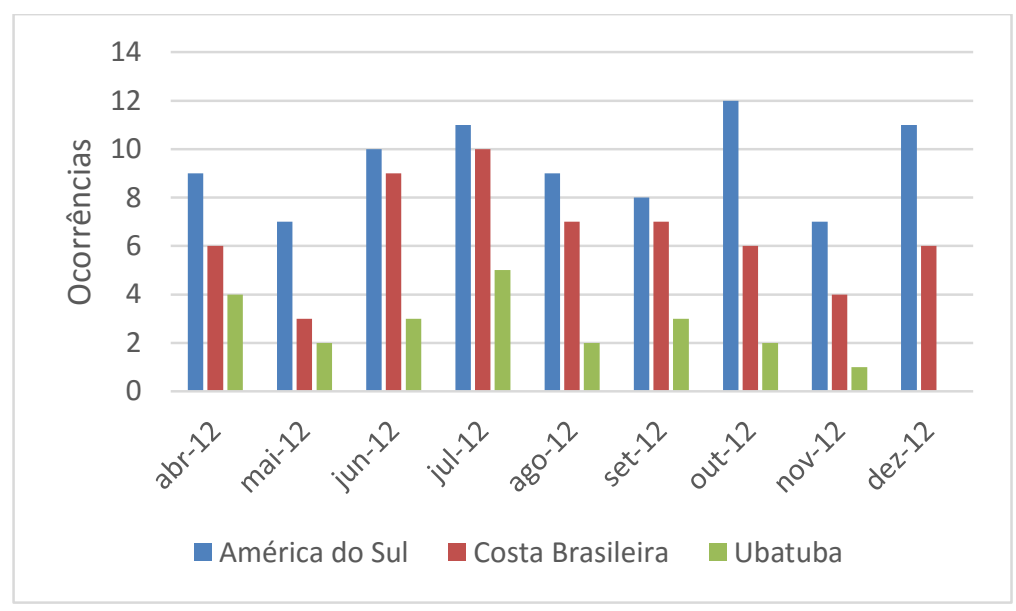

Figura 5.9: Número de sistemas frontais ao longo da América do Sul, costa brasileira e Ubatuba.

\subsection{Cúspides Praiais}

A partir da análise das imagens durante todo o período foi possível observar uma grande variedade de situações com a presença ou ausências de feições rítmicas no arco praial de Massaguaçú. Encontrou-se 2 linhas de cúspides uma na face praial inferior (CFI) e outra na face praial superior (CFS). As cúspides na face praial inferior ocorrerão em 92 dias dos 210 dias analisados, enquanto as cúspides na face praial superior ocorrerão em 176 dias.

A série de 210 dias foi subdivido em 14 momentos, do momento 1 ao 14, definidos de acordo com a predominância de feições rítmicas na face praial inferior (Tabela 5.4). 
Tabela 5.4: Subdivisões de todo o período analisado com suas respectivas datas de início e fim, $\mathrm{n}^{\circ}$ de dias analisados em cada subperíodo e a predominância, ou não, de feições rítmicas na face praial inferior (CFI) e superior (CFS)

\begin{tabular}{|c|c|c|c|c|c|}
\hline & \multirow{2}{*}{$\begin{array}{l}\text { Datas de início } \\
\text { do período }\end{array}$} & \multirow{2}{*}{$\begin{array}{l}\text { Datas do fim } \\
\text { do período }\end{array}$} & \multirow{2}{*}{$\begin{array}{l}\text { № de dias } \\
\text { analisados }\end{array}$} & \multicolumn{2}{|c|}{$\begin{array}{c}\text { Predominância de Feições } \\
\text { rítmicas }\end{array}$} \\
\hline & & & & $\mathrm{CFI}$ & CFS \\
\hline Momento 1 & 09/04/2012 & 03/05/2012 & 21 & $x$ & $\checkmark$ \\
\hline Momento2 & 04/05/2012 & 13/06/2012 & 22 & $\sqrt{ }$ & $\checkmark$ \\
\hline Momento 3 & $14 / 06 / 2012$ & 07/07/2012 & 19 & $x$ & $\checkmark$ \\
\hline Momento 4 & 08/07/2012 & $19 / 07 / 2012$ & 10 & $\checkmark$ & $\checkmark$ \\
\hline Momento 5 & $20 / 07 / 2012$ & 27/07/2012 & 8 & $x$ & $x$ \\
\hline Momento 6 & 28/07/2012 & $02 / 08 / 2012$ & 6 & $\checkmark$ & $\checkmark$ \\
\hline Momento 7 & 03/08/2012 & 04/09/2012 & 12 & $x$ & $\checkmark$ \\
\hline Momento 8 & 05/09/2012 & 29/09/2012 & 24 & $\checkmark$ & $\checkmark$ \\
\hline Momento 9 & 01/10/2012 & 10/10/2012 & 10 & $x$ & $x$ \\
\hline Momento 10 & $12 / 10 / 2012$ & $27 / 10 / 2012$ & 15 & $\checkmark$ & $\checkmark$ \\
\hline Momento 11 & $28 / 10 / 2012$ & $12 / 11 / 2012$ & 16 & $x$ & $\checkmark$ \\
\hline Momento 12 & $13 / 11 / 2012$ & 02/12/2012 & 20 & $\checkmark$ & $\checkmark$ \\
\hline Momento 13 & $03 / 12 / 2012$ & $22 / 12 / 2012$ & 19 & $x$ & $\checkmark$ \\
\hline Momento 14 & $23 / 12 / 2012$ & $30 / 12 / 2012$ & 8 & $\checkmark$ & $\checkmark$ \\
\hline
\end{tabular}

\subsubsection{Momento 1}

O primeiro momento compreende o período de 9 de abril à 3 de maio de 2012, onde foram analisados 21 dias. Cúspides são observadas na face praial superior para todos os dias analisados deste período e no caso das CFI observa-se cúspides apenas nos dias 28 e 29 de abril de 2012 (Tabela 5.6; Figuras 5.10, 5.13 e 5.14). Durante este período 4 sistemas frontais atuaram no arco praial de Massaguaçú nos dias 15, 23, 27 e 29 de abril de 2012. 
A direção média das ondas incidentes, para o período, foi de $126,64^{\circ}$ variando de $118,10^{\circ}$ à $167,70^{\circ}$, o período foi de $9,90 \mathrm{~s}$ variando de $5,88 \mathrm{~s}$ à $15,85 \mathrm{~s}$ e a altura foi de $0,42 \mathrm{~m}$ variando de $0,01 \mathrm{~m}$ à $0,94 \mathrm{~m}$.

Tabela 5.5: Características das ondas atuantes no arco praial de Massaguaçú durante o período.

\begin{tabular}{|c|c|c|c|c|c|} 
& Mínimo & Máximo & Média & Moda & Desvio Padrão \\
\hline Altura $(\mathbf{m})$ & 0.01 & 0.94 & 0.42 & 0.20 & 0.20 \\
\hline Período $(\mathbf{s})$ & 5.88 & 15.85 & 9.90 & 7.25 & 2.08 \\
\hline Direção( $\left(^{\circ}\right)$ & 118.10 & 167.70 & 126.64 & 121.70 & 12.37 \\
\hline
\end{tabular}

O espaçamento médio da CFS aumentou de $30 \mathrm{~m}$ do dia 9 para $45 \mathrm{~m}$ no dia 14 e durante esse período a direção da ondulação atuante ficou em torno de $121^{\circ}$. A partir do dia 15 essa ondulação passa a incidir com direção de $154,95^{\circ}$ e ocorre uma diminuição do espaçamento ao longo dos dias seguintes.

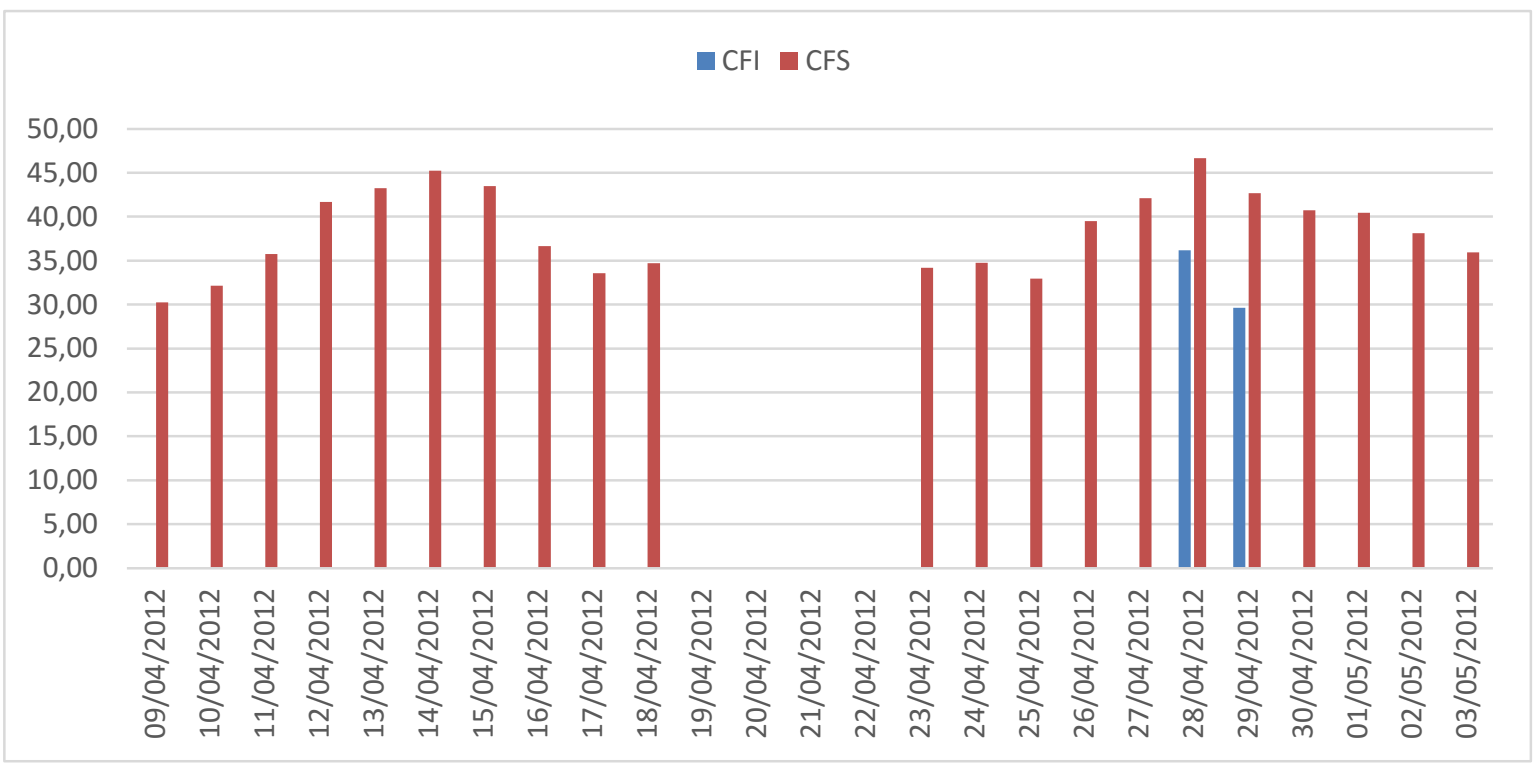

Figura 5.10: Espaçamento médio das cúspides durante o período. Em vermelho são as cúspides localizadas na face praial superior e em azul cúspides localizadas na face praial inferior.

Do dia 23 de abril à a 28 de abril o espaçamento aumentou de $34 \mathrm{~m}$ para $46 \mathrm{~m}$ e voltou a diminuir até o final do período. A direção preferencial para o período foi $121,07^{\circ}$, porém os 
valores de altura para este período estavam em torno de $0,2 \mathrm{~m}$ e $0,5 \mathrm{~m}$ e possivelmente não possuindo competência para a formação de cúspides (Tabelas 5.5 e 5.6; Figuras 5.11 e 5.12).

As alterações na CFS ocorrem devido a interação do espraiamento com a morfologia presente, fato que não ocorreu na CFI. Os dois dias com presença de cúspides na face praial inferior ocorreram pela interação do espraiamento com a morfologia da região da berma devido a subida da linha d'água na face praial.

Tabela 5.6: Espaçamento médio das cúspides na face praial inferior e superior.

\begin{tabular}{c|c|c|c|c|c|}
\hline Datas & Altura(m) & Período(s) & Direção( & CFI(m) & CFS(m) \\
\hline $\mathbf{0 9 / 0 4 / 2 0 1 2}$ & 0.18 & 9.31 & 120.26 & - & 30.23 \\
\hline $\mathbf{1 0 / 0 4 / 2 0 1 2}$ & 0.28 & 12.02 & 121.80 & - & 32.12 \\
\hline $\mathbf{1 1 / 0 4 / 2 0 1 2}$ & 0.32 & 12.19 & 121.95 & - & 35.75 \\
\hline $\mathbf{1 2 / 0 4 / 2 0 1 2}$ & 0.25 & 10.91 & 121.35 & - & 41.67 \\
\hline $\mathbf{1 3 / 0 4 / 2 0 1 2}$ & 0.30 & 11.15 & 121.24 & - & 43.22 \\
\hline $\mathbf{1 4 / 0 4 / 2 0 1 2}$ & 0.56 & 8.70 & 148.15 & - & 45.24 \\
\hline $\mathbf{1 5 / 0 4 / 2 0 1 2}$ & 0.67 & 8.14 & 154.95 & - & 43.50 \\
\hline $\mathbf{1 6 / 0 4 / 2 0 1 2}$ & 0.68 & 8.24 & 148.70 & - & 36.67 \\
\hline $\mathbf{1 7 / 0 4 / 2 0 1 2}$ & 0.09 & 7.90 & 120.63 & - & 33.57 \\
\hline $\mathbf{1 8 / 0 4 / 2 0 1 2}$ & 0.20 & 7.46 & 118.74 & - & 34.72 \\
\hline $\mathbf{2 3 / 0 4 / 2 0 1 2}$ & 0.44 & 8.14 & 139.44 & - & 34.17 \\
\hline $\mathbf{2 4 / 0 4 / 2 0 1 2}$ & 0.51 & 13.94 & 122.44 & - & 34.73 \\
\hline $\mathbf{2 5 / 0 4 / 2 0 1 2}$ & 0.45 & 12.38 & 122.10 & - & 32.94 \\
\hline $\mathbf{2 6 / 0 4 / 2 0 1 2}$ & 0.45 & 11.69 & 121.64 & - & 39.47 \\
\hline $\mathbf{2 7 / 0 4 / 2 0 1 2}$ & 0.63 & 12.05 & 121.65 & - & 42.08 \\
\hline $\mathbf{2 8 / 0 4 / 2 0 1 2}$ & 0.53 & 11.20 & 121.24 & 36.15 & 46.67 \\
\hline $\mathbf{2 9 / 0 4 / 2 0 1 2}$ & 0.69 & 11.34 & 121.65 & 29.64 & 42.69 \\
\hline $\mathbf{3 0 / 0 4 / 2 0 1 2}$ & 0.60 & 10.64 & 120.81 & - & 40.71 \\
\hline $\mathbf{0 1 / 0 5 / 2 0 1 2}$ & 0.25 & 9.30 & 120.63 & - & 40.44 \\
\hline $\mathbf{0 2 / 0 5 / 2 0 1 2}$ & 0.17 & 9.50 & 121.04 & - & 38.13 \\
\hline $\mathbf{0 3 / 0 5 / 2 0 1 2}$ & 0.34 & 8.78 & 119.94 & - & 35.94 \\
\hline & & & & & - \\
\hline
\end{tabular}



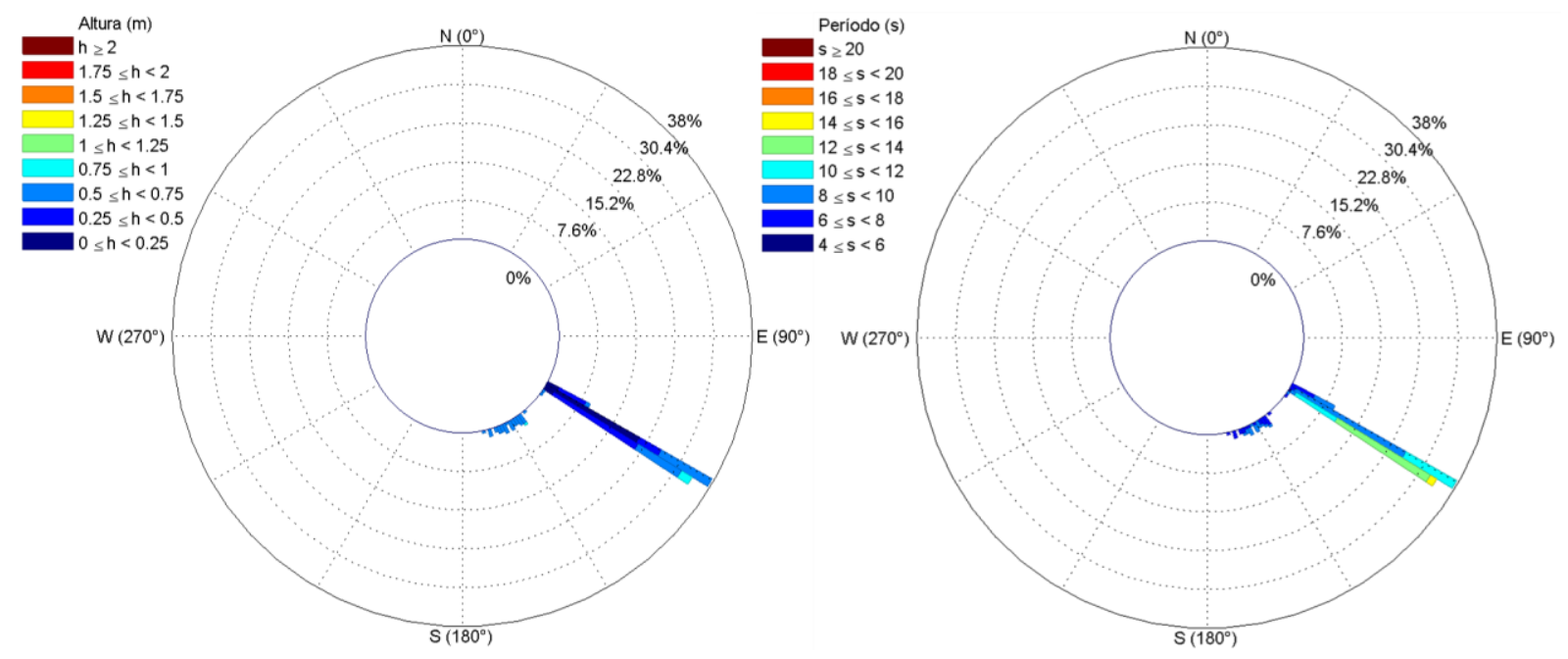

Figura 5.11: Histograma direcional de altura ( $m$, a esquerda) e período (s, a direita) das ondas atuantes durante o período.
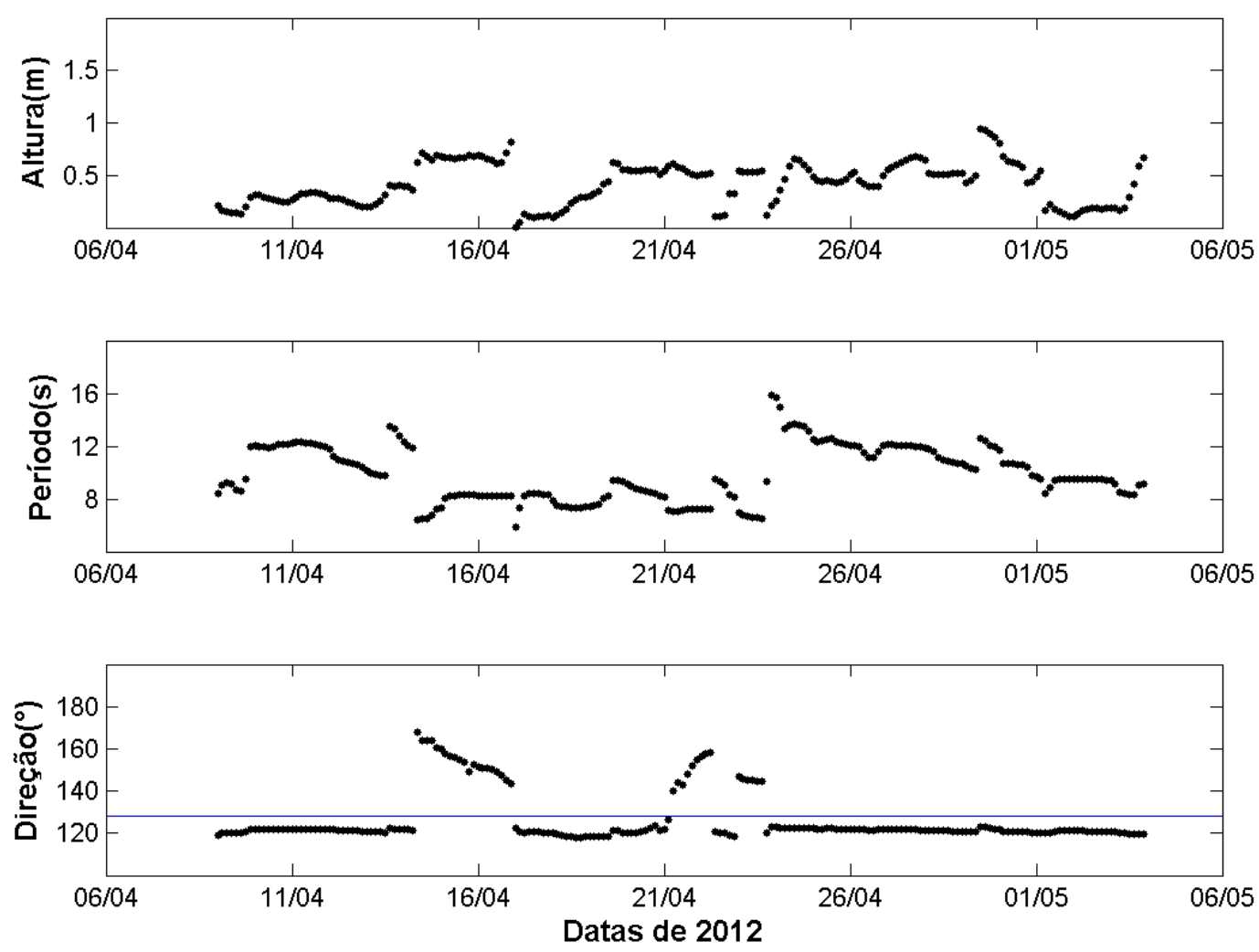

Figura 5.12: Evolução da altura, período e direção atuantes durante o período, onde a linha em azul representa a direção normal a face praial. 

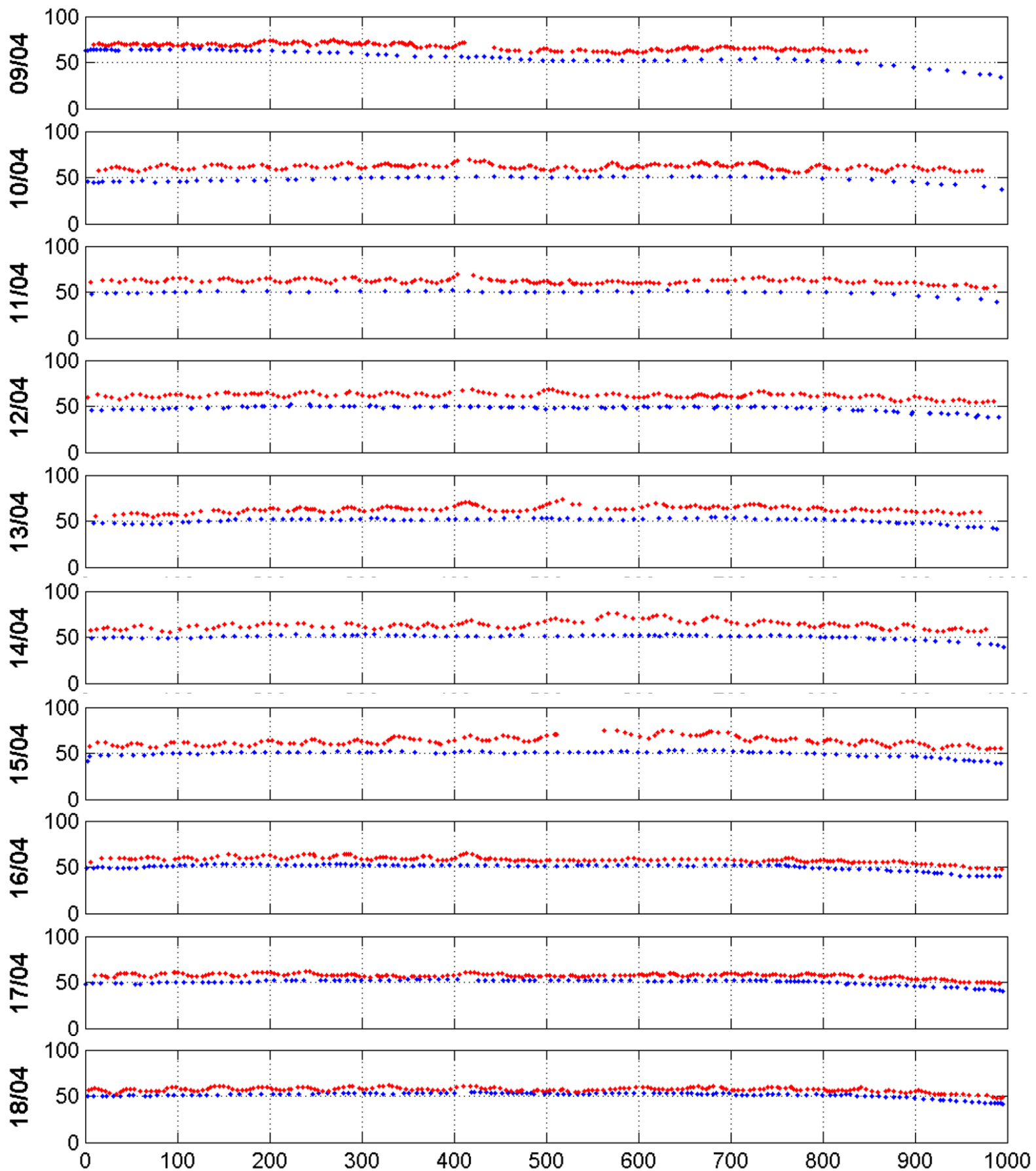

Figura 5.13: Cúspides digitalizadas durante o período (apenas os 10 primeiros dias). Em vermelho são as cúspides localizadas na face praial superior e em azul cúspides localizadas na face praial inferior. 

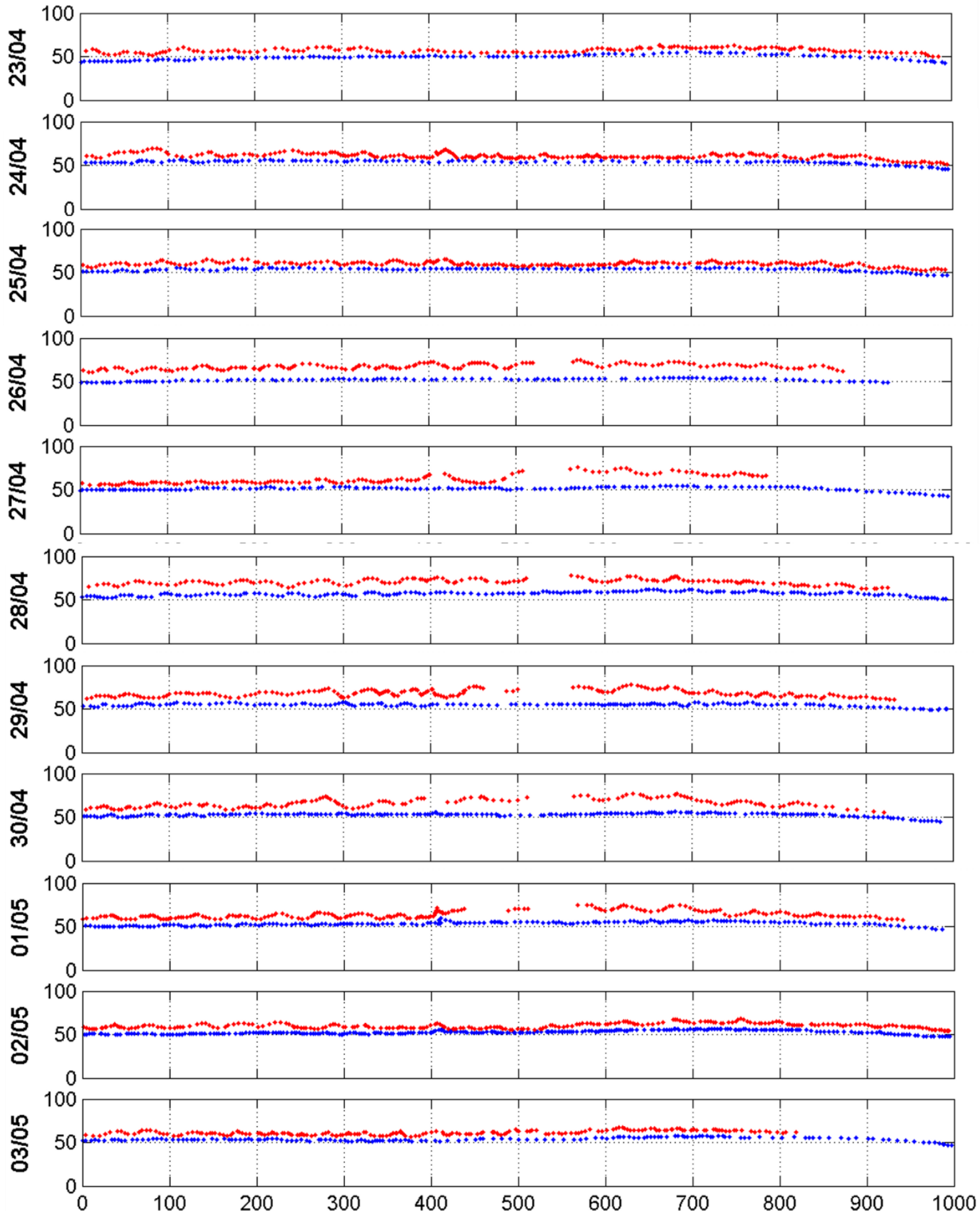

Figura 5.14: Cúspides digitalizadas durante o período (os 11 dias restantes). Em vermelho são as cúspides localizadas na face praial superior e em azul cúspides localizadas na face praial inferior. 


\subsubsection{Momento 2}

O momento 2 compreende o período de 4 de maio à 13 de junho de 2012, onde foram analisados 22 dias. Apenas em dois dias, 4 e 6 de junho, não se observa cúspides na face praial inferior. No restante dos dias observa-se cúspides para ambas regiões (Tabela 5.8; Figuras 5.15, 5.18 e 5.19). Durante este período 3 sistemas frontais atuaram no arco praial de Massaguaçú nos dias 13, 31, de maio e 5 de junho de 2012.

A direção média das ondas incidente foi de $128,09^{\circ}$ variando de $116,20^{\circ}$ à $164^{\circ}$, o período foi de $10,97 \mathrm{~s}$ variando de $4,43 \mathrm{~s}$ à $15,34 \mathrm{~s}$ e a altura foi de $0,19 \mathrm{~m}$ variando de $0,03 \mathrm{~m}$ à 1,95 m (Tabelas 5.7 e 5.8; Figuras 5.16, 5.17).

Tabela 5.7: Características das ondas atuantes no arco praial de Massaguaçú durante o período.

\begin{tabular}{|c|c|c|c|c|c|}
\hline & Mínimo & Máximo & Média & Moda & Desvio Padrão \\
\hline Altura(m) & 0.03 & 1.95 & 0.71 & 0.19 & 0.43 \\
\hline Período(s) & 4.43 & 15.34 & 10.97 & 12.15 & 1.90 \\
\hline Direção( $\left.{ }^{\circ}\right)$ & 116.20 & 164.00 & 128.09 & 122.10 & 10.00 \\
\hline
\end{tabular}

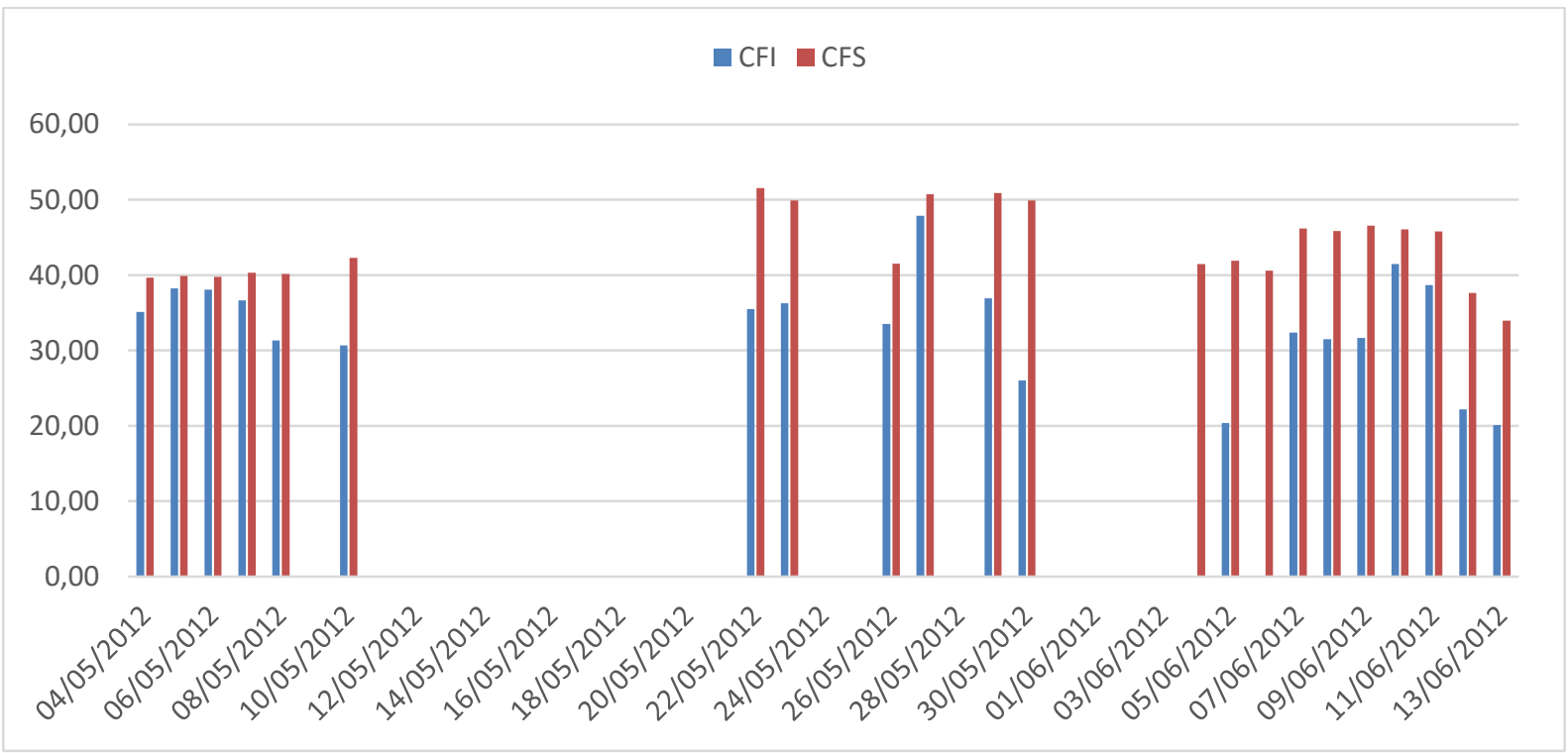

Figura 5.15: Espaçamento médio das cúspides durante o período. Em vermelho são as cúspides localizadas na face praial superior e em azul cúspides localizadas na face praial inferior. 
O momento 2 pode ser dividido em três grupamentos distintos. No primeiro grupamento a CFS é praticamente constante com o valor de espaçamento em torno de $40 \mathrm{~m}$ e o espaçamento da CFI aumenta de $35 \mathrm{~m}$, no primeiro dia, para $38 \mathrm{~m}$, no segundo dia, decrescendo nos dias seguintes para $30 \mathrm{~m}$.

Durante este primeiro grupamento a direção da onda variou de $120,75^{\circ}$ para $143,45^{\circ}$ no penúltimo dia do grupamento e no último dia foi de $123,84^{\circ}$. A altura aumentou de $0,85 \mathrm{~m}$ para $1,25 \mathrm{~m}$ no segundo dia decrescendo para 0,73 no penúltimo dia e aumentando para $1 \mathrm{~m}$ no último dia. O período foi praticamente constante com valor em torno de 9 segundos.

No segundo grupamento observa-se na CFS um decréscimo de $51 \mathrm{~m}$ para $41 \mathrm{~m}$ nos três primeiros dias e um espaçamento constante em torno de $50 \mathrm{~m}$, nos três dias restantes. Na CFI o espaçamento aumentou de $30 \mathrm{~m}$ para $47 \mathrm{~m}$ primeiramente e em seguida decresceu para $26 \mathrm{~m}$.

A direção das ondas varia de $133^{\circ}$ para $150^{\circ}$ inicialmente voltando para a direção de $122^{\circ}$. A altura decresceu de $1,82 \mathrm{~m}$ para $0,60 \mathrm{~m}$ e o período ficou em torno de $12 \mathrm{~s}$ exceto pelos dias 26 e 27 com valores de 7,7 s e 9,8 s respectivamente.

No terceiro grupamento observa-se um aumento inicial no espaçamento da CFS de 41 m para 46 m e de 20 m para $41 \mathrm{~m}$ na CFI. A direção das ondas ficou em torno de $122^{\circ}$, o período em torno de $12 \mathrm{~s}$ e a altura em torno de $0,5 \mathrm{~m}$. Nos dias seguintes o espaçamento das cúspides decresceu em ambas as regiões, na CFI e na CFS de $38 \mathrm{~m}$ para $20 \mathrm{~m}$ e de $46 \mathrm{~m}$ para $36 \mathrm{~m}$ respectivamente. 
Tabela 5.8: Espaçamento médio das cúspides na face praial inferior e superior.

\begin{tabular}{c|c|c|c|c|c|}
\hline Datas & Altura(m) & Período(s) & Direção( & CFI(m) & CFS(m) \\
\hline $\mathbf{0 4 / 0 5 / 2 0 1 2 ~}$ & 0.85 & 8.34 & 120.75 & 35.09 & 39.67 \\
\hline $\mathbf{0 5 / 0 5 / 2 0 1 2}$ & 1.25 & 9.20 & 133.93 & 38.21 & 39.88 \\
\hline $\mathbf{0 6 / 0 5 / 2 0 1 2}$ & 1.23 & 9.46 & 135.83 & 38.06 & 39.75 \\
\hline $\mathbf{0 7 / 0 5 / 2 0 1 2}$ & 0.96 & 9.45 & 139.66 & 36.62 & 40.29 \\
\hline $\mathbf{0 8 / 0 5 / 2 0 1 2}$ & 0.73 & 8.87 & 143.45 & 31.32 & 40.17 \\
\hline $\mathbf{1 0 / 0 5 / 2 0 1 2}$ & 1.00 & 12.96 & 123.84 & 30.69 & 42.31 \\
\hline $\mathbf{2 2 / 0 5 / 2 0 1 2}$ & 1.82 & 12.59 & 134.56 & 35.50 & 51.56 \\
\hline $\mathbf{2 3 / 0 5 / 2 0 1 2}$ & 1.60 & 12.61 & 133.71 & 36.25 & 49.91 \\
\hline $\mathbf{2 6 / 0 5 / 2 0 1 2}$ & 0.73 & 7.73 & 150.19 & 33.50 & 41.54 \\
\hline $\mathbf{2 7 / 0 5 / 2 0 1 2}$ & 0.67 & 9.80 & 150.26 & 47.89 & 50.71 \\
\hline $\mathbf{2 9 / 0 5 / 2 0 1 2}$ & 0.80 & 12.49 & 130.30 & 36.92 & 50.91 \\
\hline $\mathbf{3 0 / 0 5 / 2 0 1 2}$ & 0.60 & 12.05 & 122.29 & 26.00 & 49.88 \\
\hline $\mathbf{0 4 / 0 6 / 2 0 1 2}$ & 0.35 & 12.02 & 121.80 & - & 41.47 \\
\hline $\mathbf{0 5 / 0 6 / 2 0 1 2}$ & 0.24 & 11.37 & 121.59 & 20.39 & 41.88 \\
\hline $\mathbf{0 6 / 0 6 / 2 0 1 2}$ & 0.20 & 11.77 & 122.03 & - & 40.56 \\
\hline $\mathbf{0 7 / 0 6 / 2 0 1 2}$ & 0.28 & 10.81 & 121.33 & 32.38 & 46.18 \\
\hline $\mathbf{0 8 / 0 6 / 2 0 1 2}$ & 0.42 & 9.55 & 120.20 & 31.50 & 45.84 \\
\hline $\mathbf{0 9 / 0 6 / 2 0 1 2}$ & 0.46 & 11.14 & 121.33 & 31.67 & 46.56 \\
\hline $\mathbf{1 0 / 0 6 / 2 0 1 2}$ & 0.47 & 12.33 & 121.93 & 41.47 & 46.07 \\
\hline $\mathbf{1 1 / 0 6 / 2 0 1 2}$ & 0.75 & 14.41 & 122.78 & 38.67 & 45.81 \\
\hline $\mathbf{1 2 / 0 6 / 2 0 1 2}$ & 0.42 & 13.07 & 122.29 & 22.17 & 37.65 \\
\hline $\mathbf{1 3 / 0 6 / 2 0 1 2}$ & 0.28 & 11.36 & 125.61 & 20.10 & 33.95 \\
\hline
\end{tabular}



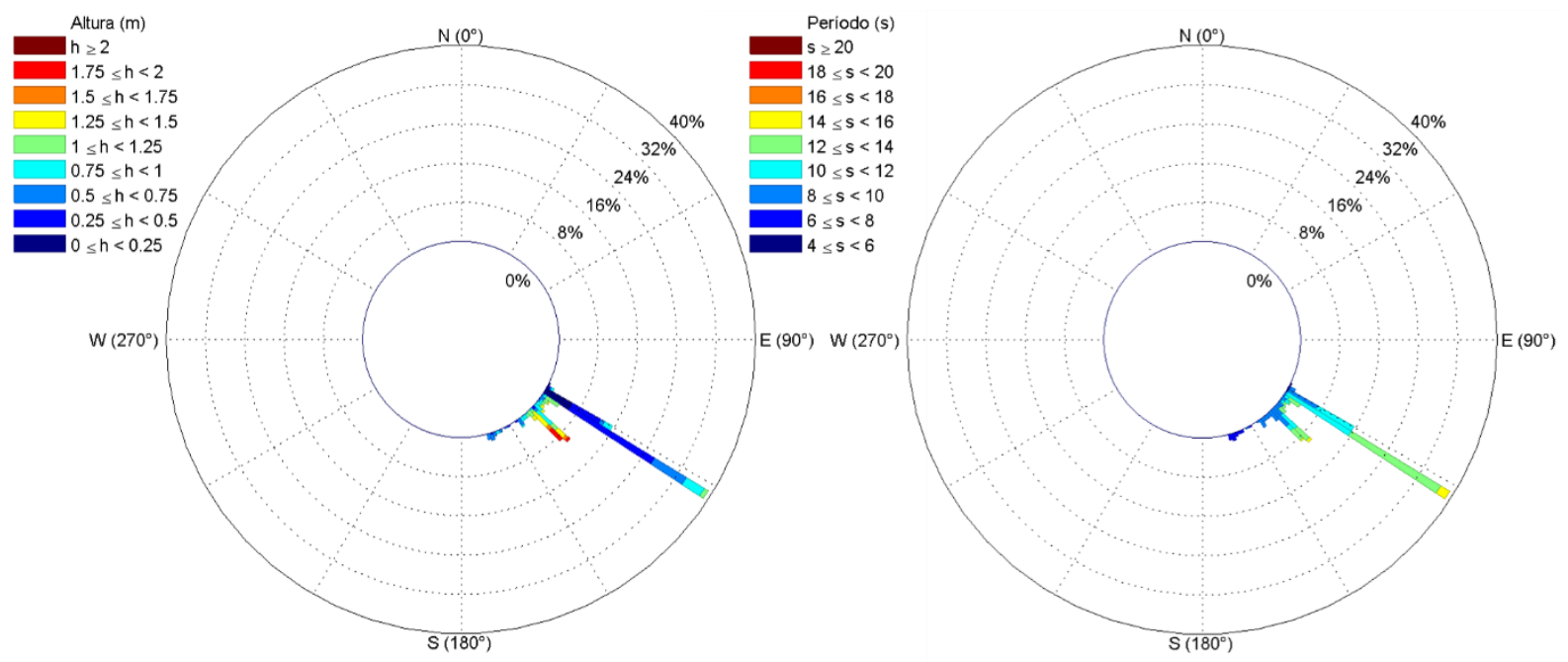

Figura 5.16: Histograma direcional de altura (m, a esquerda) e período (s, a direita) das ondas atuantes durante o período.
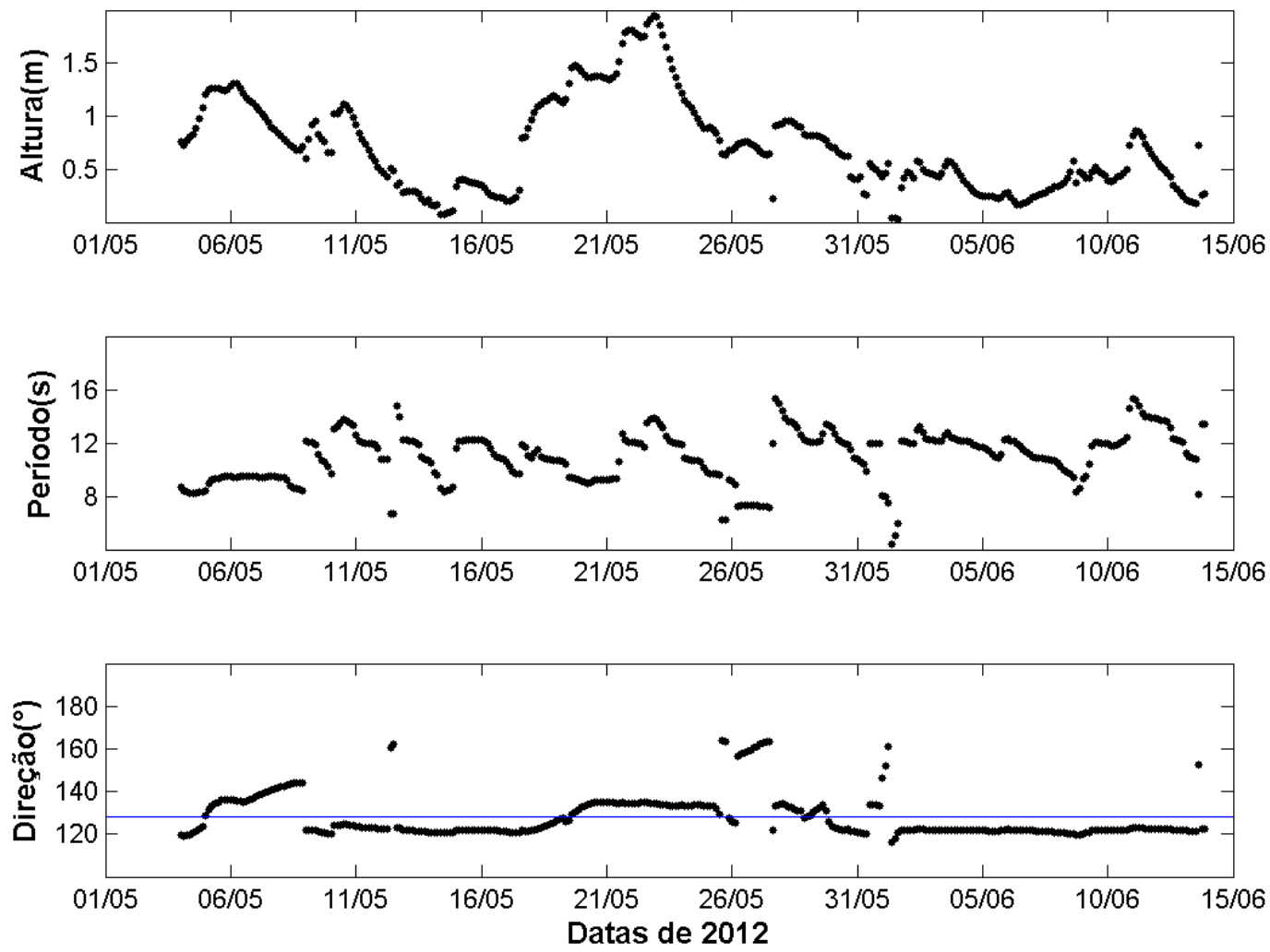

Figura 5.17: Evolução da altura, período e direção atuantes durante o período, onde a linha em azul representa a direção normal a face praial. 


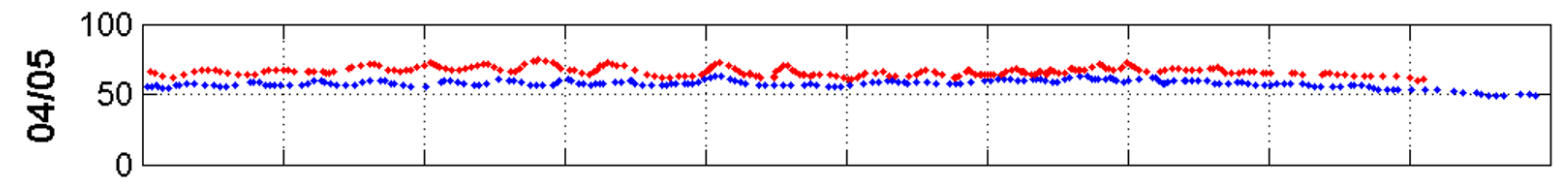

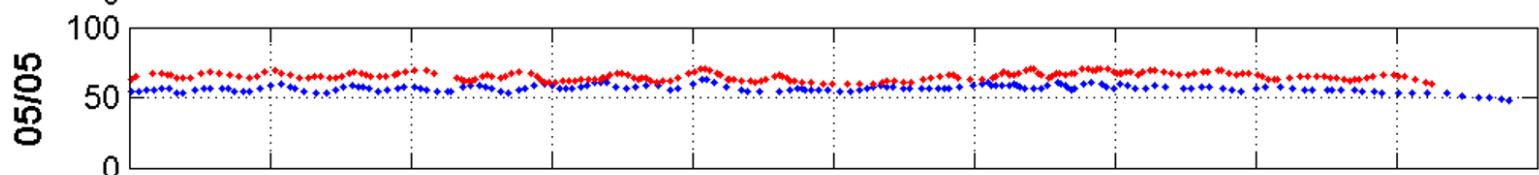

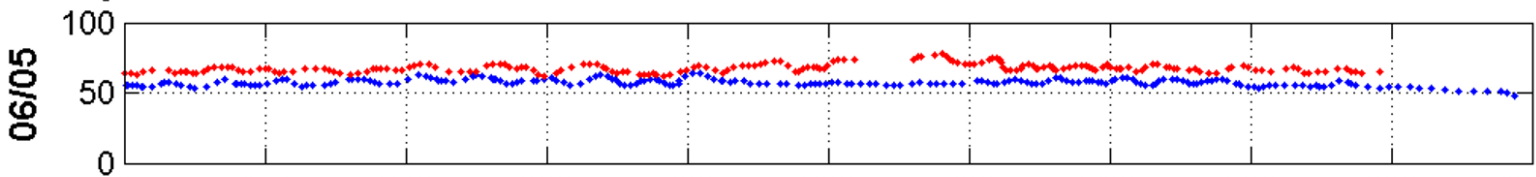

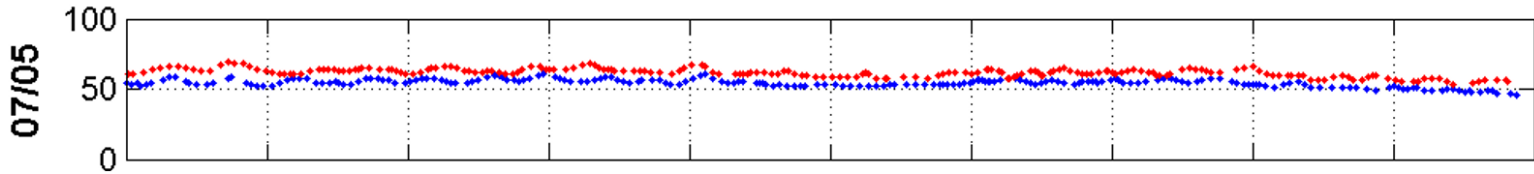

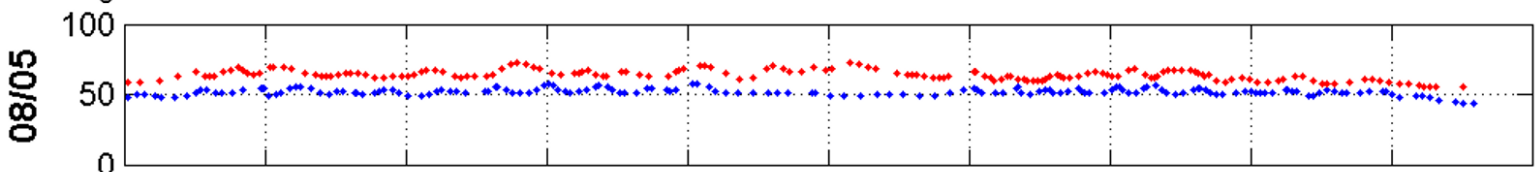

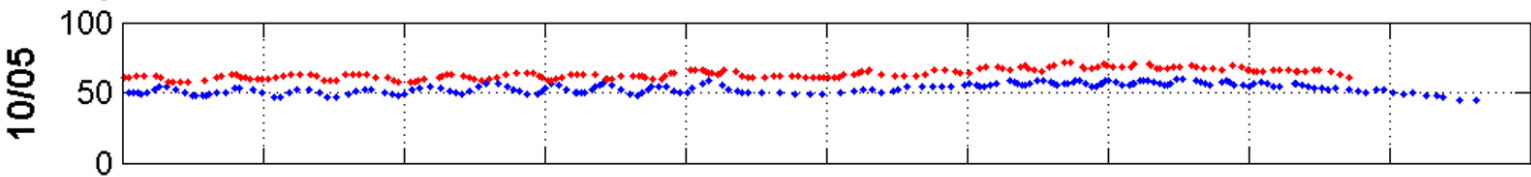

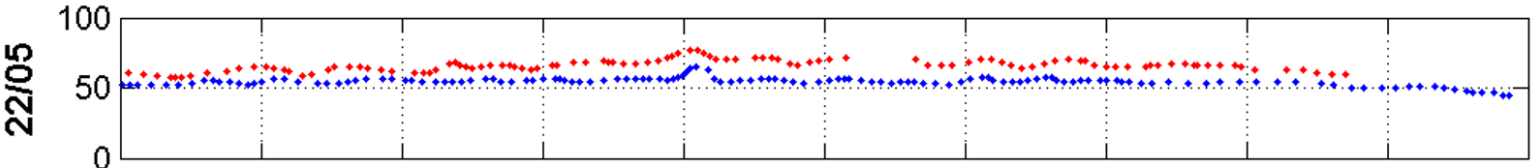

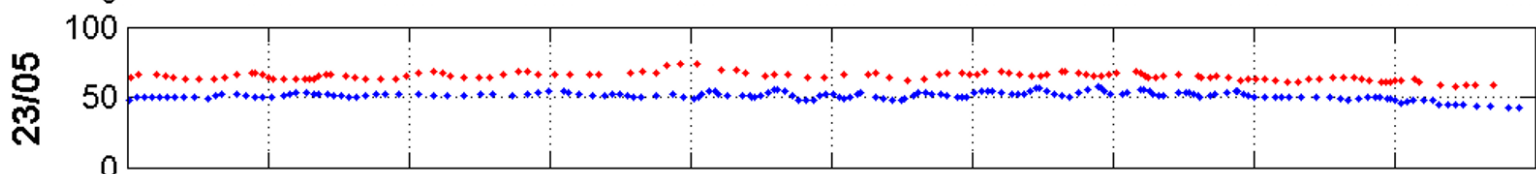

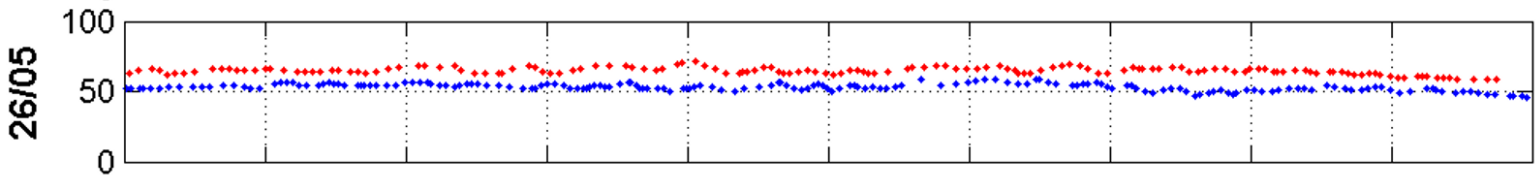

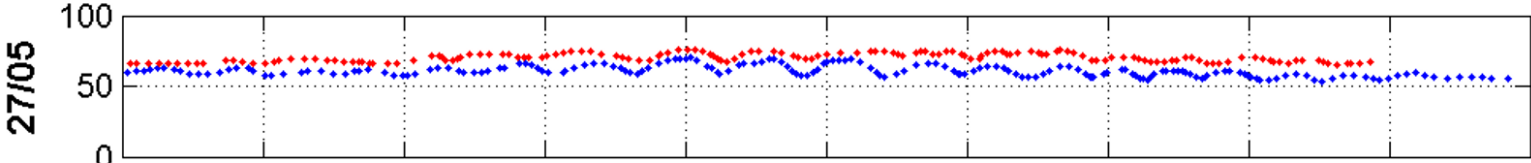
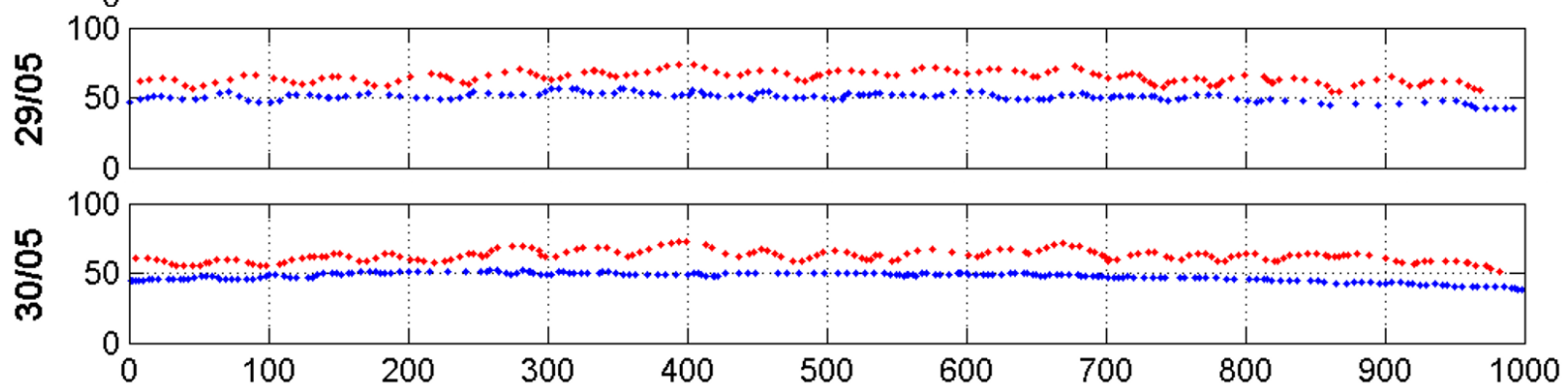

Figura 5.18: Cúspides digitalizadas durante o período (apenas os 12 primeiros dias). Em vermelho são as cúspides localizadas na face praial superior e em azul cúspides localizadas na face praial inferior. 

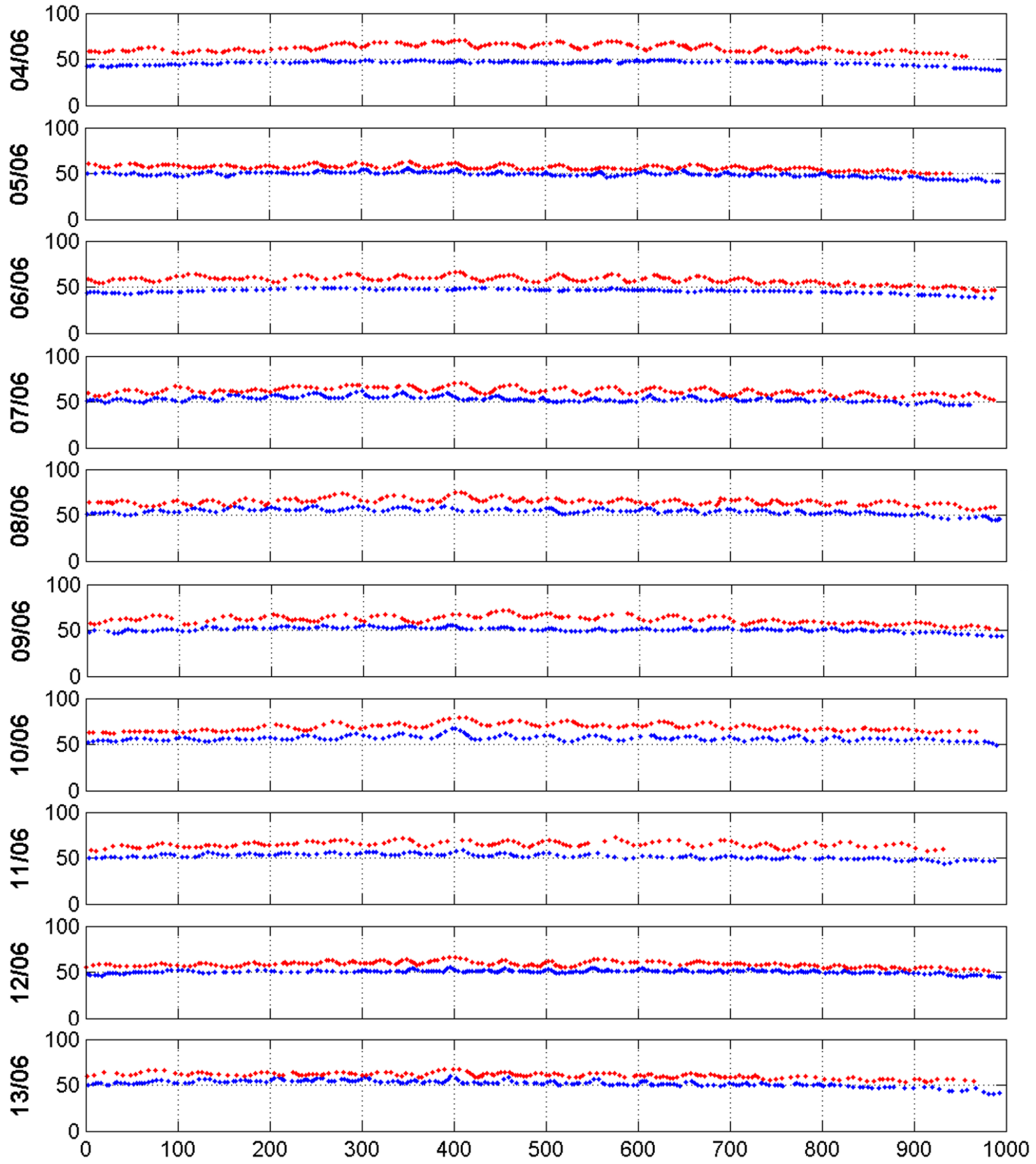

Figura 5.19: Cúspides digitalizadas durante o período (10 dias restantes). Em vermelho são as cúspides localizadas na face praial superior e em azul cúspides localizadas na face praial inferior. 


\subsubsection{Momento 3}

O momento 3 compreende o período de 14 de junho à 7 de julho, com 19 dias analisados e durante este período não se observa cúspides na face praial inferior. Em contraponto foi registrado 17 dias com a presença de cúspides na face praial superior e os dois dias sem registro de cúspide foram os dias um e dois de julho de 2012 (Tabela 5.10; Figuras 5.20, 5.23 e 5.24). Durante este período 2 sistemas frontais atuaram no arco praial de Massaguaçú nos dias 20 e 22 de junho de 2012.

A direção média das ondas incidentes, para o período, foi de $138,80^{\circ}$ variando de $117,50^{\circ}$ à $170,94^{\circ}$, o período foi de $9,54 \mathrm{~s}$ variando de $4,44 \mathrm{~s}$ à $15,62 \mathrm{~s}$ e a altura foi de $0,47 \mathrm{~m}$ variando de 0 m à 0,87 m (Tabelas 5.9 e 5.10; Figuras 5.21, 5.22).

Tabela 5.9: Características das ondas atuantes no arco praial de Massaguaçú durante o período.

\begin{tabular}{|c|c|c|c|c|c|} 
& Mínimo & Máximo & Média & Moda & Desvio Padrão \\
\hline Altura(m) & 0.00 & 0.87 & 0.47 & 0.25 & 0.20 \\
\hline Período(s) & 4.44 & 15.62 & 9.54 & 7.38 & 2.63 \\
\hline Direção( ${ }^{\circ}$ ) & 117.50 & 170.94 & 138.80 & 122.20 & 20.26 \\
\hline
\end{tabular}

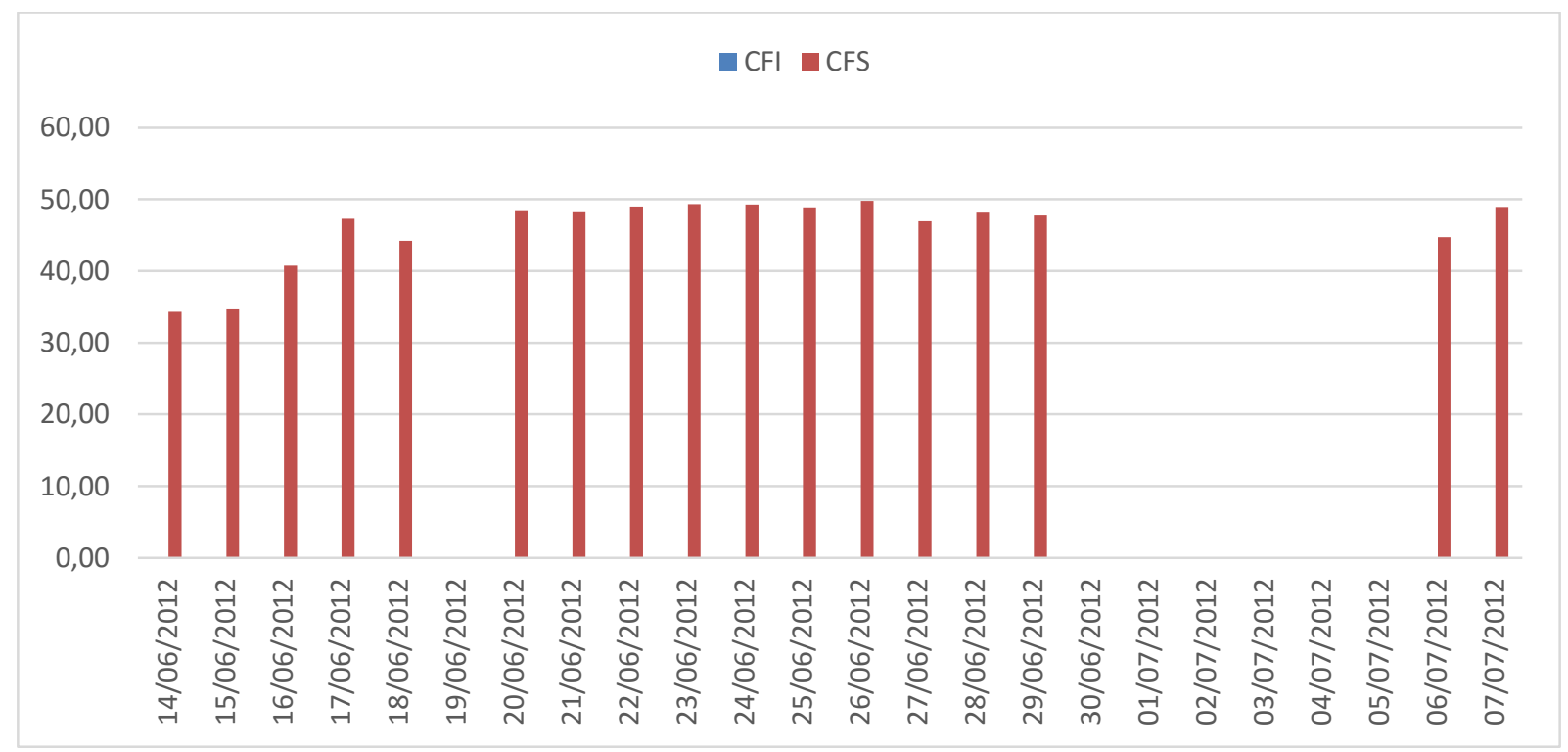

Figura 5.20: Espaçamento médio das cúspides durante o período. Em vermelho são as cúspides localizadas na face praial superior e em azul cúspides localizadas na face praial inferior. 
Na CFS é observado um aumento de $34 \mathrm{~m}$ para $47 \mathrm{~m}$ e a partir do dia 17 de julho de 2012 o espaçamento das cúspides ficou dentro de uma faixa em torno de $44 \mathrm{~m}$ a 50m.

Durante fase onde o espaçamento aumentou a direção das ondas incidente passou de $122,20^{\circ}$ para $151,91^{\circ}$, o período diminuiu de $13,04 \mathrm{~s}$ para $7,97 \mathrm{~s}$ e o a altura das ondas aumentou de $0,30 \mathrm{~m}$ à $0,65 \mathrm{~m}$.

Durante a fase em que o espaçamento se manteve dentro da faixa de $45 \mathrm{~m}$ à $51 \mathrm{~m}$ a altura das ondas incidentes se manteve entre $0.5 \mathrm{~m}$ e $0.6 \mathrm{~m}$ exceto pelos dias um, dois e sete de julho onde observou-se valores em torno de $0,3 \mathrm{~m}$. O período variou de $7,5 \mathrm{~s}$ à $14,3 \mathrm{~s}$, mas o valor ficou entre 7 e $9 \mathrm{~s}$ para a maioria dos dias. A direção variou de $120^{\circ}$ à $168^{\circ}$ sendo o valor em torno de $123^{\circ}$ para a maioria dos dias. Nos dias um e dois de julho, dias sem registro de cúspides, a direção da onda incidente foi de $168^{\circ}$, período de $7 \mathrm{~s}$ e altura de $0,3 \mathrm{~m}$.

Durante todo o período a ondulação variou de condições favoráveis a formação de cúspides para condições desfavoráveis a formação das mesmas e essa alternância de situações gerou um cenário instável para formação de cúspides na face praial inferior, causando apenas alterações nas cúspides da face praial superior.

Apenas nos dias um e dois de julho, com a ondulação de direção $168^{\circ}$, registra-se um espalhamento acentuado na morfologia rítmica da berma gerando uma descaracterização das cúspides que lá estavam no dia anterior. 
Tabela 5.10: Espaçamento médio das cúspides na face praial inferior e superior.

\begin{tabular}{c|c|c|c|c|c|} 
Datas & Altura(m) & Período(s) & Direção( & CFI(m) & CFS(m) \\
\hline $\mathbf{1 4 / 0 6 / 2 0 1 2}$ & 0.30 & 13.04 & 122.20 & - & 34.32 \\
\hline $\mathbf{1 5 / 0 6 / 2 0 1 2}$ & 0.38 & 13.60 & 122.36 & - & 34.64 \\
\hline $\mathbf{1 6 / 0 6 / 2 0 1 2}$ & 0.76 & 8.21 & 152.18 & - & 40.71 \\
\hline $\mathbf{1 7 / 0 6 / 2 0 1 2}$ & 0.65 & 7.97 & 151.91 & - & 47.27 \\
\hline $\mathbf{1 8 / 0 6 / 2 0 1 2}$ & 0.52 & 7.90 & 152.38 & - & 44.23 \\
\hline $\mathbf{2 0 / 0 6 / 2 0 1 2}$ & 0.66 & 9.15 & 124.06 & - & 48.46 \\
\hline $\mathbf{2 1 / 0 6 / 2 0 1 2}$ & 0.67 & 8.45 & 129.48 & - & 48.17 \\
\hline $\mathbf{2 2 / 0 6 / 2 0 1 2}$ & 0.56 & 7.50 & 120.33 & - & 48.99 \\
\hline $\mathbf{2 3 / 0 6 / 2 0 1 2}$ & 0.63 & 7.47 & 147.31 & - & 49.33 \\
\hline $\mathbf{2 4 / 0 6 / 2 0 1 2}$ & 0.06 & 6.99 & 120.35 & - & 49.25 \\
\hline $\mathbf{2 5 / 0 6 / 2 0 1 2}$ & 0.51 & 7.56 & 126.60 & - & 48.89 \\
\hline $\mathbf{2 6 / 0 6 / 2 0 1 2}$ & 0.55 & 11.46 & 135.28 & - & 49.76 \\
\hline $\mathbf{2 7 / 0 6 / 2 0 1 2}$ & 0.53 & 12.99 & 122.08 & - & 46.92 \\
\hline $\mathbf{2 8 / 0 6 / 2 0 1 2}$ & 0.58 & 13.31 & 122.34 & - & 48.13 \\
\hline $\mathbf{2 9 / 0 6 / 2 0 1 2}$ & 0.38 & 11.11 & 121.24 & - & 47.73 \\
\hline $\mathbf{0 1 / 0 7 / 2 0 1 2}$ & 0.36 & 7.26 & 168.43 & - & - \\
\hline $\mathbf{0 2 / 0 7 / 2 0 1 2}$ & 0.26 & 7.71 & 168.01 & - & - \\
\hline $\mathbf{0 6 / 0 7 / 2 0 1 2}$ & 0.57 & 14.30 & 122.63 & - & 44.71 \\
\hline $\mathbf{0 7 / 0 7 / 2 0 1 2}$ & 0.35 & 11.52 & 127.26 & - & 48.93 \\
\hline
\end{tabular}

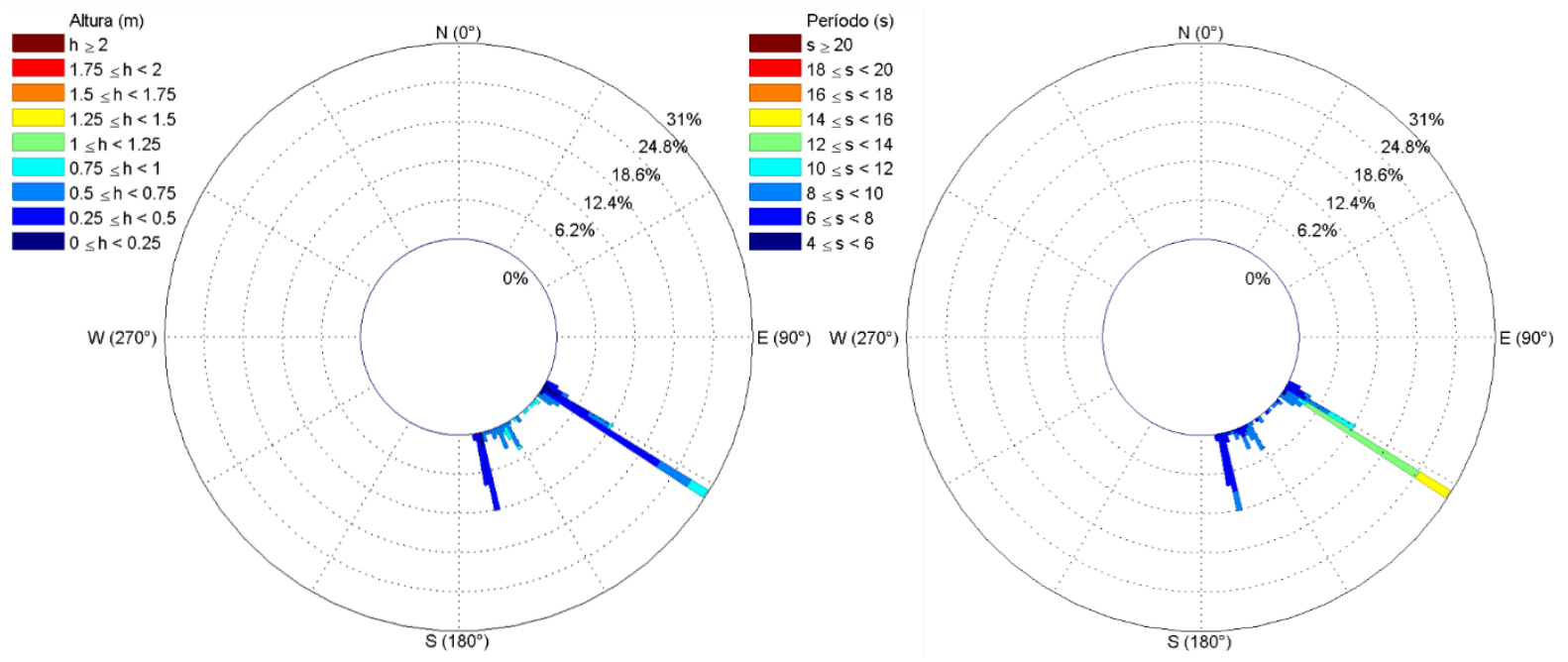

Figura 5.21: Histograma direcional de altura (m, a esquerda) e período (s, a direita) das ondas atuantes durante o período. 

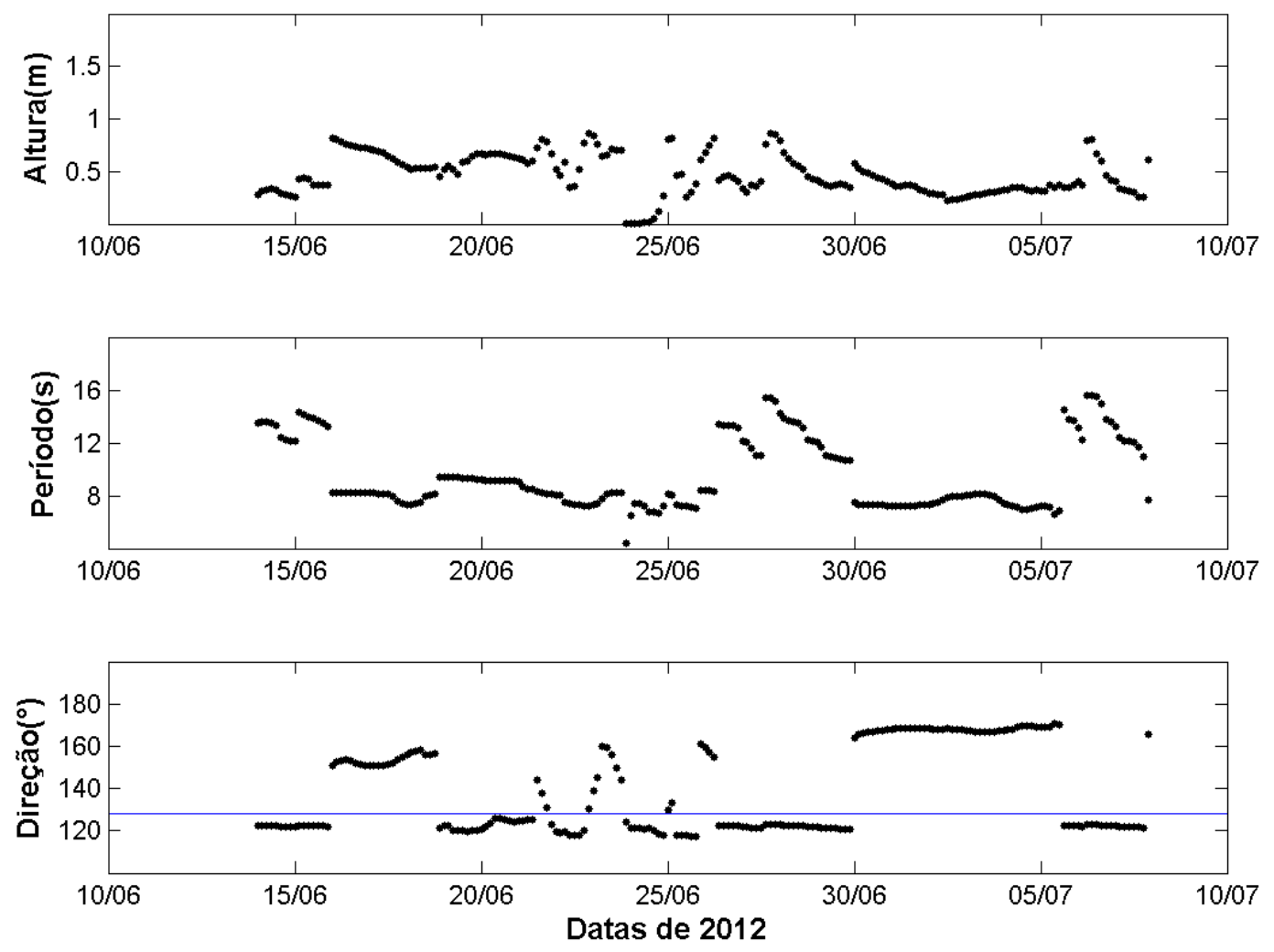

Figura 5.22: Evolução da altura, período e direção atuantes durante o período, onde a linha em azul representa a direção normal a face praial. 

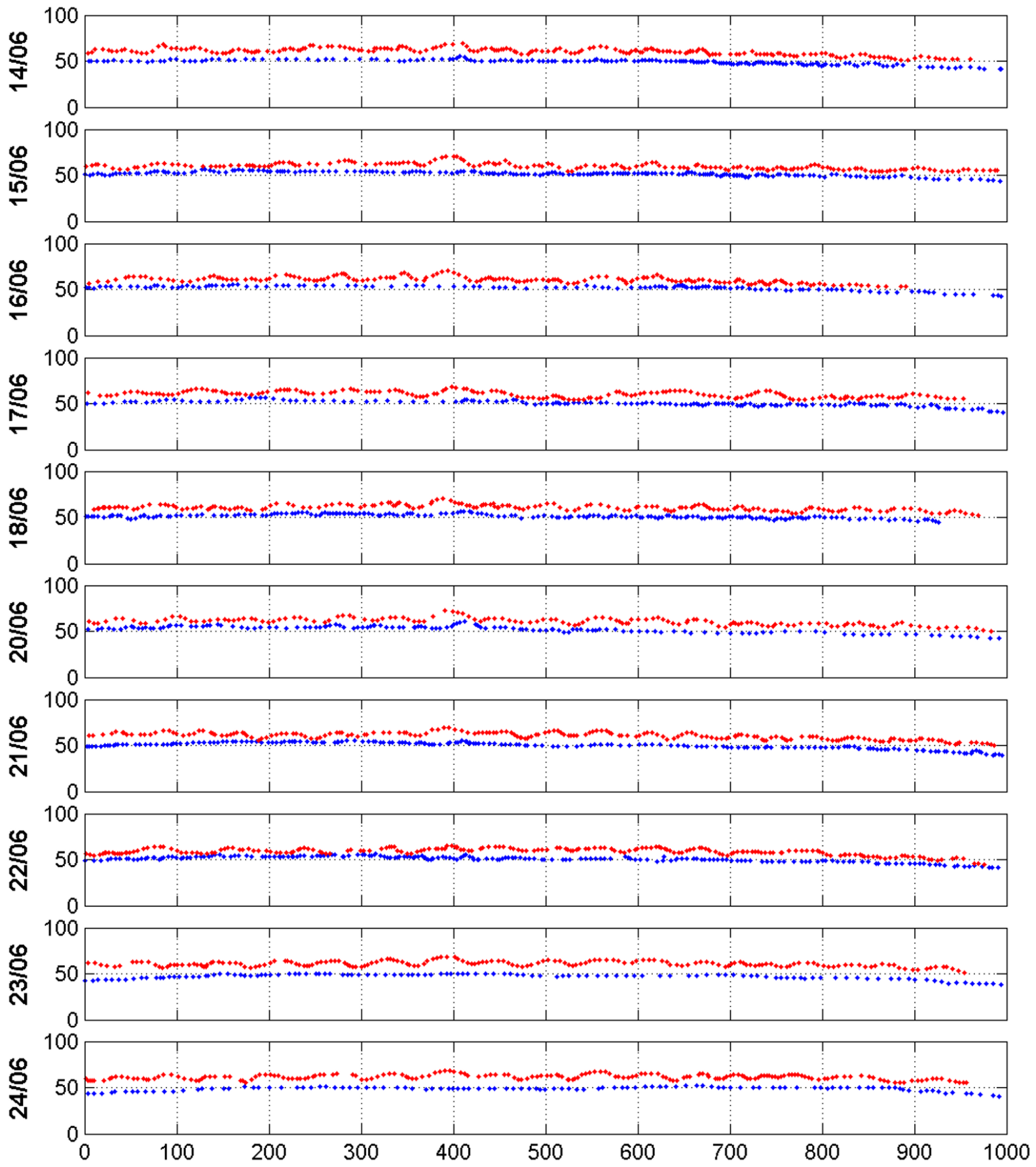

Figura 5.23: Cúspides digitalizadas durante o período (apenas os 10 primeiros dias). Em vermelho são as cúspides localizadas na face praial superior e em azul cúspides localizadas na face praial inferior. 

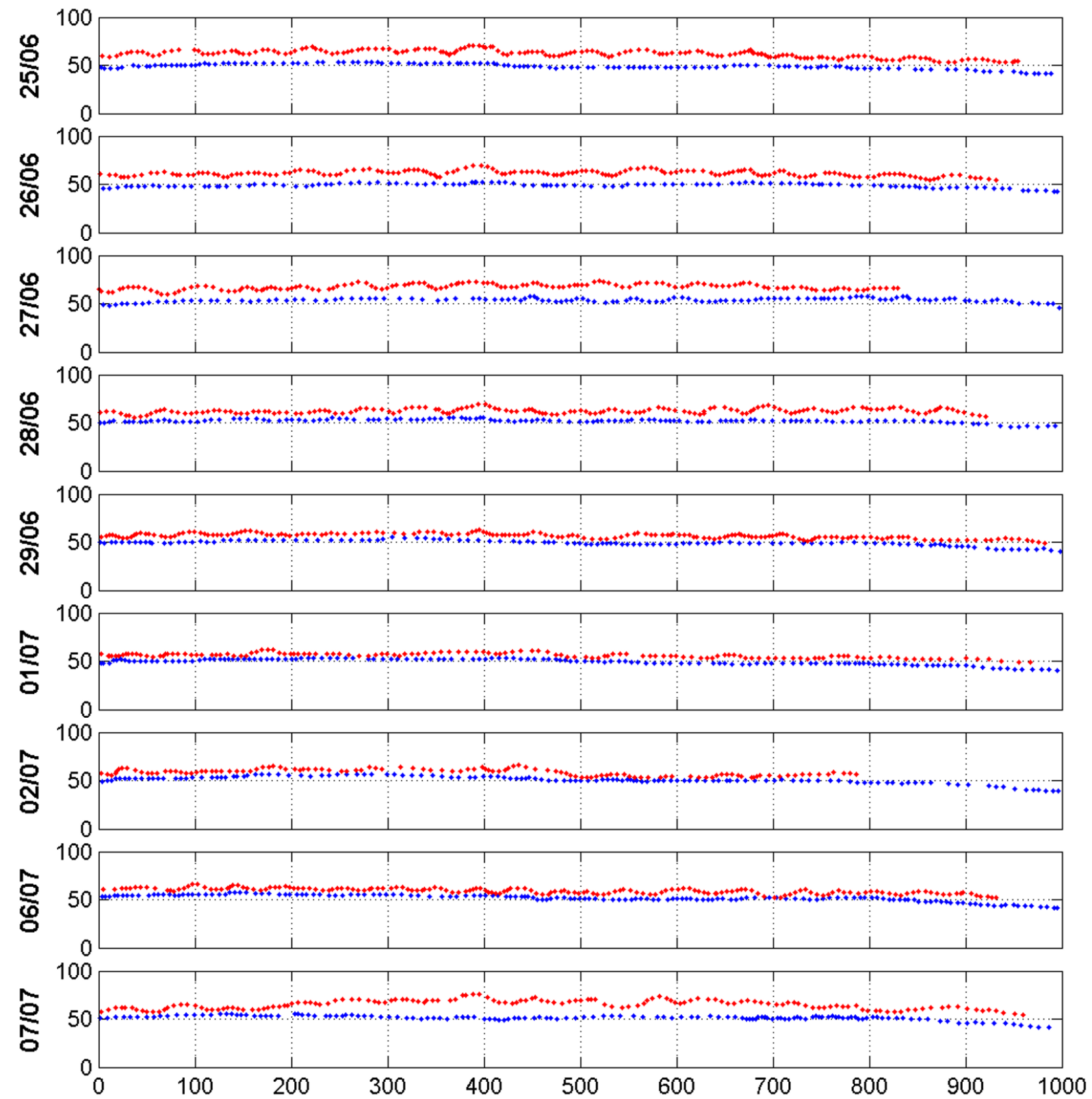

Figura 5.24: Cúspides digitalizadas durante o período (9 dias restantes). Em vermelho são as cúspides localizadas na face praial superior e em azul cúspides localizadas na face praial inferior. 


\subsubsection{Momento 4}

O momento 4 compreende o período de 8 a 19 de julho de 2012 com 10 dias analisados. Neste período observa-se cúspides em todos os dias em ambas as regiões, na face praial superior e inferior (Tabela 5.12; Figuras 5.25, 5.28 e 5.29). Durante este período 3 sistemas frontais atuaram no arco praial de Massaguaçú nos dias 8, 12 e 17 de julho de 2012.

A direção média das ondas incidentes, para o período, foi de $130,80^{\circ}$ variando de $119,90^{\circ}$ à 165,50 , o período foi de $10,04 \mathrm{~s}$ variando de $6,86 \mathrm{~s}$ à $14,04 \mathrm{~s}$ e a altura foi de $0,73 \mathrm{~m}$ variando de $0 \mathrm{~m}$ à $1,24 \mathrm{~m}$ (Tabelas 5.11 e 5.12; Figuras 5.26 e 5.27).

Tabela 5.11: Características das ondas atuantes no arco praial de Massaguaçú durante o período.

\begin{tabular}{|c|c|c|c|c|c|}
\hline & Mínimo & Máximo & Média & Moda & Desvio Padrão \\
\hline Altura(m) & 0.00 & 1.24 & 0.73 & 1.24 & 0.32 \\
\hline Período(s) & 6.86 & 14.04 & 10.23 & 9.30 & 1.70 \\
\hline Direção( $\left.{ }^{\circ}\right)$ & 119.90 & 165.60 & 130.06 & 120.50 & 14.38 \\
\hline
\end{tabular}

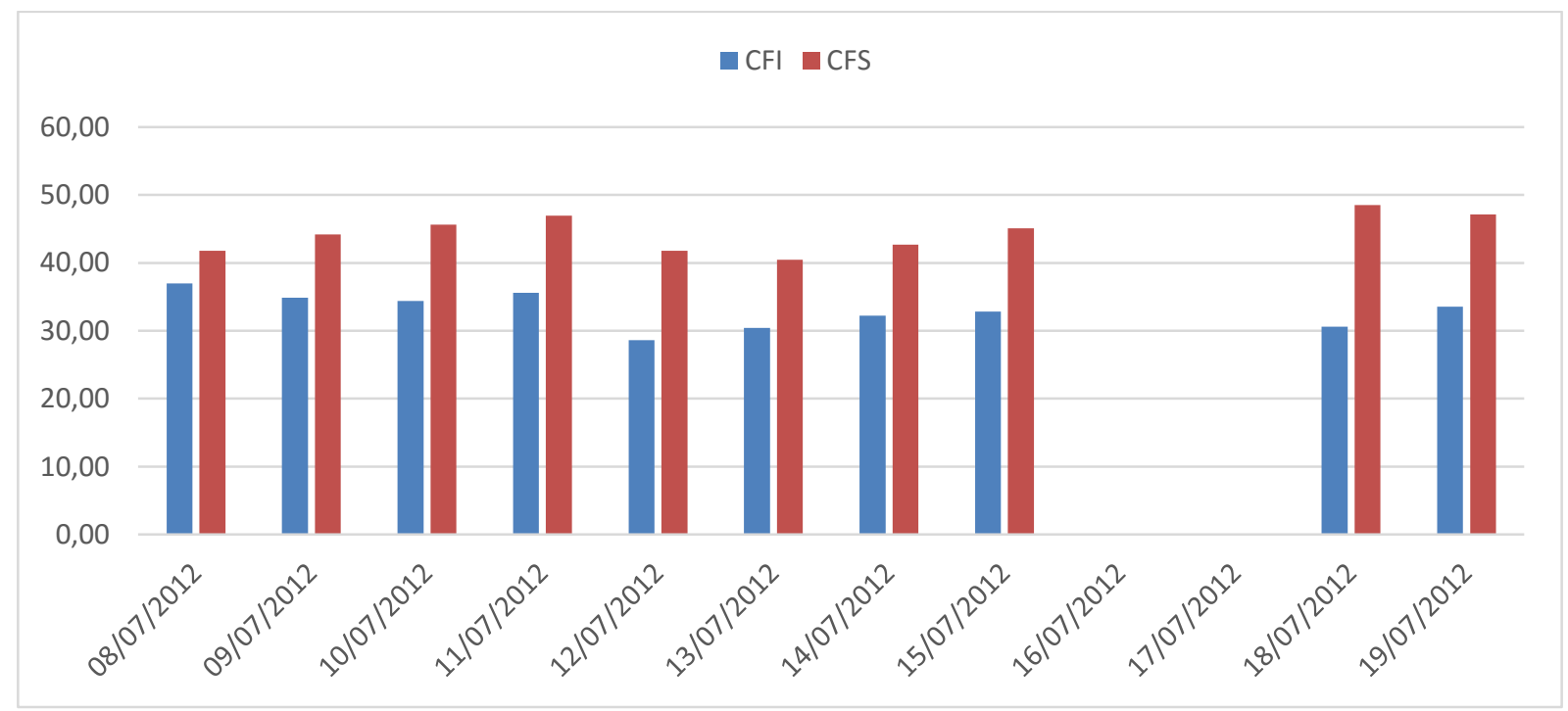

Figura 5.25: Espaçamento médio das cúspides durante o período. Em vermelho são as cúspides localizadas na face praial superior e em azul cúspides localizadas na face praial inferior.

São observadas três tendências no espaçamento na CFS, a primeira e a terceira de aumento e a segunda de decréscimo. As variações médias do espaçamento nas três tendências 
ficaram em torno de $5 \mathrm{~m}$. O espaçamento da CFI ficou em torno de $34 \mathrm{~m}$ à $36 \mathrm{~m}$ nos 4 primeiros dias e de $30 \mathrm{~m}$ à $33 \mathrm{~m}$ dos dias 13 a 19 de agosto.

Durante este período a direção ficou em torno de $122^{\circ}$ variando de $120^{\circ}$ a $164^{\circ}$, o período ficou em torno de $9 \mathrm{~s}$ variando de $8 \mathrm{~s}$ à $12 \mathrm{~s}$ e a altura ficou em torno de $0,8 \mathrm{~m}$ variando de 0,4 m à 1,2 m.

No dia 12 de julho a direção foi de $150^{\circ}$, o período foi de $9 \mathrm{~s}$ e a altura foi de $0,9 \mathrm{~m}$ produzindo uma diminuição no espaçamento de $35 \mathrm{~m}$ para $28 \mathrm{~m}$ na CFI. O restante dos dias a direção da onda incidente ficou em torno de $120,22^{\circ}$ mantendo o espaçamento médio da CFI praticamente constantes. As alterações geradas na CFS apesar de pequenas ocorrem provavelmente pela interação do espraiamento com morfologia causando um espraiamento diferencial próximo a face praial superior.

Tabela 5.12: Espaçamento médio das cúspides na face praial inferior e superior.

\begin{tabular}{|c|c|c|c|c|c|}
\hline Datas & Altura(m) & Período(s) & Direção( $\left.{ }^{\circ}\right)$ & $\mathrm{CFI}(\mathrm{m})$ & CFS $(m)$ \\
\hline 08/07/2012 & 0.61 & 8.28 & 164.26 & 36.94 & 41.79 \\
\hline 09/07/2012 & 0.41 & 9.56 & 120.44 & 34.85 & 44.19 \\
\hline $10 / 07 / 2012$ & 0.99 & 9.29 & 121.15 & 34.38 & 45.59 \\
\hline $11 / 07 / 2012$ & 1.20 & 9.02 & 134.00 & 35.56 & 46.94 \\
\hline $12 / 07 / 2012$ & 0.90 & 9.32 & 150.11 & 28.61 & 41.75 \\
\hline $13 / 07 / 2012$ & 1.01 & 9.47 & 139.46 & 30.42 & 40.44 \\
\hline $14 / 07 / 2012$ & 1.07 & 9.64 & 122.39 & 32.24 & 42.67 \\
\hline $15 / 07 / 2012$ & 0.41 & 10.06 & 120.65 & 32.83 & 45.07 \\
\hline $18 / 07 / 2012$ & 0.50 & 12.28 & 122.01 & 30.59 & 48.53 \\
\hline $19 / 07 / 2012$ & 0.57 & 9.96 & 121.96 & 33.53 & 47.11 \\
\hline
\end{tabular}



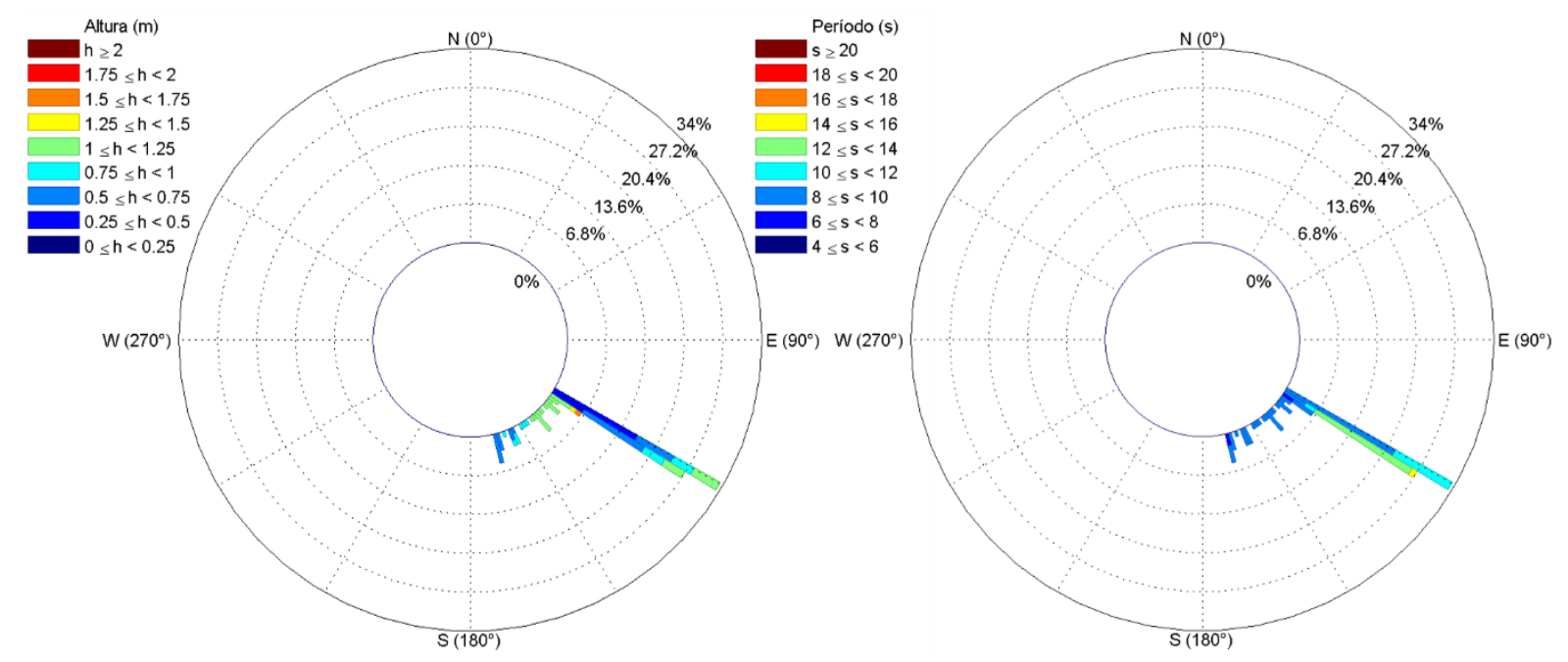

Figura 5.26: Histograma direcional de altura ( $m$, a esquerda) e período (s, a direita) das ondas atuantes durante o período.
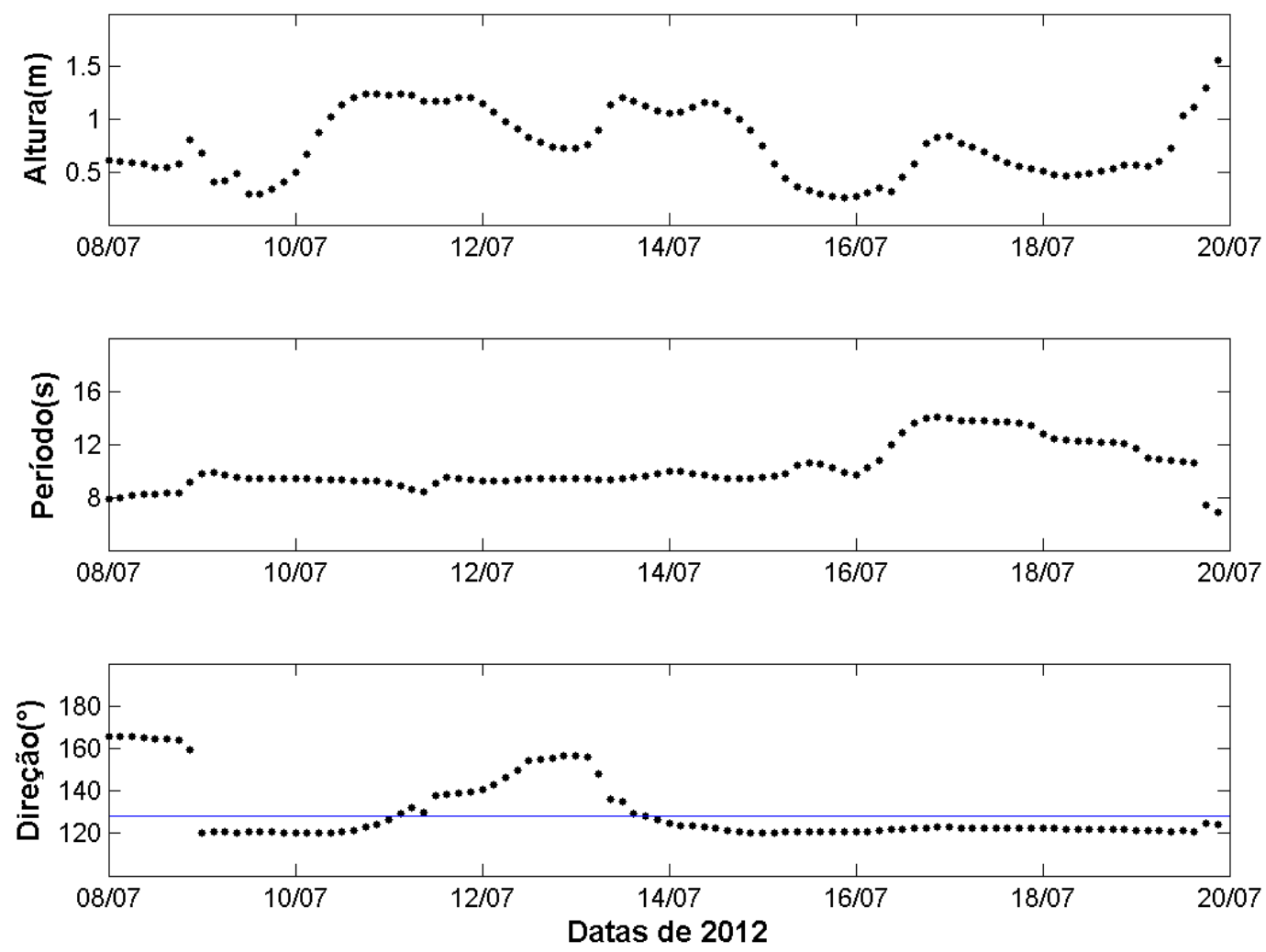

Figura 5.27: Evolução da altura, período e direção atuantes durante o período, onde a linha em azul representa a direção normal a face praial. 

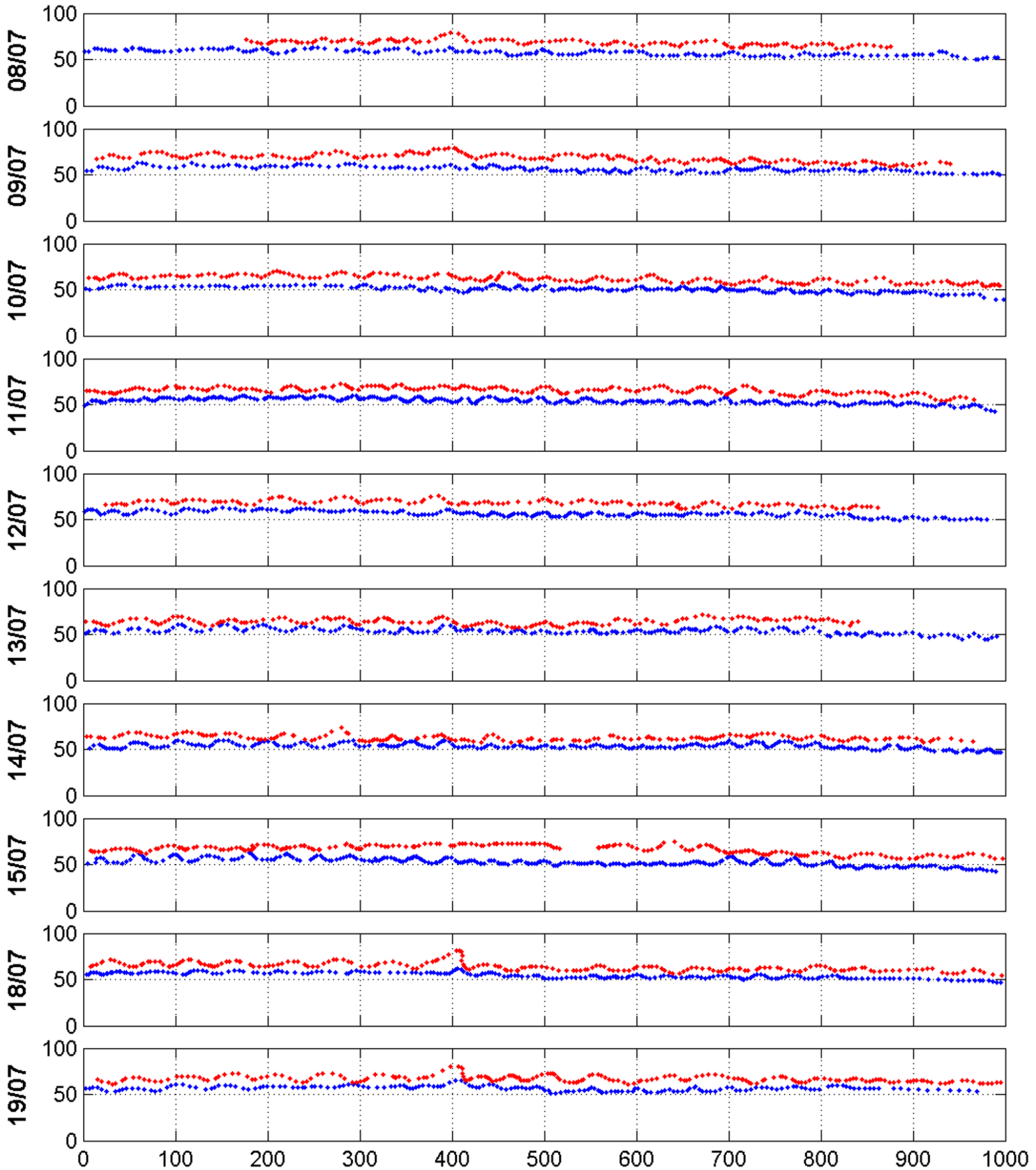

Figura 5.28: Cúspides digitalizadas durante o período. Em vermelho são as cúspides localizadas na face praial superior e em azul cúspides localizadas na face praial inferior. 


\subsubsection{Momento 5}

O momento 5 compreende o período de 20 à 27 de julho de 2012 com 8 dias analisados e com apenas uma cúspide registrada na face praial superior e nenhuma para face praial inferior (Tabela 5.14; Figuras 5.29 e 5.32). Durante este período 1 sistema frontal atuou no arco praial de Massaguaçú no dia 27 de julho de 2012.

A altura média das ondas incidentes foi de $0.5 \mathrm{~m}$ variando de $0 \mathrm{~m}$ à $1,63 \mathrm{~m}$, o período foi e $9,96 \mathrm{~s}$ variando de $4,36 \mathrm{~s}$ à $12,39 \mathrm{~s}$ e a direção foi $120,80^{\circ}$ variando de $114,90^{\circ}$ à $171,90^{\circ}$ (Tabelas 5.13 e 5.14; Figuras 5.30 e 5.31).

Tabela 5.13: Características das ondas atuantes no arco praial de Massaguaçú durante o período.

\begin{tabular}{|l|c|c|c|c|c|} 
& Mínimo & Máximo & Média & Moda & Desvio Padrão \\
\hline Altura(m) & 0.00 & 1.63 & 0.49 & 0.00 & 0.38 \\
\hline Período(s) & 4.36 & 12.39 & 9.96 & 10.73 & 1.71 \\
\hline Direção( ${ }^{\circ}$ ) & 114.90 & 171.91 & 122.74 & 120.80 & 7.17 \\
\hline
\end{tabular}

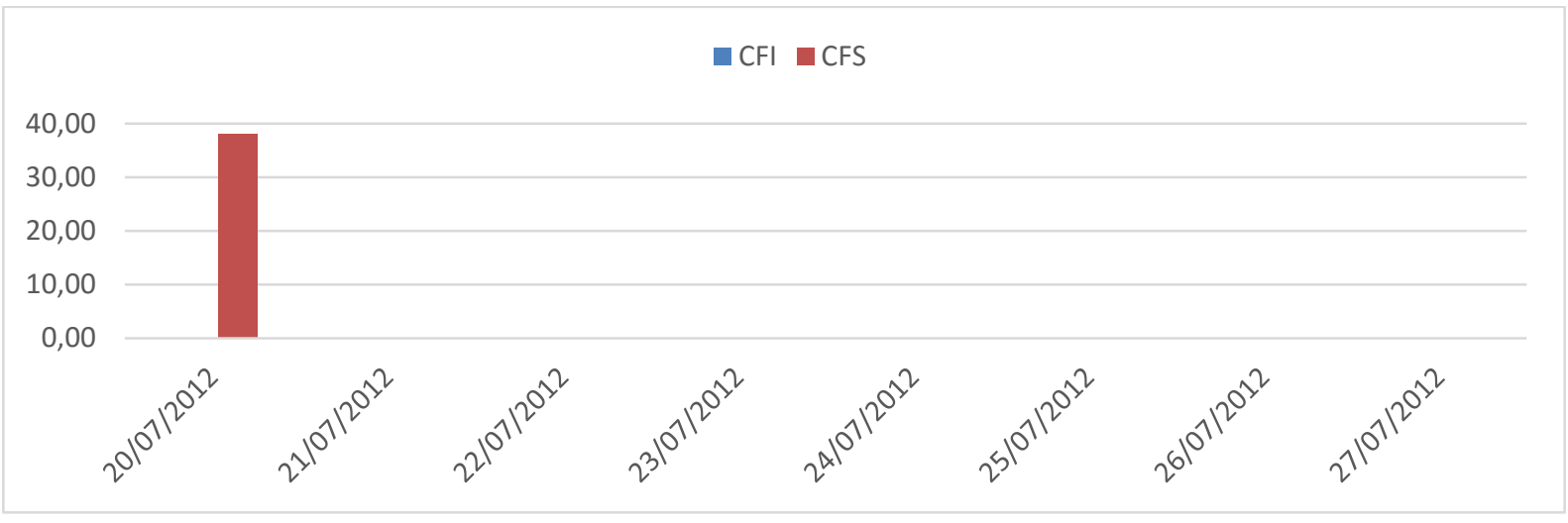

Figura 5.29: Espaçamento médio das cúspides durante o período. Em vermelho são as cúspides localizadas na face praial superior e em azul cúspides localizadas na face praial inferior.

Entre o dia 19 de agosto e 20 de agosto uma ondulação, com direção de $122^{\circ}$ incide no arco praial de Massaguaçú com valores superiores à 1,5 m de altura e período em torno de 10 s. Nos dias seguintes esta ondulação perde força e altura das ondas atuantes se reduz a valores abaixo de $0,5 \mathrm{~m}$. 
A forte ondulação do dia 20 instabiliza as cúspides do dia anterior (19/07/2012) reduzindo a uniformidade das feições existentes e por fim descaracterizando-a. Durante todo o período observou morfologia no arco praial de Massaguaçú, mas sem as características rítmicas uniforme ao longo do arco.

Em grande parte do período a direção da onda incidente ainda era favorável ao desenvolvimento das cúspides, no entanto a altura ficou abaixo de $0,5 \mathrm{~m}$ e possivelmente não teve competência para produzir novas feições rítmicas ou tempo necessário, já que com o passar dos dias a linha d'água convergia em direção ao mar.

Tabela 5.14: Espaçamento médio das cúspides na face praial inferior e superior.

\begin{tabular}{c|c|c|c|c|c|}
\multicolumn{1}{c|}{ Datas } & Altura(m) & Período(s) & Direção( & \multicolumn{1}{c}{ CFI(m) } & CFS(m) \\
\hline $\mathbf{2 0 / 0 7 / 2 0 1 2}$ & 1.39 & 10.70 & 122.31 & - & 38.08 \\
\hline $\mathbf{2 1 / 0 7 / 2 0 1 2}$ & 0.91 & 10.90 & 124.46 & - & - \\
\hline $\mathbf{2 2 / 0 7 / 2 0 1 2}$ & 0.73 & 10.12 & 123.84 & - & - \\
\hline $\mathbf{2 3 / 0 7 / 2 0 1 2}$ & 0.42 & 10.39 & 123.74 & - & - \\
\hline $\mathbf{2 4 / 0 7 / 2 0 1 2}$ & 0.32 & 11.39 & 121.63 & - & - \\
\hline $\mathbf{2 5 / 0 7 / 2 0 1 2}$ & 0.23 & 9.65 & 120.51 & - & - \\
\hline $\mathbf{2 6 / 0 7 / 2 0 1 2}$ & 0.24 & 7.88 & 125.30 & - & - \\
\hline $\mathbf{2 7 / 0 7 / 2 0 1 2}$ & 0.14 & 8.66 & 120.11 & - & - \\
\hline
\end{tabular}



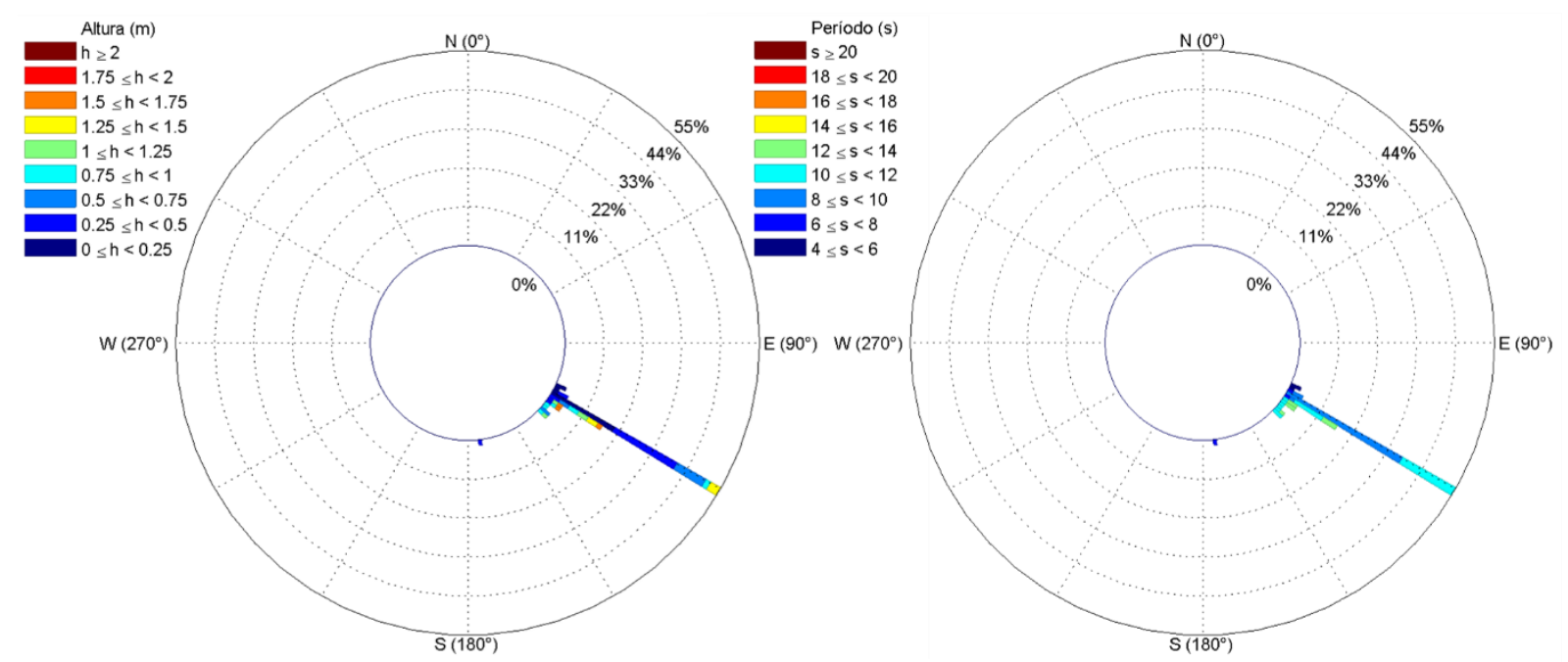

Figura 5.30: Histograma direcional de altura (m, a esquerda) e período (s, a direita) das ondas atuantes durante o período.
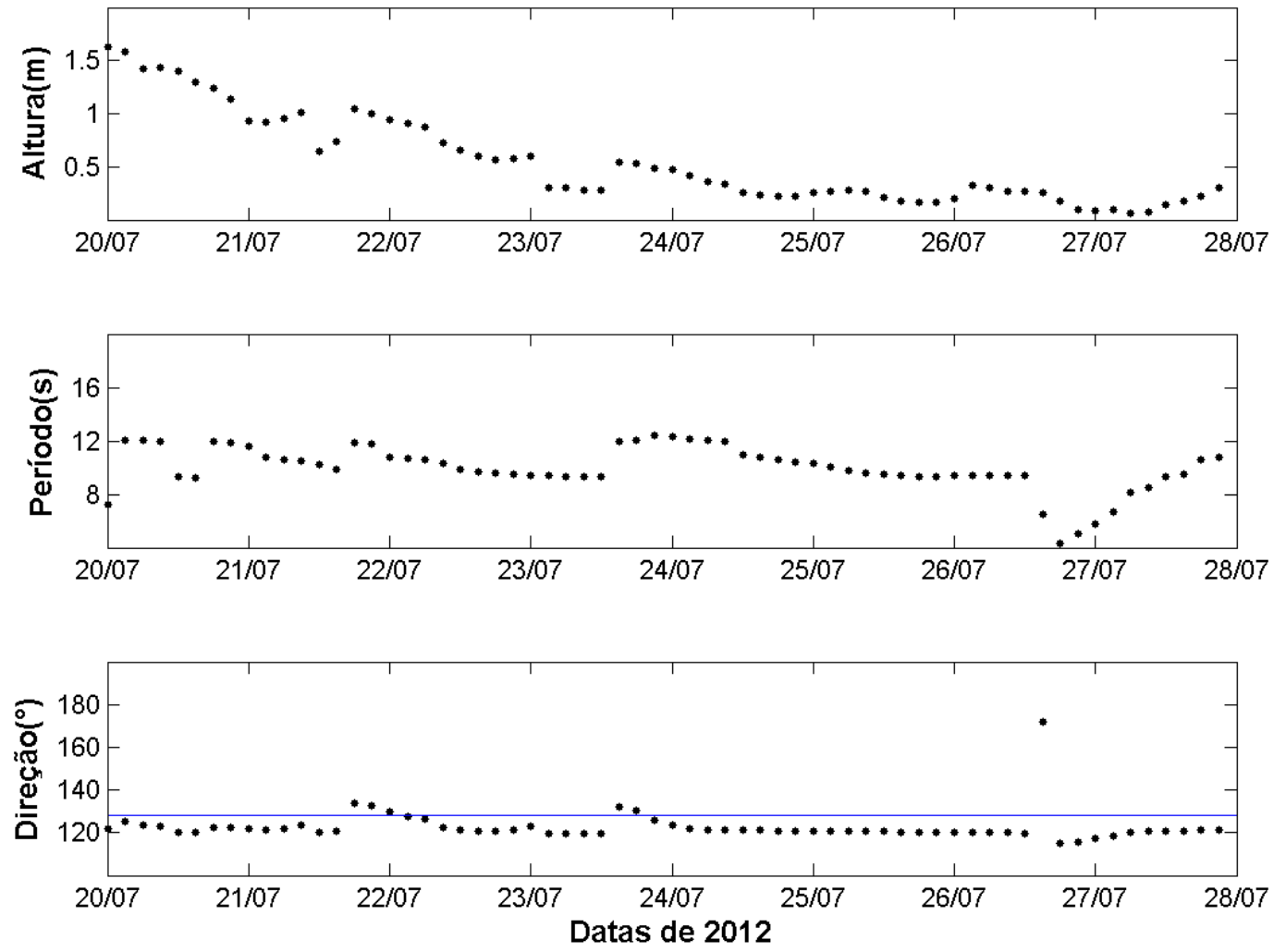

Figura 5.31: Evolução da altura, período e direção atuantes durante o período, onde a linha em azul representa a direção normal a face praial. 

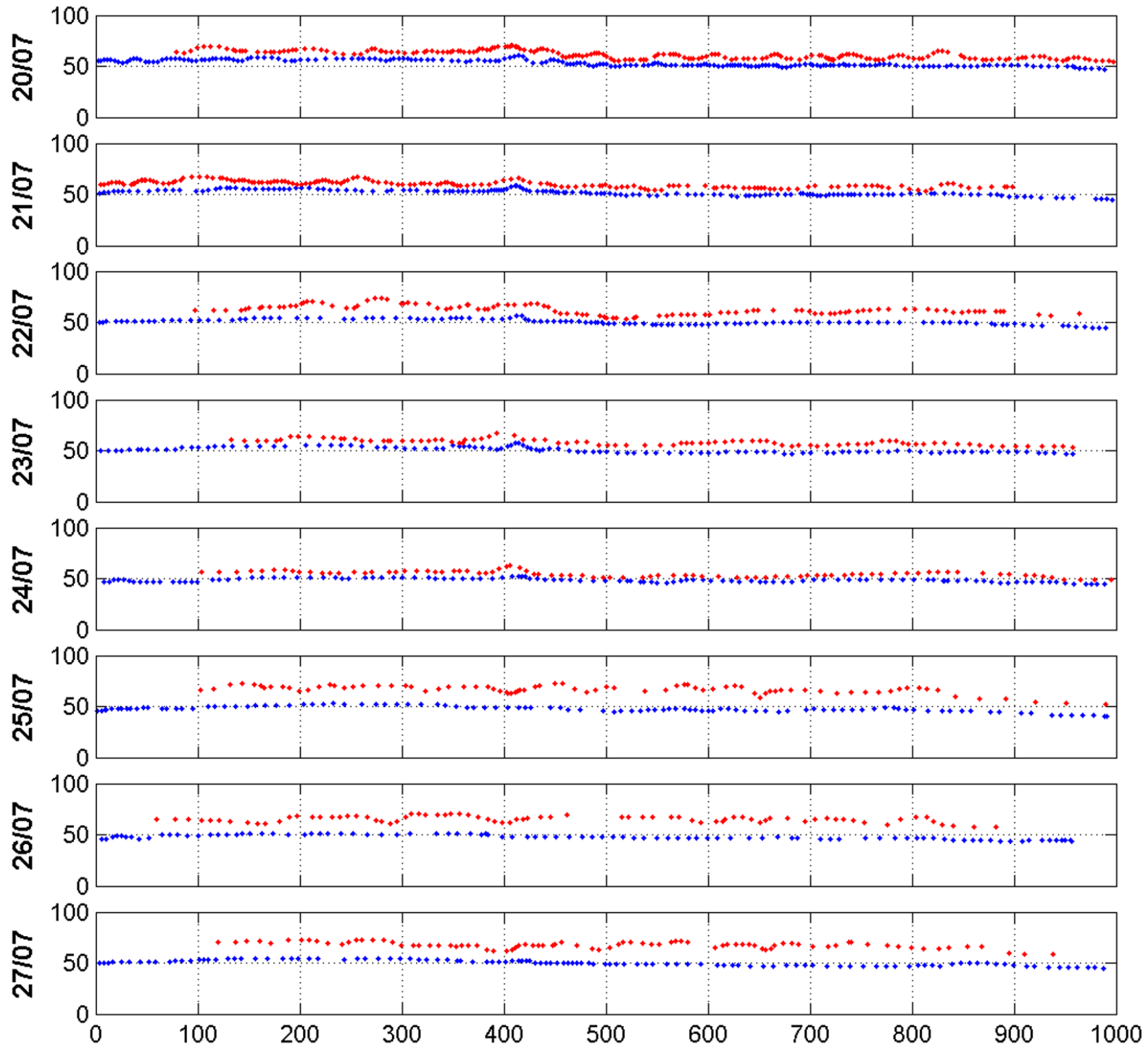

Figura 5.32: Cúspides digitalizadas durante o período. Em vermelho são as cúspides localizadas na face praial superior e em azul cúspides localizadas na face praial inferior. 


\subsubsection{Momento 6}

O momento 6 compreende o período de 28 de julho a 2 de agosto de 2012 com 6 dias analisados. Apenas no dia 30 de agosto não são observadas cúspides na face praial inferior enquanto que para o resto dos dias em ambas as regiões as cúspides foram observadas no arco praial (Tabela 5.16; Figuras 5.33, 5.36 e 5.37). Durante este período 1 sistema frontal atuou no arco praial de Massaguaçú no dia 30 de julho de 2012.

A direção média das ondas incidentes, para o período, foi de $122,66^{\circ}$ variando de $120,50^{\circ}$ à $134,00^{\circ}$, o período foi de $12,81 \mathrm{~s}$ variando de $6,43 \mathrm{~s}$ à $20 \mathrm{~s}$ e a altura foi de $0,53 \mathrm{~m}$ variando de 0,16 m à 1,28 m (Tabelas 5.15 e 5.16; Figuras 5.34 e 5.35).

Tabela 5.15: Características das ondas atuantes no arco praial de Massaguaçú durante o período.

\begin{tabular}{|c|c|c|c|c|c|}
\hline & Mínimo & Máximo & Média & Moda & $\begin{array}{l}\text { Desvio } \\
\text { Padrão }\end{array}$ \\
\hline Altura(m) & 0.16 & 1.28 & 0.57 & 0.16 & 0.28 \\
\hline Período(s) & 6.43 & 20.00 & 12.81 & 7.01 & 3.12 \\
\hline Direção( $\left.{ }^{\circ}\right)$ & 120.50 & 134.00 & 122.66 & 122.20 & 2.19 \\
\hline
\end{tabular}

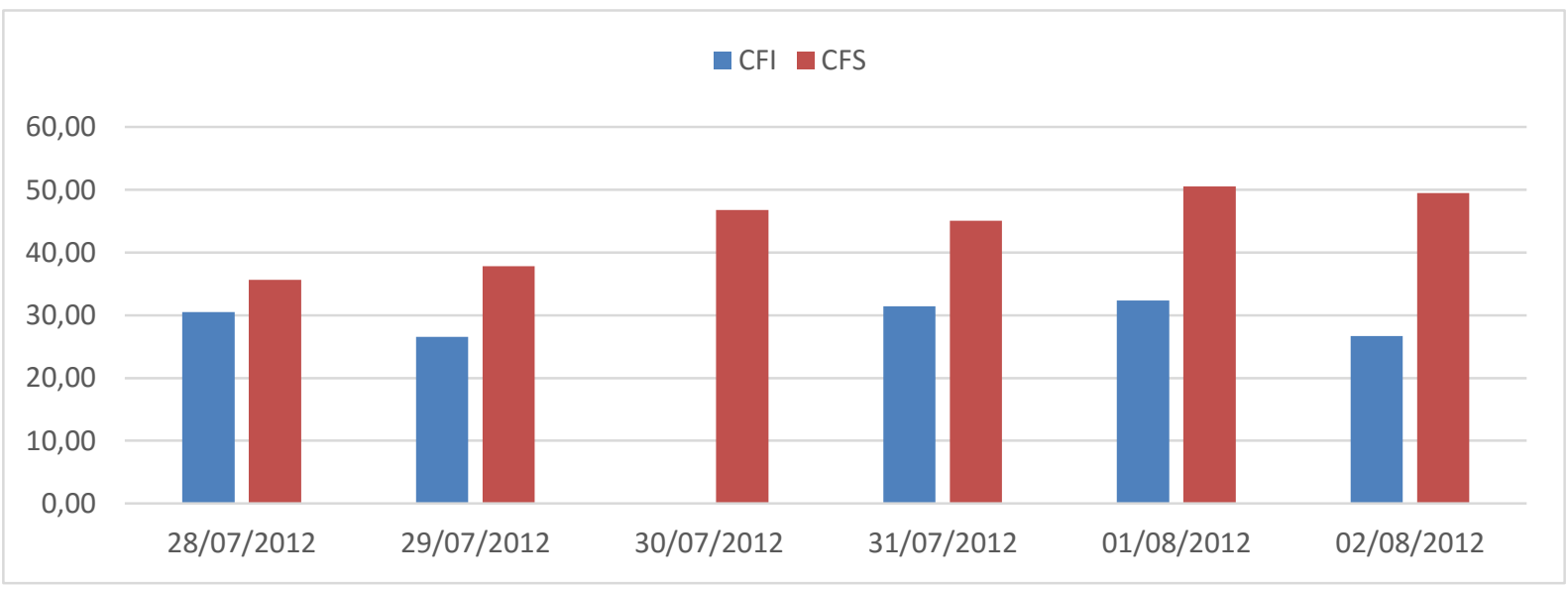

Figura 5.33: Espaçamento médio das cúspides durante o período. Em vermelho são as cúspides localizadas na face praial superior e em azul cúspides localizadas na face praial inferior. 
O espaçamento da CFS ficou em torno de $36 \mathrm{~m}$ nos dois primeiros dias aumentando para $46 \mathrm{~m}$ nos dois dias seguintes e mais uma vez aumentando para $50 \mathrm{~m}$ nos dois últimos dias. O espaçamento na CFI ficou na casa dos $30 \mathrm{~m}$ no primeiro, quarto e quinto dia e na casa dos 26 m no segundo e sexto dia. Durante este período a direção das ondas incidentes foi praticamente de $122^{\circ}$, a altura em torno de $0,7 \mathrm{~m}$, o período variou de $9 \mathrm{~s}$ à $16 \mathrm{~s}$.

No dia 27 de agosto a posição média da linha d'água estava 26 m em relação a linha de vegetação e no dia 28 de agosto esta linha estava a $20 \mathrm{~m}$ da linha de vegetação. Este recuo posicionou o espraiamento em cima da morfologia existente no arco praial. Esta interação gerou condições para um espraiamento diferencial ao longo do arco praial e por fim feições rítmicas ao longo do mesmo. No dia 30 de agosto a posição média da linha d'água aumentou para $25 \mathrm{~m}$ e o espraiamento diferencial presente não foi observado.

Tabela 5.16: Espaçamento médio das cúspides na face praial inferior e superior.

\begin{tabular}{c|c|c|c|c|c} 
Datas & Altura(m) & Período(s) & Direção( $\left.{ }^{\circ}\right)$ & CFI(m) & CFS(m) \\
\hline $\mathbf{2 8 / 0 7 / 2 0 1 2}$ & 0.25 & 10.06 & 120.94 & 30.50 & 35.63 \\
\hline $\mathbf{2 9 / 0 7 / 2 0 1 2}$ & 0.52 & 16.04 & 122.70 & 26.56 & 37.86 \\
\hline $\mathbf{3 0 / 0 7 / 2 0 1 2}$ & 0.70 & 14.90 & 122.76 & - & 46.81 \\
\hline $\mathbf{3 1 / 0 7 / 2 0 1 2}$ & 0.49 & 13.82 & 122.44 & 31.44 & 45.08 \\
\hline $\mathbf{0 1 / 0 8 / 2 0 1 2}$ & 0.90 & 9.02 & 124.98 & 32.33 & 50.57 \\
\hline $\mathbf{0 2 / 0 8 / 2 0 1 2}$ & 0.62 & 13.04 & 122.18 & 26.67 & 49.50 \\
\hline
\end{tabular}



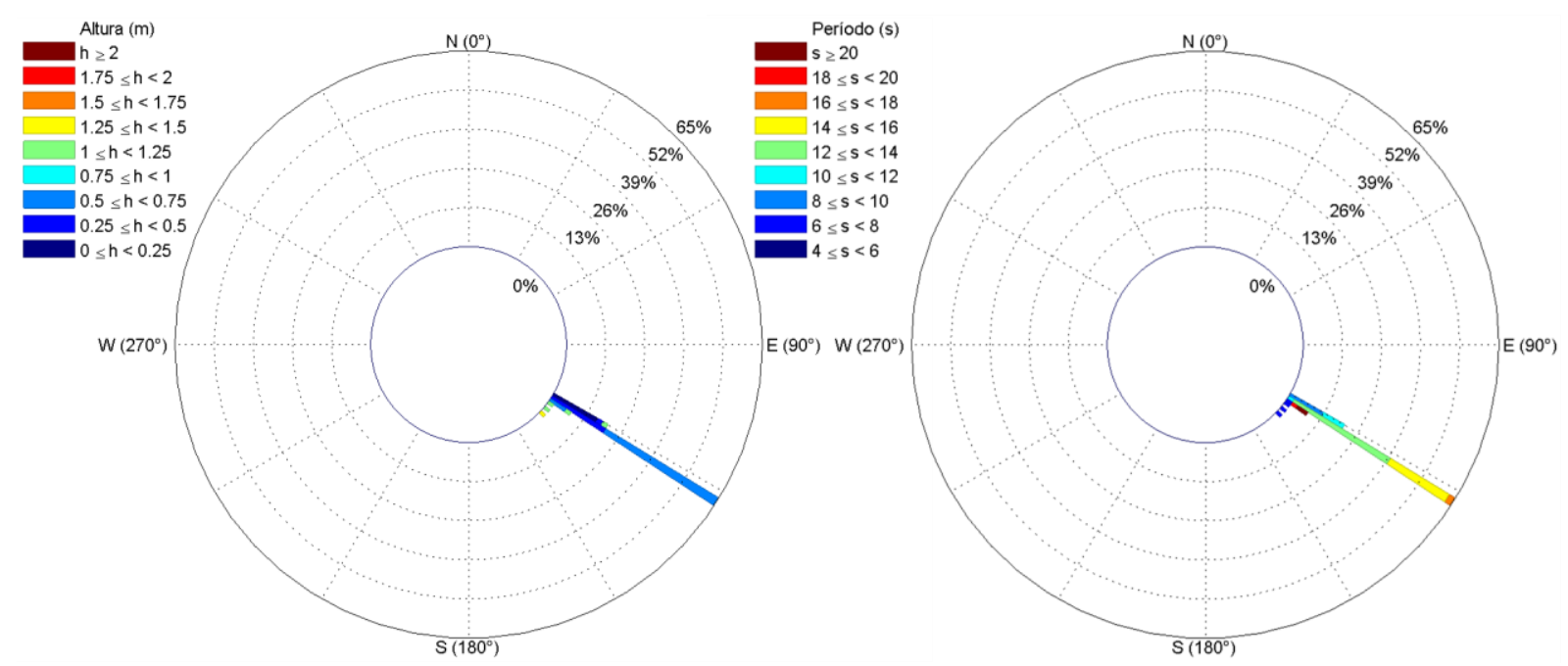

Figura 5.34: Histograma direcional de altura ( $m$, a esquerda) e período (s, a direita) das ondas atuantes durante o período.
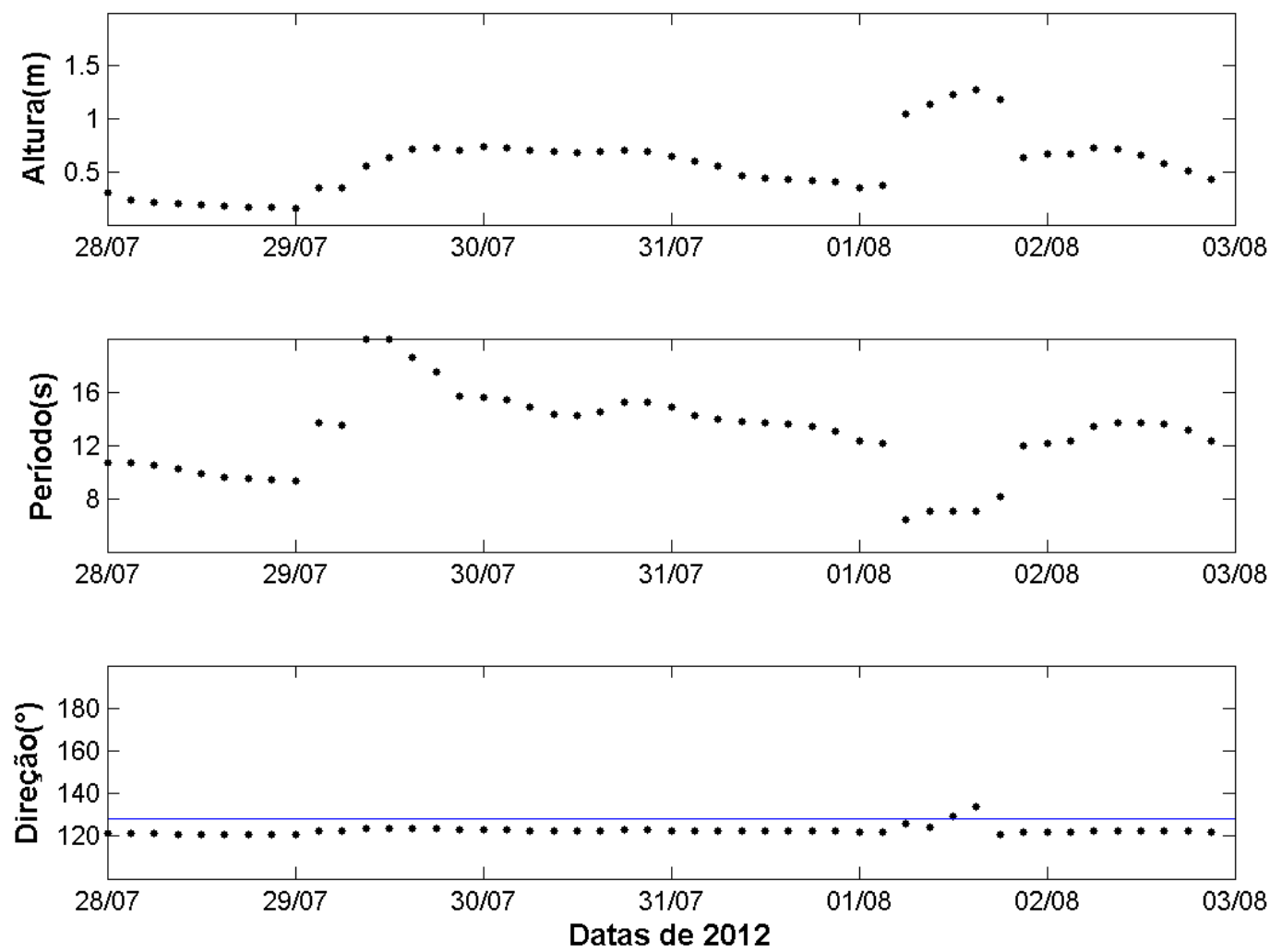

Figura 5.35: Evolução da altura, período e direção atuantes durante o período, onde a linha em azul representa a direção normal a face praial. 

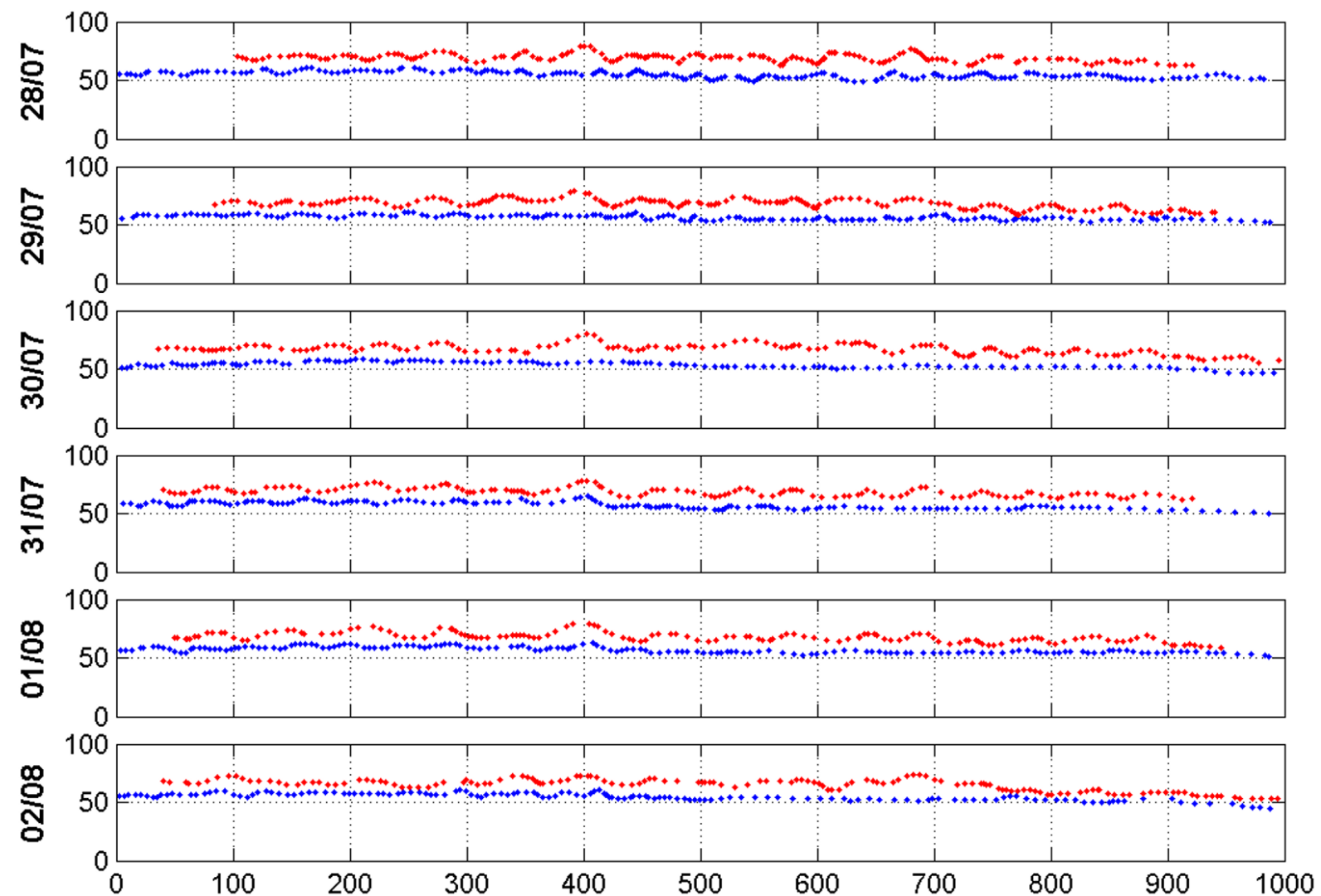

Figura 5.36: Cúspides digitalizadas durante o período. Em vermelho são as cúspides localizadas na face praial superior e em azul cúspides localizadas na face praial inferior.

$28 / 07 / 2012$

$30 / 07 / 2012$

Figura 5.37: Imagem de variação evidenciando o espraiamento diferencial devido ao afogamento da morfologia existente no arco praial de Massaguaçú. 


\subsubsection{Momento 7}

O momento 7 compreende o período de 3 de agosto à 4 de setembro 2012 com 12 dias analisados. Neste período não são observadas cúspides na face praial inferior em nenhum dos dias e na face praial superior foi registrado a presença de cúspides em todos os dias do período (Tabela 5.18; Figuras 5.38 e 5.41). Durante este período 2 sistemas frontais atuaram no arco praial de Massaguaçú nos dias 5 e 28 de agosto de 2012.

A direção média das ondas incidentes, para o período, foi de $148,63^{\circ}$ variando de $115,30^{\circ}$ à $173,32^{\circ}$, o período foi de $8,98 \mathrm{~s}$ variando de $4,71 \mathrm{~s}$ à $15,64 \mathrm{~s}$ e a altura foi de $0,83 \mathrm{~m}$ variando de $0,01 \mathrm{~m}$ à 1,54 m (Tabelas 5.17 e 5.18; Figuras 5.39 e 5.40).

Tabela 5.17: Características das ondas atuantes no arco praial de Massaguaçú durante o período.

\begin{tabular}{|c|c|c|c|c|c|}
\hline & Mínimo & Máximo & Média & Moda & Desvio Padrão \\
\hline Altura(m) & 0.01 & 1.54 & 0.83 & 1.05 & 0.25 \\
\hline Período(s) & 4.71 & 15.64 & 8.98 & 7.97 & 1.82 \\
\hline Direção( $\left.{ }^{\circ}\right)$ & 115.30 & 173.32 & 148.63 & 160.10 & 18.33 \\
\hline
\end{tabular}

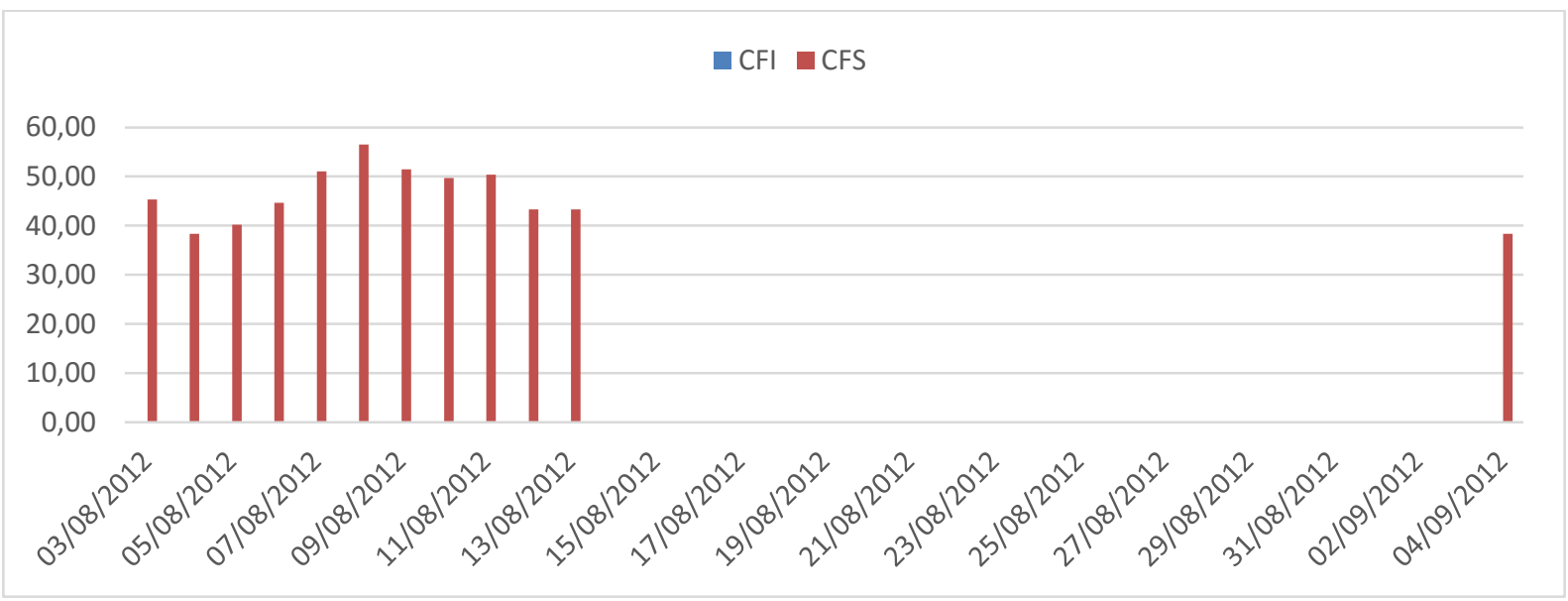

Figura 5.38: Espaçamento médio das cúspides durante o período. Em vermelho são as cúspides localizadas na face praial superior e em azul cúspides localizadas na face praial inferior.

O espaçamento na CFS decresceu nos 3 primeiros dias de $45 \mathrm{~m}$ para $40 \mathrm{~m}$, aumentando seu valor nos 3 dias seguintes de $40 \mathrm{~m}$ para $56 \mathrm{~m}$. No restante do período o espaçamento ficou em torno de 44 m de comprimento com exceção do dia 11 de setembro. 
A direção da ondulação nos 3 primeiros dias incidiu no arco praial com direção de $160^{\circ}$ causando a diminuição do espaçamento das cúspides. Nos 5 dias seguintes a ondulação passou a ter a direção em torno de $121^{\circ}$ intensificando as feições rítmicas. Para o restante do período a ondulação incidiu com direção em torno de $166^{\circ}$, período em torno de $6 \mathrm{~s}$ e altura de $0,4 \mathrm{~m}$.

Tabela 5.18: Espaçamento médio das cúspides na face praial inferior e superior.

\begin{tabular}{c|c|c|c|c|c|} 
Datas & Altura(m) & Período(s) & Direção( & CFI(m) & CFS(m) \\
\hline $\mathbf{0 3 / 0 8 / 2 0 1 2 ~}$ & 0.75 & 9.64 & 144.24 & - & 45.29 \\
\hline $\mathbf{0 4 / 0 8 / 2 0 1 2}$ & 0.88 & 8.27 & 160.21 & - & 38.33 \\
\hline $\mathbf{0 5 / 0 8 / 2 0 1 2}$ & 0.77 & 8.53 & 160.21 & - & 40.18 \\
\hline $\mathbf{0 6 / 0 8 / 2 0 1 2}$ & 0.43 & 13.75 & 127.29 & - & 44.64 \\
\hline $\mathbf{0 7 / 0 8 / 2 0 1 2}$ & 0.44 & 10.79 & 120.60 & - & 51.09 \\
\hline $\mathbf{0 8 / 0 8 / 2 0 1 2}$ & 0.46 & 9.49 & 120.10 & - & 56.54 \\
\hline $\mathbf{0 9 / 0 8 / 2 0 1 2}$ & 0.69 & 12.66 & 121.94 & - & 51.44 \\
\hline $\mathbf{1 0 / 0 8 / 2 0 1 2}$ & 0.54 & 10.91 & 127.86 & - & 49.72 \\
\hline $\mathbf{1 1 / 0 8 / 2 0 1 2}$ & 0.56 & 6.27 & 169.27 & - & 50.38 \\
\hline $\mathbf{1 2 / 0 8 / 2 0 1 2}$ & 0.67 & 6.67 & 167.41 & - & 43.33 \\
\hline $\mathbf{1 3 / 0 8 / 2 0 1 2}$ & 0.68 & 6.95 & 167.41 & - & 43.29 \\
\hline $\mathbf{0 4 / 0 9 / 2 0 1 2}$ & 0.45 & 6.76 & 135.95 & - & 38.33 \\
\hline
\end{tabular}



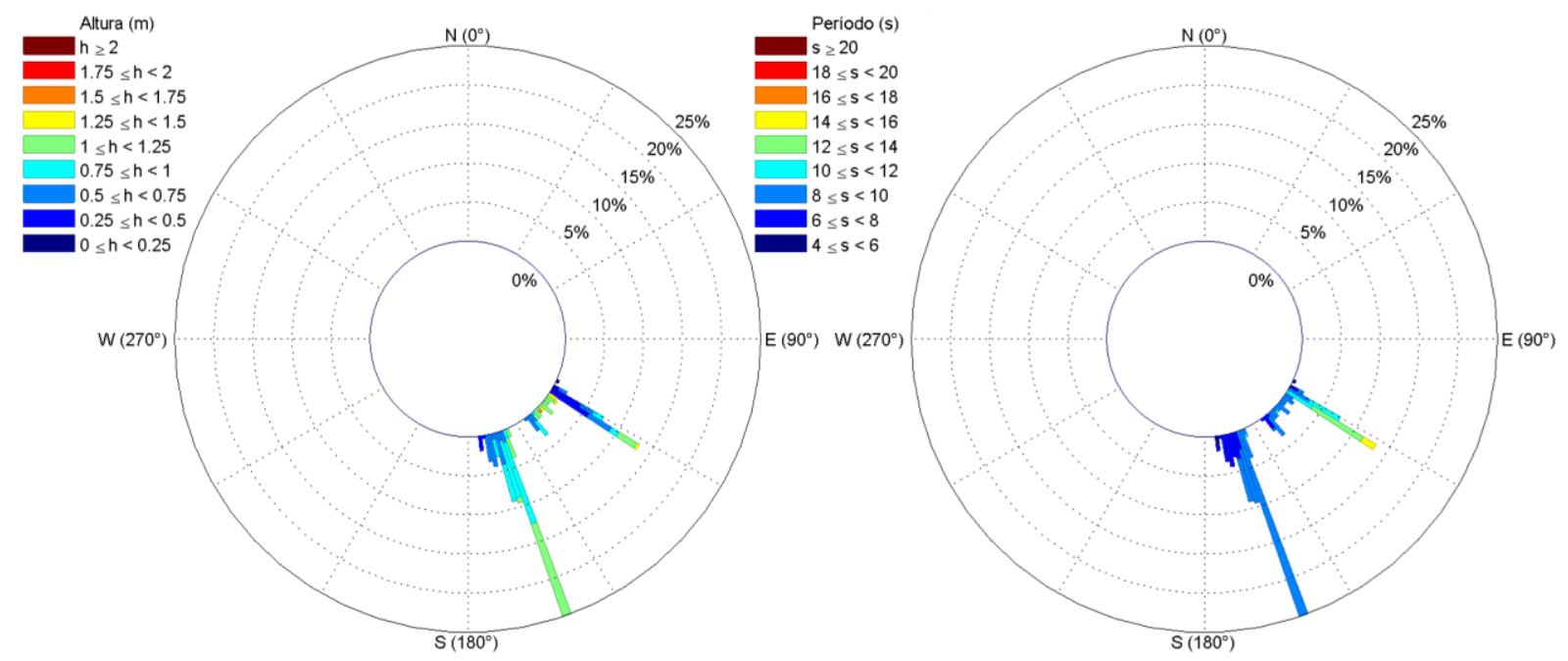

Figura 5.39: Histograma direcional de altura (m, a esquerda) e período (s, a direita) das ondas atuantes durante o período.
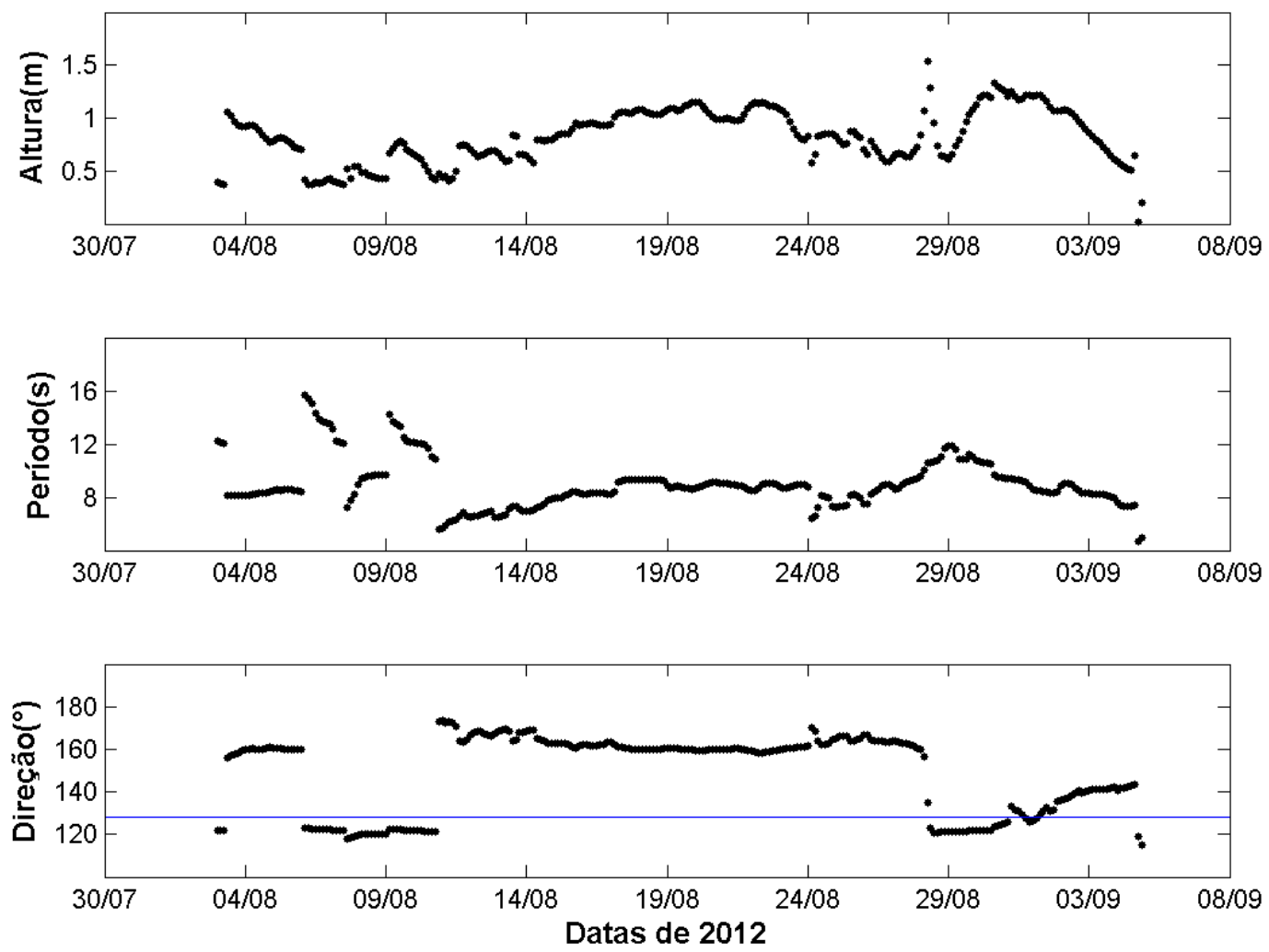

Figura 5.40: Evolução da altura, período e direção atuantes durante o período, onde a linha em azul representa a direção normal a face praial. 


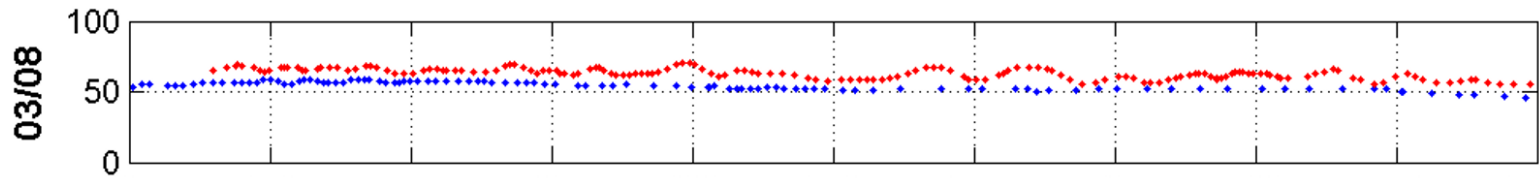

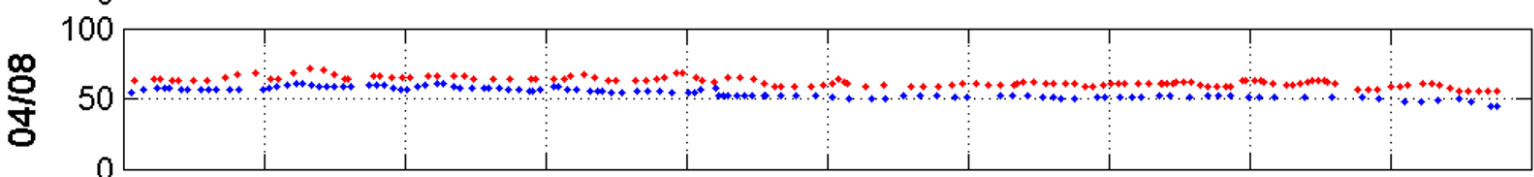

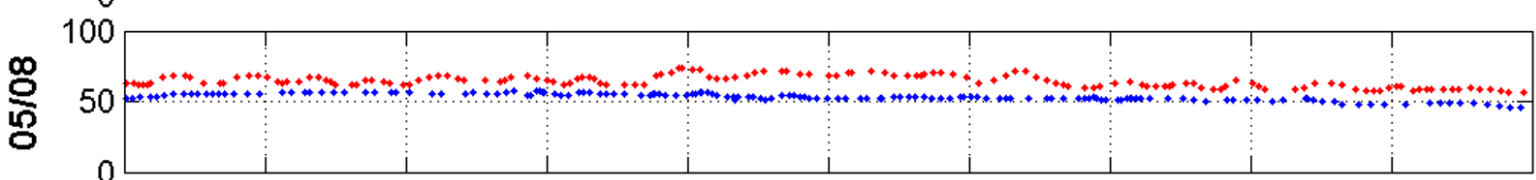

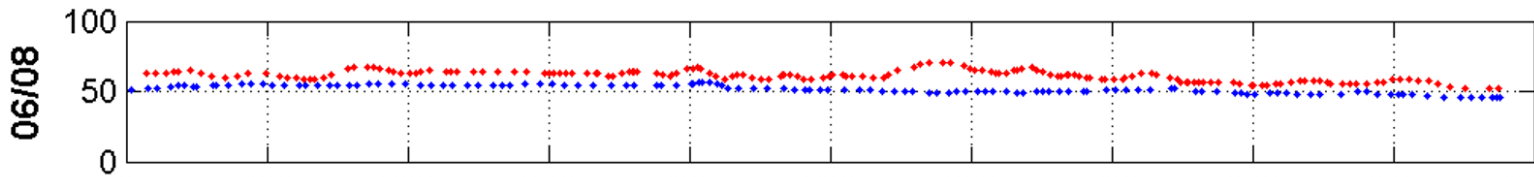
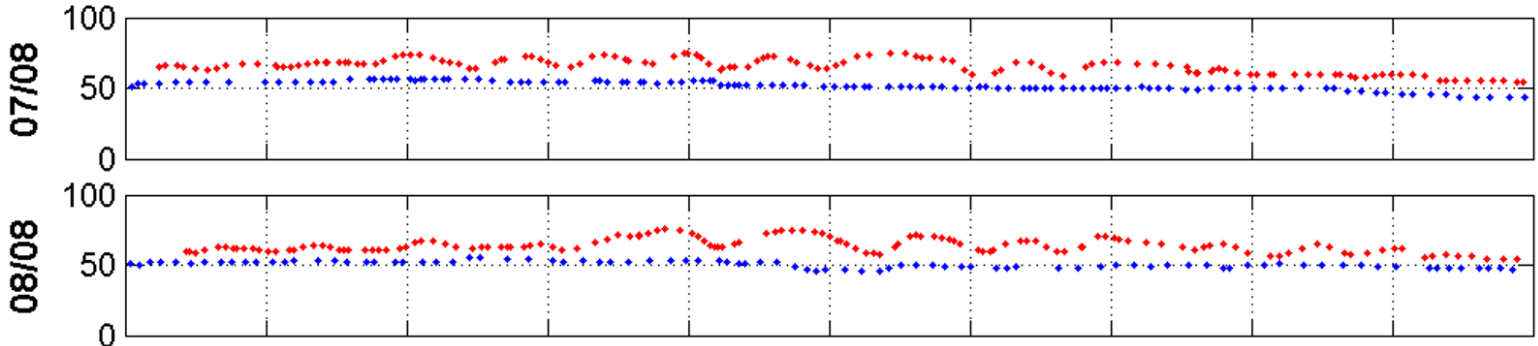

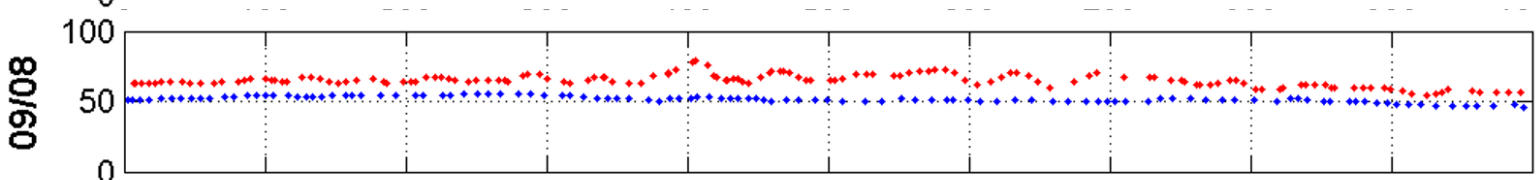
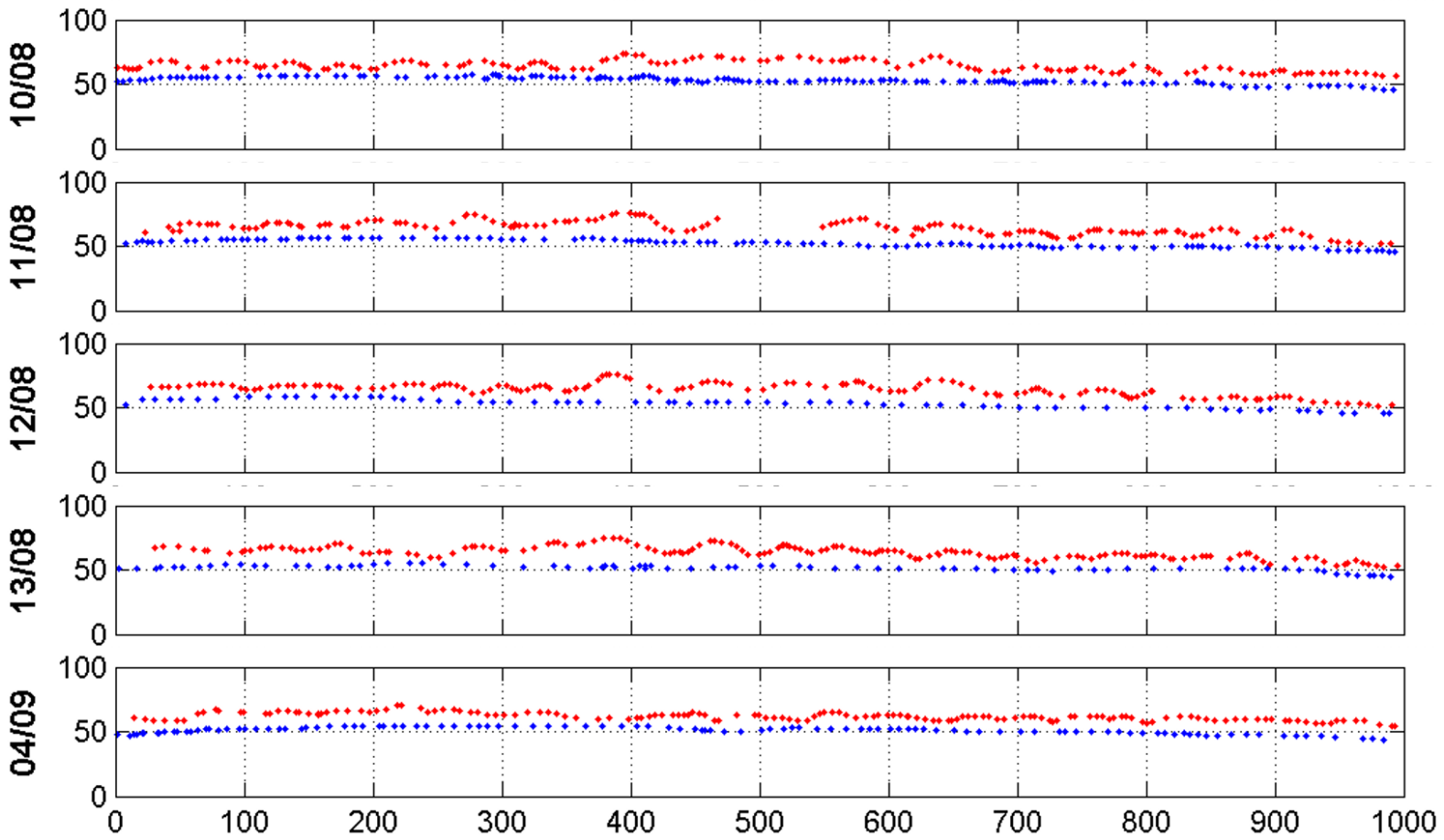

Figura 5.41: Cúspides digitalizadas durante o período. Em vermelho são as cúspides localizadas na face praial superior e em azul cúspides localizadas na face praial inferior. 


\subsubsection{Momento 8}

O Momento 8 compreende o período de 5 de setembro à 29 de setembro com 24 dias analisados. Observa-se cúspides em ambas as regiões do arco praial, na face praial superior são observados 18 registros e na face praial inferior observa-se 14 registros (Tabela 5.20; Figuras $5.42,5.45,5.46$ e 5.47). Durante este período 3 sistemas frontais atuaram no arco praial de Massaguaçú nos dias 20, 21 e 25 de setembro de 2012.

A direção média das ondas incidentes, para o período, foi de $142,23^{\circ}$ variando de $117,60^{\circ}$ à $176,41^{\circ}$, o período foi de $9,25 \mathrm{~s}$ variando de $4,74 \mathrm{~s}$ à $17,32 \mathrm{~s}$ e a altura foi de $0,51 \mathrm{~m}$ variando de 0,05 m à 1,34 m (Tabelas 5.19 e 5.20; Figuras 5.43 e 5.44).

Tabela 5.19: Características das ondas atuantes no arco praial de Massaguaçú durante o período.

\begin{tabular}{|c|c|c|c|c|c|}
\hline & Mínimo & Máximo & Média & Moda & Desvio Padrão \\
\hline Altura(m) & 0.05 & 1.34 & 0.51 & 0.05 & 0.27 \\
\hline Período(s) & 4.74 & 17.32 & 9.25 & 10.83 & 2.27 \\
\hline Direção( $\left.{ }^{\circ}\right)$ & 117.60 & 176.41 & 142.23 & 121.60 & 22.64 \\
\hline
\end{tabular}

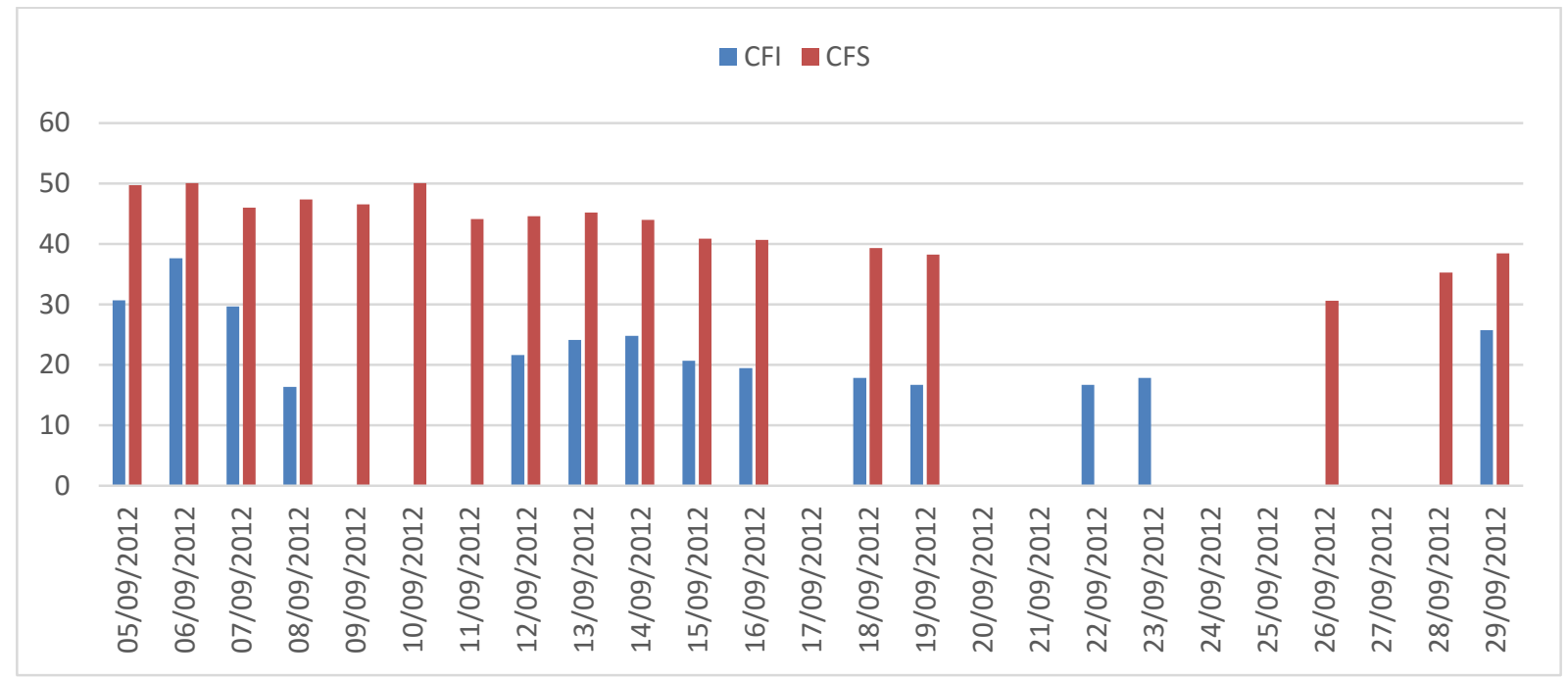

Figura 5.42: Espaçamento médio das cúspides durante o período. Em vermelho são as cúspides localizadas na face praial superior e em azul cúspides localizadas na face praial inferior.

A ondulação de sudeste-leste com altura em torno de $1 \mathrm{~m}$ atuante nos 3 primeiros dias interagiu com as cúspides do dia anterior produzindo feições rítmicas com espaçamento em 
torno de 43m na CFS e 30 metros na CFI e com a evolução da ondulação o espaçamento de ambas morfologias aumentou para $50 \mathrm{~m}$ e $37 \mathrm{~m}$ respectivamente.

No dia seguinte o espaçamento diminui com o gradativo aumento no ângulo de incidência da ondulação culminando com destruição das cúspides na CFI.

Durante este declínio as cúspides da face praial superior estabilizam e mantem o espaçamento praticamente constante, devido a pequena altura da ondulação. Nos dias seguintes, diferente dos dias anteriores, o espraiamento foi diferencial e a posição média da linha d'água diminuiu em relação a linha de vegetação, produzindo interação do espraiamento com a morfologia da berma e por fim gerando cúspides na face praial inferior.

Este espraiamento diferencial também ocorreu nos dias 22 e 23 de setembro produzindo cúspides na CFI. A CFS se manteve sem feições rítmicas e sem interação com o espraiamento devido as baixas condições hidrodinâmicas.

Nos dias subsequentes o espraiamento foi homogêneo e as condições se mantiveram baixas com valores em torno de $0,3 \mathrm{~m}$ com exceção do último dia que foi de $0,5 \mathrm{~m}$. As cúspides formadas nesses dias provavelmente foram geradas devido a interação entre a morfologia existente no arco praial e o espraiamento. 
Tabela 5.20: Espaçamento médio das cúspides na face praial inferior e superior.

\begin{tabular}{|c|c|c|c|c|c|}
\hline Datas & Altura(m) & Período(s) & Direção( & CFI(m) & CFS(m) \\
\hline $\mathbf{0 5 / 0 9 / 2 0 1 2 ~}$ & 0.90 & 8.78 & 120.25 & 30.67 & 43.69 \\
\hline $\mathbf{0 6 / 0 9 / 2 0 1 2}$ & 1.13 & 11.69 & 122.00 & 37.62 & 50.06 \\
\hline $\mathbf{0 7 / 0 9 / 2 0 1 2}$ & 1.08 & 10.73 & 123.55 & 29.63 & 46.00 \\
\hline $\mathbf{0 8 / 0 9 / 2 0 1 2}$ & 0.64 & 8.10 & 146.93 & 16.36 & 47.33 \\
\hline $\mathbf{0 9 / 0 9 / 2 0 1 2}$ & 0.43 & 7.04 & 169.74 & - & 46.53 \\
\hline $\mathbf{1 0 / 0 9 / 2 0 1 2}$ & 0.34 & 7.37 & 169.06 & - & 50.08 \\
\hline $\mathbf{1 1 / 0 9 / 2 0 1 2}$ & 0.33 & 7.85 & 167.28 & - & 44.08 \\
\hline $\mathbf{1 2 / 0 9 / 2 0 1 2}$ & 0.53 & 7.99 & 161.99 & 21.60 & 44.56 \\
\hline $\mathbf{1 3 / 0 9 / 2 0 1 2}$ & 0.82 & 7.85 & 143.55 & 24.14 & 45.19 \\
\hline $\mathbf{1 4 / 0 9 / 2 0 1 2}$ & 0.46 & 14.34 & 124.90 & 24.80 & 43.94 \\
\hline $\mathbf{1 5 / 0 9 / 2 0 1 2}$ & 0.37 & 11.72 & 125.13 & 20.65 & 40.86 \\
\hline $\mathbf{1 6 / 0 9 / 2 0 1 2}$ & 0.35 & 6.74 & 161.20 & 19.48 & 40.67 \\
\hline $\mathbf{1 8 / 0 9 / 2 0 1 2}$ & 0.58 & 7.23 & 167.39 & 17.86 & 39.33 \\
\hline $\mathbf{1 9 / 0 9 / 2 0 1 2}$ & 0.47 & 7.53 & 167.76 & 16.71 & 38.21 \\
\hline $\mathbf{2 0 / 0 9 / 2 0 1 2}$ & 0.47 & 7.88 & 167.04 & - & - \\
\hline $\mathbf{2 1 / 0 9 / 2 0 1 2}$ & 0.47 & 8.36 & 165.24 & - & - \\
\hline $\mathbf{2 2 / 0 9 / 2 0 1 2}$ & 0.44 & 10.15 & 122.61 & 16.67 & - \\
\hline $\mathbf{2 3 / 0 9 / 2 0 1 2}$ & 0.46 & 9.58 & 120.39 & 17.82 & - \\
\hline $\mathbf{2 4 / 0 9 / 2 0 1 2}$ & 0.40 & 10.65 & 120.91 & - & - \\
\hline $\mathbf{2 5 / 0 9 / 2 0 1 2}$ & 0.42 & 12.16 & 121.95 & - & - \\
\hline $\mathbf{2 6 / 0 9 / 2 0 1 2}$ & 0.27 & 9.47 & 133.50 & - & 30.62 \\
\hline $\mathbf{2 7 / 0 9 / 2 0 1 2}$ & 0.16 & 9.44 & 121.08 & - & - \\
\hline $\mathbf{2 8 / 0 9 / 2 0 1 2}$ & 0.26 & 10.81 & 121.58 & - & 35.27 \\
\hline $\mathbf{2 9 / 0 9 / 2 0 1 2}$ & 0.46 & 11.05 & 121.38 & 25.73 & 39.41 \\
\hline & & & & & \\
\hline
\end{tabular}



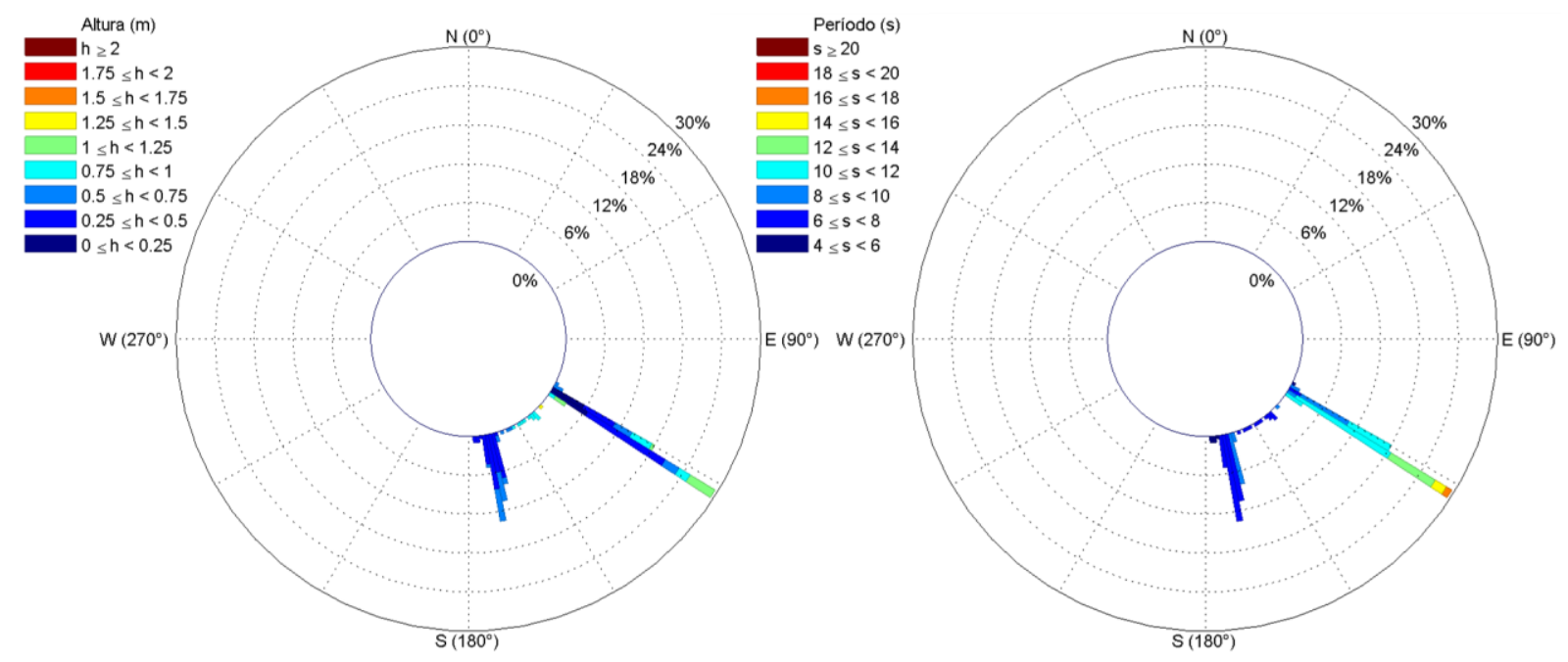

Figura 5.43: Histograma direcional de altura ( $m$, a esquerda) e período (s, a direita) das ondas atuantes durante o período.
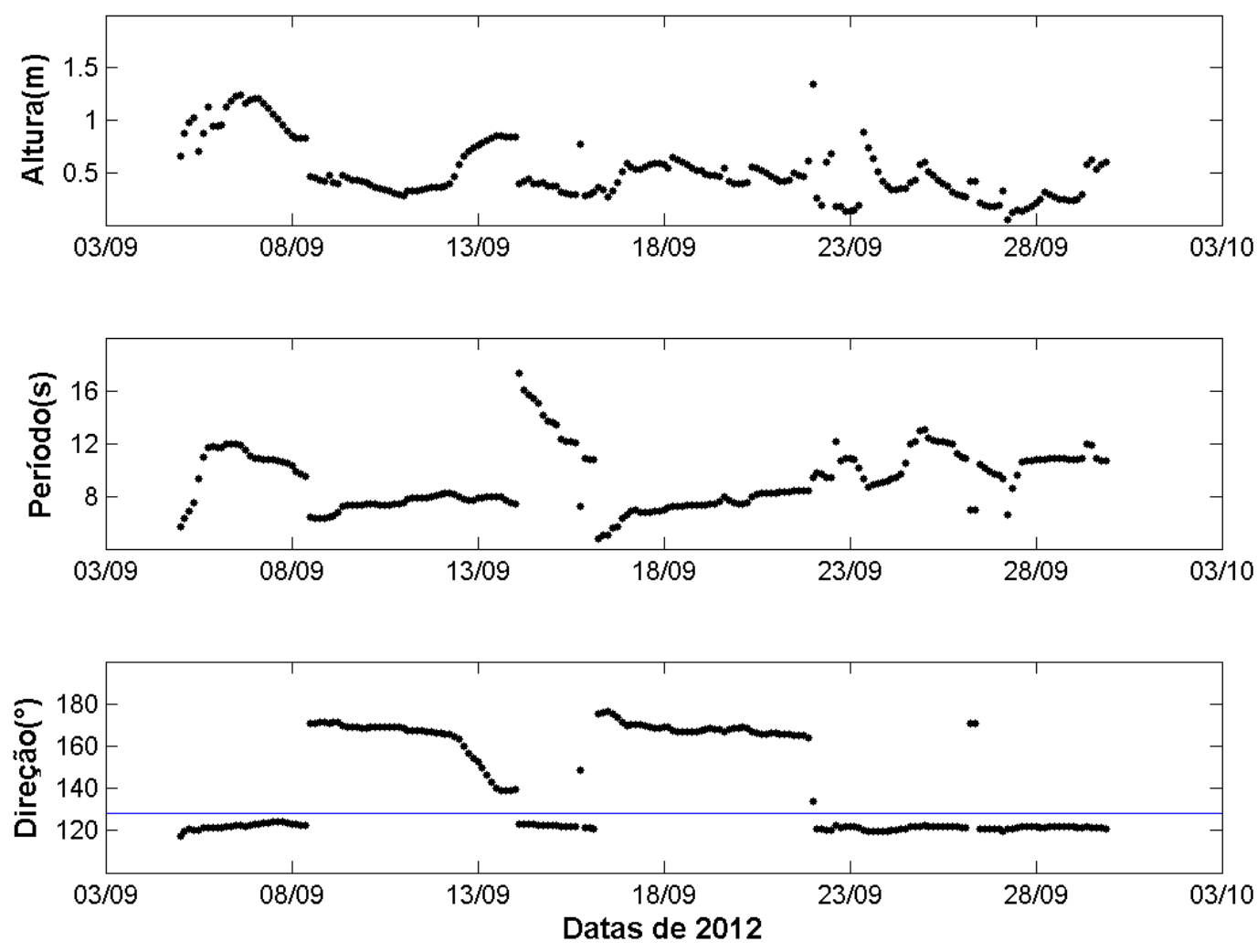

Figura 5.44: Evolução da altura, período e direção atuantes durante o período, onde a linha em azul representa a direção normal a face praial. 
응 5000

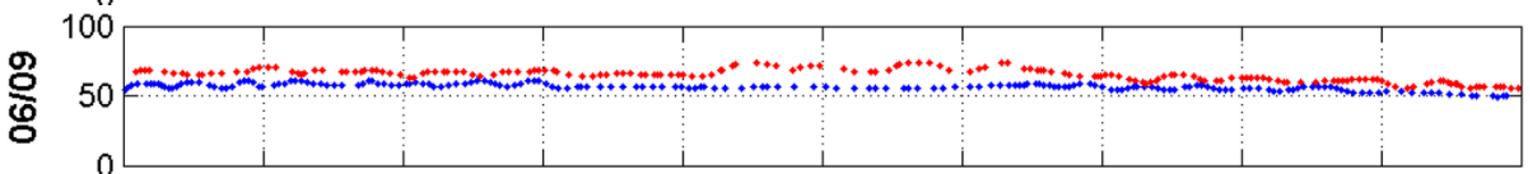

옹 5000
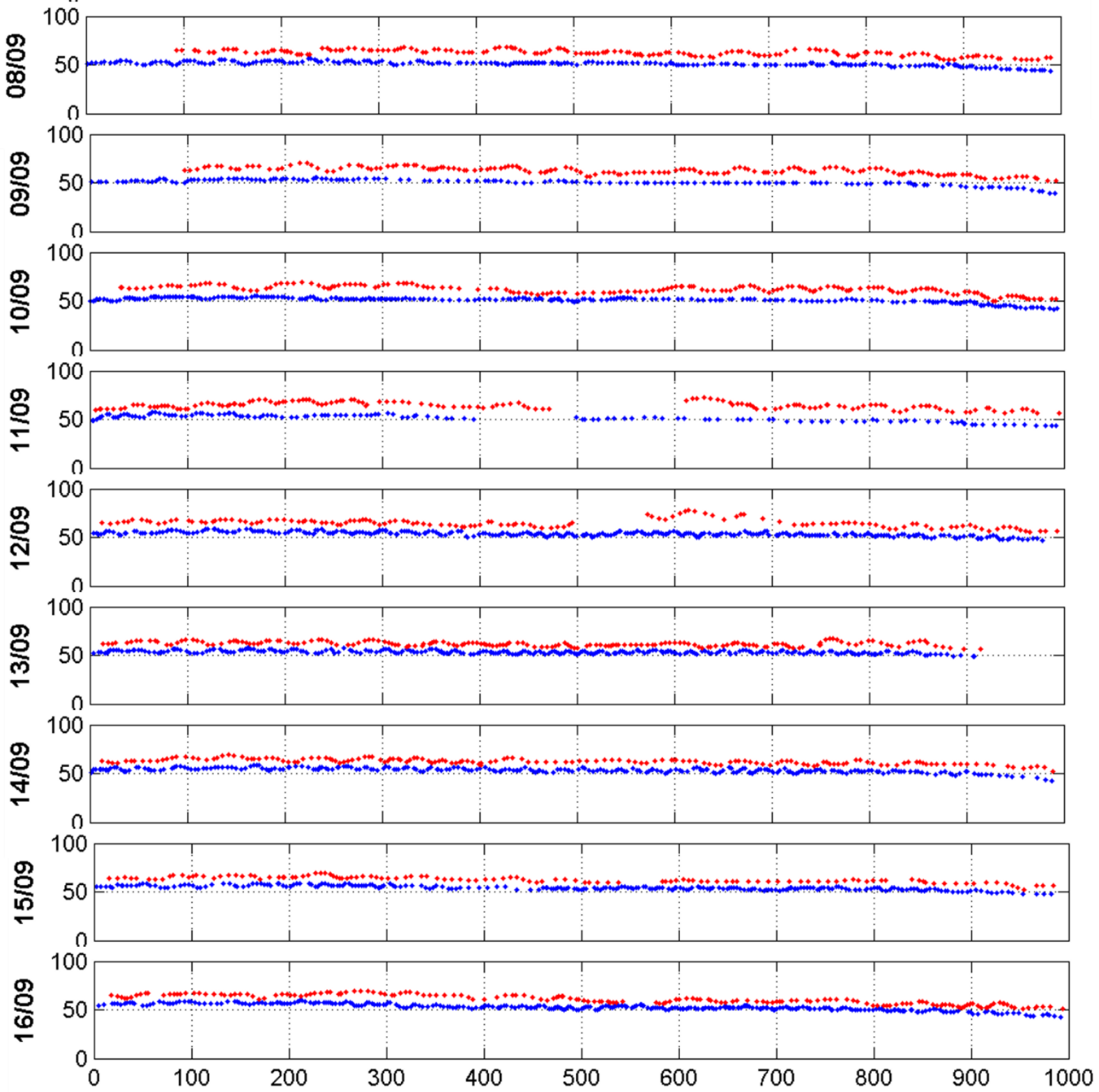

Figura 5.45: Cúspides digitalizadas durante o período (apenas os 12 primeiros dias). Em vermelho são as cúspides localizadas na face praial superior e em azul cúspides localizadas na face praial inferior. 

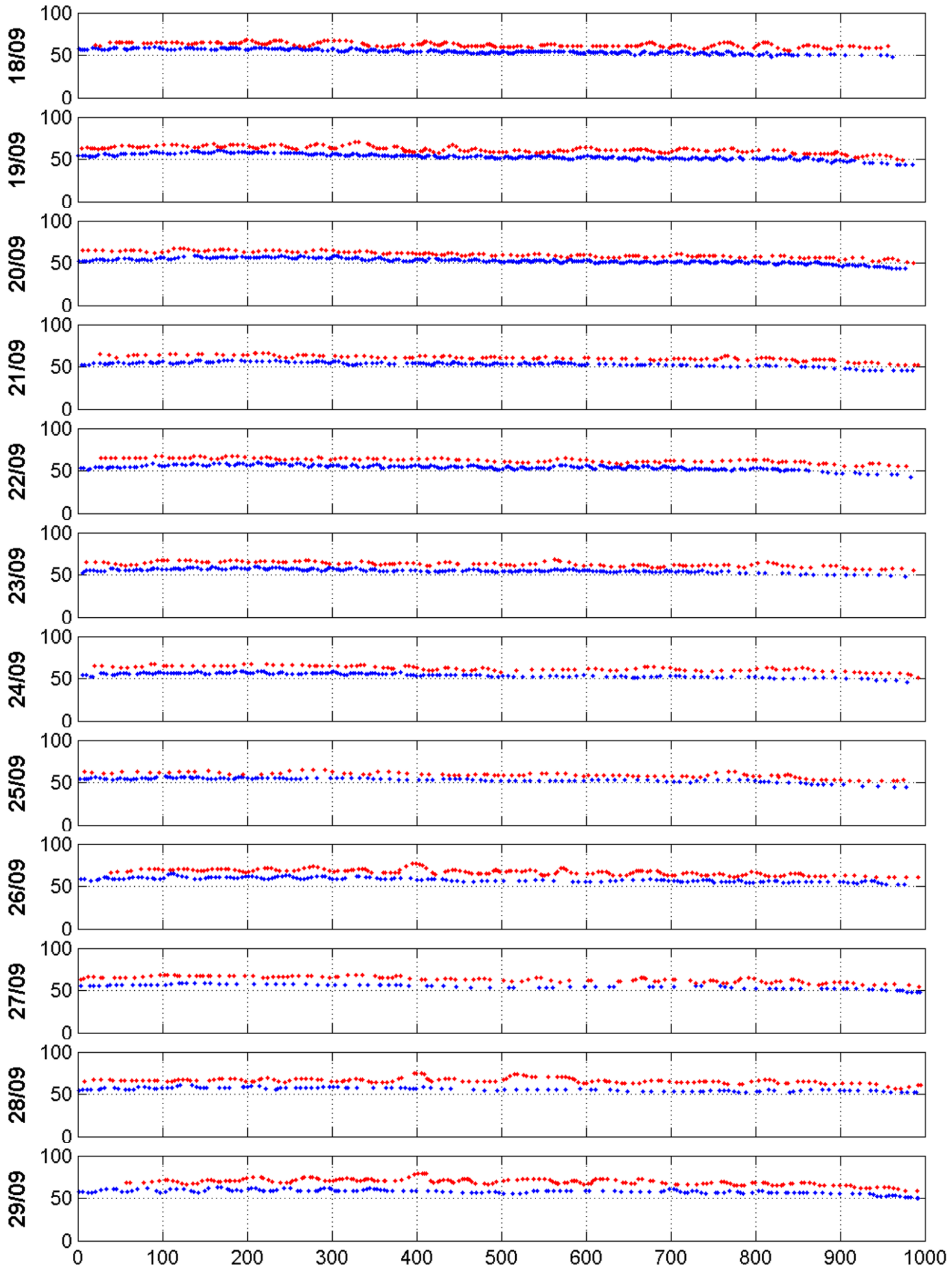

Figura 5.46: Cúspides digitalizadas durante o período (12 dias restantes). Em vermelho são as cúspides localizadas na face praial superior e em azul cúspides localizadas na face praial inferior. 
Figura 5.47: Imagem da interação entre a morfologia existente e o espraiamento atuante.

\subsubsection{Momento 9}

O momento 9 compreende o período de 01 à 10 de outubro de 2012 com 10 dias analisados, sem registros de cúspides na face praial inferior e com quatro registros de cúspides na face praial superior (Tabela 5.22; Figuras 5.48 e 5.51).

A direção média das ondas incidentes, para o período, foi de $158,92^{\circ}$ variando de $128,70^{\circ}$ à $166,70^{\circ}$, o período foi de $9,62 \mathrm{~s}$ variando de $7,07 \mathrm{~s}$ à $9,62 \mathrm{~s}$ e a altura foi de $0,94 \mathrm{~m}$ variando de $0,68 \mathrm{~m}$ à $1,52 \mathrm{~m}$ (Tabelas 5.21 e 5.22; Figuras 5.49 e 5.50).

Tabela 5.21: Características das ondas atuantes no arco praial de Massaguaçú durante o período.

\begin{tabular}{|c|c|c|c|c|c|}
\hline & Mínimo & Máximo & Média & Moda & Desvio Padrão \\
\hline Altura(m) & 0.68 & 1.52 & 0.94 & 0.68 & 0.24 \\
\hline Período(s) & 7.07 & 9.62 & 7.85 & 7.33 & 0.80 \\
\hline Direção( $\left.{ }^{\circ}\right)$ & 128.70 & 166.70 & 158.92 & 165.00 & 11.94 \\
\hline
\end{tabular}

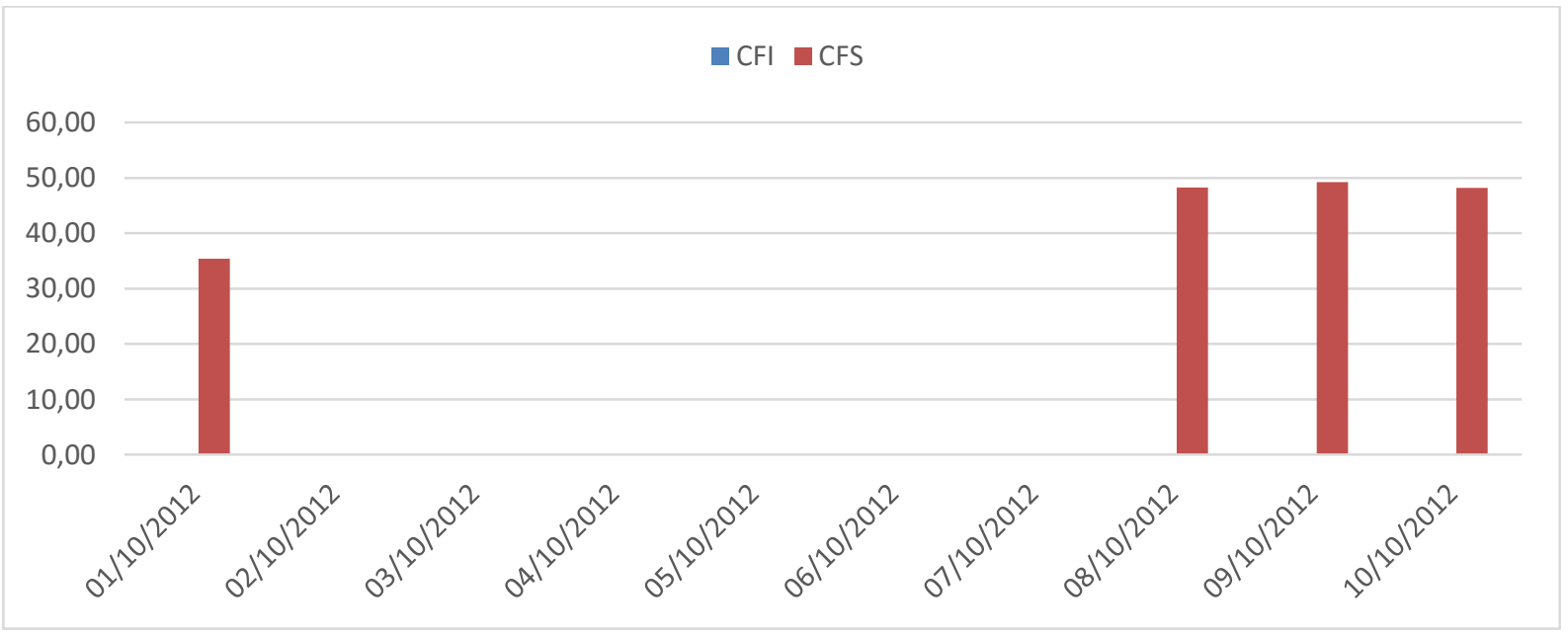

Figura 5.48: Espaçamento médio das cúspides durante o período. Em vermelho são as cúspides localizadas na face praial superior e em azul cúspides localizadas na face praial inferior. 
No primeiro dia de outubro uma ondulação de direção $132^{\circ}$ incidiu no arco praial com altura de 1,5 m e a interação com o espaçamento existente de $35 \mathrm{~m}$ resultou em uma arco praial sem feições rítmicas no segundo dia. Nos dias 8,9 e 10 de outubro observou-se cúspides praiais com espaçamento em torno de $49 \mathrm{~m}$ apesar de a ondulação se manter praticamente constante com o passar dos dias onde as ondas incidiam na direção $165^{\circ}$, período de 7,44 s e altura de em torno de $0,9 \mathrm{~m}$.

A largura do espraiamento variou ao longo dos dias devido a variação da ondulação atuante, porém foi homogênea durante todo o arco praial.

Tabela 5.22: Espaçamento médio das cúspides na face praial inferior e superior.

\begin{tabular}{cccccc} 
Datas & Altura(m) & Período(s) & Direção( $\left.^{\circ}\right)$ & CFI(m) & CFS(m) \\
\hline $\mathbf{0 1 / 1 0 / 2 0 1 2}$ & 1.49 & 9.55 & 132.56 & - & 35.44 \\
$\mathbf{0 2 / 1 0 / 2 0 1 2}$ & 1.29 & 9.19 & 139.05 & - & - \\
$\mathbf{0 3 / 1 0 / 2 0 1 2}$ & 0.92 & 7.32 & 159.38 & - & - \\
\hline $\mathbf{0 4 / 1 0 / 2 0 1 2}$ & 0.87 & 7.54 & 165.04 & - & - \\
\hline $\mathbf{0 5 / 1 0 / 2 0 1 2}$ & 0.81 & 7.77 & 165.29 & - & - \\
\hline $\mathbf{0 6 / 1 0 / 2 0 1 2}$ & 0.79 & 7.41 & 165.31 & - & - \\
\hline $\mathbf{0 7 / 1 0 / 2 0 1 2}$ & 0.81 & 7.44 & 165.60 & - & - \\
\hline $\mathbf{0 8 / 1 0 / 2 0 1 2}$ & 0.85 & 7.39 & 165.39 & - & 48.30 \\
\hline $\mathbf{0 9 / 1 0 / 2 0 1 2}$ & 0.85 & 7.51 & 165.26 & - & 49.29 \\
$\mathbf{1 0 / 1 0 / 2 0 1 2}$ & 0.75 & 7.39 & 166.31 & - & 48.21
\end{tabular}



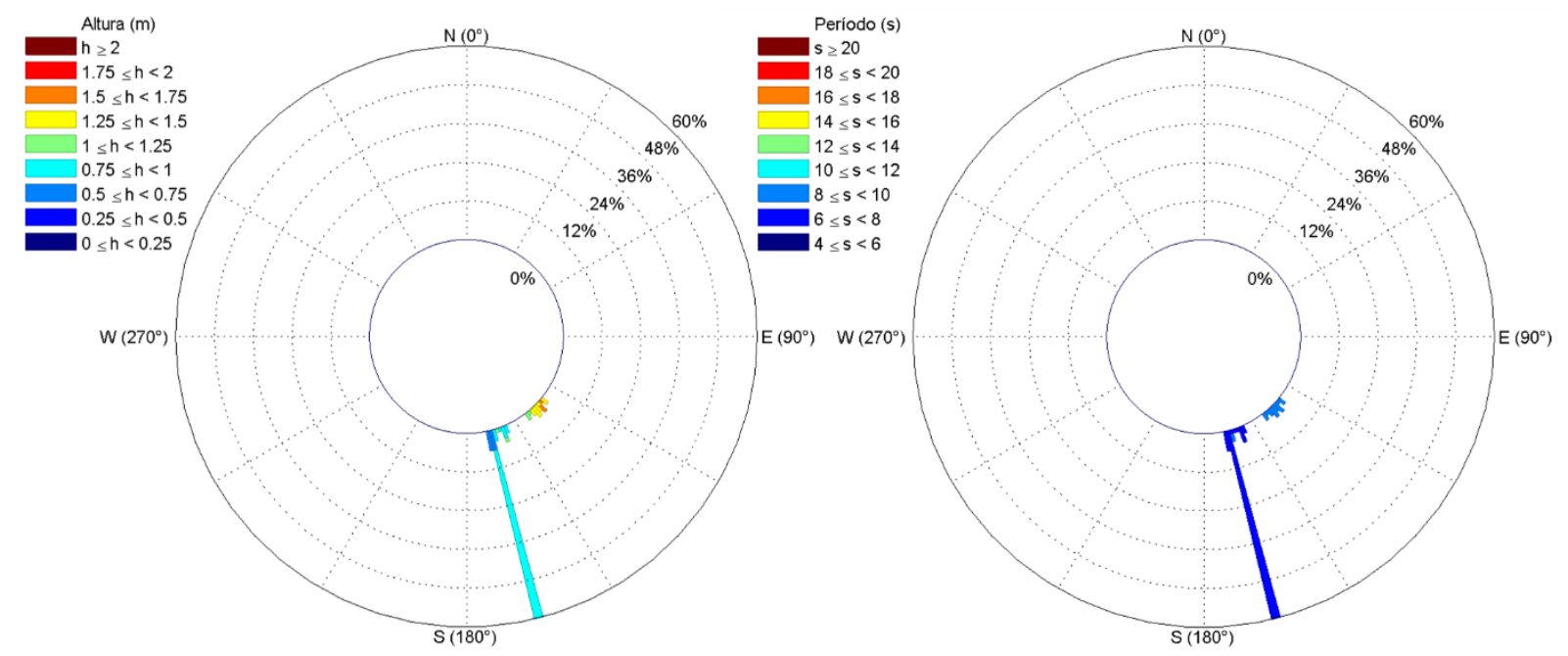

Figura 5.49: Histograma direcional de altura (m, a esquerda) e período (s, a direita) das ondas atuantes durante o período.
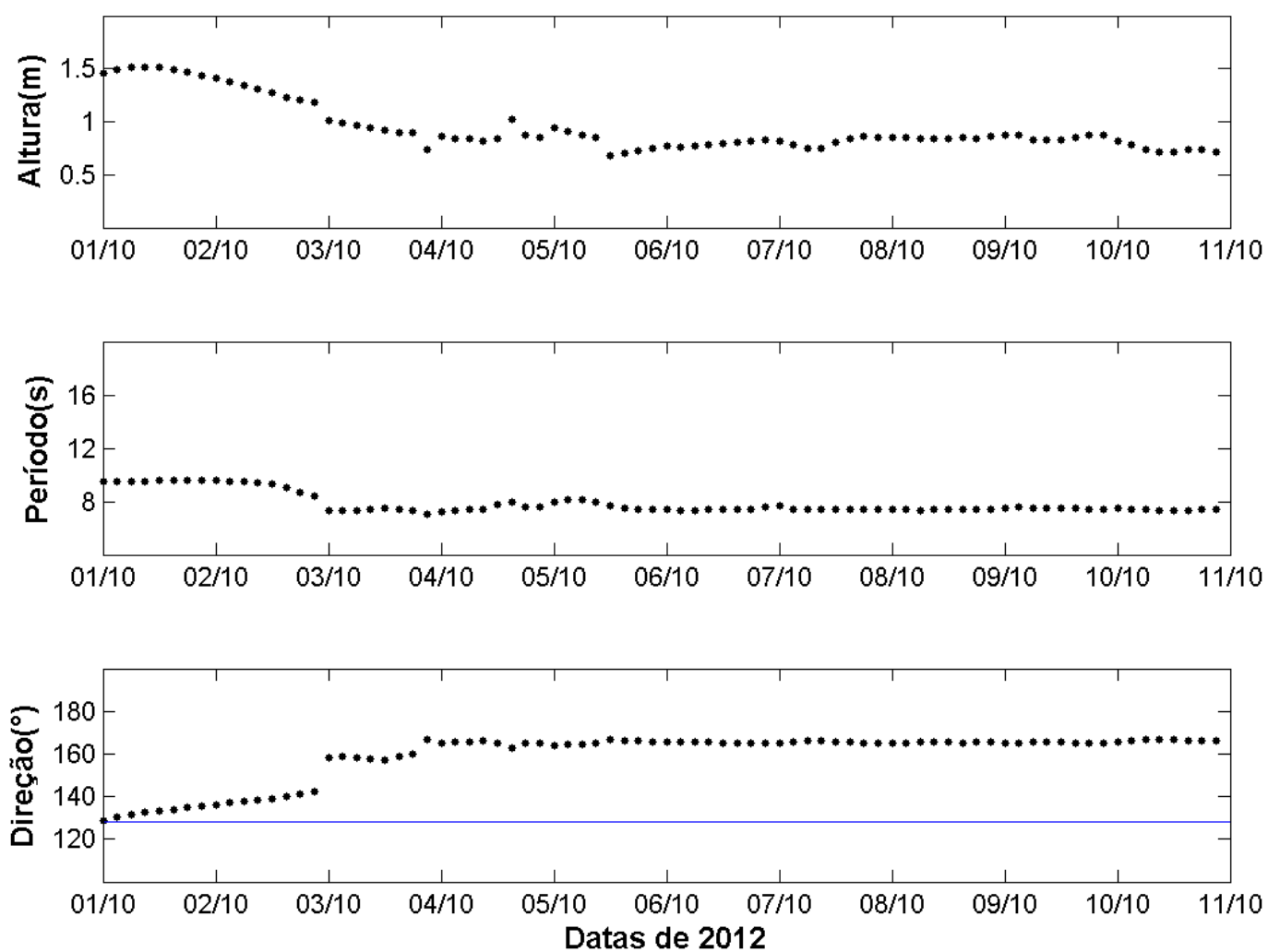

Figura 5.50: Evolução da altura, período e direção atuantes durante o período, onde a linha em azul representa a direção normal a face praial. 

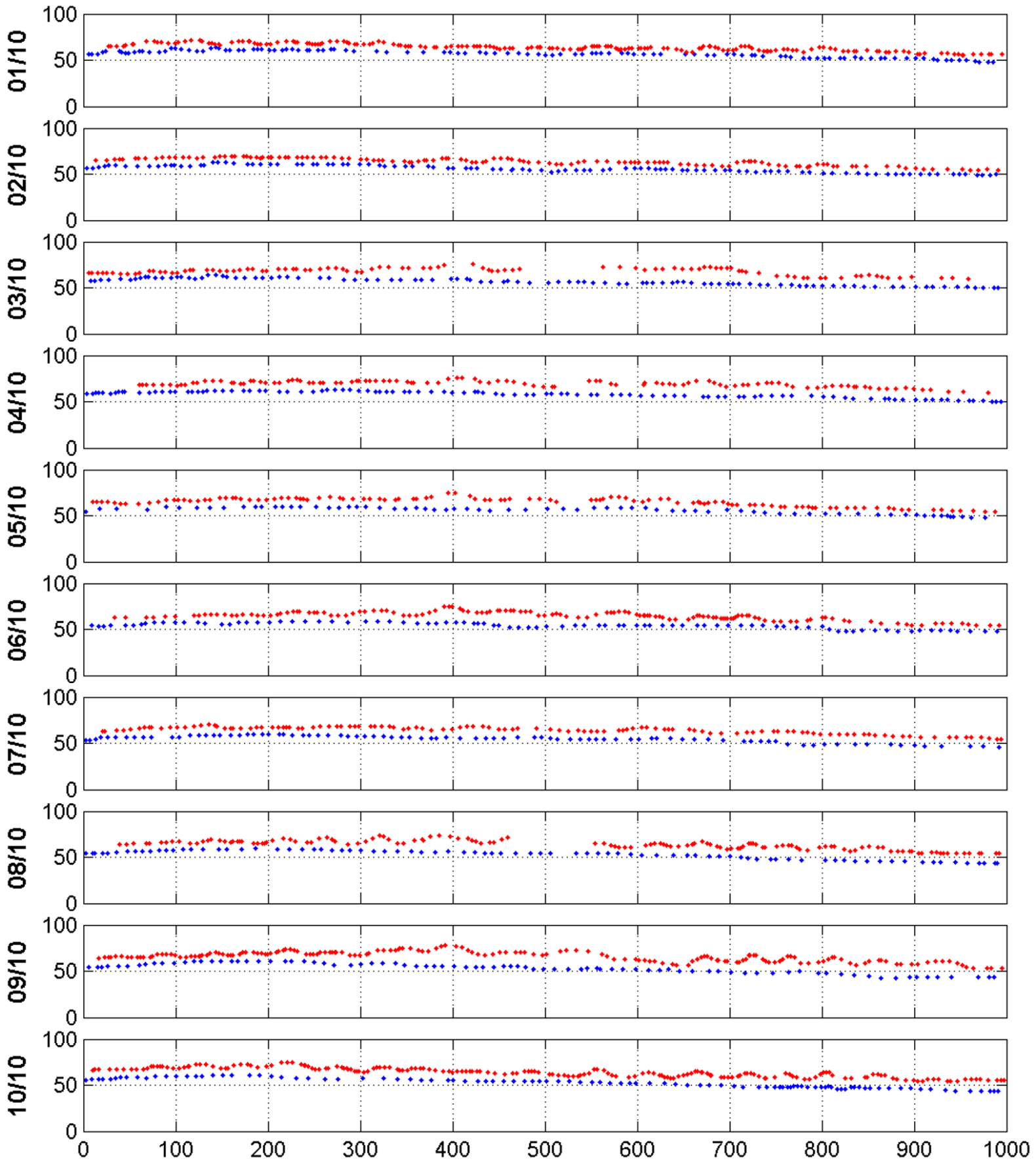

Figura 5.51: Cúspides digitalizadas durante o período. Em vermelho são as cúspides localizadas na face praial superior e em azul cúspides localizadas na face praial inferior. 


\subsubsection{Momento 10}

O momento 10 compreende o período de 12 à 27 de outubro de 2012 com 15 dias analisados e com a presença de feições rítmicas na face praial inferior e superior para todos os dias do período (Tabela 5.24; Figuras 5.52 e 5.55). Durante este período 2 sistemas frontais atuaram no arco praial de Massaguaçú nos dias 13 e 24 de outubro de 2012.

A direção média das ondas incidentes, para o período, foi de $136,75^{\circ}$ variando de $120,10^{\circ}$ à $171,08^{\circ}$, o período foi de $10 \mathrm{~s}$ variando de $5,95 \mathrm{~s}$ à $15,86 \mathrm{~s}$ e a altura foi de $0,8 \mathrm{~m}$ variando de 0,34 m à 1,53 m (Tabelas 5.23 e 5.24; Figuras 5.53 e 5.54).

Tabela 5.23: Características das ondas atuantes no arco praial de Massaguaçú durante o período.

\begin{tabular}{|l|c|c|c|c|c|} 
& Mínimo & Máximo & Média & Moda & Desvio Padrão \\
\hline Altura(m) & 0.34 & 1.53 & 0.80 & 0.60 & 0.35 \\
\hline Período(s) & 5.95 & 15.86 & 10.00 & 12.10 & 2.02 \\
\hline Direção( ${ }^{\circ}$ ) & 120.10 & 171.08 & 136.75 & 121.80 & 18.21 \\
\hline
\end{tabular}

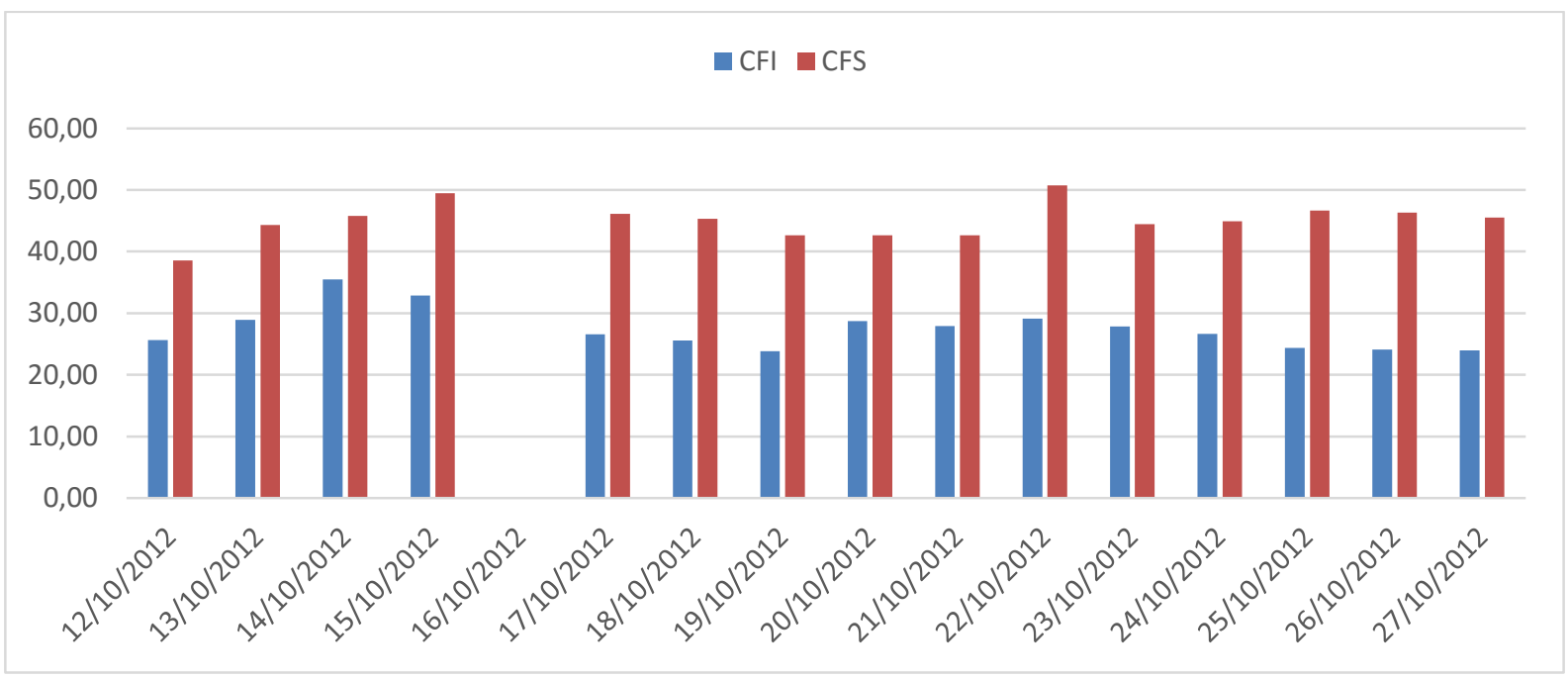

Figura 5.52: Espaçamento médio das cúspides durante o período. Em vermelho são as cúspides localizadas na face praial superior e em azul cúspides localizadas na face praial inferior.

No primeiro dia do período observa-se cúspides com espaçamento de $38 \mathrm{~m}$ para CFS e $25 \mathrm{~m}$ para CFI, valores que aumentaram para $45 \mathrm{~m}$ e $35 \mathrm{~m}$ nos dois dias seguintes com a 
presença de uma ondulação incidindo com direção média de $127^{\circ}$, período em torno de $10 \mathrm{~s} \mathrm{e}$ altura aumentando de $1,15 \mathrm{~m}$ no segundo dia para 1,39 $\mathrm{m}$ no terceiro dia.

A partir do quarto dia a ondulação rotacionou para sul com a direção da onda incidente variando de $128^{\circ}$ para $160^{\circ}$ causando uma diminuição no espaçamento das cúspides na CFI e na CFS. A diminuição no espaçamento das cúspides na CFI foi maior do que na CFS devido à altura da onda incidente possuir valores de altura em torno de $0,5 \mathrm{~m}$ e período de $6 \mathrm{~s}$.

No oitavo dia do período, a direção da onda incidente variou de $122^{\circ}$ à $130^{\circ}$ com valores de altura variando de $0,59 \mathrm{~m}$ para $0,37 \mathrm{~m}$ e depois para $0,57 \mathrm{~m}$. O espaçamento durante este período aumentou no oitavo e no décimo dia se mantendo constante nono dia devido a pequena altura da onda incidente.

No dia 23 de outubro a direção da onda incidente foi de $162^{\circ}$ causando uma diminuição no espaçamento médio da CFI e poucas alterações na CFS.

No restante do período, a direção da onda incidente volta a ficar em torno de $122^{\circ}$, com período de $11 \mathrm{~s}$ e altura em torno de 0,5 $\mathrm{m}$. Estas condições propiciam um espaçamento de 24 m para CFI e $45 \mathrm{~m}$ para CFS. 
Tabela 5.24: Espaçamento médio das cúspides na face praial inferior e superior.

\begin{tabular}{c|c|c|c|c|c|} 
Datas & Altura(m) & Período(s) & Direção( & \multicolumn{1}{c}{ CFI(m) } & CFS(m) \\
\hline $\mathbf{1 2 / 1 0 / 2 0 1 2}$ & 0.75 & 8.93 & 161.61 & 25.67 & 38.57 \\
\hline $\mathbf{1 3 / 1 0 / 2 0 1 2}$ & 1.15 & 9.39 & 129.15 & 28.95 & 44.33 \\
\hline $\mathbf{1 4 / 1 0 / 2 0 1 2}$ & 1.39 & 10.23 & 122.35 & 35.45 & 45.81 \\
\hline $\mathbf{1 5 / 1 0 / 2 0 1 2}$ & 1.44 & 9.33 & 128.71 & 32.88 & 49.50 \\
\hline $\mathbf{1 7 / 1 0 / 2 0 1 2}$ & 1.10 & 8.64 & 138.86 & 26.56 & 46.15 \\
\hline $\mathbf{1 8 / 1 0 / 2 0 1 2}$ & 0.67 & 6.91 & 166.72 & 25.56 & 45.33 \\
\hline $\mathbf{1 9 / 1 0 / 2 0 1 2}$ & 0.67 & 9.75 & 154.10 & 23.85 & 42.65 \\
\hline $\mathbf{2 0 / 1 0 / 2 0 1 2}$ & 0.59 & 13.78 & 122.39 & 28.72 & 42.62 \\
\hline $\mathbf{2 1 / 1 0 / 2 0 1 2}$ & 0.37 & 11.77 & 121.65 & 27.92 & 42.63 \\
\hline $\mathbf{2 2 / 1 0 / 2 0 1 2}$ & 0.57 & 9.78 & 130.16 & 29.13 & 50.76 \\
\hline $\mathbf{2 3 / 1 0 / 2 0 1 2}$ & 0.73 & 8.18 & 162.23 & 27.84 & 44.42 \\
\hline $\mathbf{2 4 / 1 0 / 2 0 1 2}$ & 0.54 & 10.32 & 148.44 & 26.64 & 44.92 \\
\hline $\mathbf{2 5 / 1 0 / 2 0 1 2}$ & 0.70 & 11.46 & 124.00 & 24.35 & 46.67 \\
\hline $\mathbf{2 6 / 1 0 / 2 0 1 2}$ & 0.49 & 11.99 & 121.70 & 24.12 & 46.35 \\
\hline $\mathbf{2 7 / 1 0 / 2 0 1 2}$ & 0.46 & 10.63 & 120.89 & 24.00 & 45.54 \\
\hline
\end{tabular}



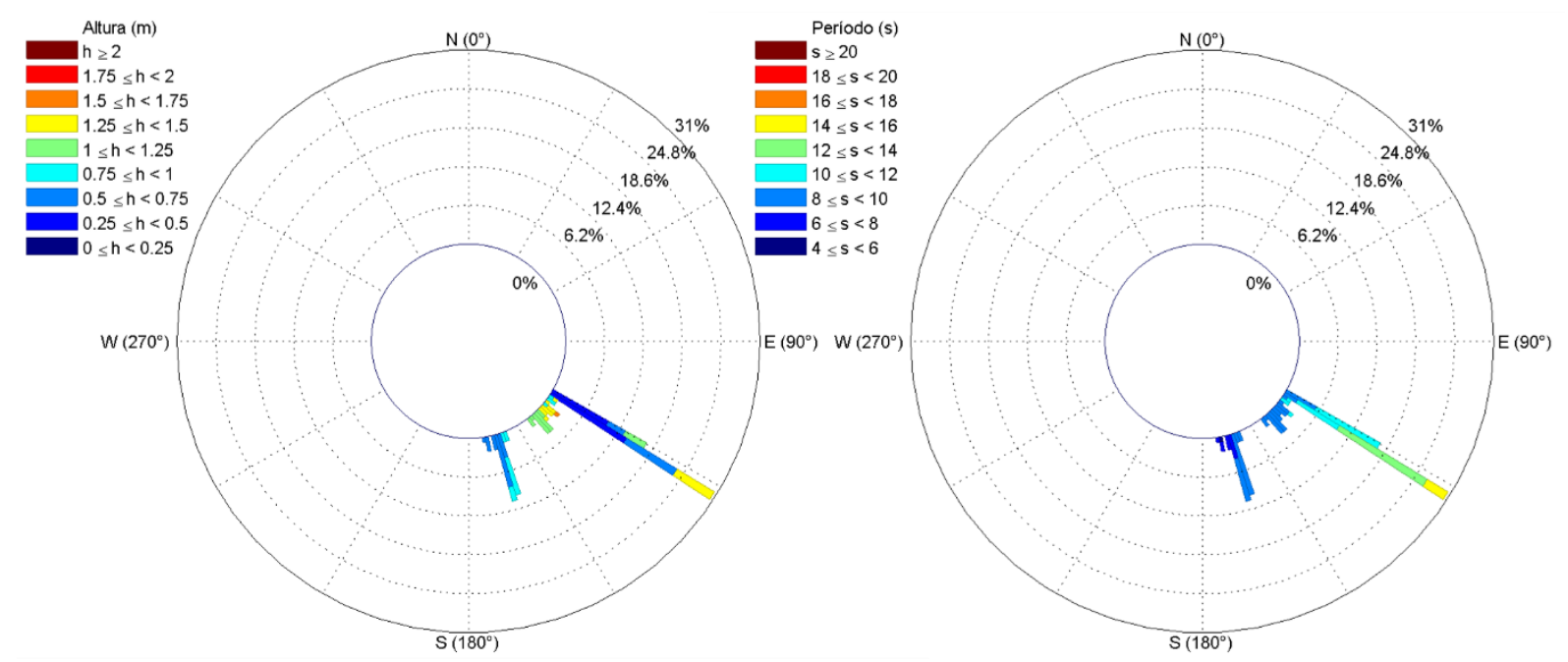

Figura 5.53: Histograma direcional de altura ( $m$, a esquerda) e período (s, a direita) das ondas atuantes durante o período.
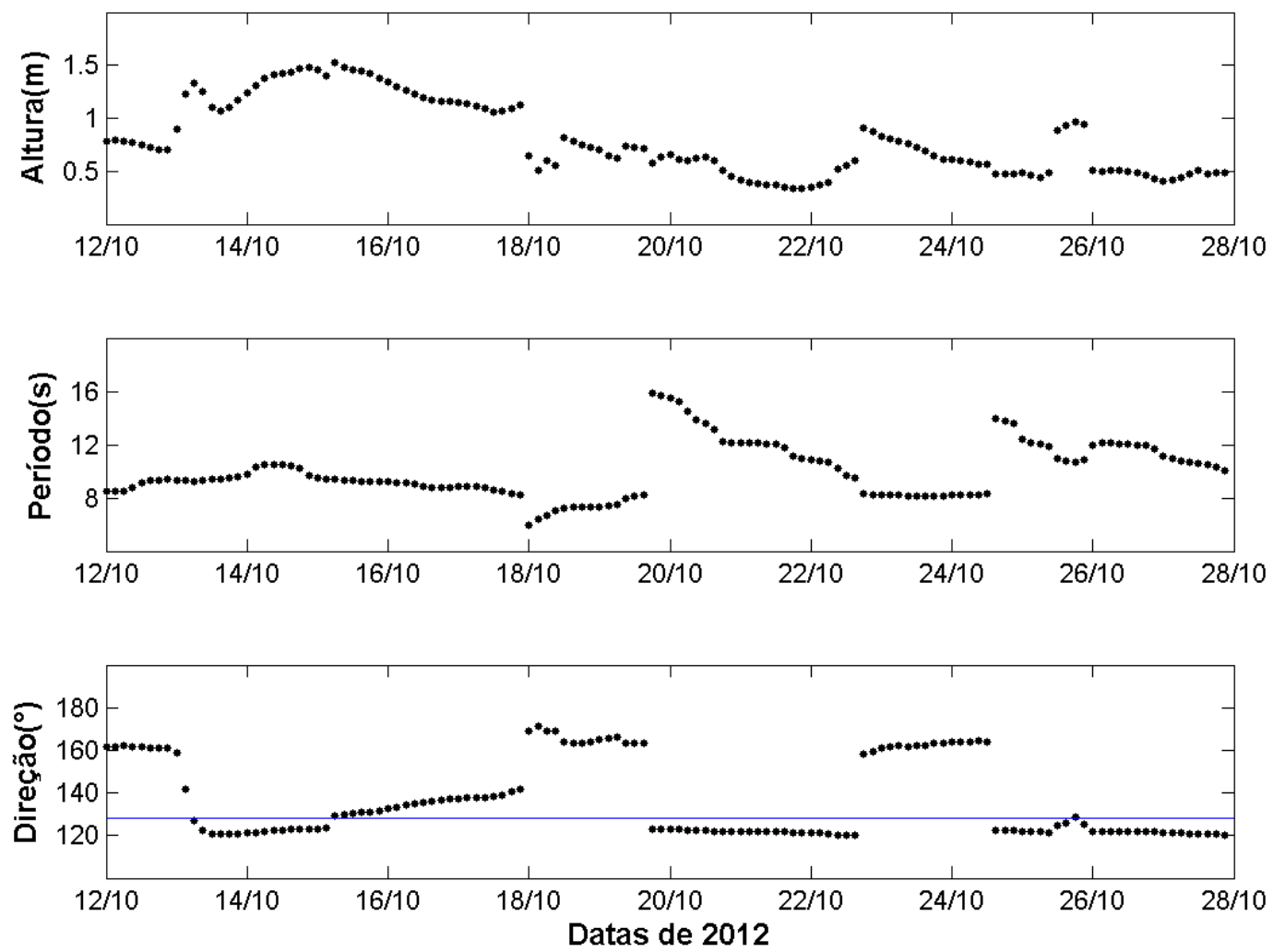

Figura 5.54: Evolução da altura, período e direção atuantes durante o período, onde a linha em azul representa a direção normal a face praial. 


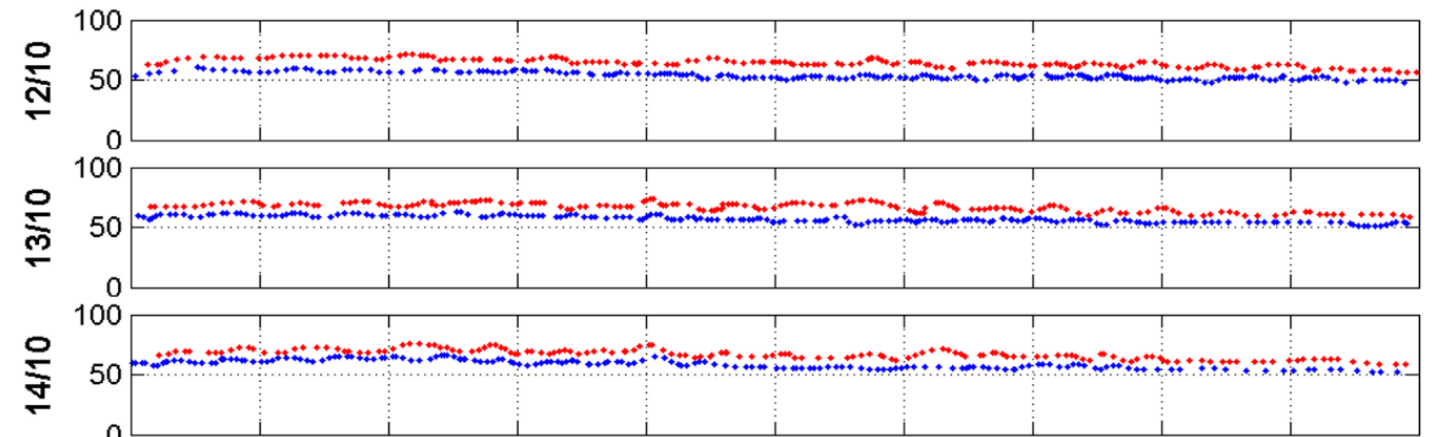

$\frac{1}{\circ} 5000$

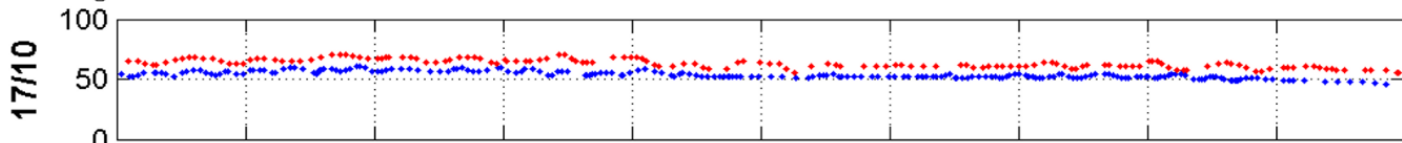

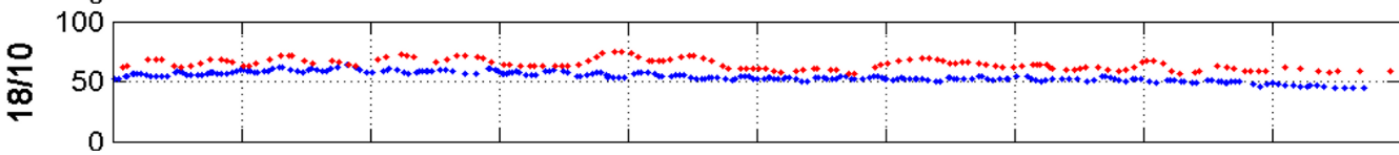

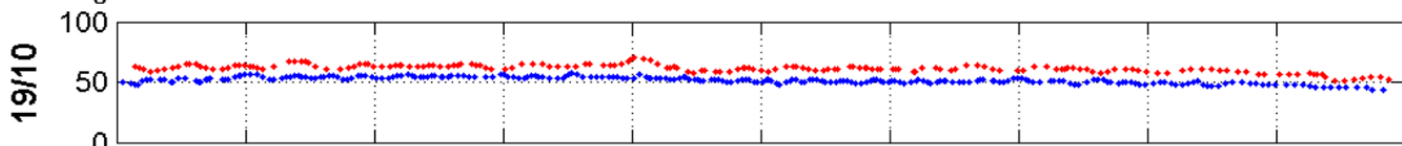

응 ${ }^{100} 50$ م

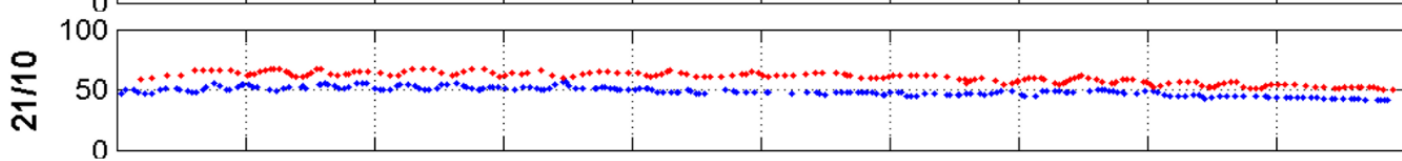

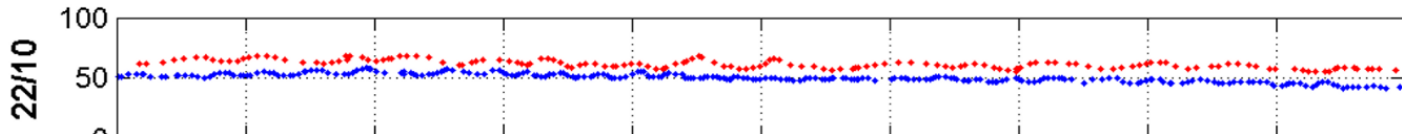

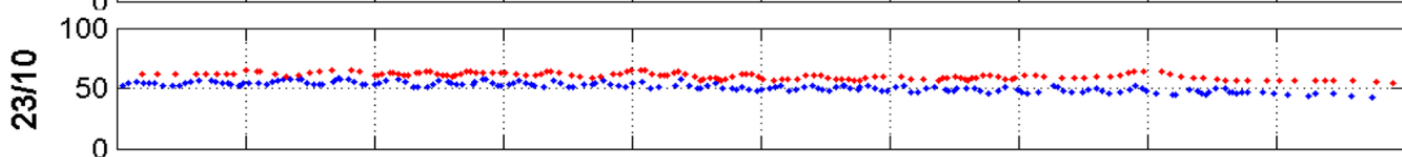

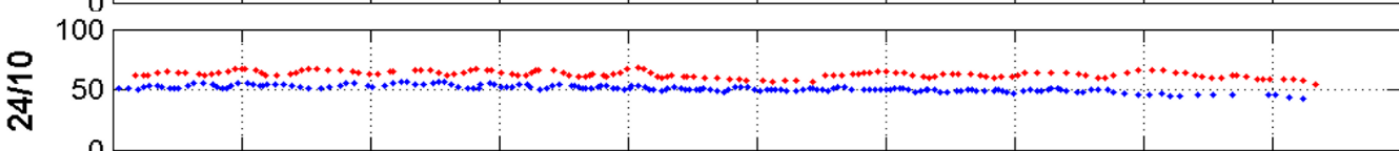

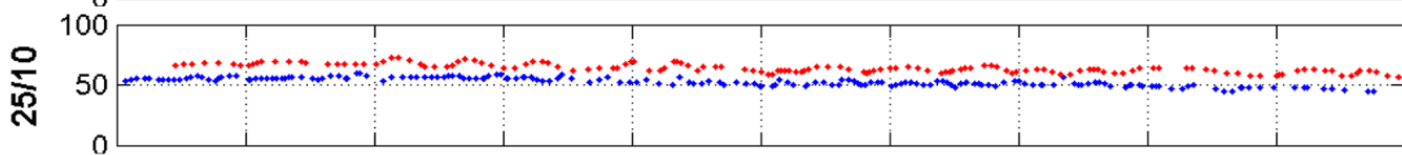

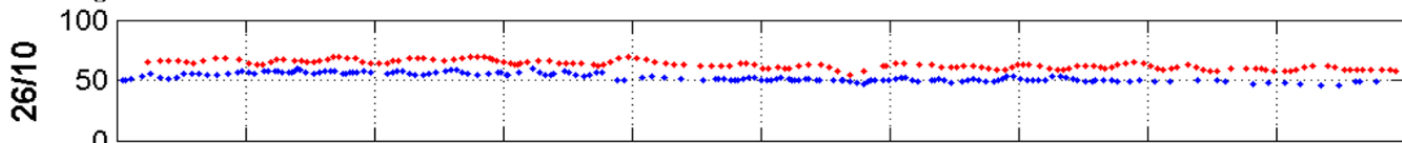

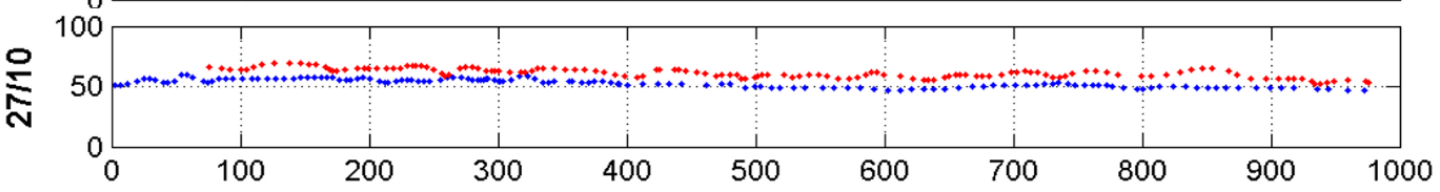

Figura 5.55: Cúspides digitalizadas durante o período (apenas os 10 primeiros dias). Em vermelho são as cúspides localizadas na face praial superior e em azul cúspides localizadas na face praial inferior. 


\subsubsection{Momento 11}

O momento 11 compreende o período de 28 de outubro à 12 de novembro com 16 dias analisados. Na face praial inferior observa-se 2 registros de cúspides em quanto que na face praial superior observa-se 12 registros de cúspides ao longo do período (Tabela 5.26; Figuras 5.56 e 5.59$)$

A direção média das ondas incidentes, para o período, foi de $140,76^{\circ}$ variando de $118,60^{\circ}$ à $172,69^{\circ}$, o período foi de $8,60 \mathrm{~s}$ variando de $4,95 \mathrm{~s}$ à $17,39 \mathrm{~s}$ e a altura foi de $0,49 \mathrm{~m}$ variando de 0,04 m à 0,86 m (Tabelas 5.25 e 5.26; Figuras 5.57 e 5.58).

Tabela 5.25: Características das ondas atuantes no arco praial de Massaguaçú durante o período.

\begin{tabular}{|c|c|c|c|c|c|} 
& Mínimo & Máximo & Média & Moda & $\begin{array}{c}\text { Desvio } \\
\text { Padrão }\end{array}$ \\
\hline Altura(m) & 0.04 & 0.86 & 0.51 & 0.49 & 0.21 \\
\hline Período(s) & 4.95 & 17.39 & 8.60 & 7.32 & 2.43 \\
\hline Direção( $\left.{ }^{\circ}\right)$ & 118.60 & 172.69 & 140.76 & 120.10 & 21.79 \\
\hline
\end{tabular}

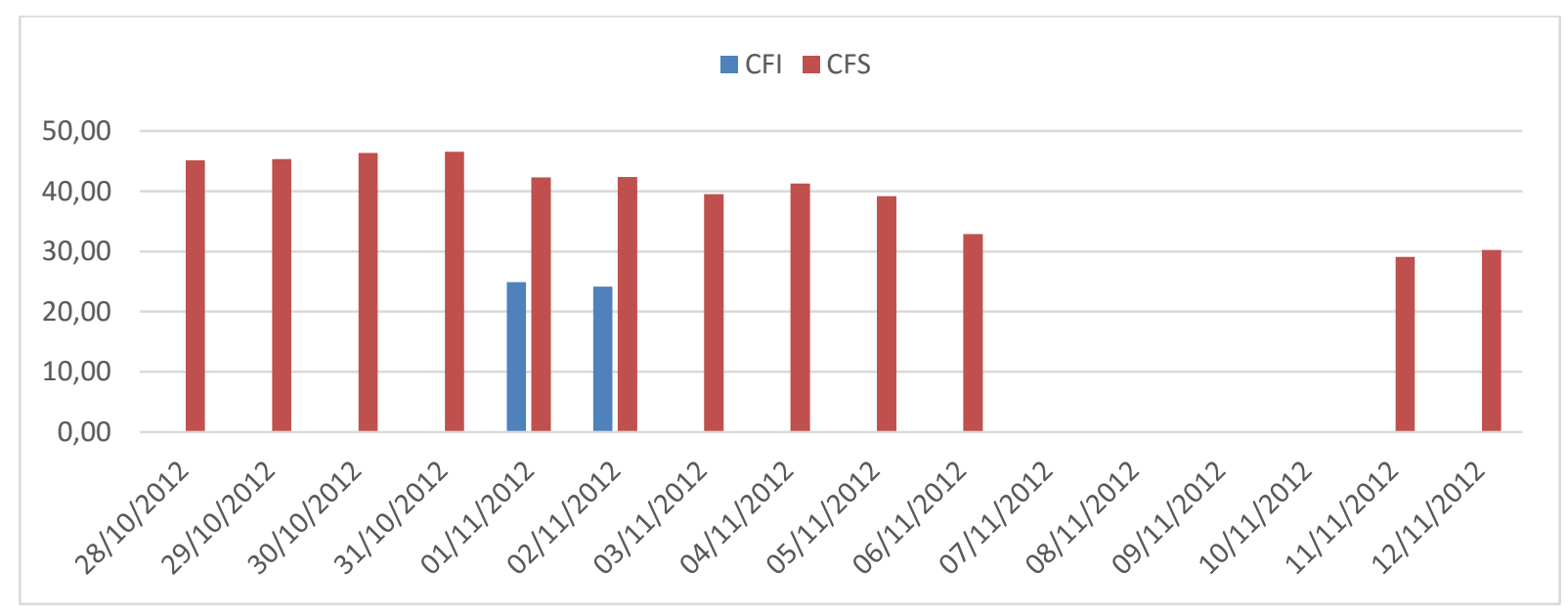

Figura 5.56: Espaçamento médio das cúspides durante o período. Em vermelho são as cúspides localizadas na face praial superior e em azul cúspides localizadas na face praial inferior.

Nos quatro primeiros dias o espaçamento das cúspides ficou em torno de $45 \mathrm{~m}$, o espraiamento foi homogêneo ao longo do arco praial e quase não ocorreram alterações no espaçamento durante esses dias. 
A partir do quinto dia a interação entre o espraiamento e a morfologia da berma provocou um decréscimo no espaçamento da CFS e a formação de feições rítmicas na CFI.

No sexto dia observa-se apenas cúspides na CFS com espaçamento de $40 \mathrm{~m}$ que se manteve até o dia 5 de novembro e no dia seguinte decresceu para 33 m. Após uma sequência de 4 dias sem cúspides no arco praial de Massaguaçú ocorre o reaparecimento de cúspides na face praial superior com espaçamento em torno de $30 \mathrm{~m}$.

Durante este período a direção da onda incidente variou entre $120^{\circ}$ e $168^{\circ}$, a altura variou em torno de $0,5 \mathrm{~m}$ e período em torno $8 \mathrm{~s}$. O espraiamento foi homogêneo durante praticamente todo o período com exceção dos dias onde ocorreram as cúspides na face praial inferior.

Tabela 5.26: Espaçamento médio das cúspides na face praial inferior e superior.

\begin{tabular}{c|c|c|c|c|c|} 
Datas & Altura(m) & Período(s) & Direção( & CFI(m) & CFS(m) \\
\hline $\mathbf{2 8 / 1 0 / 2 0 1 2}$ & 0.48 & 9.58 & 120.05 & - & 45.14 \\
\hline $\mathbf{2 9 / 1 0 / 2 0 1 2}$ & 0.62 & 8.22 & 132.40 & - & 45.33 \\
\hline $\mathbf{3 0 / 1 0 / 2 0 1 2}$ & 0.52 & 7.30 & 161.95 & - & 46.33 \\
\hline $\mathbf{3 1 / 1 0 / 2 0 1 2}$ & 0.28 & 11.86 & 121.56 & - & 46.56 \\
\hline $\mathbf{0 1 / 1 1 / 2 0 1 2}$ & 0.24 & 9.47 & 133.42 & 24.92 & 41.14 \\
\hline $\mathbf{0 2 / 1 1 / 2 0 1 2}$ & 0.23 & 10.54 & 128.74 & 24.17 & 41.35 \\
\hline $\mathbf{0 3 / 1 1 / 2 0 1 2}$ & 0.44 & 10.05 & 120.66 & - & 39.54 \\
\hline $\mathbf{0 4 / 1 1 / 2 0 1 2}$ & 0.78 & 8.27 & 124.45 & - & 41.25 \\
\hline $\mathbf{0 5 / 1 1 / 2 0 1 2}$ & 0.83 & 9.10 & 133.13 & - & 39.17 \\
\hline $\mathbf{0 6 / 1 1 / 2 0 1 2}$ & 0.69 & 8.90 & 130.21 & - & 32.92 \\
\hline $\mathbf{0 7 / 1 1 / 2 0 1 2}$ & 0.37 & 8.14 & 121.65 & - & - \\
\hline $\mathbf{0 8 / 1 1 / 2 0 1 2}$ & 0.52 & 5.99 & 154.74 & - & - \\
\hline $\mathbf{0 9 / 1 1 / 2 0 1 2}$ & 0.54 & 6.60 & 164.64 & - & - \\
\hline $\mathbf{1 0 / 1 1 / 2 0 1 2}$ & 0.62 & 6.77 & 168.71 & - & - \\
\hline $\mathbf{1 1 / 1 1 / 2 0 1 2}$ & 0.57 & 7.55 & 167.94 & - & 29.06 \\
\hline $\mathbf{1 2 / 1 1 / 2 0 1 2}$ & 0.49 & 7.51 & 168.38 & - & 30.24 \\
\hline
\end{tabular}



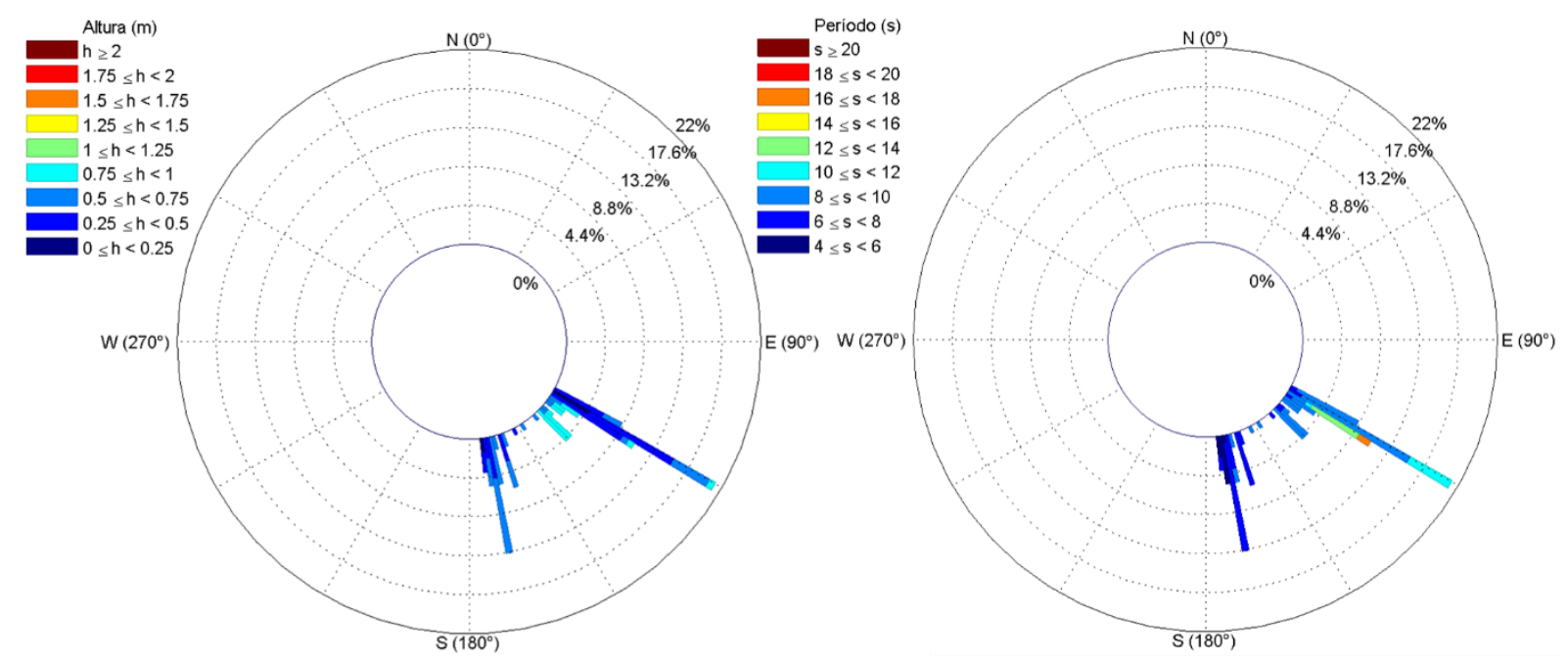

Figura 5.57: Histograma direcional de altura (m, a esquerda) e período (s, a direita) das ondas atuantes durante o período.
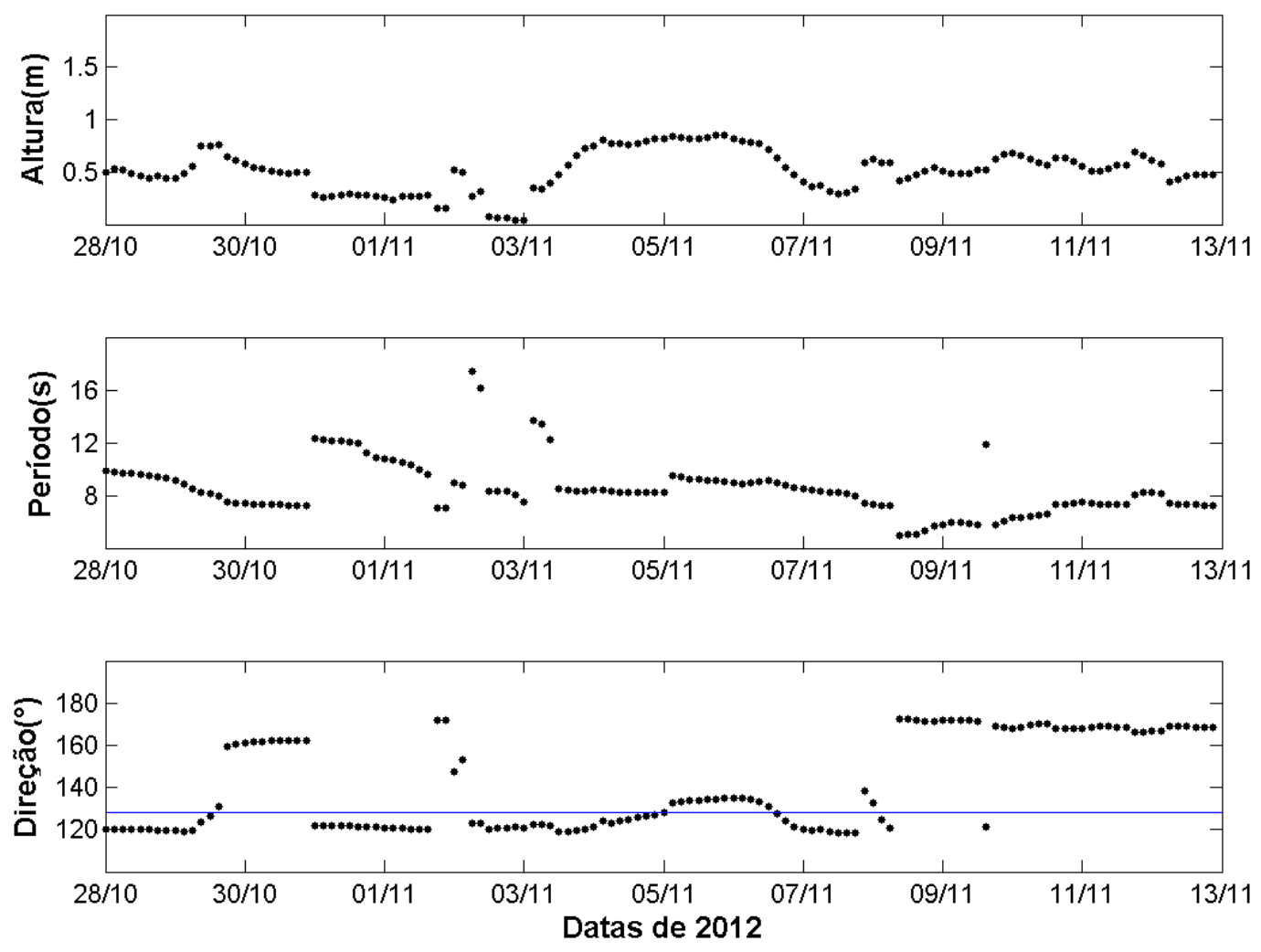

Figura 5.58: Evolução da altura, período e direção atuantes durante o período, onde a linha em azul representa a direção normal a face praial. 


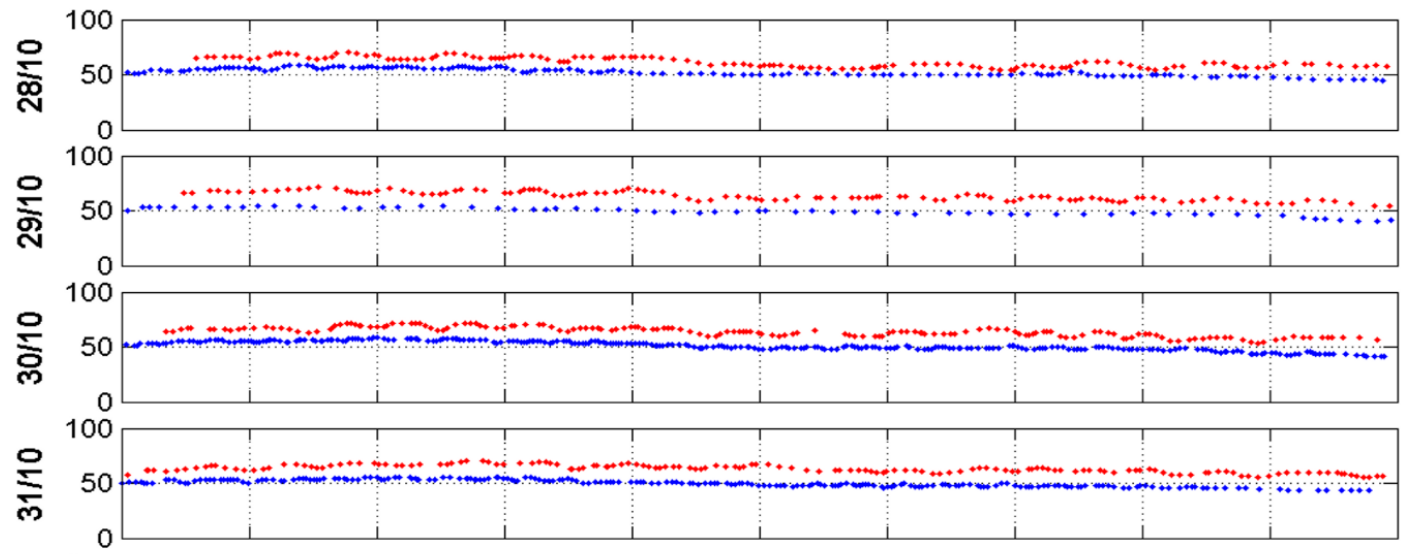

$\sum_{0}^{100} \begin{array}{r}50 \\ \hline\end{array}$

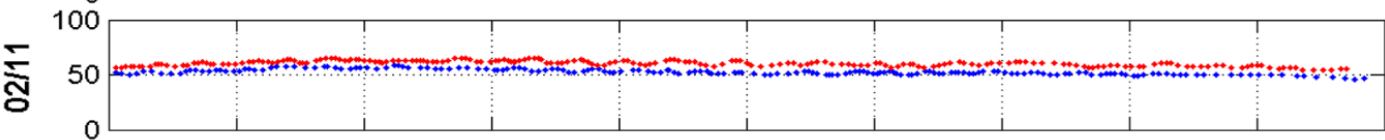

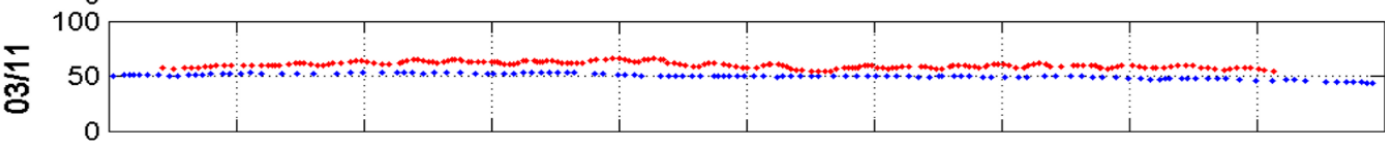

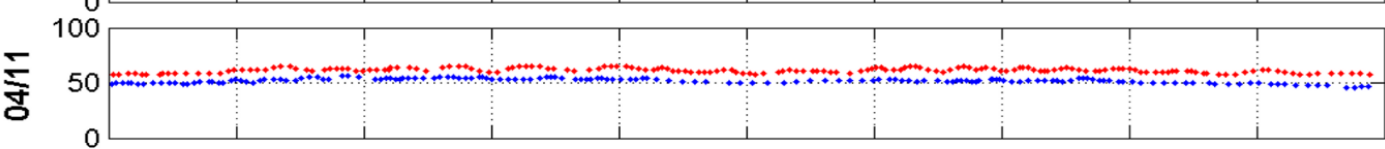

Е 500 \%

Е 50 \begin{tabular}{l|l|l|l|l|}
100 & \\
\hline
\end{tabular}

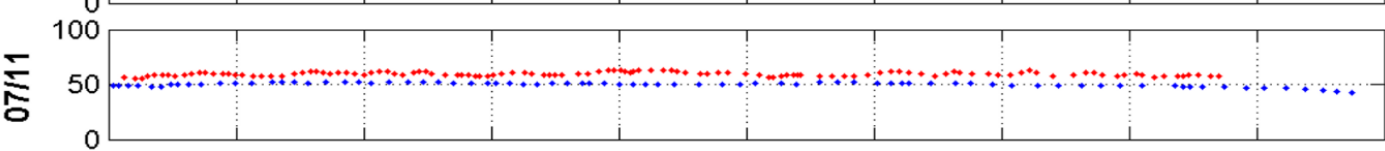

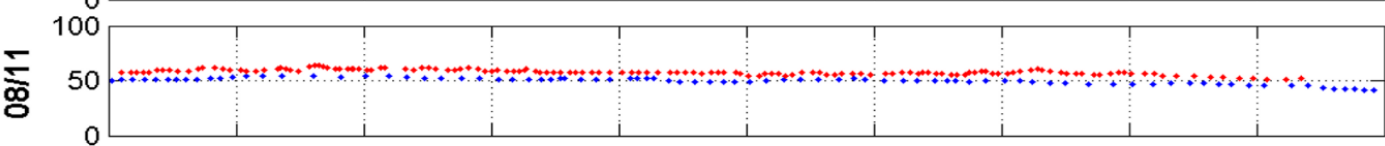

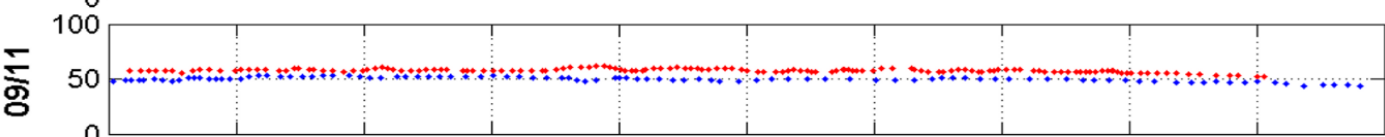

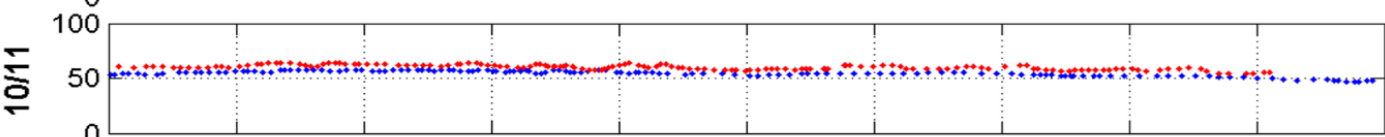

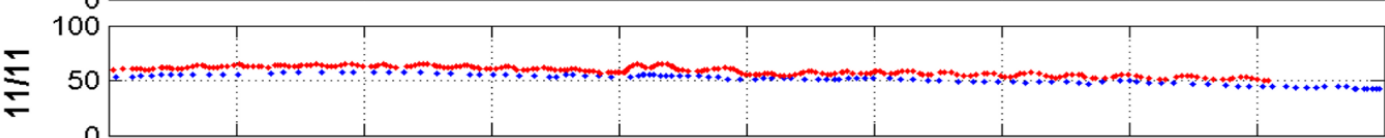

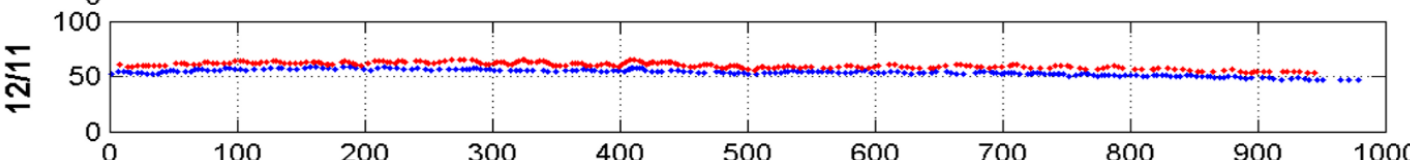

Figura 5.59: Cúspides digitalizadas durante o período. Em vermelho são as cúspides localizadas na face praial superior e em azul cúspides localizadas na face praial inferior. 


\subsubsection{Momento 12}

O momento 12 compreende o período de 13 de novembro à 2 de dezembro de 2012 com 20 dias analisados, registros de cúspides em quase todos os dias em ambas regiões com exceção dos dias 22 e 23 de novembro, onde não se observou cúspides na face praial inferior (Tabela 5.28; Figuras 5.60, 5.63 e 5.64). Durante este período 1 sistema frontal atuou no arco praial de Massaguaçú no dia 13 de novembro de 2012.

A direção média das ondas incidentes, para o período, foi de $133,89^{\circ}$ variando de $117,50^{\circ}$ à $173,31^{\circ}$, o período foi de $9,62 \mathrm{~s}$ variando de $7,07 \mathrm{~s}$ à $9,62 \mathrm{~s}$ e a altura foi de $0,61 \mathrm{~m}$ variando de 0,18 m à 1,29 m (Tabelas 5.27 e 5.28; Figuras 5.61 e 5.62).

Tabela 5.27: Características das ondas atuantes no arco praial de Massaguaçú durante o período.

\begin{tabular}{|c|c|c|c|c|c|}
\hline & Mínimo & Máximo & Média & Moda & Desvio Padrão \\
\hline Altura(m) & 0.18 & 1.29 & 0.61 & 0.18 & 0.27 \\
\hline Período(s) & 5.05 & 17.59 & 9.42 & 6.29 & 2.86 \\
\hline Direção( $\left.{ }^{\circ}\right)$ & 117.50 & 173.31 & 133.89 & 121.30 & 18.49 \\
\hline
\end{tabular}

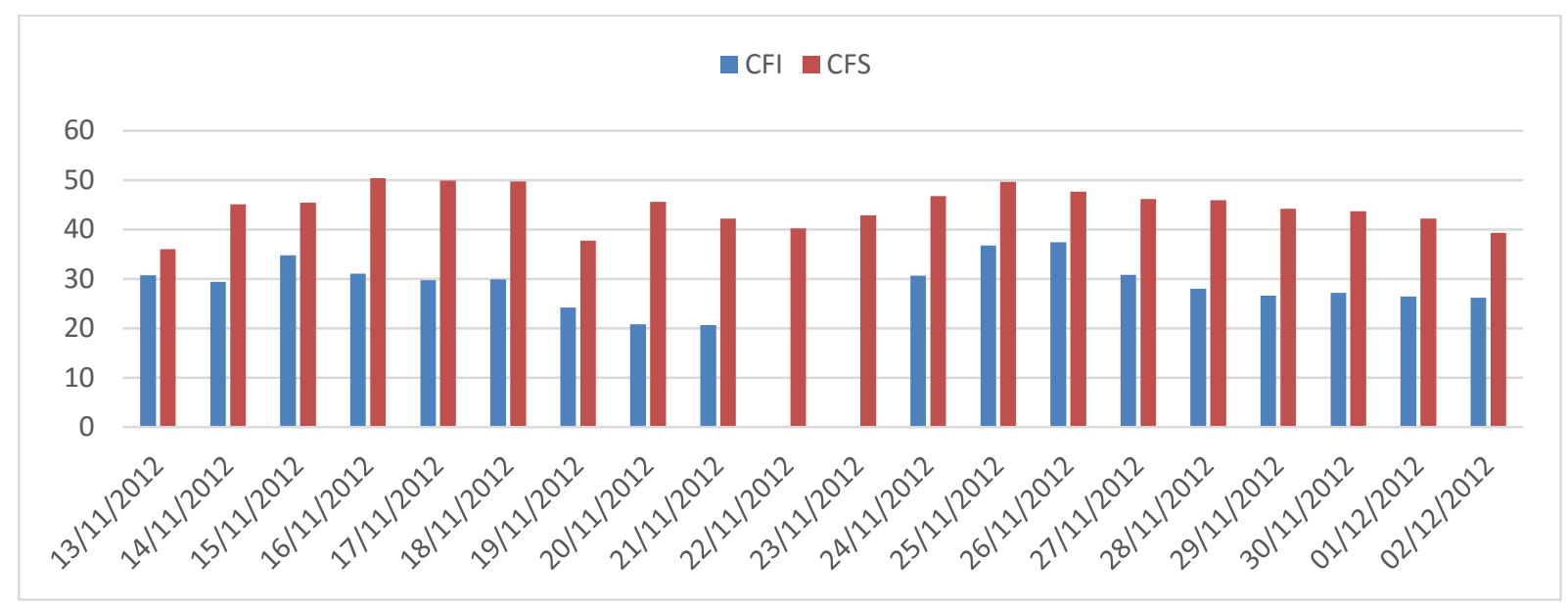

Figura 5.60: Espaçamento médio das cúspides durante o período. Em vermelho são as cúspides localizadas na face praial superior e em azul cúspides localizadas na face praial inferior.

O período começa com o aparecimento de cúspides na CFI devido a interação do espraiamento com a morfologia existente na CFS resultando em um espaçamento em torno de $30 \mathrm{~m}$. 
Do segundo dia ao quinto dia o espaçamento da CFS aumentou de $45 \mathrm{~m}$ para $50 \mathrm{~m}$ e a CFI manteve o espaçamento em torno de $30 \mathrm{~m}$. A direção das ondas incidente variou de $120^{\circ}$ para $130^{\circ}$ com altura em torno de $0,9 \mathrm{~m}$ e período em torno de $9 \mathrm{~s}$.

A partir do dia 19 a direção das ondas ficou com valores em torno de $160^{\circ}$ e altura em torno de $0,6 \mathrm{~m}$ e com o passar dos dias o espaçamento das cúspides diminui de $50 \mathrm{~m}$ para $40 \mathrm{~m}$ na CFS e na CFI o espaçamento diminui até o desaparecimento das mesmas.

Do dia 24 de novembro à 2 de dezembro a direção da ondulação ficou em torno de $122^{\circ}$ e o espaçamento da CFS aumentou de $42 \mathrm{~m}$ para $49 \mathrm{~m}$, decrescendo logo em seguida a uma taxa $1 \mathrm{~m}$ por dia até o espaçamento de $40 \mathrm{~m}$. No caso das cúspides da face praial inferior o espaçamento aumentou de $30 \mathrm{~m}$ para $37 \mathrm{~m}$ decaindo para $26 \mathrm{~m}$ no último dia do período.

Tabela 5.28: Espaçamento médio das cúspides na face praial inferior e superior.

\begin{tabular}{|c|c|c|c|c|c|}
\hline Datas & Altura(m) & Período(s) & Direção( $\left.{ }^{\circ}\right)$ & $\mathrm{CFI}(\mathrm{m})$ & $\mathrm{CFS}(\mathrm{m})$ \\
\hline $13 / 11 / 2012$ & 0.42 & 9.83 & 157.41 & 30.71 & 36.05 \\
\hline $14 / 11 / 2012$ & 0.61 & 14.25 & 122.55 & 29.44 & 45.12 \\
\hline $15 / 11 / 2012$ & 0.55 & 11.02 & 120.98 & 34.79 & 45.44 \\
\hline $16 / 11 / 2012$ & 0.86 & 9.37 & 121.06 & 31.07 & 50.35 \\
\hline $17 / 11 / 2012$ & 0.93 & 8.95 & 125.90 & 29.71 & 49.90 \\
\hline $18 / 11 / 2012$ & 0.92 & 7.66 & 131.86 & 29.88 & 49.75 \\
\hline $19 / 11 / 2012$ & 0.78 & 6.48 & 139.66 & 24.17 & 37.78 \\
\hline $20 / 11 / 2012$ & 0.61 & 5.55 & 161.22 & 20.83 & 45.59 \\
\hline $21 / 11 / 2012$ & 0.50 & 6.15 & 170.76 & 20.67 & 42.25 \\
\hline $22 / 11 / 2012$ & 0.46 & 6.16 & 168.23 & - & 40.21 \\
\hline $23 / 11 / 2012$ & 0.52 & 6.24 & 156.53 & - & 42.89 \\
\hline $24 / 11 / 2012$ & 0.77 & 9.86 & 122.33 & 30.63 & 46.79 \\
\hline $25 / 11 / 2012$ & 1.16 & 11.58 & 124.84 & 36.78 & 49.67 \\
\hline $26 / 11 / 2012$ & 0.84 & 10.20 & 126.21 & 37.42 & 47.63 \\
\hline $27 / 11 / 2012$ & 0.66 & 7.51 & 120.60 & 30.83 & 46.19 \\
\hline $28 / 11 / 2012$ & 0.34 & 9.94 & 120.63 & 28.00 & 45.89 \\
\hline $29 / 11 / 2012$ & 0.24 & 10.95 & 121.33 & 26.59 & 44.19 \\
\hline $30 / 11 / 2012$ & 0.30 & 11.83 & 121.65 & 27.17 & 43.67 \\
\hline $01 / 12 / 2012$ & 0.41 & 13.18 & 122.28 & 26.47 & 42.25 \\
\hline $02 / 12 / 2012$ & 0.34 & 11.71 & 121.75 & 26.23 & 39.29 \\
\hline
\end{tabular}




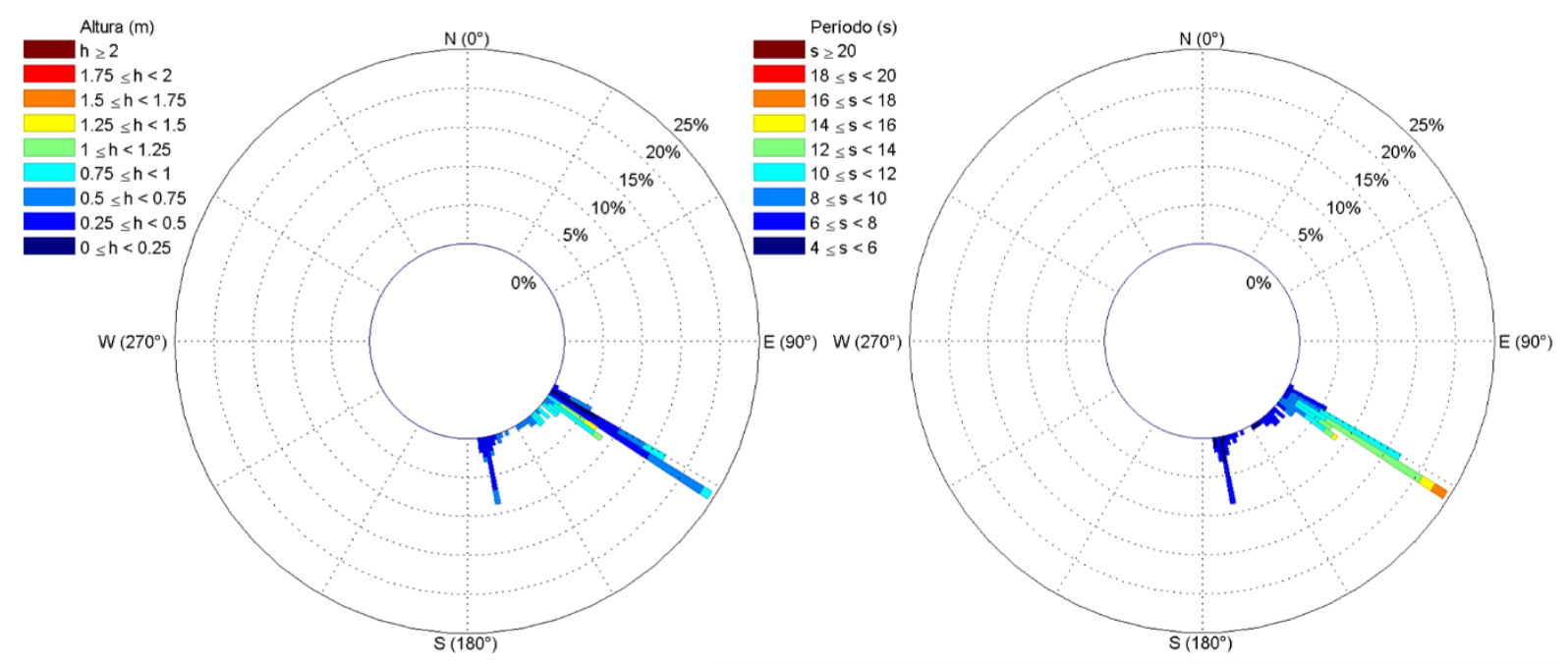

Figura 5.61: Histograma direcional de altura ( $m$, a esquerda) e período (s, a direita) das ondas atuantes durante o período.
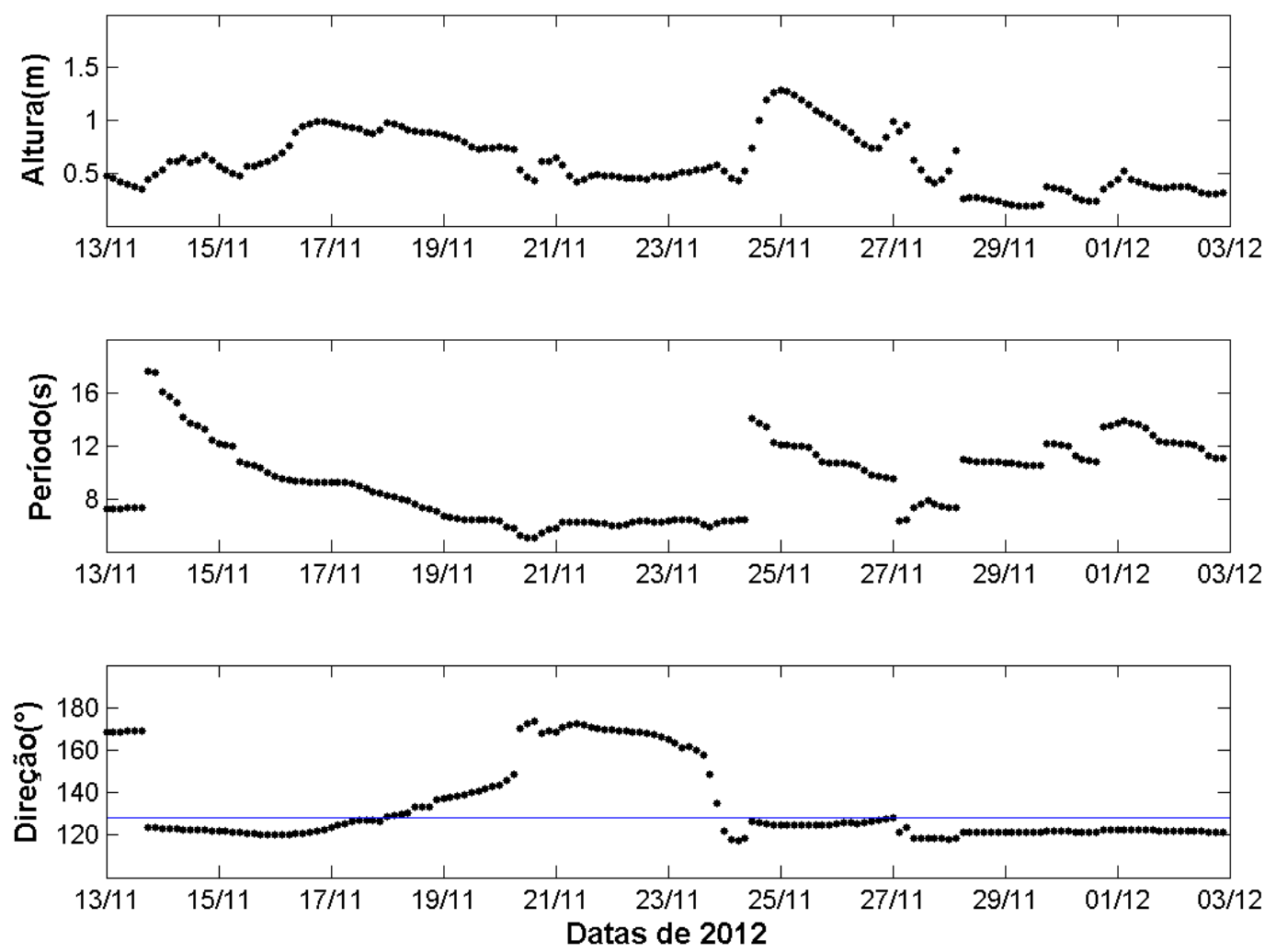

Figura 5.62: Evolução da altura, período e direção atuantes durante o período, onde a linha em azul representa a direção normal a face praial. 

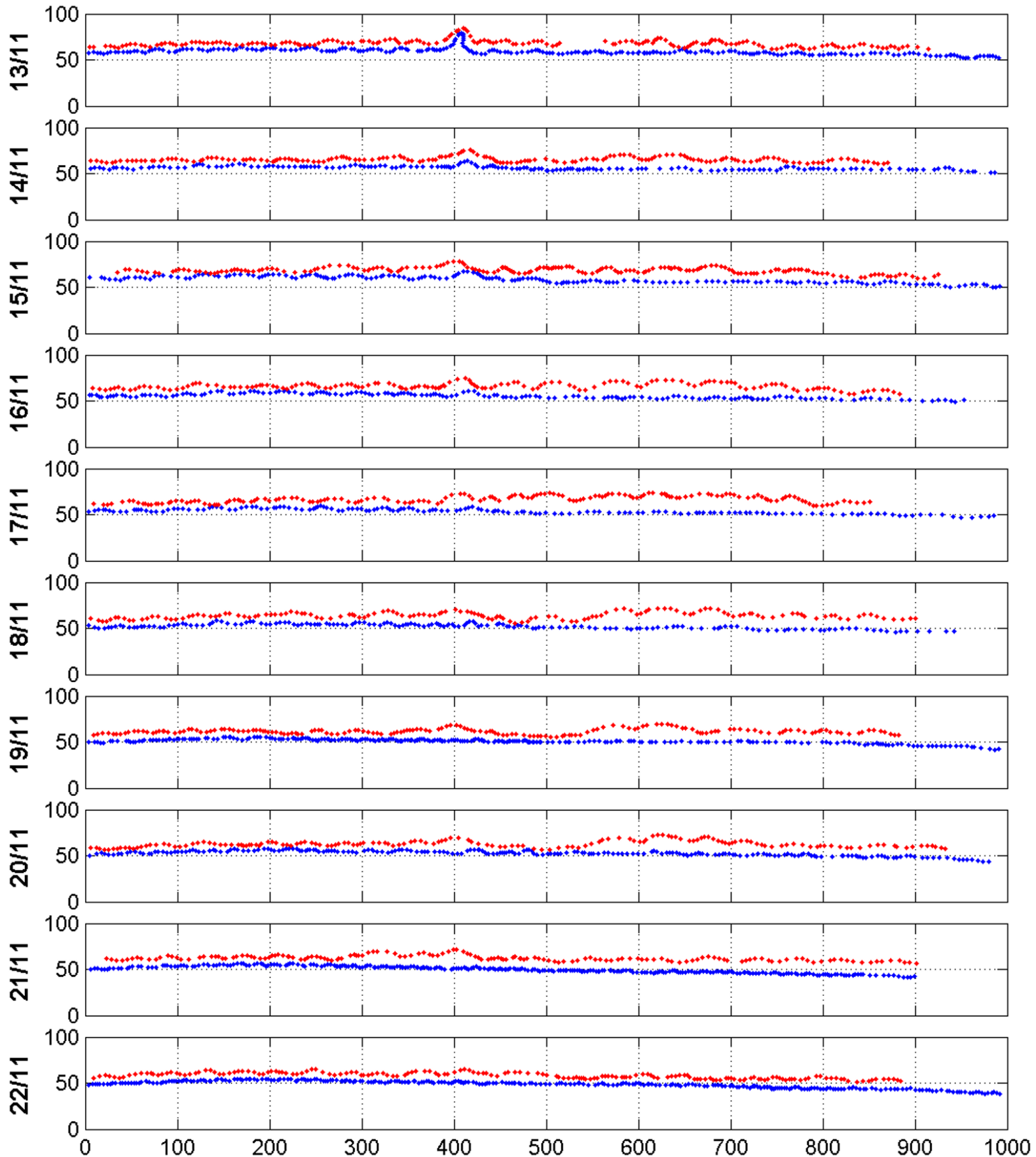

Figura 5.63: Cúspides digitalizadas durante o período (apenas os 10 primeiros dias). Em vermelho são as cúspides localizadas na face praial superior e em azul cúspides localizadas na face praial inferior. 

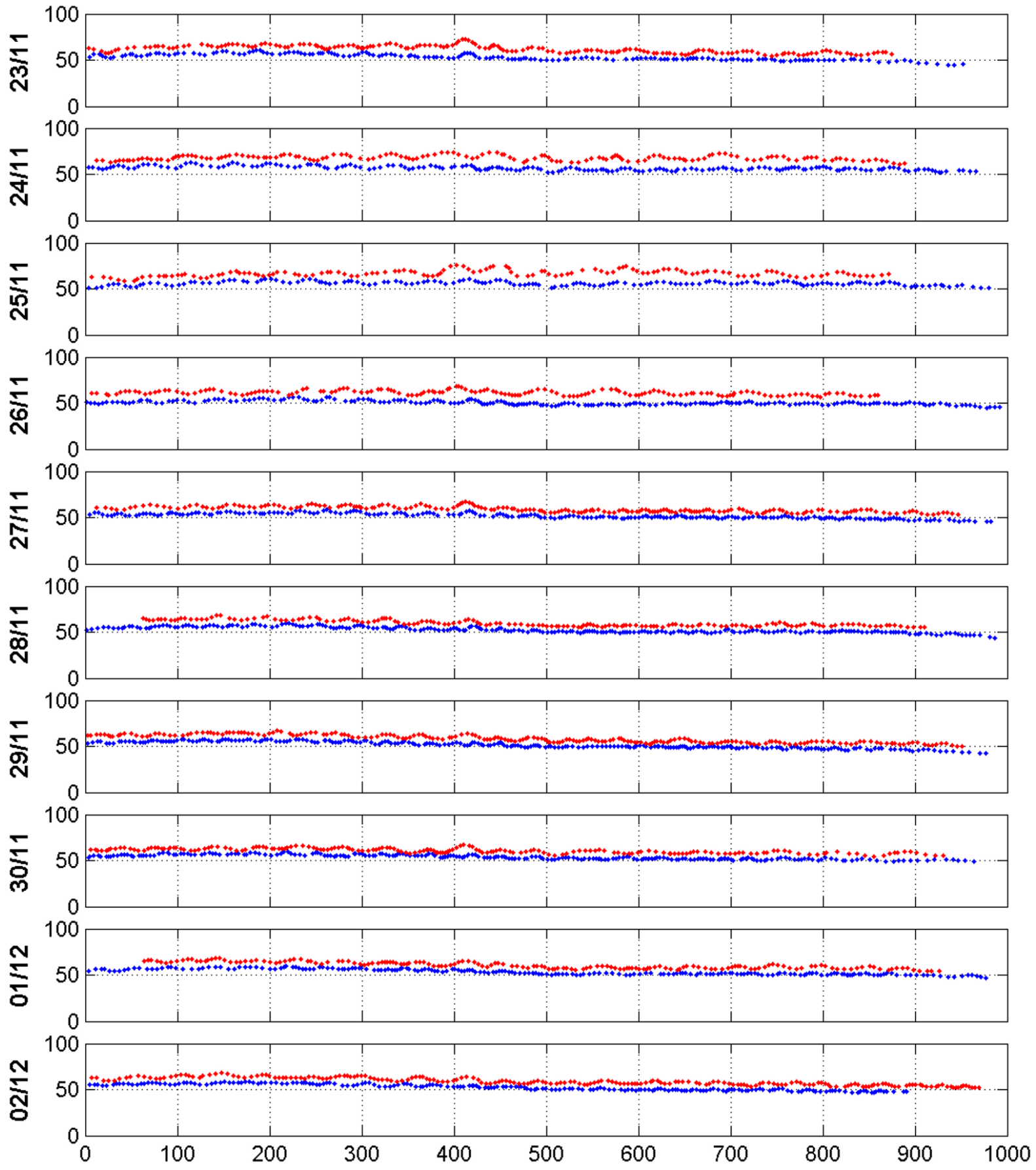

Figura 5.64: Cúspides digitalizadas durante o período (10 dias restantes). Em vermelho são as cúspides localizadas na face praial superior e em azul cúspides localizadas na face praial inferior. 


\subsubsection{Momento 13}

O momento 13 compreende o período de 03 à 22 de dezembro de 2012 com 19 dias analisados, sem registros de cúspides na face praial inferior e com 11 registros de cúspides na face praial superior (Tabela 5.30; Figuras 5.65, 5.68 e 5.69).

A direção média das ondas incidentes, para o período, foi de $141,98^{\circ}$ variando de $119,20^{\circ}$ à $173,92^{\circ}$, o período foi de $9,04 \mathrm{~s}$ variando de $5,64 \mathrm{~s}$ à $15,32 \mathrm{~s}$ e a altura foi de $0,37 \mathrm{~m}$ variando de 0,12 m à 0,81 m (Tabelas 5.29 e 5.30; Figuras 5.66 e 5.67).

Tabela 5.29: Características das ondas atuantes no arco praial de Massaguaçú durante o período.

\begin{tabular}{|c|c|c|c|c|c|}
\hline & Mínimo & Máximo & Média & Moda & Desvio Padrão \\
\hline Altura(m) & 0.12 & 0.81 & 0.37 & 0.17 & 0.17 \\
\hline Período(s) & 5.64 & 15.32 & 9.04 & 7.95 & 2.13 \\
\hline Direção( $\left.{ }^{\circ}\right)$ & 119.20 & 173.92 & 141.98 & 119.30 & 22.99 \\
\hline
\end{tabular}

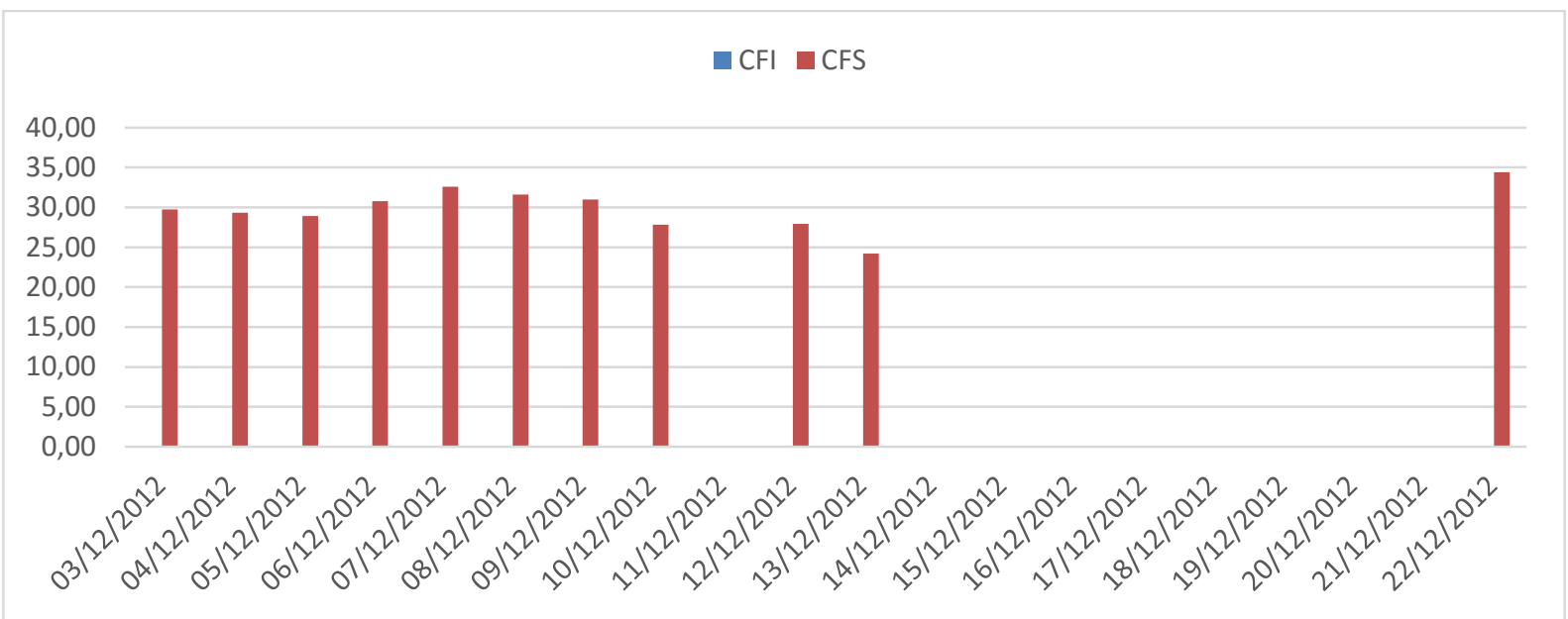

Figura 5.65: Espaçamento médio das cúspides durante o período. Em vermelho são as cúspides localizadas na face praial superior e em azul cúspides localizadas na face praial inferior.

O espaçamento das cúspides na CFS se manteve praticamente constante do dia 3 à 9 de dezembro com valores em torno de $31 \mathrm{~m}$. No dia 13 o espaçamento das cúspides diminuiu de 31 metros para 27 metros em 4 dias devido a direção da ondulação atuante de $165^{\circ}$ primeiramente e de $142^{\circ}$ posteriormente. 
Do dia 14 ao dia 21 de dezembro não houve registro de cúspides no arco praial de Massaguaçú. A direção da onda incidente variou de $120^{\circ}$ à $156^{\circ}$, o período ficou em torno de 9 $\mathrm{s}$ e a altura ficou em torno de $0,3 \mathrm{~m}$.

As ondas incidentes iniciais exibem valores de altura em torno de $0,5 \mathrm{~m}$ e período em torno de $7 \mathrm{~s}$ interagindo, provavelmente em momentos de maré alta, com as cúspides na face praial superior culminando na destruição das mesmas.

Apesar da proximidade entre as feições rítmicas e a linha d'água o espraiamento não conseguiu efetividade na formação das cúspides devido as baixas condições hidrodinâmicas presentes para o restante do período.

No último dia do período as CFS retornam ao arco praial com a intensificação das condições hidrodinâmicas e a aproximação da linha d'água em relação a linha de vegetação proporcionando interação entre espraiamento e morfologia existente. 
Tabela 5.30: Espaçamento médio das cúspides na face praial inferior e superior.

\begin{tabular}{c|c|c|c|c|c|} 
Datas & Altura(m) & Período(s) & Direção( & \multicolumn{1}{c}{ CFI(m) } & CFS(m) \\
\hline $\mathbf{0 3 / 1 2 / 2 0 1 2}$ & 0.44 & 10.04 & 131.18 & - & 29.72 \\
\hline $\mathbf{0 4 / 1 2 / 2 0 1 2}$ & 0.61 & 7.31 & 163.19 & - & 29.35 \\
\hline $\mathbf{0 5 / 1 2 / 2 0 1 2}$ & 0.32 & 9.37 & 137.68 & - & 28.90 \\
\hline $\mathbf{0 6 / 1 2 / 2 0 1 2}$ & 0.41 & 6.65 & 165.53 & - & 30.80 \\
\hline $\mathbf{0 7 / 1 2 / 2 0 1 2}$ & 0.55 & 6.54 & 169.16 & - & 32.60 \\
\hline $\mathbf{0 8 / 1 2 / 2 0 1 2}$ & 0.54 & 7.07 & 167.53 & - & 31.58 \\
\hline $\mathbf{0 9 / 1 2 / 2 0 1 2}$ & 0.47 & 7.96 & 165.29 & - & 31.00 \\
\hline $\mathbf{1 0 / 1 2 / 2 0 1 2}$ & 0.33 & 9.20 & 142.83 & - & 27.81 \\
\hline $\mathbf{1 2 / 1 2 / 2 0 1 2}$ & 0.45 & 12.70 & 122.05 & - & 27.94 \\
\hline $\mathbf{1 3 / 1 2 / 2 0 1 2}$ & 0.20 & 11.23 & 121.54 & - & 24.23 \\
\hline $\mathbf{1 4 / 1 2 / 2 0 1 2}$ & 0.17 & 9.91 & 120.90 & - & - \\
\hline $\mathbf{1 5 / 1 2 / 2 0 1 2}$ & 0.23 & 8.81 & 131.30 & - & - \\
\hline $\mathbf{1 6 / 1 2 / 2 0 1 2}$ & 0.32 & 8.36 & 156.54 & - & - \\
\hline $\mathbf{1 7 / 1 2 / 2 0 1 2}$ & 0.18 & 9.91 & 120.68 & - & - \\
\hline $\mathbf{1 8 / 1 2 / 2 0 1 2}$ & 0.40 & 8.49 & 126.86 & - & - \\
\hline $\mathbf{1 9 / 1 2 / 2 0 1 2}$ & 0.33 & 8.04 & 140.78 & - & - \\
\hline $\mathbf{2 0 / 1 2 / 2 0 1 2}$ & 0.22 & 10.38 & 146.62 & - & - \\
\hline $\mathbf{2 1 / 1 2 / 2 0 1 2}$ & 0.28 & 10.47 & 128.00 & - & - \\
\hline $\mathbf{2 2 / 1 2 / 2 0 1 2}$ & 0.44 & 9.67 & 140.10 & - & - \\
\hline
\end{tabular}




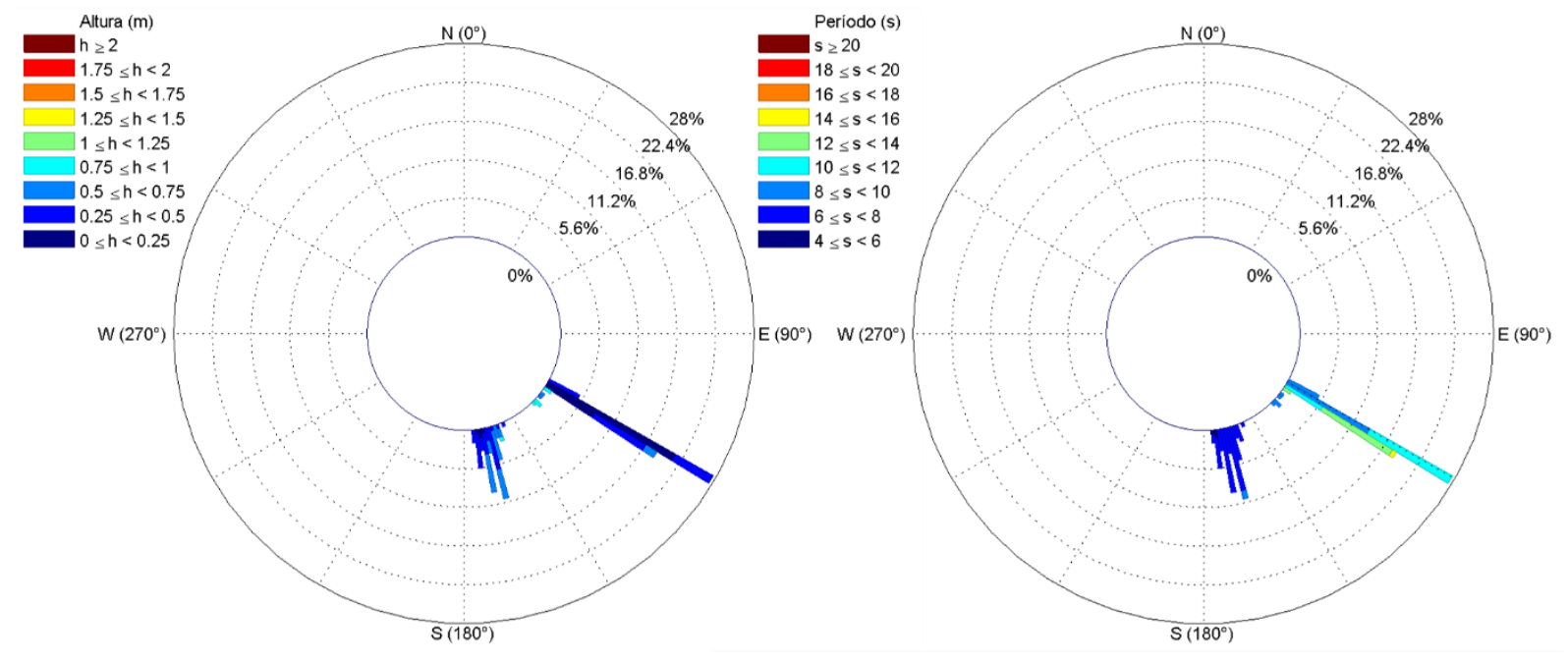

Figura 5.66: Histograma direcional de altura ( $m$, a esquerda) e período (s, a direita) das ondas atuantes durante o período.
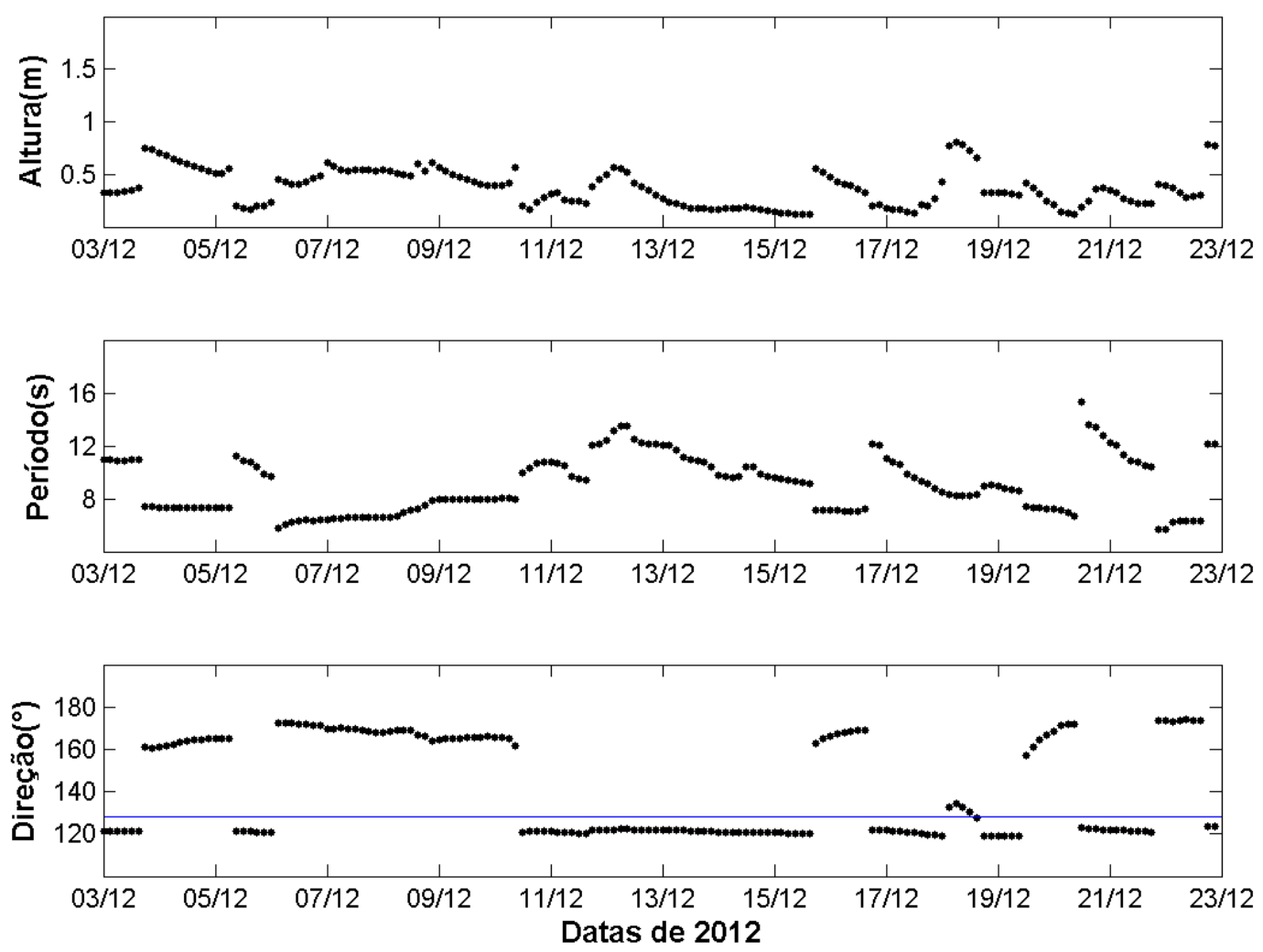

Figura 5.67: Evolução da altura, período e direção atuantes durante o período, onde a linha em azul representa a direção normal a face praial. 

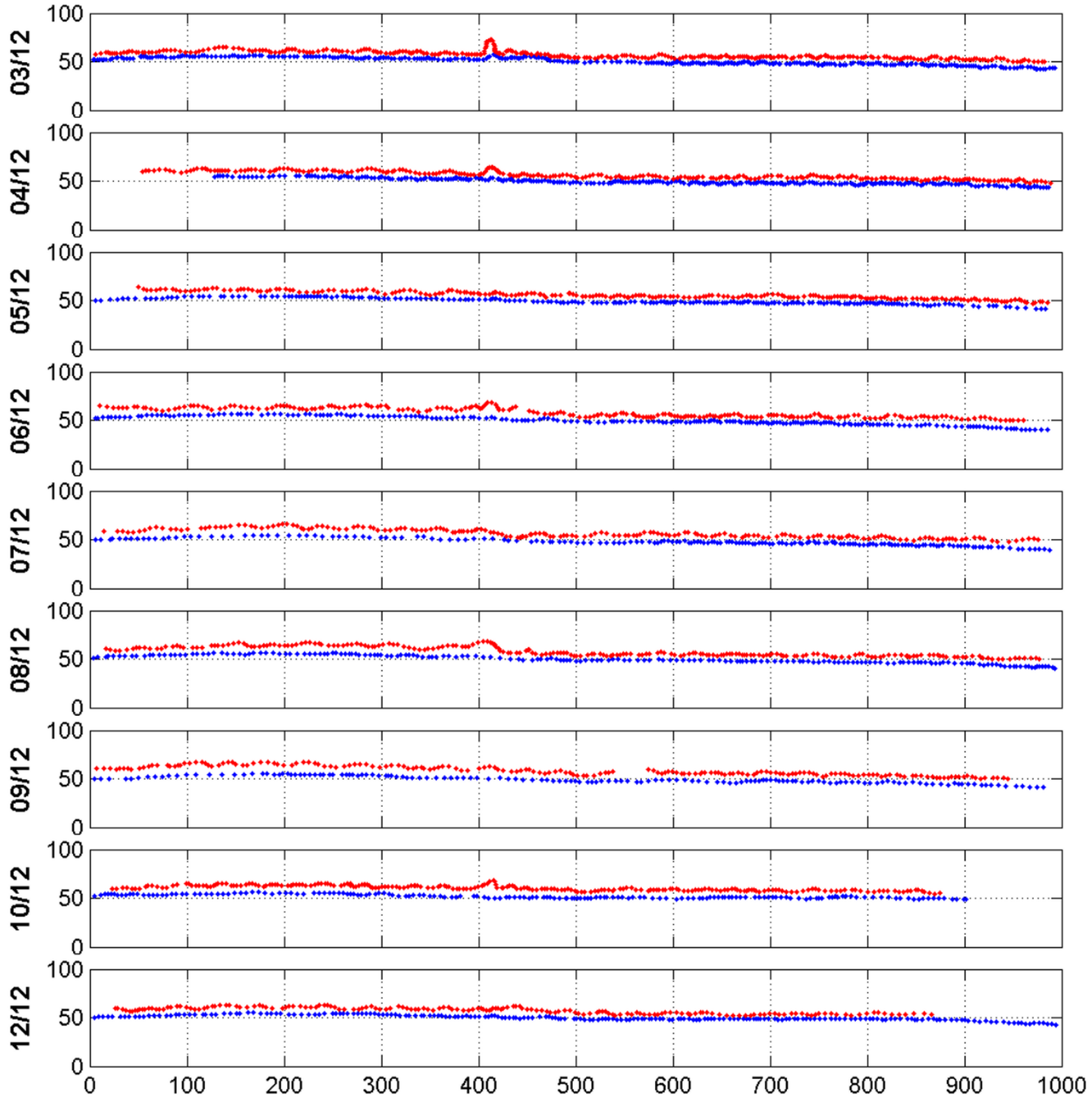

Figura 5.68: Cúspides digitalizadas durante o período (apenas os 9 primeiros dias). Em vermelho são as cúspides localizadas na face praial superior e em azul cúspides localizadas na face praial inferior. 

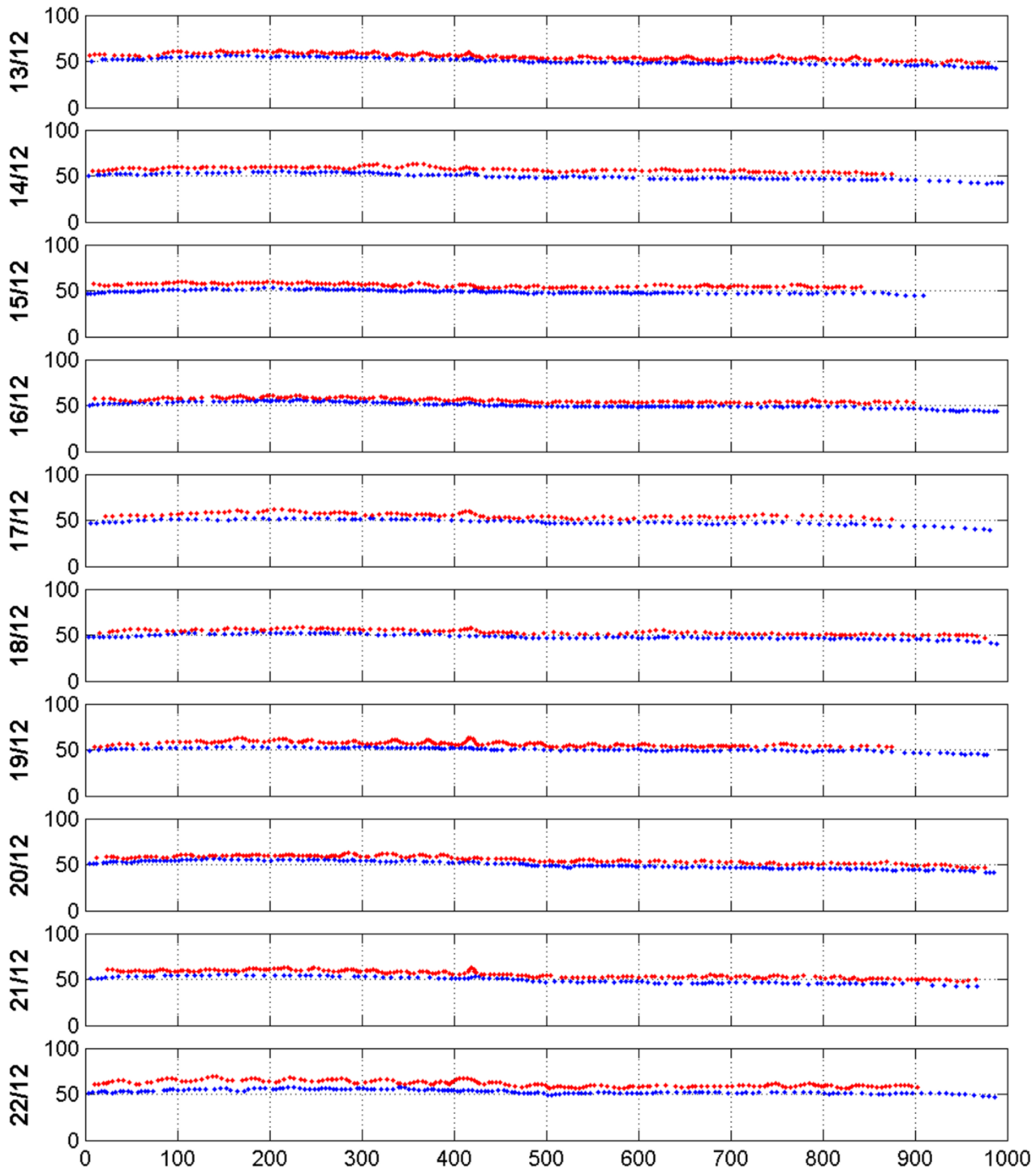

Figura 5.69: Cúspides digitalizadas durante o período (10 dias restantes). Em vermelho são as cúspides localizadas na face praial superior e em azul cúspides localizadas na face praial inferior. 


\subsubsection{Momento 14}

O momento 14 compreende o período de 23 à 30 de dezembro de 2012 com 8 dias analisados, 6 registros de cúspides na face praial inferior e 8 registros de cúspides na face praial superior para todos os dias do período (Tabela 5.32; Figuras 5.70 e 5.73).

A direção média das ondas incidentes, para o período, foi de $142,08^{\circ}$ variando de $118,30^{\circ}$ à $174,54^{\circ}$, o período foi de $9,68 \mathrm{~s}$ variando de $5,63 \mathrm{~s}$ à $13,88 \mathrm{~s}$ e a altura foi de $0,55 \mathrm{~m}$ variando de 0,19 m à 1,05 m (Tabelas 5.31 e 5.32; Figuras 5.71 e 5.72).

Tabela 5.31: Características das ondas atuantes no arco praial de Massaguaçú durante o período.

\begin{tabular}{|c|c|c|c|c|c|} 
& Mínimo & Máximo & Média & Moda & Desvio Padrão \\
\hline Altura(m) & 0.19 & 1.05 & 0.55 & 0.19 & 0.25 \\
\hline Período(s) & 5.63 & 13.88 & 9.68 & 10.91 & 2.99 \\
\hline Direção( ${ }^{\circ}$ ) & 118.30 & 174.54 & 142.08 & 129.80 & 23.36 \\
\hline
\end{tabular}

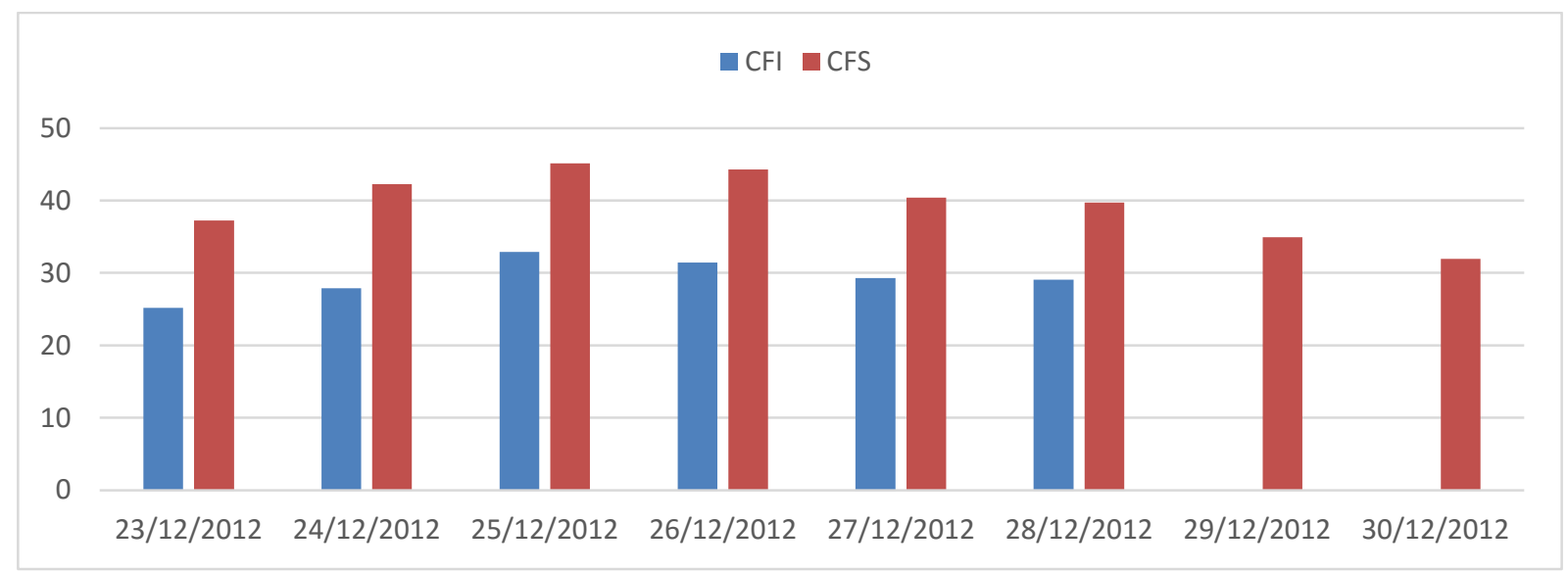

Figura 5.70: Espaçamento médio das cúspides durante o período. Em vermelho são as cúspides localizadas na face praial superior e em azul cúspides localizadas na face praial inferior.

Do dia 23 ao dia 25 o espaçamento da CFS aumentou de $37 \mathrm{~m}$ para $45 \mathrm{~m}$ e o espaçamento da CFI de $25 \mathrm{~m}$ para $32 \mathrm{~m}$. A direção de da onda incidente ficou em torno de $127^{\circ}$, o período em torno de $11 \mathrm{~s}$ e a altura em torno de $0,8 \mathrm{~m}$. 
Nos 3 dias seguintes o espaçamento decaiu de 45 m para 39 na CFS e de 32 m para 29 $\mathrm{m}$ na CFI. A direção da onda incidente ficou em torno de $170^{\circ}$, o período em torno de $6 \mathrm{~s}$ e a altura em torno de $0,35 \mathrm{~m}$.

Nos dois últimos dias do período o espaçamento continuou diminuindo para ambas as regiões, no caso da CFS o espaçamento decaiu de 34 para $31 \mathrm{~m}$ e na face praial inferior as cúspides não formam observadas.

Tabela 5.32: Espaçamento médio das cúspides na face praial inferior e superior.

\begin{tabular}{c|c|c|c|c|c} 
Datas & Altura(m) & Período(s) & Direção( $\left.{ }^{\circ}\right)$ & CFI(m) & CFS(m) \\
\hline $\mathbf{2 3 / 1 2 / 2 0 1 2}$ & 0.71 & 11.32 & 123.83 & 25.18 & 37.22 \\
\hline $\mathbf{2 4 / 1 2 / 2 0 1 2}$ & 0.94 & 11.46 & 128.73 & 27.86 & 42.25 \\
\hline $\mathbf{2 5 / 1 2 / 2 0 1 2}$ & 0.80 & 11.36 & 128.10 & 32.92 & 45.11 \\
\hline $\mathbf{2 6 / 1 2 / 2 0 1 2}$ & 0.40 & 7.28 & 160.86 & 31.44 & 44.28 \\
\hline $\mathbf{2 7 / 1 2 / 2 0 1 2}$ & 0.34 & 6.25 & 172.27 & 29.29 & 40.38 \\
\hline $\mathbf{2 8 / 1 2 / 2 0 1 2}$ & 0.32 & 6.31 & 173.33 & 29.08 & 39.74 \\
\hline $\mathbf{2 9 / 1 2 / 2 0 1 2}$ & 0.53 & 10.39 & 127.26 & - & 34.93 \\
\hline $\mathbf{3 0 / 1 2 / 2 0 1 2}$ & 0.48 & 13.07 & 122.26 & - & 31.92 \\
\hline
\end{tabular}



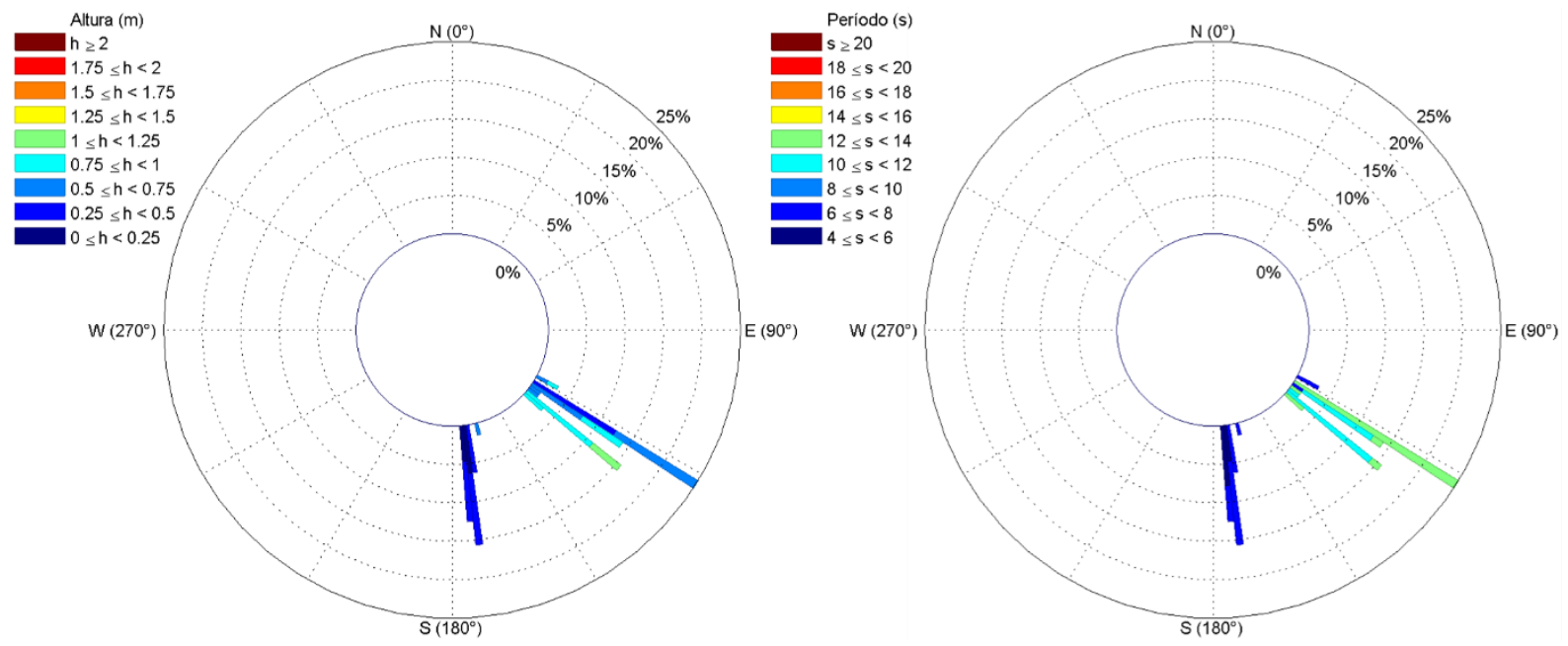

Figura 5.71: Histograma direcional de altura (m, a esquerda) e período (s, a direita) das ondas atuantes durante o período.
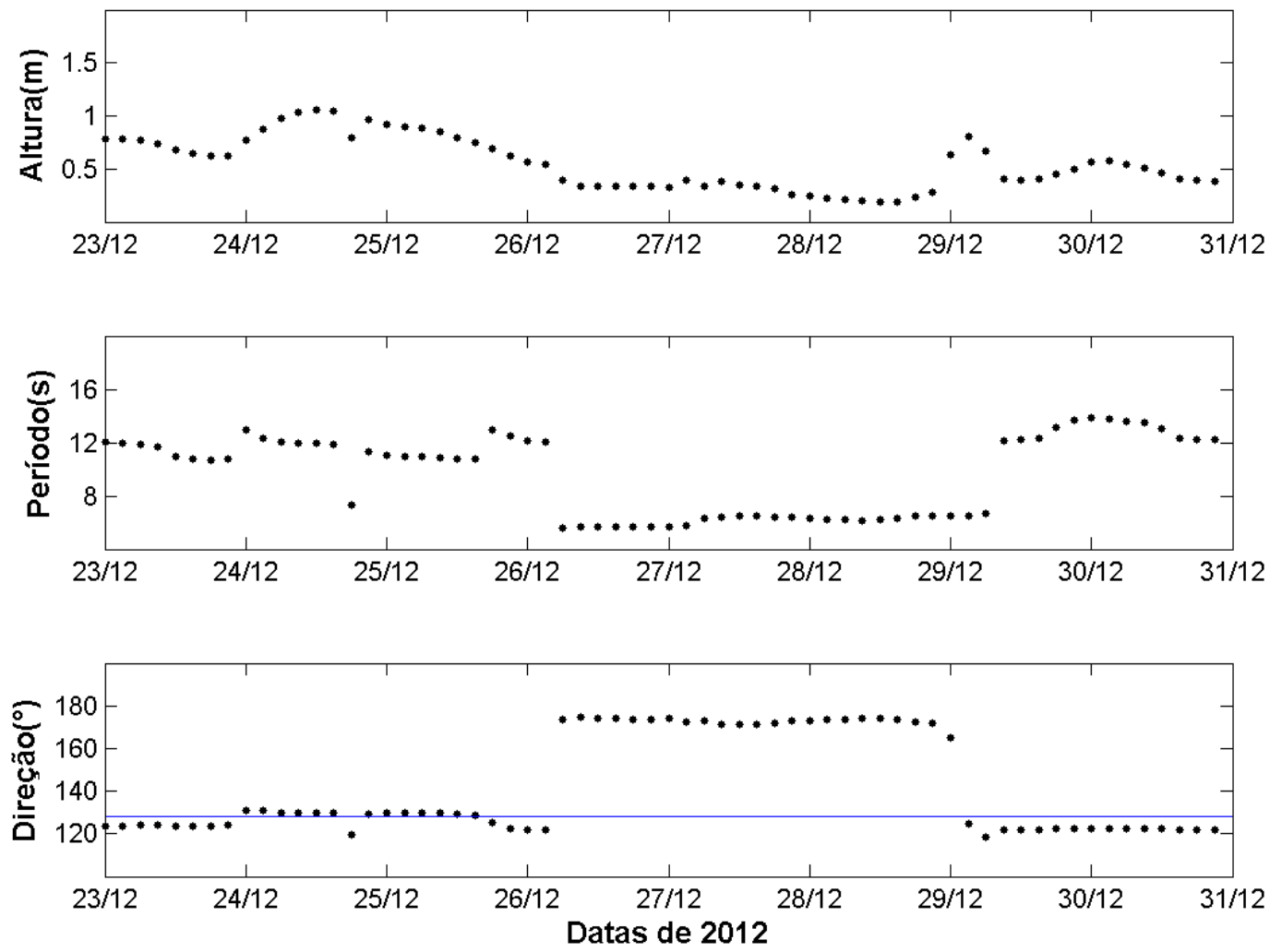

Figura 5.72: Evolução da altura, período e direção atuantes durante o período, onde a linha em azul representa a direção normal a face praial. 

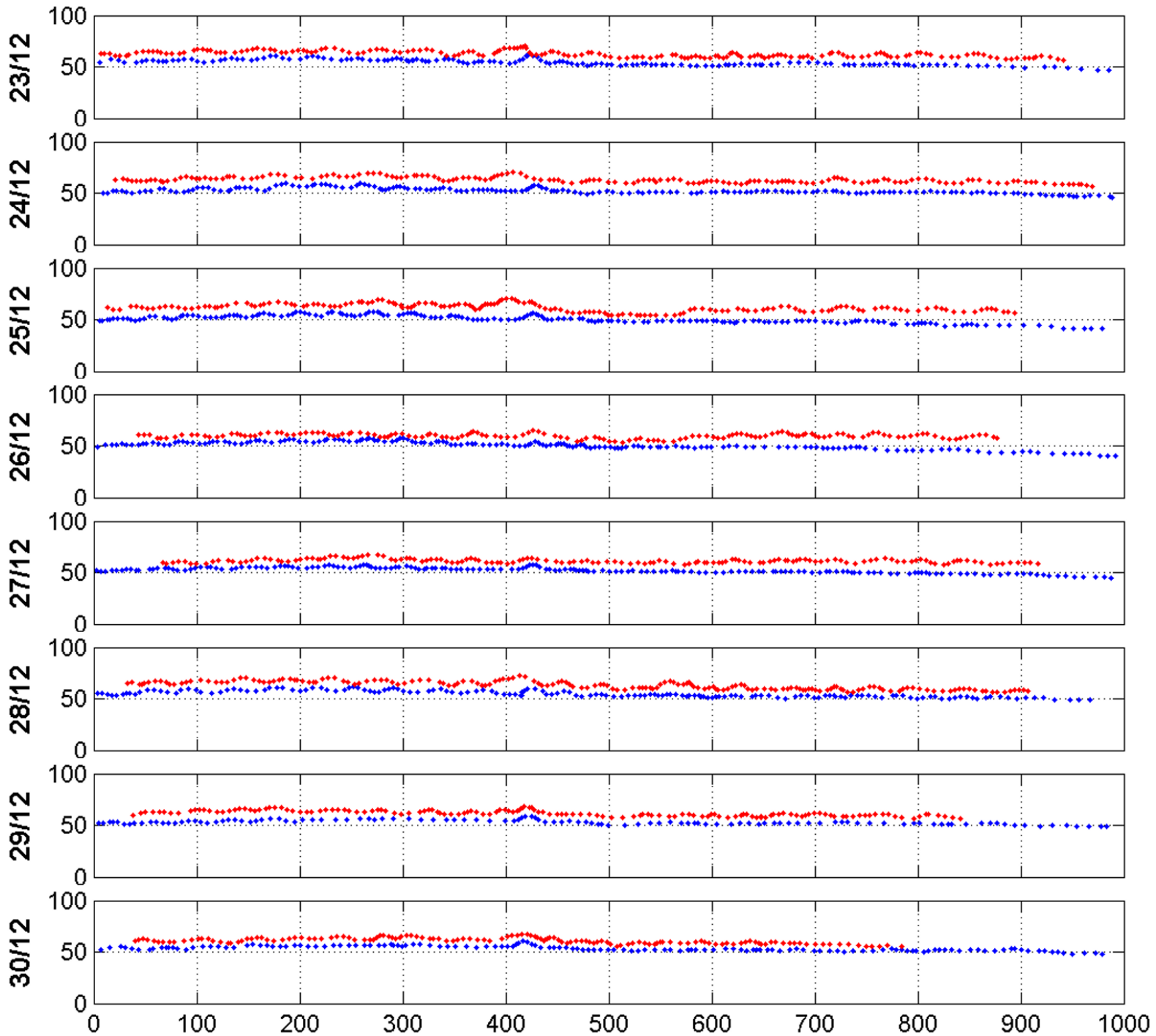

Figura 5.73: Cúspides digitalizadas durante o período. Em vermelho são as cúspides localizadas na face praial superior e em azul cúspides localizadas na face praial inferior. 


\section{Discussão}

De forma a facilitar a discussão entre a relação das condições atuantes e a resposta morfológica das feições rítmicas no arco praial de Massaguaçú, as informações de altura e período de ondas foram resumidas de acordo com a classificação apresentada na Tabela 6.1

Tabela 6.1: Classificação de condição energética de ondas incidentes.

\begin{tabular}{c|c|c} 
Altura $(\mathbf{m})$ & Período $(\mathbf{s})$ & Condição energética \\
\hline $0-0.5$ & $<8$ & Baixa \\
\hline $0.5-1$ & $8-12$ & Média \\
\hline $1-1.5$ & $12-16$ & Alta \\
\hline $1.5-2$ & $>16$ & Extrema \\
\hline
\end{tabular}

\subsection{Momentos}

Durante o momento 1 o espaçamento da CFS aumentou sobre condições baixas de altura e período com direção incidente da onda quase normal a face praial. A diminuição do espaçamento da CSF ocorreu sobre condições baixas de altura e período e com incidência obliqua das ondas. Sobre baixas condições energéticas a morfologia da região superior da face praial se alterou devido a modulação da maré e a interação do espraiamento com a morfologia existente, fatores também observados por Masselink \& Hughes (2003).

As cúspides da CFI não foram presentes para grande parte do período por causa de baixas condições energéticas, exceto por dois dias onde a interação entre as cúspides da CFS e o aumento das condições energéticas provocaram a formação da CFI, também descrito por Dubois (1978).

No momento 2, tanto a CFS e a CFI estavam presentes e sofreram diminuição de seus espaçamentos sobre condições de baixa a média energia e direção obliqua a face praial. Sobre condições médias e direção quase normal a face praial, o espaçamento da CSF e da CSI aumentou. Vousdoukas (2012), também relata que as ações hidrodinâmicas atuantes na face 
praial é mais constante sobre as morfologias presentes na face praial inferior em comparação com a face praial superior.

Em dois dias deste momento as cúspides desapareceram na face praial devido a condições baixas das ondas. Sobre estas condições o espraiamento atuou de forma a preencher os embaiamento com a diminuição do espraiamento lateral das cristas para as cavas conforme observado por Masselink \& Pattiaratchi (1998) e Almar et al. (2008).

No momento 3 a CFI não foi presente devido as condições desfavoráveis, ora com incidência obliqua, ora com baixas a médias condições energéticas somado a inconstância de condições atuantes, da mesma forma que constatado por Ortega-Sanchez et al. (2008) sobre a necessidade da manutenção do regime de ondas para a produção de efetivas mudanças na morfologia da face praial. A CFS foi predominante por praticamente todo período exceto por dois dias com direção incidente de $40^{\circ}$ em relação a normal.

A CFS e a CSI do momento 4 foram presentes durante todo o período sobre condições favoráveis a presença de cúspides sofrendo alterações positivas com o aumento das condições energéticas e negativas com rotação do ângulo de incidência de normal para oblíquo (Holland, 1998). Ortega-Sanchez et al. (2008) observa a importância da consistência temporal para as alterações morfológicas na face praial e da mesma maneira essa dependência foi observada neste momento pois condições desfavoráveis não possuíram ação temporal suficiente para destruição das cúspides devido as condições energéticas médias demandarem maior tempo de ação na imposição de suas características, diferentemente de condições extremas como ondulações de tempestade.

No momento seguinte a presença de condições altas de energia provocou a instabilização das feições rítmicas na CFI e CFS e por fim sua descaracterização. Masselink \& Pattiaratchi (1998) relatam que o espraiamento gerado em condições de alta energia causa a erosão das cristas devido a convergência de fluxos. Com o passar dos dias as condições 
energéticas baixas não produziram um espraiamento substancial na quase plana morfologia da face praial inferior e não alcançaram a morfologia irregular na face praial superior.

As condições energéticas foram médias durante o momento 6 o que causou o desenvolvimento das cúspides durante o período na CFS e CFI. O aumento das cúspides ocorreu sobre condições altura e períodos médios. Porém, períodos considerados altos e extremos causaram a diminuição do espaçamento da CFI, e por fim, sua destruição devido a presença de condições de formação de espaçamento muito diferentes causando uma condição instável, primeiramente, e a formação da morfologia no dia seguinte. Masselink \& Pattiaratchi (1998) também observam que uma das causas de destruição das cúspides é a presença de um clima de ondas favorável a construção de uma morfologia de grandes diferenças em relação ao espaçamento presente.

O momento 7 se alterou sobre condições energéticas médias com direção oblíqua e quase normal a face praial, produzindo a diminuição e o aumento da CFS respectivamente. A CFI não ocorreu devido, primeiramente, a direção oblíqua do ângulo de incidência da ondulação atuante, seguido da alternância das condições energéticas entre baixa e média causando uma inconsistência temporal para a formação das cúspides na CFI, da mesma forma que observado por Ortega-Sanchez et al. (2008)

Semelhante aos momentos anteriores as cúspides da face praial inferior e superior comportaram-se com o aumento de seus espaçamentos relacionados com condições energéticas médias a altas e direção quase normal ao arco praial e a diminuição relacionado a condições médias a baixas e direção de incidência oblíqua. Em condições baixas poucas alterações ocorreram na CFS e na CFI.

Masselink \& Pattiaratchi (1998) e Ciriano et al., (2005) observam que a presença de cúspides praiais estimulam a formação de futuras feições rítmicas. Neste momento ocorreu o reaparecimento de cúspides com condições de média a baixa energia provavelmente devido 
afogamento de estruturas morfológicas irregulares e devido a interação do espraiamento com essa morfologia as cúspides se fizeram presentes.

No momento 9 as CFS e CFI praticamente não foram presentes devido a condições altas a extremas que causaram a desestabilização das feições rítmicas em toda face praial de Massaguaçú. Garnier et al., (2010) observa que sob condições extremas processos atuantes na zona de surfe atuam nas feições rítmicas causando a destruição das mesmas. Durante o restante do período a incidência oblíqua impossibilitou a formação das cúspides na CFI e na CFS. No entanto, apesar das condições adversas encontrou-se cúspides na CFS no final do período devido ao espraiamento interagir com a morfologia existente gerando a formação de feições rítmicas (Figura 6.1).

As condições médias de energia do momento 10 causaram alterações de aumento de espaçamento relacionado a direções normais a face praial e a diminuição relacionado com direções oblíquas.

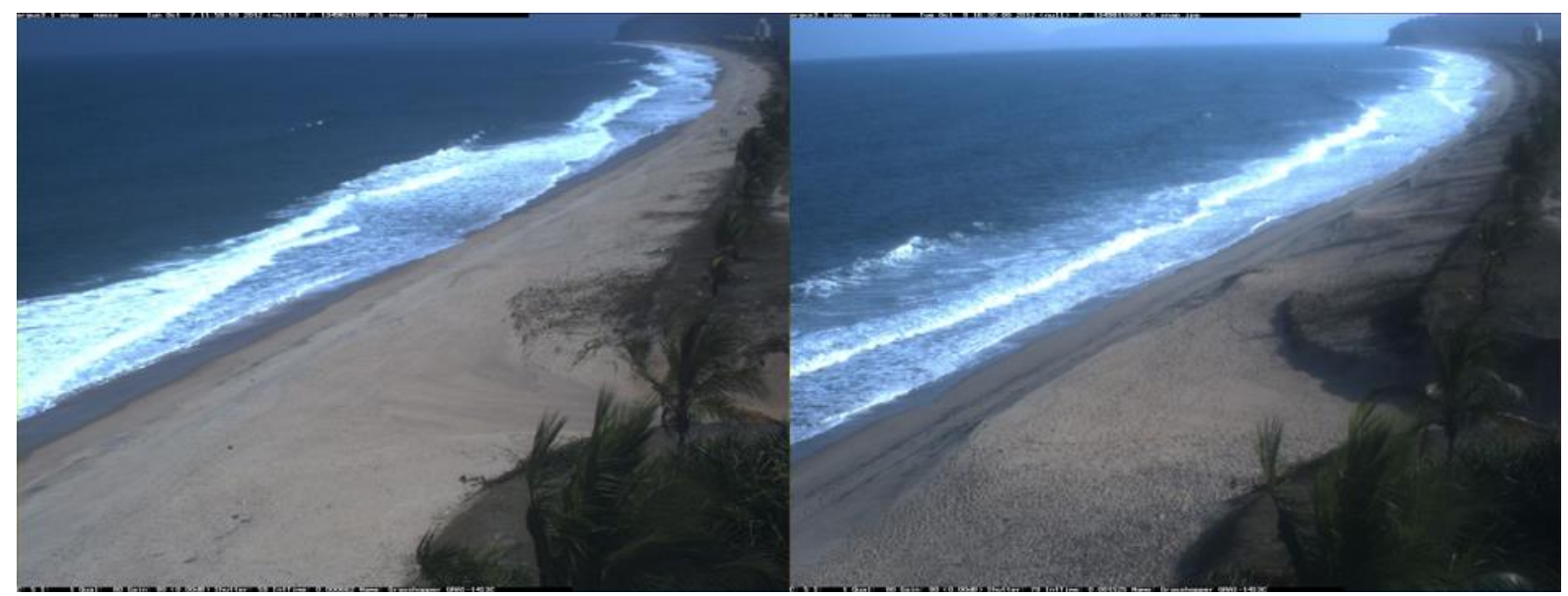

Figura 6.1: Formação de feições rítmicas causadas pela incursão do espraiamento na face praial superior

Diferentemente do momento 10, no momento 11 a CFI quase não foi presente e em grande parte do período as condições energéticas foram médias a baixas e possivelmente a variação das condições não proporcionou constância necessária para formação das feições rítmicas. No caso da CFS, as alterações iniciais foram pequenas devido pequena atuação do 
espraiamento na face praial superior. Com o aumento dessas interações a proximidade da morfologia da face praial superior em relação a face praial inferior diminuiu causando uma interação construtiva na formação da CFI, da mesma forma que relatado por van Gaalen, et al. (2011) sobre a interação entre a morfologia e o espraiamento na construção de feições rítmicas. Com essas interações intensificadas devido à proximidade o espaçamento da CFS diminui até se extinguir. A CFS volta a aparecer no arco praial devido a interação entre o espraiamento e a morfologia pretérita.

O momento 12 consistiu com a presença de CFS e CFI durante praticamente todo o período sobre condições médias de energia causou aumento do espaçamento com a incidência quase normal da ondulação e a diminuição com a incidência oblíqua. Neste momento, a destruição das feições da CFI ocorreu após uma sequência de dias com direção desfavorável a permanência das feições rítmicas.

No momento 13 a CFI não foi presente por condições desfavoráveis a permanência das cúspides. As condições energéticas foram médias a baixas em grande parte do período e a incidência oblíqua das ondas, somada a condições médias energéticas atuou com a variação do nível d'água causando a gradativa diminuição do espaçamento da CFS. O restante do período as condições energéticas foram baixas impossibilitando a formação das cúspides na face praial de Massaguaçú, exceto pelo fim do período onde a CFS reaparece, de maneira tênue, sobre condição de média energia.

No último momento analisado da série de dados, a CFI e a CFS estavam presentes no arco praial de Massaguaçú sob condições de média energia onde constatou aumento relacionado com ondas incidindo quase normal a face e a diminuição relacionado com a incidência oblíqua da ondulação. 


\subsection{Considerações Finais}

A série de dados utilizada para este trabalho indicou a presença de mais de um nível de cúspides no arco praial de Massaguaçú da mesma forma que relatado por diversos autores (p. ex. Carter, 1989; Holland \& Holman, 1996; Nolan et al., 1999; Masselink \& Hughes, 2003; Ortega-Sanchez et al., 2008; Garnier et al., 2010; van Gaalen et al., 2011; Vousdoukas, 2012). As cúspides no arco praial estavam presentes em $85 \%$ dos dias analisados e em muitos dos dias onde não ocorreu a presença de cúspides uma morfologia era presente, porém não possuía a regularidade característica de feições rítmicas ou a continuidade das mesmas.

Tessler (1988) e Rogacheski (2010) relatam a proteção geomorfológica no arco praial de Massaguaçú às condições hidrodinâmicas devido a presença da Ilha de São Sebastião que impede as ondulações de Sul atuarem de forma competente. Neste trabalho observa-se a presença extensiva de feições rítmicas devido a uma seleção natural de ondulações atuantes no arco praial de Massaguaçú.

Outro fator observado por Masselink \& Pattiaratchi (1998) e também visto neste trabalho é que a presença de uma morfologia na face praial superior tende a persistir a menos que extremas condições hidrodinâmicas se estabeleçam ou que condições radicalmente diferentes para a formação de feições rítmicas atuem na face praial.

Diversos autores também relatam a constância na presença de cúspide (p. ex. Almar et al., 2008 e Vousdoukas, 2012) e confirmam que a existência de feições rítmicas na face praial atua como 'facilitador' de futuras morfologias e por isso grande parte das cúspides relatadas neste trabalho podem ser considerados como reorganização de padrões rítmicos.

Neste trabalho relatou-se uma relação entre ao aumento do espaçamento das cúspides na face praial com a incidência da ondulação atuante quase normal, e uma diminuição das feições rítmicas com a incidência oblíqua com ângulo superior a $20^{\circ}$ em relação a normal. 
As condições energéticas onde ocorreram o aumento de espaçamento para as cúspides presentes na face praial superior foram condições de alta e extrema energia sendo que está por vezes causou a destruição das feições rítmicas. No caso de condições médias de energia o pequeno aumento registrado parece ter uma relação maior com a interação do espraiamento atuante com a morfologia existente na face praial superior.

Sob baixas condições energéticas o espaçamento das cúspides se manteve praticamente constante devido a pequena incursão do espraiamento que por vezes não conseguiu atuar na face praial superior. No entanto, quando esta condição consegue atuar na face praial superior causa a descaracterização das feições pela destruição das cristas e preenchimento das cavas o que também foi constatado na face praial inferior. Esse processo de retirada de sedimento das cristas e deposição nas cavas pela pequena incursão do espraiamento é observado por Almar et al. (2008) e Vousdoukas (2012).

Sob condições energéticas baixas ocorre a diminuição do espaçamento das cúspides da face praial inferior. No caso de condições energéticas médias registrou-se o aumento das feições rítmicas devido ao aumento da intensidade do espraiamento atuante no arco praial de Massaguaçú. Para condições energéticas altas o aumento das feições rítmicas também foi observado resultando em cúspides com espaçamento maiores e por vez se aproximando de valores encontrados na face praial superior. Sob condições energéticas extremas as cúspides na face praial praticamente foram destruídas com a remoção do sedimento da porção emersa para a porção submersa da praia.

Holland (1998), Masselink \& Pattiaratchi (1988) relacionaram o tamanho do espectro de ondas com a formação de cúspides e também concluindo que a geração das feições é mais proeminente com a consistência das condições, ou seja, quanto menor o espectro de ondas atuantes maior o efeito observado na alteração do espaçamento nas cúspides 
Vousdoukas (2012) também constatou que a presença de cúspides em diferentes níveis mostrou que as feições ocorreram e por muitas vezes interagem de forma construtiva com o espraiamento em direção ao mar gerando fluxos diferenciais na face praial e geralmente produzindo feições rítmicas em níveis inferiores. Esta interação entre diferentes níveis é intensificado com condições energéticas médias à altas e com a modulação da maré elevando o alcance do espraiamento.

Tabela 6.2: Resumo sobre os principais efeitos e seus processos geradores.

\begin{tabular}{|c|c|c|c|}
\hline \multicolumn{3}{|c|}{ Processos e forçantes } & Efeitos \\
\hline & & CFI & CFS \\
\hline \multirow{4}{*}{$\begin{array}{l}\text { Condição } \\
\text { energética }\end{array}$} & Baixa & Diminuição do espaçamento & Manutenção do espaçamento \\
\hline & Média & Aumento do espaçamento & Tênue aumento do espaçamento \\
\hline & Alta & Aumento do espaçamento & Aumento do espaçamento \\
\hline & Extrema & Destruição & $\begin{array}{l}\text { Aumento do espaçamento ou } \\
\text { destruição }\end{array}$ \\
\hline \multirow{2}{*}{$\begin{array}{l}\text { Ângulo de } \\
\text { Incidência }\end{array}$} & Normal & Aumento do espaçamento & Aumento do espaçamento \\
\hline & $\begin{array}{l}\text { Oblíqua } \\
\left(>20^{\circ}\right)\end{array}$ & Diminuição do espaçamento & Diminuição do espaçamento \\
\hline \multicolumn{2}{|c|}{ Formação de cúspides } & \multicolumn{2}{|c|}{$\begin{array}{c}\text { Relacionado com condições médias a altas e com } \\
\text { consistência temporal }\end{array}$} \\
\hline \multicolumn{2}{|c|}{ Destruição de cúspides } & \multicolumn{2}{|c|}{$\begin{array}{c}\text { Relacionado com condições baixas e extremas e sem } \\
\text { consistência temporal }\end{array}$} \\
\hline \multicolumn{2}{|c|}{$\begin{array}{l}\text { Interação entre morfologia de } \\
\text { diferentes níveis }\end{array}$} & \multicolumn{2}{|c|}{$\begin{array}{c}\text { Geralmente relacionado com a formação de cúspides no } \\
\text { nível inferior }\end{array}$} \\
\hline \multicolumn{2}{|c|}{ Diminuição da largura praial } & \multicolumn{2}{|c|}{$\begin{array}{l}\text { Relacionado com a formação de cúspides na face praial } \\
\text { inferior }\end{array}$} \\
\hline \multicolumn{2}{|c|}{$\begin{array}{l}\text { Interação entre espraiamento } \\
\text { e morfologia }\end{array}$} & \multicolumn{2}{|c|}{ Relacionado com a formação de feições rítmicas } \\
\hline
\end{tabular}




\section{Conclusões}

O presente trabalho analisou 210 dias com o intuito de avaliar o comportamento de cúspides praiais com a alternância de condições hidrodinâmicas durante a evolução do clima de ondas.

As observações indicaram a presença de cúspides no arco praial em $85 \%$ dos dias analisados. Este número deve ser maior quando se olha para o ano todo, já que o verão praticamente não foi analisado.

Durante o período analisado observou-se a presença de cúspides na face praial superior e inferior e a ocorrência simultânea das feições rítmicas corresponde à metade das ocorrências totais registradas. Essa diferença na presença simultânea em relação a simples presença de cúspides no arco praial ocorre pela variedade das condições hidrodinâmicas que atuam na face praial inferior.

As cúspides na face praial superior e inferior parecem responder de maneira similar as condições atuantes com algumas diferenças: (i) diferentes graus de exposição a essas condições atuantes; (ii) se posicionam em níveis de diferente potencial. Essas diferenças produzem resultados mais proeminentes para a as cúspides da face praial superior e menores para as cúspides da face praial inferior.

O aumento no espaçamento das feições rítmicas está relacionado com a incidência quase normal da ondulação sob condições de média a alta energia e com consistência temporal. Enquanto que a diminuição do espaçamento das cúspides está relacionada com condições energéticas baixas e extremas, incidência oblíqua da ondulação atuante e inconsistência temporal.

A consistência no clima de ondas atuante é um fator importante para a produção de respostas no arco praial de Massaguaçú principalmente para as feições rítmicas na face praial 
inferior. Essa dependência da consistência no clima de ondas diminui à medida que as condições energéticas aumentam.

Sob condições extremas observou destruição da morfologia na face praial superior e inferior. No entanto, para as cúspides da face praial superior também se observou um aumento do espaçamento. Neste último caso a ondulação evoluiu gradativamente enquanto que no caso onde houve a destruição das feições rítmicas a mudança foi brusca de uma condição energética baixa para extrema. Essa 'sensibilidade' a grandes variações foi um senso comum no arco praial de Massaguaçú independentemente das condições energéticas.

A interação entre o espraiamento e a morfologia foi um grande mecanismo de formação de feições rítmicas no arco praial de Massaguaçú. Em contrapartida o mecanismo mais responsável pela redução do espaçamento foi o preenchimento das cavas em condições persistentes de calmaria, principalmente em cúspides com espaçamento superior a $35 \mathrm{~m}$.

Sobre as teorias de formação, ondas de borda e auto-organização, elas implicam em um estado de equilíbrio difícil de se manter em um ambiente exposto a uma variedade de ondulações produzindo espraiamentos modulados pela maré e alterados a medida que interagem com as morfologias presentes. Devido a isso, é difícil a comparação entre espaçamentos medidos e espaçamentos previstos se fazendo necessário uma abordagem espacial e temporal de grande resolução. Com essa abordagem pode-se quantificar sobre os processos formadores das cúspides praiais a fim de coloca-los a prova e por fim chegar a um consenso comum. 


\section{Referências Bibliográficas}

ALMAR, Rafael, Giovanni COCO, Karin R. BRYAN et al. 2008. Videoobservations of beach cusps morphodynamics. Marine Geology., pp.216-223.

BAGNOLD, R. 1940. Beach formation by waves: some model experiments in a wave tank. Journal of the Institution of Civil Engineers. 15, pp.27-52.

BOWEN, A. J. and D. J. INMAN. 1969. Wave "set-down" and "set-up". Journal of Geophysical Reaserch., pp.69-77.

BOWEN, A. J. and D. J. INMAN. 1971. Edge Waves and Crescentic Bars. Journal of Geophysical Research., p.36.

CARTER, R. W. G. 1989. Coastal Enviroment: An Introduction to the Physical, Ecological an Cultural Systems of Coastlines. Academic Press.

CARTER, R. W. G. and C.D. WOODROFFE. 1994. Coastal Evolution: an introduction.In: Carter R. W. G. and Woodroffe C. D (org.), 1994. Coastal Evolution: later quaternary shoreline morphodynamics. Cambridge: Cambridge University Press.

CIRIANO, Y, G. COCO, K. R. BRYAN, and S. ELGAR. 2005. Field observation of swash zone infagravity mtions and beach cusp evolution. Journal of Geophysics Research., p.110.

COCO, G., T. K. BURNET, and B.T. WERNER. 2003. Test of self-organization beach cusp formation. Journal of Geophysics Research. 46, pp.1-11.

COCO, G., T.K. BURNET, and B.T. WERNER. 2004. The role of tides in beach cusp development. Journal of Geophysical Research. 109, pp.1-12.

COCO, G., T. A. O'HARA, and D. HUNTLEY. 1999. Beach cusps: a comparison of data and theoris for their formation. Journal Coastal Research. 15, pp.741-749.

DUBOIS, R.N. 1978. Beach topography and beach cusps. Geological Society of America Bulletin. 89, pp.1133-1139. 
GAALEN J., F., S., E. KRUSE, G. COCO et al. 2011. Observation of beach cusp evolution at Melbourne Beach, Florida, USA. Geomorphology. 129, pp.131-140.

GARNIER, R., M. ORTEGA-SÁNCHEZ, M. A. LOSADA et al. 2010. Beach cusps and inner surf zone processes: growth or destruction? A case study of Trafalgar Beach (Cádiz, Spain). Sciencia Marina. 74, pp.539-553.

HOLLAND, K. T. 1998. Beach cusp formation and spacings at Duck, USA. Continental Shelf Research. 18, pp.1081-1098.

HOLLAND, K. T. and R. A. HOLMAN. 1996. Field observations of beach cusps and swash motions. Marine Geology., p.17.

HOLMAN, R. A. and J. STANLEY. 2007. The history and technical capabilities of Argus. Coastal Engineering., pp.477-491.

INMAN, D. L. and R. T. GUZA. 1982. The Origin of Swash Cusps on Beaches. Marine Geology., pp.133-148.

JOHNSON, D. W. 1919. Shore Processes and Shoreline Development. New York: Wiley.

KOMAR, Paul D. 1973. Observation of beach cusps at Mono Lake, California. Geological Society of American Bulletin. 84, pp.3593-3600.

KOMAR, Paul D. 1976. Beach Process and Sedimentation. Englewood Cliffs, New Jersey: Prentice-Hall.

KOMAR, Paul D. 1998. Beach Process and Sedimentation. Upper Saddle River, New Jersey: Prentice-Hall.

MASSELINK, G., B.J. HEGGE, and C.B. PATTIARATCHI. 1997. Beach cusp morphodynamics. Earth Surf. Process. Land. 22, pp.1139-1155.

MASSELINK, G. and M. G. HUGHES. 2003. Introduction to Coastal Processes and Geomorphology. Hodder Education. 
MASSELINK, G. and C. B. PATTIARATCHI. 1998. Morphological evolution of beach cusps and associated swash circulation patterns. Marine Geology. 146, pp.93-113.

MASSELINK, G. and J. PULEO. 2006. Swash zone morphodynamics. Continental Shelf Research. 26(5), pp.661-680.

MODENESI, M. C., M. G. TESSLER, O. CRUZ, and A. M. COIMBRA. 1983. Influence of Marine and Continental Processes on Dynamics of a Sand-Ridge at the Mouth of the Massaguaçú River (Caraguatatuba, SP): preliminary conditions. Boletim do Instituto Oceanográfico da USP., pp.77-81.

NOLAN, T. J., R. M. KIRK, and J. SHULMEISTER. 1999. Beach cusp morphology on sand and mixed sand and gravel beaches, South Island, New Zealand. Marine Geology. 157, pp.185-198.

NUBER, E. 2008. Evolução morfológica e sedimentológica do arco praial de Massaguaçú, Litoral Norte de São Paulo. Dissertação de Mestrado, Universidade de São Paulo, Instituto Oceanográfico., p.143.

ORTEGA-SÁNCHEZ, M., S. FACHIN, F. SANCHO, and M. A. LOSADA. 2008. Relation between beachface morphology and wave climate at Trafalgar beach (Cádiz, Spain). Geomorphology. 99, pp.171-185.

PIANCA, C., P. L. F. MAZZINI, and Siegle E. 2010. Brazilian offshore wave climate based on NWW3 reanalysis. Brazilian Journal of Oceanography. 58, pp.53-70.

POÇANO, W. L., M. G. TESSLER, C. G. L. FREITAS, and M. M. MAHIQUES. 1999. Tendências regionais de transporte de sedimentos arenosos ao longo das praias paulistas. Rev. Univ. Guarulhos/Geociências. 4, pp.102-115.

PULEO, J., R. BEACH, R. HOLMAN, and J. ALLEN. 2000. Swash zone sediment suspension and transport and the importance of bore-generated turbulence. Journal of Geophysical Research. 105, pp.17.021-17.044. 
ROGACHESKI, Carlos Eduardo. 2010. A Dinâmica Sedimentar e a Caracterização de Zonas de Erosão Acentuada (ZEA) ao Longo do Arco Praial de Massaguaçú. Dissertação de Mestrado. Instituto Oceanografico. Universidade de São Paulo., p.182.

RUSSEL, R. and W. G. MCINTIRE. 1965. Beach cusps. Geological Society of American Bulletin. 76, pp.307-320.

SALLENGER JR., A. H. 1979. Beach-cusp formation. Marine Geology. 29, pp.23-37.

SIEGLE, E. 2003. Sediment Transport and Morphodynamics at an Estuary Mouth: a Study using Coupled Remote Sensing and Numerical Modelling. Doctor of Philosophy of University of Plymouth., p.278.

SOUSA, P. H. G. O., E. SIEGLE, and M. G. TESSLER. 2011. Environmental and Anthropogenic Indicators for Coastal Risk. Journal of Coastal Research. SI 64, pp.319 $-323$.

SOUZA, C. R. G. 1990. Considerações sobre os Processos Sedimentares Quaternários e Atuais na Região de Caraguatatuba, Litoral Norte de São Paulo. Dissertação de Mestrado, Universidade de São Paulo, Instituto Oceanográfico., p.334.

SUGUIO, K. and L. MARTIN. 1978. Quaternary marine formations of the State of São Paulo and Southern-Rio de Janeiro. International Symposium on Coastal Evolution in the Quaternary., p.55 p.

TESSLER, Moysés Gonzales. 1988. Dinâmica Sedimentar Quaternária do Litoral Paulista. Tese de Doutorado, Universidade de São Paulo, Insituto Oceanográfico., p.276.

TOLMAN, H. L. 1999. User manual an system documentation of WAVEWATCH III version 1.18. NOAA / NWS / NCEP / OMB technical note166, $110 \mathrm{pp}$.

VOUSDOUKAS, M.I. 2012. Erosion/accretion and multiple beach cusp systems on a mesotidal, steeply-sloping beach. Geomorphology. 141-142, pp.34-46. 
WELLEN, E. V., T. BALDOCK, A. CHADWICK, and D. SIMMONDS. 2000. Longshore sediment transport in the swash zone. Proceedings 27th International Conference on Coastal Engineering, ASCE., pp.3139-3150.

WERNER, B. T. and T. M. FINK. 1993. Beach cusps as self-organizationed patterns. Science., pp.968-971.

WRIGHT, L. D. and B. G. THOM. 1977. Coastal depositional landforms: a morphodynamic approach. Progress in Physical Geography. 1, pp.412 - 459. 